
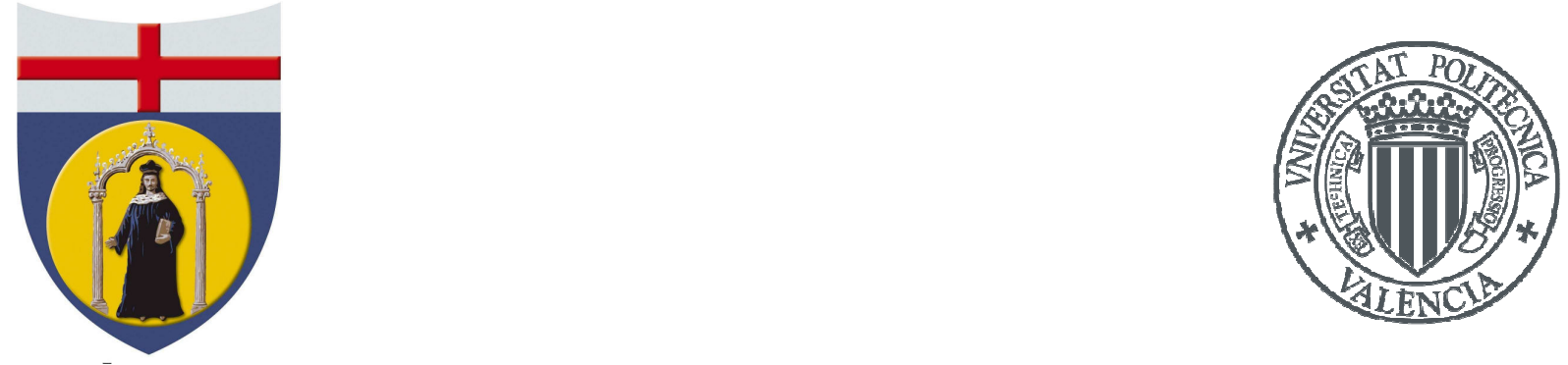

\title{
Valorisation of agricultural residues
}

Cristina Moliner Estopiñán

June 2016

Supervisors

Prof. Amparo Ribes

Prof. Elisabetta Arato

Prof. Barbara Bosio 

" Siempre hay un lugar donde perderse para poder encontrarse"

La tierra de las mujeres. Sandra Barneda

"Vivo ogni secondo come l'ultimo secondo Credo in poche cose ma ci credo fino in fondo Amo irresponsabilmente tanto ...."

Stupendo fino a qui. Alessandra Amoroso

"Lo que me llevará al final serán mis pasos, no el camino"

Antes de que cuente diez. Fito y Fitipaldis 





\section{Valorisation of agricultural residues}

The aim of the present $\mathrm{PhD}$ Thesis is to define, develop and evaluate a methodology for an improved and more sustainable management of waste, in particular agricultural residues, turning them into a new source of energy and into added value products. Particular attention is paid to the use of rice straw as an energy vector and as a precursor of silica-based compounds.

The recovery of energy was carried through the gasification of biomass within a Spouted Bed Reactor. An initial definition of the main physico-chemical and thermal properties of the feed was performed. The design and operational parameters of the reactor were set according to the characteristics of the biomass. Due to the particular configuration of the reactor, its fluid dynamic properties were analysed in detail in a lab scale unit. The conditions of stability of the reactor and the prevention of segregation phenomena were studied. A scaled-up unit was used for the evaluation of the reactions of gasification of the different residues. The behaviour of the system was modelled at both fluid dynamic and thermo-chemical levels with the aid of different commercial softwares.

Finally, a material valorisation was performed. The extraction of silica from the ashes resulting from the thermo-chemical process was studied. Their application as adsorbent materials for the removal of nitrates in water was discussed. 



\section{Valorizzazione di rifiuti agricoli}

Lo scopo di questa tesi di dottorato è definire, sviluppare e valutare una metodologia per la efficiente gestione dei rifiuti, in particolare agricoli, per farli diventare una nuova fonte di energia e trasformare $\mathrm{i}$ residui in prodotti a valore aggiunto. Particolare attenzione è stata dedicata all'utilizzo della paglia di riso come vettore energetico e come precursore di prodotti a base di silice.

In particolare sono state studiate le reazioni di recupero energetico attraverso la gassificazione della biomassa utilizzando reattori di tipo spouted bed e inoltre sono state definite le proprietà fisico-chimiche e il comportamento termico dei rifiuti studiati. I parametri di progettazione e funzionamento del reattore sono stati definiti in funzione delle caratteristiche del materiale trattato. Per la particolare configurazione del reattore, le proprietà fluidodinamiche del sistema sono state analizzate in dettaglio in una unità pilota di laboratorio a freddo dove sono state studiate le condizioni di stabilità e la prevenzione degli effetti di segregazione del reattore, mentre le prove di gassificazione dei rifiuti sono state realizzate in un impiantino pilota costruito ad hoc. Infine, il comportamento del reattore è stato descritto a livello fluido dinamico e termo-chimico utilizzando codici commerciali di simulazione.

E' stato poi studiato un processo di valorizzazione del materiale basato sull'estrazione di silice dalle ceneri del processo di valorizzazione termica e da ultimo sono state fatte prove preliminari sulla possibile applicazione della silice estratta in processi di adsorbimento di nitrati nelle acque reflue. 



\section{Valorización de residuos agrícolas}

El objetivo de la presente tesis doctoral es definir, desarrollar y evaluar una metodología eficiente de gestión de residuos, en particular agrícolas, para convertirlos en una nueva fuente de energía y en productos de valor añadido. Se estudia con especial atención el uso de la paja de arroz como vector energético y como precursor de productos basados en sílice.

Las reacciones de recuperación energética se han llevado a cabo a través de la gasificación de la biomasa en reactores de tipo Spouted Bed. Para ello, se han definido las propiedades físico-químicas y de comportamiento térmico de los residuos estudiados. Los parámetros de diseño y operación del reactor han sido definidos de acuerdo a las características del material tratado. Debido a la particular configuración del reactor, las propiedades fluido- dinámicas del sistema se han analizado en detalle en una unidad a escala de laboratorio. En ella se han estudiado las condiciones de estabilidad del reactor y aquellas que previenen los procesos de segregación. Se ha utilizado una unidad escalada a dimensiones de planta piloto para llevar a cabo las pruebas de gasificacion de los residuos. El comportamiento del reactor se ha modelado tanto a nivel fluido dinámico como a nivel térmico mediante el uso de diversos códigos comerciales de simulación.

Finalmente, se ha realizado una valorización material basada en la extracción de sílice de las cenizas resultantes del proceso de valorización térmica. Por último, se han realizado pruebas preliminares de la posible aplicación de dicha sílice en procesos de adsorción de nitratos presentes en agua. 



\section{Valorització de residus agrícoles}

L'objectiu de la present tesi doctoral és definir, desenvolupar i evaluar una metodologia eficient de gestió de residus, en particular agrícoles, per convertir-los en una nova font d'energia i en productes de valor afegit. S'estudia amb especial atenció l'ús de la palla d'arròs com a vector energètic i com a precursor de productes basats en sílice.

Les reaccions de recuperació energètica s'han dut a terme a través de la gasificació de la biomassa en uns reactors de tipus Spouted Bed. Per això, s'han definit les propietats físico-químiques i de comportament tèrmic dels residus estudiats. Els paràmetres de disseny i operació del reactor han estat definits d'acord a les característiques del material tractat. A causa de la particular configuració del reactor, les propietats fluid dinàmiques del sistema s'han analitzat amb detall en una unitat a escala de laboratori. S'hi han estudiat les condicions d'estabilitat del reactor i aquelles que prevenen els processos de segregació. S'ha utilitzat una unitat escalada a dimensions de planta pilot per dur a terme les proves de gasificació dels residus. El comportament del reactor s'ha modelat tant a nivell fluid dinàmic com a nivell tèrmic mitjançant l'ús de diversos codis comercials de simulació.

Finalment, s'ha realitzat una valorització material basada en l'extracció de sílice de les cendres resultants del procés de valorització tèrmica. Per ùltim, s'han realitzat proves preliminars de la possible aplicació d'aquesta sílice en processos d'adsorció de nitrats presents en aigua. 



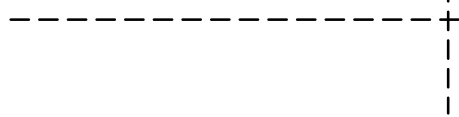

The aim of this doctoral thesis was to contribute to the development of sustainable alternatives for the use of agricultural residues as potential feedstock for new conversion processes.

The methodology followed to achieve this purpose is presented in the Figure below. Initially, an initial characterisation of the biomass was performed in order to evaluate its physico-chemical and thermal properties. The biomass was used as feed of gasification reactions carried out within a spouted bed reactor. The fluid dynamic behaviour of this reactor was studied in a lab scale plant working at room temperature. The study of the reactions of gasification at high temperature was performed in a scaled-up unit of the reactor. Lastly, the ashes obtained from the thermo-chemical reactions were treated and converted into silica whose adsorbent properties were tested.

\section{Agricultural residues}

\section{Energy valorisation $\stackrel{\text { Ashes }}{\longrightarrow}$ Material valorisation}

\section{Products assessment}





\section{Structure of the thesis}

The text of the thesis is structured under the following topics:

Firstly, two background chapters are introduced to frame the generalities regarding the problem that wants to be satisfied and the technology that will be applied:

Chapter 1. Introduction, motivation and main aim of the thesis

Chapter 2. Spouted Bed Technologies

Afterwards, two chapters are focused on both the characterisation of the biomass under study and the technology of Spouted Bed Reactors (SBR). Each chapter is sub-structured according to the general scheme: (i) short introduction and description of activities carried out; (ii) summary of relevant results; (iii) contributions of the thesis

Chapter 3. Biomass and its characterisation

Chapter 4. Characterisation of Spouted Bed Reactor

One further chapter is addressed to the study of the high temperature process applying all the information gathered in the previous chapters.

Chapter 5. Gasification in Spouted Bed Reactors

Another chapter is dedicated to the utilisation and conversion of the ashes into silica, its main properties and its principal applications.

\section{Chapter 6. Extraction of silica}

Finally, all the conclusions are gathered in the last chapter where the main results are highlighted. To conclude, some future lines of study are suggested.

Chapter 7. Conclusions and further work 



\section{Table of contents}

Summary

Riassunto

Resumen

Resum

Aim of the study

Structure of the thesis

Table of contents

Chapter 1. Introduction

1.1 Overview of the energy framework 27

1.2 Agricultural residues as a resource 30

1.3 Biomass conversion technologies

1.3.1 Thermo-chemical conversion reactions

1.3.2 Physico-chemical conversion processes

1.4 Motivation and main objectives

References in this chapter

Chapter 2. Spouted Bed Technologies

2.1 Types of gasifiers

2.2 Spouted Bed Reactors

2.2.1 Properties of Spouted Bed Reactors

2.2.2 Segregation phenomena

2.2.3 Additional devices

2.2.4 State of the art in gasification reactions within SBR

2.3 Modelling activity

2.3.1 Computational Fluid Dynamic modelling (CFD)

2.3.1.1 Eulerian-Eulerian approach

2.3.1.2 Eulerian-Lagrangian approach

2.3.2 Thermodynamic equilibrium models 
Gibbs free energy

2.3.2.3 Quasi-Equilibrium Temperatures approach

References in this chapter

Chapter 3. Biomass and its characterisation

I Summary

3.1 Physical characterisation of biomass

3.1.1 Density 78

3.1.2 Shape and dimension of samples

3.1.3 Influence of the moisture content of the samples

3.2 Chemical characterisation of biomass

3.2.1 Composition of biomass

3.2.2 Ultimate analysis

3.2.3 Proximate analysis

3.2.4 Calorific value

3.3 Thermal characterisation of biomass

3.3.1 Fundamentals of the TGA

3.3.2 Equipment

3.3.3 Analysis of the TGA experimental results

3.3.4 Kinetic analysis methodology

3.3.4.1 Obtaining of the Activation Energy

3.3.4.2 Obtaining of the mechanism and order of reaction

3.3.4.3 Obtaining of the pre-exponential factor: independence of the heating rate

3.4 Main results

References in this chapter

Chapter 4. Characterisation of Spouted Bed Reactors

I Summary

4.1 Fluid dynamic characterisation of the SBR

4.1.1 Experimental set-up

4.1.2 Experimental procedure 
Chapter 5. Reactions of gasification in a SBR

I Summary $\quad$............... 189

5.1 Generalities on gasification reactions

5.1.1 Reactions of gasification

5.1.2 Important parameters in gasification reactions

5.2 Experimental studies on a SBR

5.2.1 Description of the pilot unit and experimental procedure 198

5.2.2 Preliminary experimental tests 200

5.3 Modelling activities 202

5.3.1 Description of the models 202

5.3.2 Description of the methodology 204

5.4 Main results 207

References in this chapter 208

Chapter 6. Extraction of silica

I Summary

6.1 Chemical extraction of silica from ashes

6.1.1 Preparation of rice straw ash

6.1.2 Extraction of silica from rice straw ash

6.2 Characterisation of silica

6.2.1 Fundamentals of EDS

6.2.2 Results

6.3 Preliminary adsorption tests

6.3.1 Description of methodology

6.3.2 Experimental results

6.4 Main results

References in this chapter

\section{Chapter 7. Conclusions}

7.1 Conclusions 
Glossaries

List of Tables

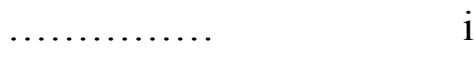

List of Figures ii

Abbreviations iii

Main symbology iv

Gracias. Grazie. Thank you. Gràcies 


\section{1}

\section{INTRODUCTION}

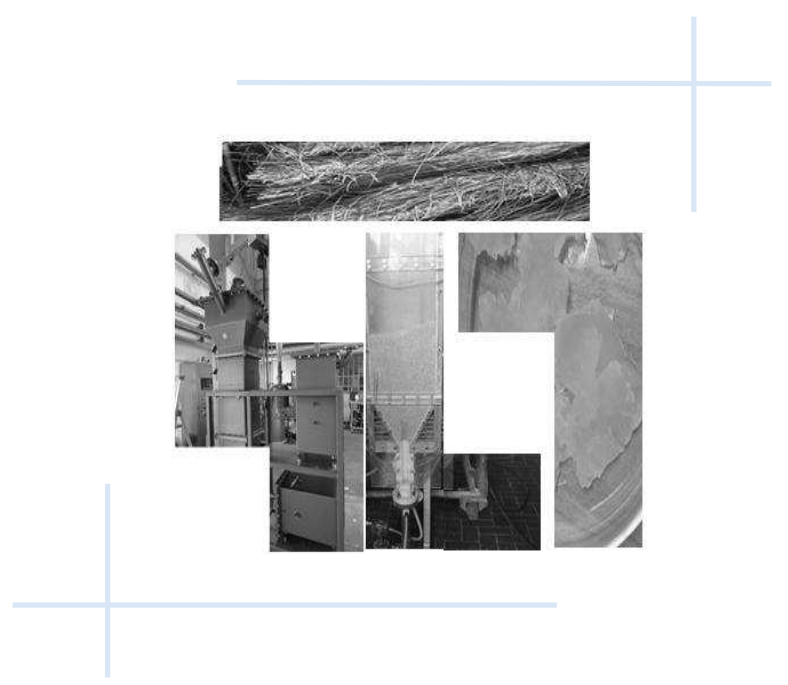

1.1 Overview of energy framework

1.2 Agricultural residues as a resource

1.3 Biomass conversion technologies

36

1.4 Motivation and main objectives

42

References in this chapter 

“...We have met the enemy.

He is us..."

Walt Kelly

\subsection{Overview of the energy framework}

As a result of world industrial development, a rapid increase in the use of fossil fuels has been encountered by all economic and social sectors to fulfill the new energy requirements. This high demand has led to a huge overuse of coal and oil based fuels, which has consequently resulted in a rapid consumption of these traditional fuels, raising concern about the depletion of fossil fuels. Also, a vast negative impact on the environment is caused by the massive use of these fuels, resulting in increased social awareness regarding their associated environmental problems (greenhouse effect, earth overheating, increased level of pollution).

For these reasons, new policies to support the production of energy from clean and renewable sources are being promoted by local, national and European entities in order to develop different alternatives to the use of fossil fuels worldwide. The European Union Member States (MS) committed to an increase in the use of Renewable Energy Sources (RES) to 20\% of gross total energy consumption and to $10 \%$ in the transport sector in each MS by 2020 (Directive 2009/28/EC). As a result of the new policies and support measures, the renewable energy share has already gone up from $8.5 \%$ in 2005 to $12.4 \%$ in 2010 and to $15 \%$ in 2013 (EurObserv'Er Report, 2014). At the moment, the Renewable Energy Progress Report issued by the European Commission in 2015 (Renewable Progress Report, 2015) shows that the gross final energy consumption was $15.3 \%$ in 2014, with the majority of MS advancing well towards 2020 targets. Renewable energy share in the heating and cooling sector was estimated to be $16.6 \%$ in 2014 and already $10 \%$ for electricity, mainly produced from wind and solar sources.

Biomass is expected to maintain a major role (57\% share) in meeting the EU's objectives followed by wind (17.6\%), hydrothermal (13.3\%), solar (6.3\%), heat pumps (4.9\%) and geothermal $(1.1 \%)$ sources (Scarlat N. et al, 2013). According to the aggregated data of the National Renewable Energy Action Plans-NREAPs (National Renewable Energy Action Plans, 2011), the total expected contribution of bioenergy in Europe should reach 5281 PJ by 2020. Biomass is expected to represent $17.4 \%$ of the projected EU heating and cooling systems and $6.6 \%$ of the electricity consumption.

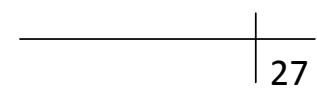


Table 1.1 shows the gross consumption of solid biomass for energy production of the 10 top consumer countries in the European Union during 2012 and 2013 (EurObserv'ER, 2014).

Table 1.1 Gross consumption of solid biomass for energy production in the European Union (Mtoe)

\begin{tabular}{|l|c|c|}
\multicolumn{1}{|c}{ Country } & Year 2012 & Year 2013 \\
\hline Germany & 10.931 & 10.902 \\
France & 9.779 & 10.842 \\
Sweden & 9.563 & 9.211 \\
Italy & $\mathbf{8 . 3 8 3}$ & $\mathbf{8 . 8 3 7}$ \\
Finland & 7.963 & 8.146 \\
Poland & 6.988 & 6.497 \\
Spain & $\mathbf{4 . 9 6 4}$ & $\mathbf{5 . 4 4 3}$ \\
Austria & 5.021 & 4.971 \\
Romania & 3.655 & 4.233 \\
United Kingdom & 2.512 & 3.319 \\
TOTAL EU & 88.639 & 91.459
\end{tabular}

The table shows a general increasing trend in the consumption of solid biomass. Italy and Spain are highlighted as $4^{\text {th }}$ and $7^{\text {th }}$ top consumer countries respectively, accounting for a $9.7 \%$ and $6 \%$ of the total within the European Union.

The Second Progress Reports on the progress in the promotion and use of energy from renewable sources (Progress Reports issued by Italy and Spain, 2013) showed that the main sources of biomass were wood and woody waste, municipal solid waste and biogas. Biomass from agriculture (by-products and residues) accounted around 3 million tons in Italy and 5 million tons in Spain.

These reports also show the importance of the uptake of renewable energies in saving greenhouse emissions. Table 1.2 shows that increasing savings have been produced both in Italy and Spain over the evaluated period, with the same trend followed by all MS. 
Table 1.2 Estimated greenhouse emissions savings from the use of renewable energy $\left(\mathrm{t} \mathrm{CO}_{2} \mathrm{eq} \cdot 10^{6}\right)$

(Data extracted from the Second Progress Reports by Italy and Spain, 2013)

\begin{tabular}{l|c}
\hline \multicolumn{1}{|c}{ Environmental aspects } & $\mathbf{2 0 1 2}$ \\
\hline Estimated total net greenhouse gas emission savings - Italy & $\mathbf{7 1}$ \\
\hline Estimated net GHG savings from the use of renewable electricity & 48 \\
\hline Estimated net GHG savings from the use of renewable energy in heating and cooling & 20 \\
\hline Estimated net GHG savings from the use of renewable energy in transport & 3 \\
\hline Estimated total net greenhouse gas emission savings - Spain & $\mathbf{5 7}$ \\
Estimated net GHG savings from the use of renewable electricity & 38 \\
Estimated net GHG savings from the use of renewable energy in heating and cooling & 12 \\
\hline Estimated net GHG savings from the use of renewable energy in transport & 7
\end{tabular}

In 2014, the European Commission presented a new EU framework on climate and energy for 2030, (Communication from the EC, 2014) setting new targets for reduction in greenhouse gas emissions to $40 \%$ below the 1990 levels and increasing the use of renewable energy to at least $27 \%$ of total consumption. This results in renewed ambitions for energy efficiency policies.

The future of the world's energy production and consumption patterns will mostly depend on the success or failure of the present technological and socioeconomic developments. And these developments are likely to rely on new sources of energy, yet to be discovered, or those coming from a breakthrough in the renewable field and its energy transport systems.

Within this framework, it is clear that biomass is expected to provide a high contribution to the use of renewable energy, especially in countries like Italy and Spain. However, more effort is still needed to further develop new technologies (or adapt existing ones) to make them suitable for the exploitation of renewable sources in an efficient and reliable way. 


\subsection{Agricultural residues as a resource}

The Renewable Energy Directive (Directive 2009/28/EC, 2009) defines biomass as the biodegradable fraction of products, waste and residues with biological origin from agriculture (including vegetable and animal substances), forestry and related industries including fisheries and aquaculture, as well as the biodegradable fraction of the industrial and municipal solid waste.

They can convert sunlight, water and nutrients in their cellular structures via photosynthesis and store the energy in chemical bonds. When the bonds between adjacent carbon, hydrogen and oxygen atoms are broken by digestion, combustion or decomposition, the energy that was stored in the chemical bonds is released. Figure 1.1 depicts the overall carbon cycle: trees take in carbon dioxide from the atmosphere which reacts with water and, in presence of sunlight, convert it into biomass. Typically, photosynthesis converts less than $1 \%$ of the available sunlight to stored chemical energy. If biomass is processed correctly (either thermal or biologically), the energy stored in the chemical bonds can be extracted and the carbon is oxidised to produce $\mathrm{CO}_{2}$ and water. This $\mathrm{CO}_{2}$ becomes available to produce new biomass becoming a cyclic process.

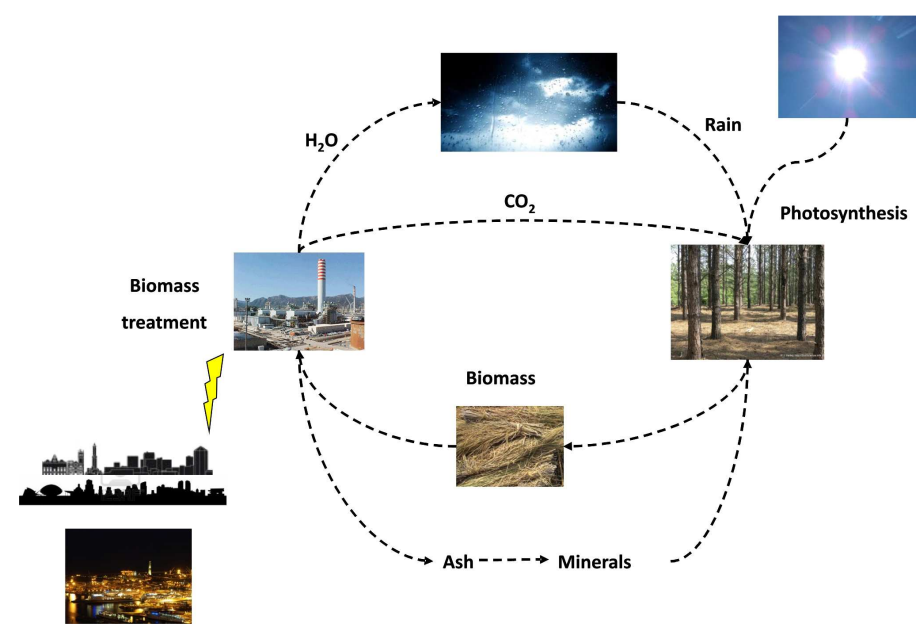

Figure 1.1. Carbon natural cycle

Biomass can follow different routes and be converted into three main types of products:

- Energy: electricity and/or heat

- Transport fuel

- Chemical feedstock 
Of particular interest of this thesis is the application of biomass as energy vector. Its renewable character, either through natural processes or as a by-product from human activities (i.e. organic waste) and its wide availability in most countries, make biomass a suitable source of energy. Its application might diversify the fuel-supply chain which in turn would lead to more secure and clean energy technologies. For this reason, attention is focused on the search of alternative biomass species that would replace conventional fossil fuels in an efficient way. The adequate energy conversion process and the specific operational conditions that need to be applied, define the required type of biomass for each case. As a result of high temperature reactions, a gaseous fuel is obtained that can be either further burnt in a turbine to produce electricity, or directed to heating purposes.

According to their properties and source, biomass can be divided into four different categories (McKendry P., 2002):

- Woody plants: bark, chips, foliage, trimming, forestry residues, sawmills, sawdust

- Herbaceous and agricultural residues: grass, straw, fruit harvest residues

- Aquatic plants: algae

- Animal and human waste: food processing, municipal solid waste, manure

Their main properties will define the most adequate conversion process in each case. Moisture content will play an important role: herbaceous biomass with high moisture content as for example residues from the harvest of fruit, will be more suitable for biological conversions (fermentation) while "dry" biomass like wood chips will be adequate for thermo-chemical reactions. Other parameters that need to be taken into account in the selection of a conversion technology are the ash content and its composition, which may have a negative impact on thermal processes, and the cellulose content, which has a great influence in biological processes.

For the purpose of this thesis, attention will be paid to "dry" biomass, more suitable for thermo-chemical conversions. Specifically, agricultural residues, and more precisely rice straw, will be studied in great detail (Figure 1.2). A wide description of its characteristics and composition will be performed in Chapter 3.

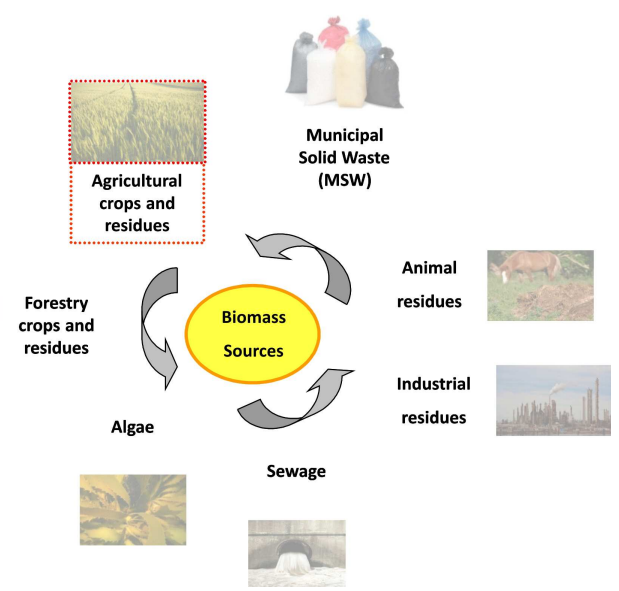

Figure 1.2. Biomass sources

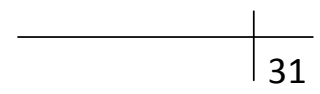


The increasing quantity of waste encountered in all sectors, especially in the agricultural area with an estimated production of 32.7 Mtoe/year in EU countries (Panoutsou et al, 2009), represents an environmental problem that needs to be tackled. Current practices like landfill or incineration present severe environmental and human health problems. Undesirable increased $\mathrm{CO}_{2}$ emissions and the abandonment on fields constitute an important hazard to fight against, due to the high land and water contamination that the decomposition of the materials exacerbate. Economic problems are also derived from an incorrect management of residual streams as they constitute extra costs for their producers, who need to pay for a correct waste dealing. A better use of these residues, co-products and by-products (always taking into account their environmental constraints) would not only help in the sustainable development of our society, but also tackle difficulties related to the shortage of energy sources and the necessity of new economic vectors as a way to promote industrial realities.

The estimates of the agricultural crop residues available for bio-products and bioenergy in each Member State show large spatial and temporal variations, due to different specific geographic and climatic conditions and status of agriculture activities, closely related to the crop production. Farm products like corn, sugar cane, sugar beet or wheat are traditionally sent to the production of bioethanol whereas rape seed, soybean, palm sunflower seed or jatropha are usual precursors of biodiesel. On the other hand, lignocellulosic materials such as straw or cereal plants, husk or wood can be either used for gas production and the further obtaining of energy or to the production of ethanol or bio-liquids.

The use of agricultural residues presents several advantages respect to traditional fossil fuels:

- Biomass is typically a waste material and its use reduces its disposal and mitigates potential associated environmental problems on soil, water and air.

- It is a renewable source and it contributes to the elimination of dependence on fossil fuels.

- It reduces greenhouse emissions and provides a carbon-neutral source of energy.

- Sulfur is emitted in little quantities in the form of $\mathrm{H}_{2} \mathrm{~S}$ in contrast to the $\mathrm{SO}_{2}$ emissions obtained in the combustion of fossil fuels. $\mathrm{H}_{2} \mathrm{~S}$ can be easily removed by absorption and sulfur can be further extracted, adding an extra value to the product.

- Nitrogen products of gasification are $\mathrm{N}_{2}$ or $\mathrm{NH}_{3}$, easily removed from the output stream, instead of $\mathrm{NO}$ and $\mathrm{N}_{2} \mathrm{O}$, obtained through combustion reactions.

- Socio-economic benefits can be obtained from biomass technologies: it can be a locally grown resource and a way to decentralise the energy economy, especially helpful in developing countries. 
There are, however, challenges to be overcame to fully develop this technology:

- Biomass fuels have low density and its collection, transportation and preparation prior to conversion must be carefully evaluated.

- Compared to fossil fuels, biomass has a high oxygen content (around 50\% in most cases), which lowers its combustion value compared to traditional fuels.

- It is seasonal and is greatly dependent on climate conditions. In addition, large storage volumes are required to ensure the availability of feedstock at any time and condition.

In particular, the present thesis explores the further possible uses for rice straw (Figure 1.3).

Rice is one of the most consumed crops worldwide, with an annual production of 700 million tons according to the Food and Agriculture Organization of the United Nations database (FAOSTAT, 2015). China and India are the major producers, with $28.7 \% \%$ and $19.5 \%$ of the total amount respectively.

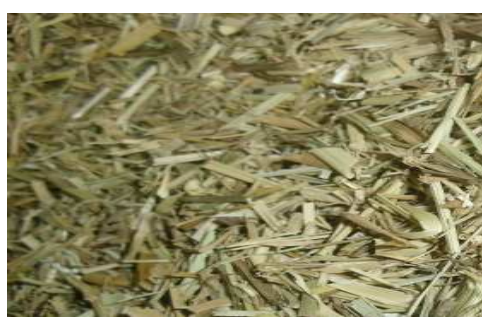

Figure 1.3. Rice straw residues Moreover, rice demand is expected to increase in future decades due to population and economic growth, especially in under-developed countries (Mohanty S, 2008). Overall, rice demand is expected to remain sustainable and, consequently, also the availability of these residues can be guaranteed.

The two main residual products from the rice industry are rice straw (crop residue that remains in fields after harvest) and rice husk (by-product obtained after rice post-processing). Figure 1.4 shows the annual quantity produced of each of the residues provided that for every kilogram of harvested paddy, 1 kilogram of straw and 0.2 of husk are produced. If fully converted, and assuming 700 million tons of rice is harvested, 191.8 billion litres of ethanol (Kim and Dale, 2004) could be produced form rice straw, which is equivalent to 199.9 billion litres of gasoline (Pimentel and Patzek, 2005). Italy and Spain account for an $80 \%$ of the European rice production: Italy is the leading European producer with a total cultivated surface of 220,000 ha. The crop is grown mainly in the Po basin (the Piedmont, Lombardy, Venetia, and the Romagna). The second European rice producer is Spain with 117,000 ha, Andalucía and Valencia are the main rice-producing regions, the latter enjoying a more stable water supply which benefits the production. Taking into account this production and the necessary environmental constraints, it is expected that straw could provide potential values of 3,205 kToe and 2,153 kToe in Italy and Spain respectively by 2020, which represents the $12 \%$ from the total biomass potential (Panoutsou et al, 2009).

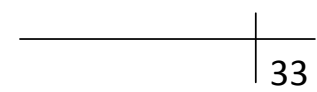




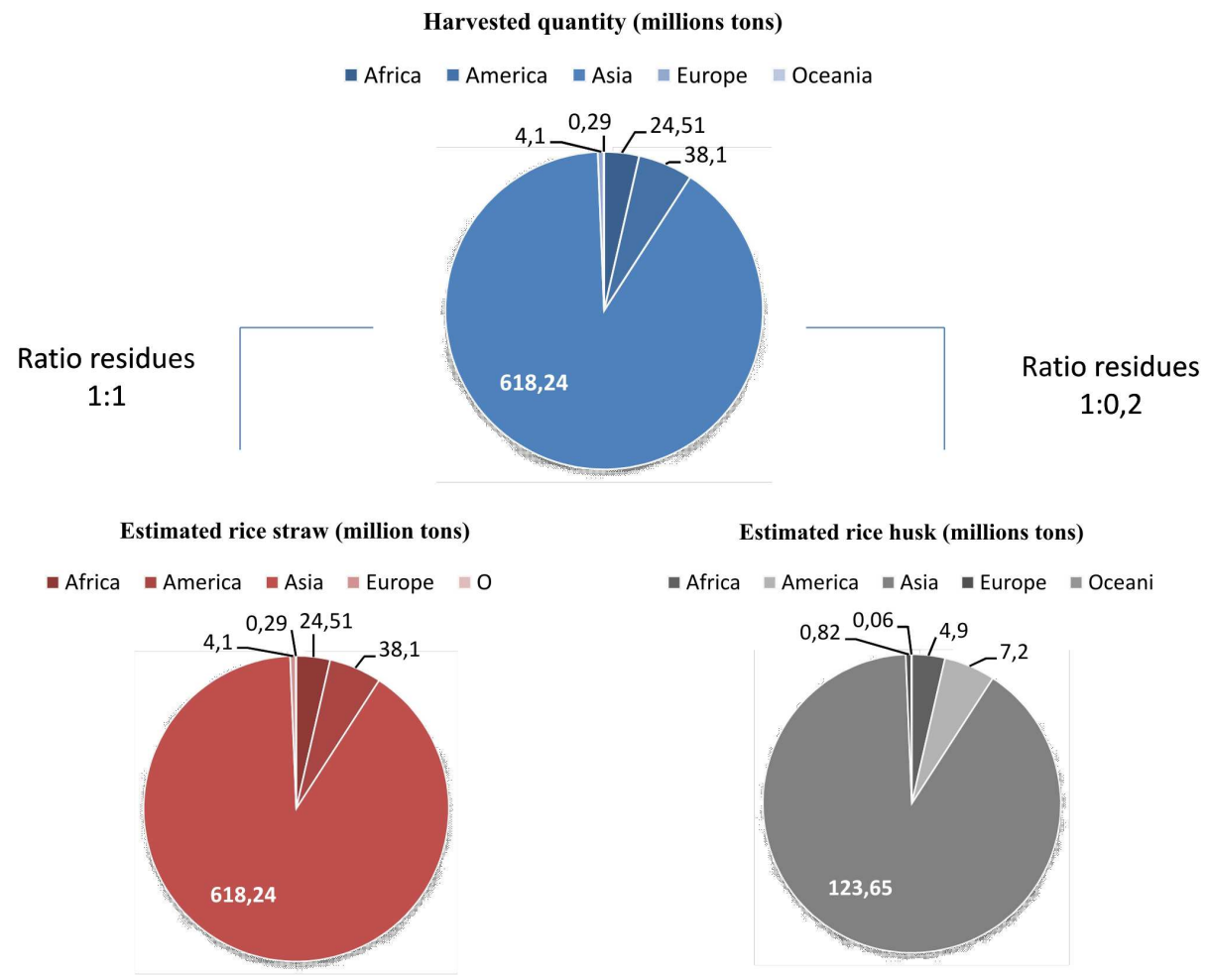

Figure 1.4. Production of rice, straw and husk (FAOSTAT, 2015)

For years, rice waste generated during harvesting was abandoned and left of decompose in fields, causing major die-offs of fish and other aquatic fauna in deeper areas. In order to alleviate this type of elimination, current European moratoria are permitting uncontrolled burning which also provokes harmful consequences related to air, flora and fauna pollution in wetlands.

Studies performed at the Albufera (Figure 1.5) (http://bit.ly/11dKntN), have shown that the emission of $\mathrm{CO}_{2}$ as a consequence of burning is about $2600 \mathrm{~kg} / \mathrm{acres}$, whereas its abandonment generates $18 \%$ more, along with methane, increasing the greenhouse effect. This is causing health problems in nearby municipalities such as headaches, asthma or rhinitis.

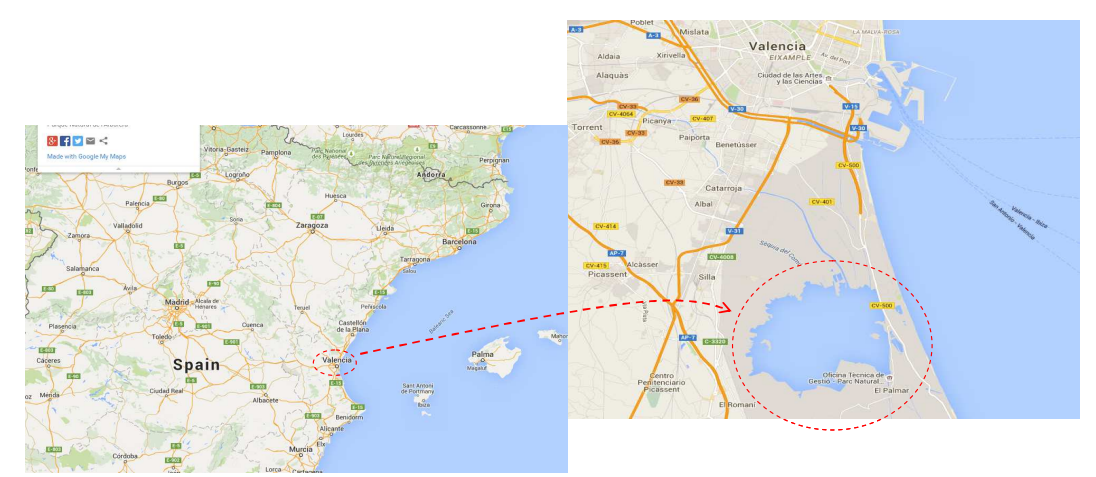

Figure 1.5. Location of Albufera - Valencia (Spain). Source: Google Maps 
New methods based on the waste-to-resource methodology have been proposed for these residues: rice straw and husk have been used as construction materials (Yang et al, 2003), adsorbents of heavy metals (Lakshmi et al, 2009) and for the production of energy and fuels.

The characteristic properties that these materials present make them suitable as feedstock with valorisation purposes. Rice straw is composed of cellulose, hemicellulose and lignin, that can undergo hydrolysis treatments and be converted into fermentable sugars and further conversions into ethanol (Chandrakant and Bisaria, 1998). Thermo-chemical conversions have also been proposed as an alternative to these management strategies taking advantage of its capacity for energy production, with high heating values around $15 \mathrm{MJ} / \mathrm{Kg}$ as stated by Lim et al (2012).

Even though the favorable properties, gasification of rice straw has not been totally developed at large scale (as it is the case for rice husk) due to logistic aspects: handling and collection or densification of materials to minimise costs, storage and transportation.

In general, one significant aspect to take into account when dealing with agricultural residues is the seasonal variation of the supply. Large residue volumes follow harvests, but residues throughout the rest of the year are minimal. Biomass facilities that depend significantly on agricultural residues must be either able to adjust output to follow the seasonal variation, or have the capacity to stockpile a significant amount of fuel. 


\subsection{Biomass conversion technologies}

Biomass can be converted into valuable products through three different routes:

- thermo-chemical: combustion, gasification, pyrolysis and liquefaction;

- physico-chemical: drying, dewatering, extraction;

- biochemical: digestion, fermentation.

The type of feedstock and the product that it is meant to be obtained will determine the most appropriate path to be followed. Figure 1.6 shows a schematic map of technologies, their resulting products and the potential end-user applications.

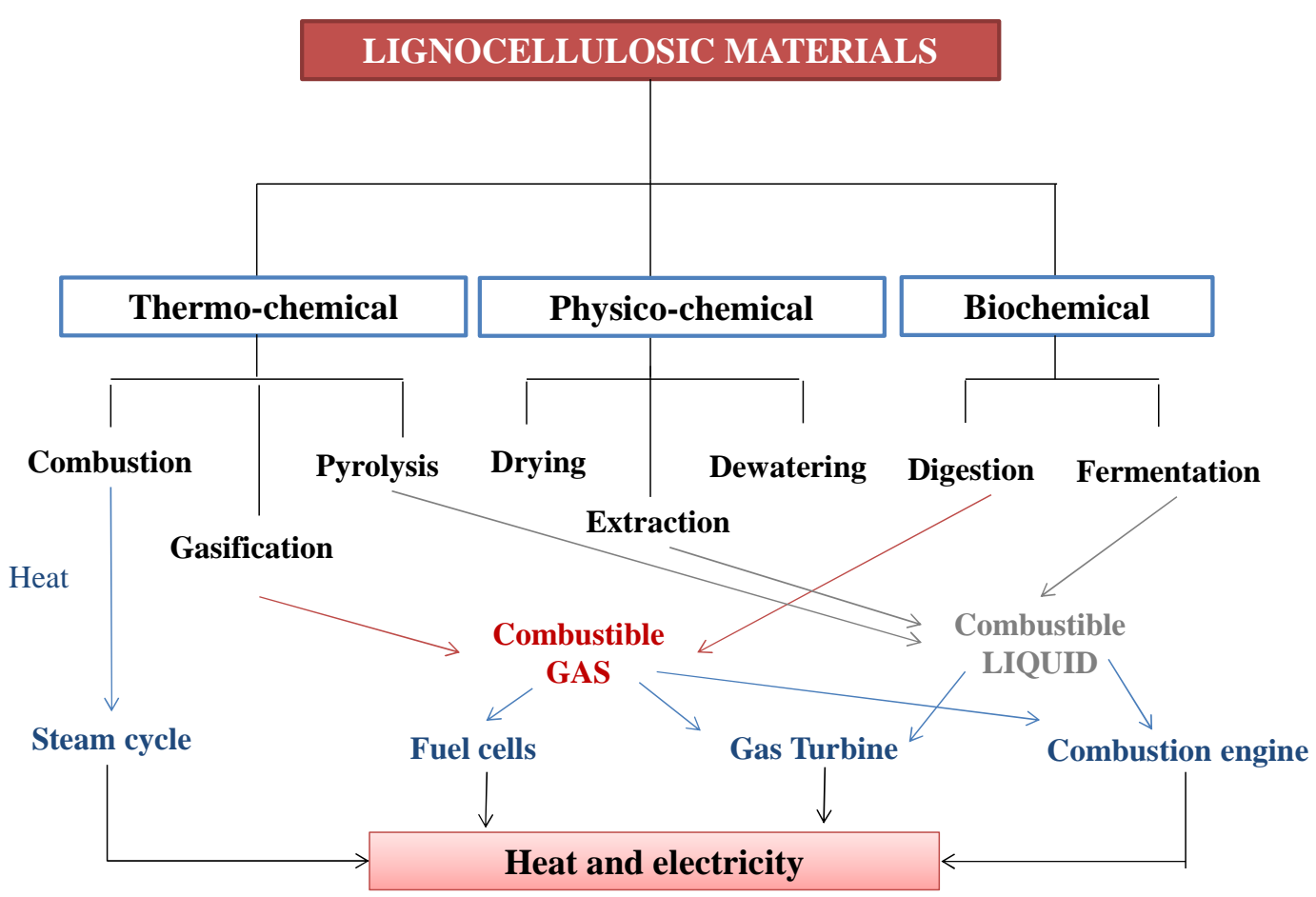

Figure 1.6. Map of technologies for lignocellulosic materials 
Biochemical conversions can be divided into aerobic and anaerobic reactions according to the presence (or not) of air during the process. The most common feedstock used is oilseeds (rapeseed, sunflowers ...) and sugary plants (corn, wheat, sugar beet ...). The main product is a bio-oil that can be used as received (after purification) or transesterified to produce biodiesel. Starch and sugar can be fermented to obtain either fuels (methane, alcohol), or bio-chemical products like organic acids.

The present work, however, will focus its attention on thermochemical reactions, more precisely on the gasification of the agricultural residues with the aim to obtain syngas to be further used with energy purposes. Moreover, new added value products (i.e. silica) will be produced by extraction from the ashes resulting in the former thermal process. In this way, a cyclic process is obtained and the zero-waste scenario methodology is promoted.

\subsubsection{Thermo-chemical conversion reactions}

The main thermo-chemical processes are combustion, gasification and pyrolysis. The difference among them is the quantity of oxidant used (if any) and, as a consequence, the percentages of the different products obtained from the thermal reactions.

Combustion is a well-established process to extract energy from the chemical bonds forming the biomass. The fuel is completely oxidised by the oxidant agent entering into the system in stoichiometric conditions. As a result, heat is released (exothermic process) and $\mathrm{CO}_{2}$ and $\mathrm{H}_{2} \mathrm{O}$ are obtained as main products. Combustion can be applied to any type of biomass and scale (i.e. from domestic applications to large power plants). Net bio-energy conversion efficiencies for biomass combustion plants range from 20 to $40 \%$ (electricity generation) and the highest efficiencies are obtained when biomass is co-combusted in coal-fired power plants (McKendry, 2002a).

Pyrolysis (from the latin decomposition by fire) reactions consist of the reduction of the biomass with no chemical reagents being introduced in the system. The heat needed to carry out the reactions is supplied externally (endothermic process) and the main product is bio-oil. Solid and gaseous fractions are also obtained in less quantity. Bio-oil can be used in engines and turbines as well as feedstock for refineries. There are, however, still problems to overcome like the poor thermal stability of the oil and its corrosivity which makes necessary a previous step of upgrading before certain applications.

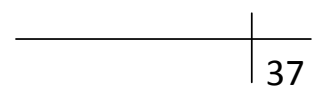


In gasification reactions, the oxidant agent (oxygen, air, steam or a mixture of them) is introduced to partially oxidise the biomass. The heat produced in the first instance is used to carry out the endothermic reactions (i.e. auto thermal process). The main product of these reactions is syngas.

The characteristics of the available feedstock, together with the product requirements, provide the necessary information for the correct decision on the most adequate parameters of the process to obtain maximum yields. The present thesis will provide a deep insight in gasification reactions and its advantages (and disadvantages) respect to the other two thermo-chemical routes.

\section{Reactions of Gasification}

Gasification is defined as the thermo-chemical conversion of carbonaceous materials into a combustible fuel, known as syngas. The reactions occur when a controlled quantity of oxygen (or air or steam or the combination of them) reacts at high temperature with the available carbon fraction of the biomass within a gasifier (McKendry, 2002b).

Gasification has been a well-known process since the end of the $18^{\text {th }}$ century when coal was the principal feed used to power gasification plants. The combustible gas was used for lighting and cooking purposes. In fact, lighting was one of the factors that helped the Industrial Revolution, allowing extended working hours in factories. The major gasification technologies (Winkler's fluidized bed gasifier in 1926 or pressurized moving-bed gasifier in 1931) were developed in this period. With the discovery of natural gas, the need for coal or biomass for gasification decreased and it was not until the Second World War that gasification regained attention. Oil supplies greatly diminished and the need to fuel Germany's massive war machinery led to the development of new synthetic routes to obtain oil from coal. A large number of cars operated on biomass onboard gasifiers (Figure 1.7). After the end of the Second World War, the availability of abundant oil from the Middle East eliminated the need for gasification for transportation.

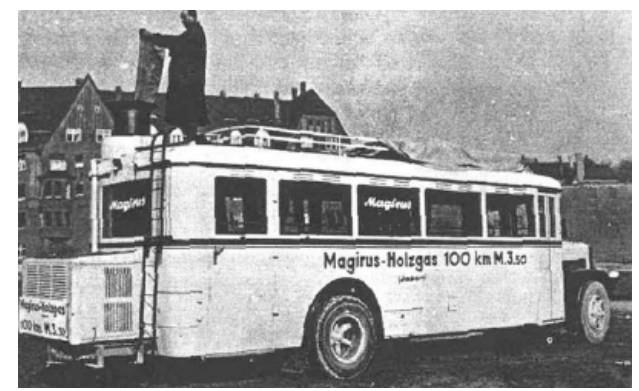

Figure 1.7. Bus with onboard gasifier used during the Second World War (http://www. woodgas.com/history.htm) 
Oil crisis in 1973 once again triggered the interest in biomass gasification, in order to reduce the dependence on imported oil. Global warming and political instability in some oil-producing countries boosted the renewed attention on renewable energies and IGCC (Integrated Gasification Combined Cycle) plants are in constant development (Basu, 2010).

The basis of gasification is to supply less oxidant than required for a stoichiometric combustion of the fuel. As a result, a gas containing a mixture of carbon monoxide (CO) and hydrogen $\left(\mathrm{H}_{2}\right)$ is obtained at high temperatures. This syngas can be further combusted, for example in a turbine to generate electricity, or used for heating purposes. The main stages involved in gasification are:

- Drying: the moisture content of the biomass is reduced at the temperature range of $100-150^{\circ} \mathrm{C}$. Contents below $10 \%$ are preferable in order to achieve high overall efficiencies.

- Devolatilisation: the biomass is decomposed in the absence of oxygen resulting in a reduction of the volatile matter. The biomass is reduced to solid charcoal. This stage is considered to be instantaneous (McKendry, 2002b).

- Oxidation: the solid carbonised biomass reacts with oxygen to form $\mathrm{CO}_{2}$. The hydrogen is also oxidised producing $\mathrm{H}_{2} \mathrm{O}$. If oxygen is in substoichiometric conditions, the carbon is partially oxidised resulting in the generation of $\mathrm{CO}$. These reactions are highly exothermic releasing a large amount of heat.

- Reduction: in absence (or substoichiometric presence) of oxygen, endothermic reactions of reduction take place above $800^{\circ} \mathrm{C}$. The main reactions describing the whole process of gasification are presented in Table 1.3.

Table 1.3. Main gasification reactions (McKendry, 2002b)

\begin{tabular}{lll} 
Reaction & \\
\hline $\mathrm{C}+0.5 \mathrm{O}_{2} \rightarrow \mathrm{CO}$ & $\begin{array}{l}\text { Partial carbon } \\
\text { combustion }\end{array}$ & $\mathrm{R} 1$ \\
$\mathrm{C}+\mathrm{O}_{2} \rightarrow \mathrm{CO}_{2}$ & Carbon combustion & $\mathrm{R} 2$ \\
$\mathrm{H}_{2}+0.5 \mathrm{O}_{2} \rightarrow \mathrm{H}_{2} \mathrm{O}$ & Hydrogen combustion & $\mathrm{R} 3$ \\
$\mathrm{C}+\mathrm{H}_{2} \mathrm{O} \rightarrow \mathrm{H}_{2}+\mathrm{CO}$ & Water-gas reaction & $\mathrm{R} 4$ \\
$\mathrm{C}+\mathrm{CO}_{2} \leftrightarrow 2 \mathrm{CO}$ & Boudouard reaction & $\mathrm{R} 5$ \\
$\mathrm{C}+2 \mathrm{H}_{2} \leftrightarrow \mathrm{CH}_{4}$ & Methane reaction & $\mathrm{R} 6$ \\
$\mathrm{CO}+\mathrm{H}_{2} \mathrm{O} \leftrightarrow \mathrm{CO}_{2}+\mathrm{H}_{2}$ & Shift reaction & $\mathrm{R} 7$ \\
$\mathrm{H}_{2}+\mathrm{S} \leftrightarrow \mathrm{H}_{2} \mathrm{~S}$ & $\mathrm{H}_{2} \mathrm{~S}$ formation & $\mathrm{R} 8$ \\
$0.5 \mathrm{~N}_{2}+1.5 \mathrm{H}_{2} \leftrightarrow \mathrm{NH}_{3}$ & $\mathrm{NH}_{3}$ formation & $\mathrm{R} 9$
\end{tabular}

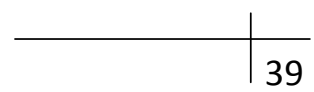


The low calorific value gas produced (typically around 4-6 $\mathrm{MJ} / \mathrm{Nm}^{3}$ ) can be burnt directly or used as a fuel for gas engines and turbines. Besides this, it can also be used as feedstock in the production of chemicals. (i.e. methanol). The overall efficiency will be determined by the initial composition of the biomass and also by the adequacy of the technology applied to carry out the conversion process. For this reason, an initial characterisation of the fuel is necessary to evaluate the suitability of the produced gas as energy carrier. diagram of Van Krevelen (1950) provides a useful tool to assess the energy content of a fuel through the analysis of its atomic ratios $\mathrm{O} / \mathrm{C}$ and $\mathrm{H} / \mathrm{C}$. The lower the respective ratios are, the greater the energy content of the material is.

A detailed description of the gasifiers and gasification reactions of several agricultural residues will further discussed in great detail in Chapter 4 and 5 respectively.

\subsubsection{Physico-chemical conversion processes}

Lignocellulosic biomass is widely recognised as a potential low-cost source for the production of high, added value materials when the adequate transformations are carried out. The main aim is to make use of its functional groups in order to generate novel products with new and improved properties for replacement of existing chemicals or for new applications. It is widely known that wood can be converted to paper pulp (39\%), chemicals such as xylose, acetic acid and furfural (11\%), black liquor (50\%) and energy. Wheat is converted to ethanol, grain residues and $\mathrm{CO}_{2}$ (generally captured and re-used to carbonate soda drinks) in approximately equal proportions and the sugar industry can produce a whole range of different products, of varying market size and value, such as ethanol, beet pulp for animal feed or high value chemicals.

By producing multiple products, the value derived from the biomass feedstock can be maximised by taking advantage of the differences in its components and intermediates. Many diverse industries such as food processing, pharmaceuticals, chemical, petroleum, mining, nuclear, automobile and vacuum manufacturing, can benefit from these inexpensive and renewable new resources.

Among all the potential applications, the use of agricultural by-products as precursors for the production of materials with high adsorptive capacity has been extensively studied recently (Bhatnagar and Sillanpa, 2010). Adsorption is defined as the process of collecting soluble substances that are in solution on a suitable interface. Innovative techniques based on adsorption are considered among the best for the removal of pollutants from water due to its ease of operation. 
Moreover, the possibility of removing different types of pollutants gives it a wider applicability in quality control for both domestic and industrial contaminated waters. Due to its porosity, highly specific surface area and capacity, activated carbon is the most widely used adsorbent to remove various classes of compounds from contaminated streams. However, the main disadvantages of activated carbon are high production and regeneration costs.

As an alternative, rice waste stands out as a good precursor of adsorbent materials for the removal of metals such as $\mathrm{Pb}$ (II) and $\mathrm{Hg}$ (Khalid et al, 1999), Cd (II) (Kumar and Bandyopadhyay, 2006) among others. Also, Orlando et at (2002) achieved a maximum adsorption capacity for nitrate from rice hull with values of $1.21 \mathrm{mmol} / \mathrm{g}$.

As a major challenge, the conditions for the production of "low-cost adsorbents" after surface modification for higher uptake of pollutants can be optimised once the feasibility is proven. In addition, the recovery of the adsorbate as well as adsorbent by regeneration, helps in the increase of the economic feasibility of the process.

Within this framework, the ashes resulting from the thermo-chemical reactions undergone by the rice straw (Chapter 5) will be submitted to a physico-chemical transformation process in order to extract the silica present in the material. This silica will be used as adsorbent material for the removal of pollutant species present in contaminated water. All this process will be studied in detail in Chapter 6. 


\subsection{Motivation and main objectives of the thesis}

An efficient use of resources plays a key role in activating economic agents and ensuring social welfare state and life quality. The development of new strategies for energy supply and for incentivising new markets must be paramount in policies all over the European Union. In this respect, biomass represents a major source of alternative energy vectors and the successful achievement of the challenges encountered nowadays by biomass-based technologies will ensure a sustainable social, economic and environmental development.

Within this framework, the main aim of this doctoral thesis is the development of a methodology for an improved and more sustainable management of waste, in particular agricultural residues, turning them into an alternative source of energy and added value products based on silica compounds.

This way, if operational conditions are well controlled, a potential hazardous compound during the thermal conversion becomes the source of renewable silica, closing a re-use cycle in which all the generated waste is addressed to recovery purposes to obtain new valuable materials, promoting the zero-waste scenario policies (Figure 1.8).

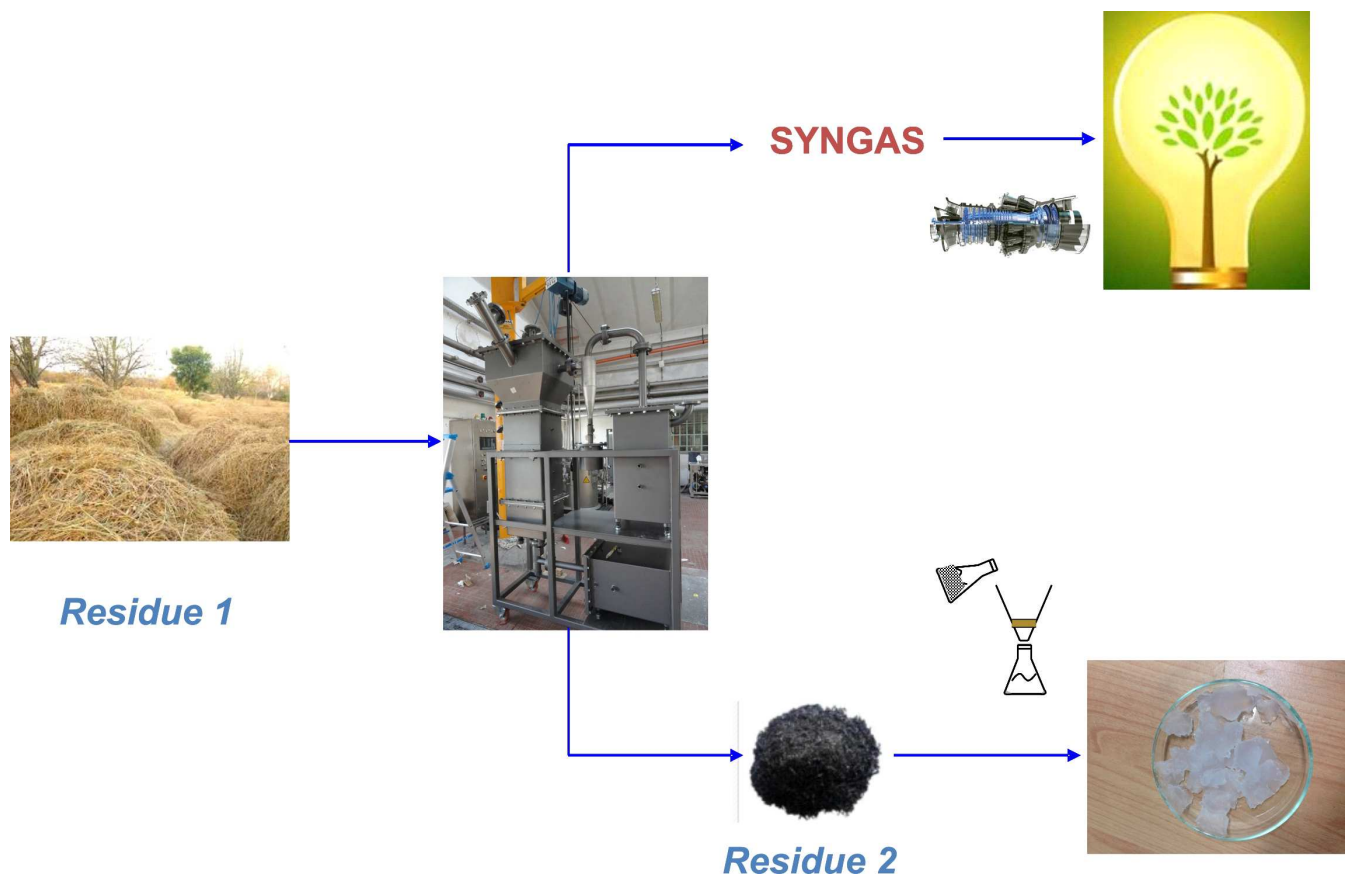

Figure 1.8. Scheme of the methodology and main aims of the thesis 


\section{References Chapter 1}

Basu P., Biomass Gasification and Pyrolysis. Practical design and theory. Ed. Elsevier Inc. (2010).

Bhatnagar A., Sillanpaa M. Utilization of agro-industrial and municipal waste materials as potential adsorbents for water treatment-A review. Chemical Engineering Journal 157, 277-296 (2010).

Chandrakant P., Bisaria V. Simultaneous conversion of cellulose and hemicellulose to ethanol. Critical Reviews in Biotechnology 18, 295-331 (1998).

Communication from the Commission to the European parliament, the Council, the European economic and social Committee and the Committee of the regions. A policy framework for climate and energy in the period from 2020 to 2030 (2014).

Directive 2009/28/EC of the European Parliament and of the Council of 23 April 2009 on the promotion of the use of energy from renewable sources and amending and subsequently repealing Directives 2001/77/EC and 2003/30/EC (2009).

EurObserv'Er. The state of renewable energies in Europe. The 14th EurObserv'Er report (2014).

Eurostat, Available at http://epp.eurostat.ec.europa.eu/portal/page/portal/eurostat/home, accessed August 2015

FAOSTAT - World Agriculture: towards 2015-2030. Summary report. Food and Agriculture Organisation of the United Nations, ISBN 92-5-104761-8 (2002).

FAOSTAT - Food and Agriculture Organization of the United Nations. Production crops (2013) $<$ faostat3.fao.org> accessed 12.11.2014.

Italy's Second Progress Report under Directive 2009/28/EC (2013).

Khalid, N., Ahmad, S., Kiani, S.N., Ahmed, J. Removal of mercury from aqueous solutions by adsorption to rice husks. Separation Science and Technology 34 (16), 3139-3153 (1999).

Kim S., Dale BE. Global potential bioethanol production from wasted crops and crop residues. Biomass and Bioenergy 26, 361-375 (2004).

Kumar U., Bandyopadhyay M. Sorption of cadmium from aqueous solution using pretreated rice husk. Bioresource Technology 97, 104-109 (2006).

Lakshmi UR, Srivastava VC, Mall ID, Lataye DH. Rice husk ash as an effective adsorbent: evaluation of adsorptive characteristics for Indigo Carmine dye. J. Environmental Management, 90, 710-720 (2009).

Lim J.S., Manan Z.A., Rafidah S., Alwi W., Hashim H., A review on utilisation of biomass from rice industry as a source of renewable energy, Renewable and Sustainable Energy Reviews 16, 3084-3094 (2012).

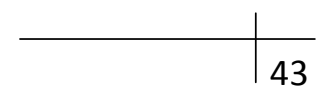


McKendry P. Energy Production from biomass (part 1): overview of biomass. Review Paper. Bioresource Technology 83, 37-46 (2002a).

McKendry P. Energy production from biomass (part 3): gasification technologies. Bioresource Technology 83, 55-63 (2002b).

Mohanty S. Rice crisis: the aftermath. Rice Today 7 (2008).

National Renewable Energy Action Plans, Italy (2011).

Orlando US, Baes AU. Nishijima W., Okada M. Preparation of Agricultural Residue Anion Exchangers and its Nitrate Maximum Adsorption Capacity. Chemosphere 48,1041-1046 (2002).

Panoutsou C., Eleftheriadis J., Nikolaou A., Biomass supply in EU27 from 2010 to 2030, Energy Policy $37,5675-5686$ (2009).

Pimentel D., Patzek TW. Ethanol production using corn, switchgrass and wood: biodiesel production using soybean and sunflower. Nat. Resource Res. 14, 65-76 (2005).

Regulation (EU) No 1291/2013 of the European Parliament and of the Council of 11 December 2013 establishing Horizon 2020 - the Framework Programme for Research and Innovation (2014-2020).

Renewable Energy Progress Report, Report from the Commission to the European Parliament, the Council, the European Economic and Social Committee and the Committee of the Regions (2015).

Report on progress in the promotion and use of energy from renewable sources pursuant to Article 22 of Directive 2009/28/EC Spain (2013).

Scarlat N., Dallemand J.F. Motola, V., Monforti-Ferrario F. Bioenergy production and use in Italy: recent developments, perspectives and potential. Renewable Energy 57, 448-461 (2013).

Van Krevelen D.W. Graphical-statistical method for the study of structure and reaction processes of coal. Fuel 29, 269-284 (1950).

Yang HS, Kim DJ, Kim HJ. Rice straw-wood particle composite for sound absorbing wooden construction materials. Bioresource Technology 86, 117-121 (2003). 


\section{SPOUTED BED TECHNOLOGIES}

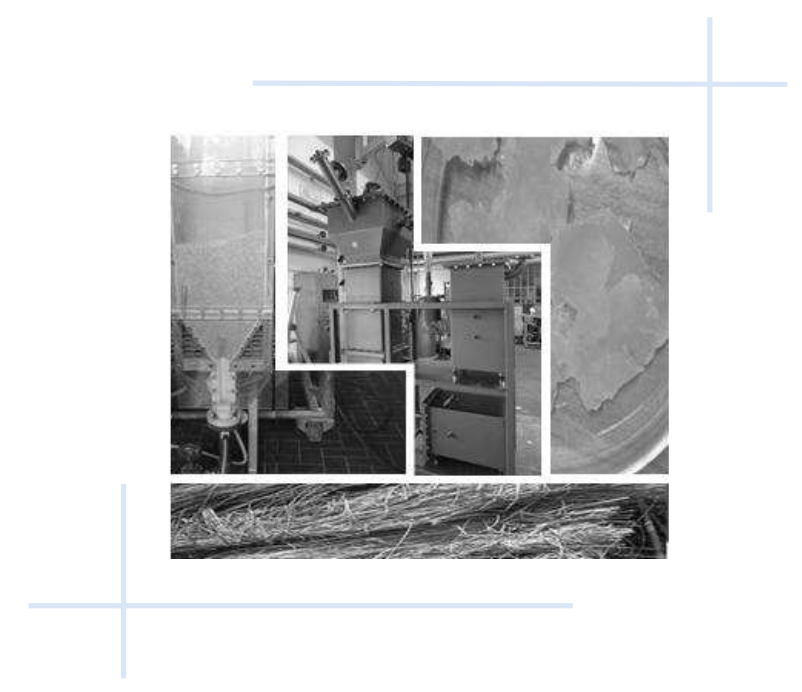

2.1 Types of gasifiers

2.2 Spouted Bed Reactors $\quad$....... 50

2.3 Modelling activity $\quad$....... 59

References in this chapter $\quad$...... 70 

"Voglio trovare un senso a tante cose anche se tante cose un senso non ce l'ha." Un senso. Vasco Rossi.

\subsection{Types of gasifiers}

The accurate selection of the gasifier and its operational conditions is key factors in the thermochemical conversion of the biomass. They can be classified in two major types of gasifiers according to the relative movement of the fuel and the gasifying medium: fixed beds and fluidised beds.

Solids move either countercurrently or concurrently to the gasifying flow in fixed bed reactors. This category can be divided into updraft gasifiers (where the flow of fuel and gas go countercurrent to each other), downdraft gasifiers (where feedstock is introduced at the top and the gas is introduced through a set of nozzles located on the side of the reactor) and cross-flow gasifiers (where the feed moves downwards while the air is introduced from one side). Two different configurations are presented in Figure 2.1.

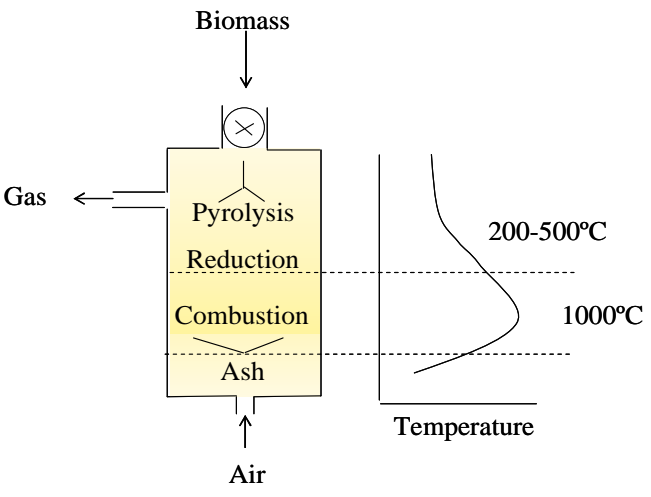

(a)

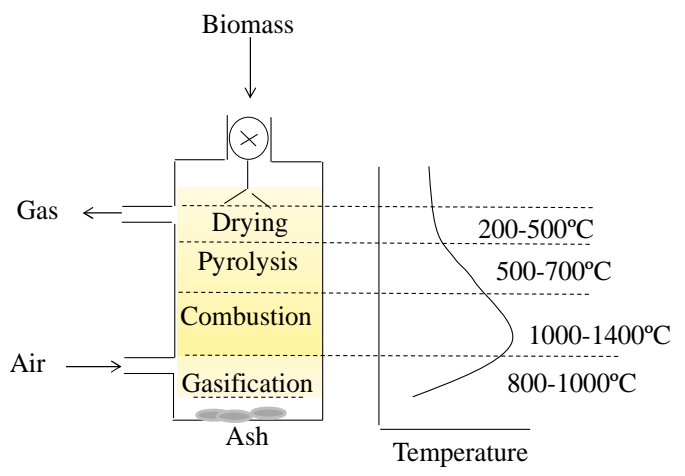

(b)

Figure 2.1. Scheme of an updraft gasifier (a) and a cross-flow gasifier (b)

The main advantage of fixed bed reactors is the simplicity of the process and the high operative temperatures achieved (above $1000^{\circ} \mathrm{C}$ ). This high temperature can, however, cause several corrosion problems due to it being unsuitable for fuels with high ash content such as crop residues. Furthermore, the product of reaction has a high tar content and a low heating value.

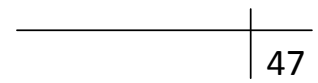


Fluidised Bed Reactors (FBR) were originally developed for coal gasification on a large scale. Their main advantage is the uniform temperature in the gasification zone, thanks to the addition of inert material to the bed which improves the heat exchange rates, the perfect contact between gas and solid achieved and the high level of turbulence (Gomez-Barea and Leckner, 2010). The produced syngas has a higher heating value and a lesser tar content respect to that from fixed bed reactors. Their main disadvantages are the large pressure drops of the system and the eventual erosion of the reactors.

Two configurations can be found for FBR: bubbling bed (BFB) (See Figure 2.2) and circulating fluidized bed (CFB).

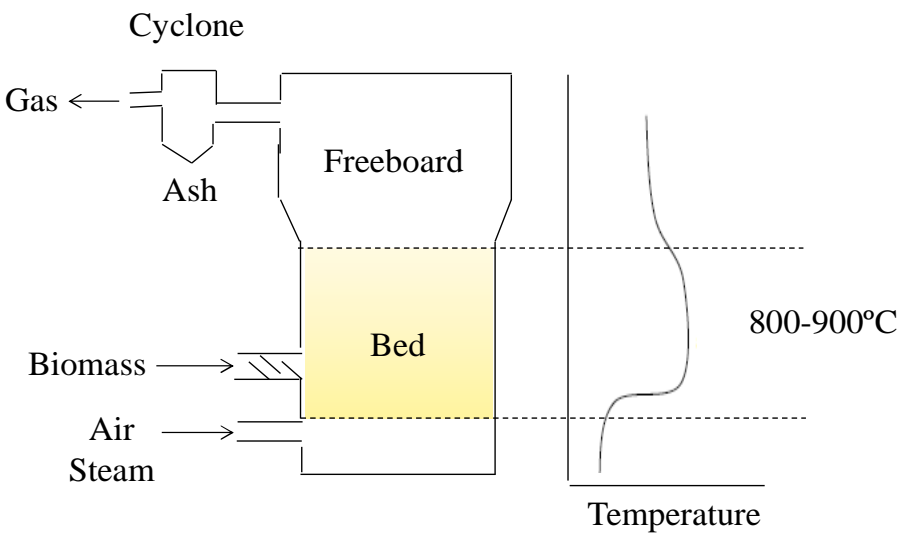

Figure 2.2. Scheme of a bubbling bed reactor

The BFB reactor is divided into two differentiated regions: a bed of particles in the lower part and a freeboard in the upper part. The gasifying agent entering into the reactor has to be adjusted so the particles of the bed are not carried out from the reactor. In addition, a cyclone is placed after the reactor to further purify the outgoing stream. If air is used as gasifying agent, the produced gas heating value can lie between 3.6-5.9 $\mathrm{MJ} / \mathrm{Nm}^{3}$.

No clear separation between the bed and the freeboard is found in the CFB. The flow velocity entering into the reactor is higher than in BFB and, as a consequence, the mixing of the bed material and feed is promoted and fully isothermal conditions are achieved. A higher quantity of particle matter is blown out of the gasifier and the solid material collected by the cyclone is recirculated into the gasifier. High char conversions are obtained and the syngas produced has low tar contents and high heating values. 
In particular, Spouted Bed Reactors (SBR) are a type of fluidised units in which the perforated base is replaced by one with a single orifice, normally in a central position. This configuration enhances the recirculation of particles providing higher yields and lower energy requirements respect to the traditional fluidised technologies (Mathur and Epstein, 1974). The technology based on fluidisation processes by means of spouted bed reactors will be studied in greater detail within this thesis. Section 2.2 provides an exhaustive description of the processes and basic concepts involved and Chapter 4 discusses the specific fluid dynamic properties of the device under study. 


\subsection{Spouted Bed Reactors}

The terms spouting and spouted bed were coined by Gishler and Mathur (1954) at the National Research Council (NRC) of Canada to describe an innovative device based on fluidisation technologies. It was first applied in 1954 as an alternative for the drying of badly slugged and moist wheat particles. The vigorous movement of particles achieved inside the reactor enabled the drying of the grain without damaging it. Soon, more applications were studied, varying the type of solids and the fluidising agents obtaining promising results. Having carried out these preliminary tests, Gishler and Mathur described this technology as "a flowing mechanism for solids and gas different from fluidisation but it achieves the same purpose for coarse particles as fluidisation does for fine materials".

Interest in these devices has been triggered in recent years and they are now applied in a broad range of industrial applications, mostly related to drying processes, due to the high fluid-solid contact achieved. Several applications of these devices acting as chemical reactors are being developed, with SBR currently standing out as a promising technology to carry out thermo-chemical reactions such as pyrolysis (Fernandez Akarregui et al, 2013), gasification (Erkiaga et al, 2014) and combustion (San Jose et al, 2014) of coal and different waste materials, as well as for reforming reactions (Lopez et al, 2013a) and solids coating, blending and granulation (Mathur and Epstein, 1974).

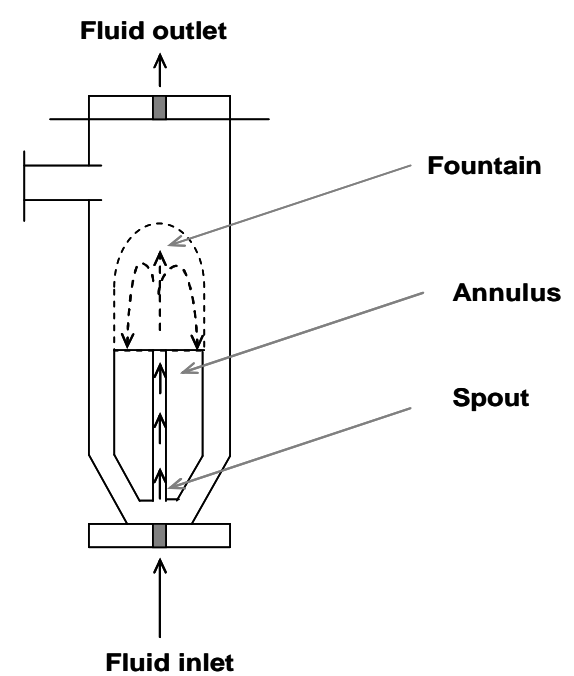

Figure 2.3. Schematic representation of a SBR Spouted Bed Reactors (SBR) are obtained by the perforated plate of a conventional reactor of fluidisation being replaced by a plate with a single orifice, normally centred in the base. This modification provides the system with an enhanced recirculation of solids which results in increased mass and energy transfer rates respect to that obtained with conventional techniques. Three different regions (annulus, spout and fountain) can be distinguished in a SBR. The central core of the reactor through which air flows is the spout, the surrounding annular region is the annulus and the solids above the bed surface entrained by the spout and going down the annulus 
form the so-called fountain. To eliminate dead zones at the bottom of the vessel, a conical base is normally used. Cylindrical column are most commonly used with fluid injection at the apex of the cone.

The overall process is composed of a dilute phase central core with upwards moving solids flowing in a concurrent fluid and a dense phase going down the annulus with counter-current percolation of fluid. As a result, a systematic cyclic pattern is achieved enhancing the effective contact between solid and gas. From a fluid dynamic point of view, the spout and fountain behaviours are similar to those in fluidised beds with particles dynamically suspended whereas the annulus acts more like a packed/moving bed. Figure 2.3 shows a schematic diagram of the spouting process.

A successful design and scale-up of these reactors must include a detailed study of the fluid dynamics properties of the system. The spouting phenomenon, its stability and the operating conditions depend on many factors and it occurs only with a specific combination of gas, solids and vessel configurations over a range of gas velocities. Map flow regimes are needed to characterise the behaviour of the system in first instance. Figure 2.4 represents a typical flow regime representation for the system PET-rice straw with rice straw present at $5 \% \mathrm{v} / \mathrm{v}$ and an initial bed height of $50 \mathrm{~cm}$. As shown in the figure, the bed contained in the vessel goes from a static condition (fixed bed - a) to an expanding bed when the incoming air is increased. When the spout reaches the surface of the bed (b), an initial unstable fountain is formed and, when air is sufficiently increased, the fountain becomes stable with the system considered to be in a spouting condition (c). If air is increased beyond the stable conditions, bubbling and slugging regimes are obtained.

These transitions can be also quantitatively represented in diagrams of pressure drop versus superficial gas velocity. Figure 2.5 shows the evolution of pressure drop across the bed particles $\left(\Delta \mathrm{P}_{\mathrm{b}}\right)$ with air velocity $\left(\mathrm{U}_{\text {in }}\right)$ for a silica-rice straw $(10 \% \mathrm{v} / \mathrm{v})$ mixture at an initial static bed of $35 \mathrm{~cm}$. Both figures were obtained from the experimental campaign performed in collaboration with Politecnico di Torino. 


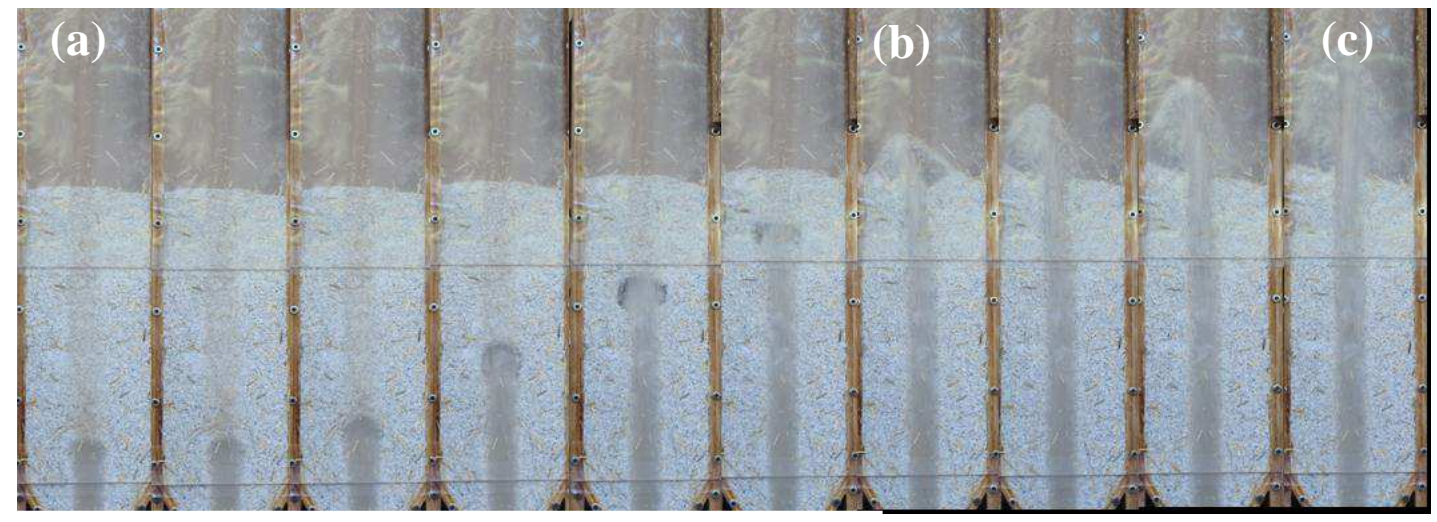

Figure 2.4. Flow regime for the system PET-rice straw (5\%v/v). Initial bed height: $50 \mathrm{~cm}$

$\Delta \mathrm{P}_{\mathrm{b}}$ increases as $\mathrm{U}_{\text {in }}$ goes up (corresponding to the situation (a) described in Figure 2.4) showing a linear trend $(\diamond)$. At certain point, $\Delta \mathrm{P}_{\mathrm{b}}$ reaches a peak value $\left(\Delta \mathrm{P}_{\max }\right)$. This situation is the equivalent as that described in Figure 2.4 (b) when the fountain is formed. Then, $\Delta \mathrm{P}_{\mathrm{b}}$ sharply decreases when the air velocity is further increased until a value that remains constant $\left(\Delta \mathrm{P}_{\mathrm{s}}\right)$ for a wide range of velocities (situation (c) in Figure 2.4).

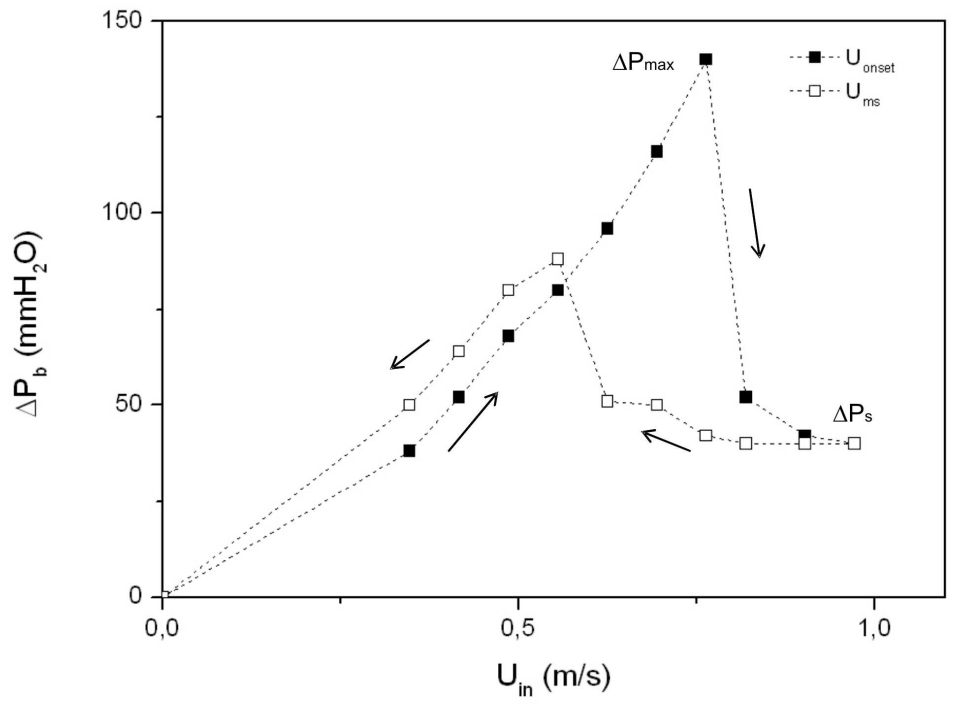

Figure 2.5. Evolution of the pressure drop across the bed with the inlet velocity (Rice straw $10 \% \mathrm{v} / \mathrm{v})$

Figure 2.5 also shows a hysteretic process characteristic of these devices. Once the stable conditions are achieved, the fluid velocity is decreased ( $\mathbf{a})$, and hysteresis is observed as the pressure required to break the bed and form the spout is higher due to the compacted initial situation in the ascending process no longer present in the descending path. 
General regime maps in which $\mathrm{H}$ (bed depth) is plotted versus $\mathrm{U}$ (superficial velocity) (Figure 2.6) are used in order to characterise the fluid dynamic behaviour of a given material contacted by a specific fluid (at a given temperature and pressure) in a fixed geometry.

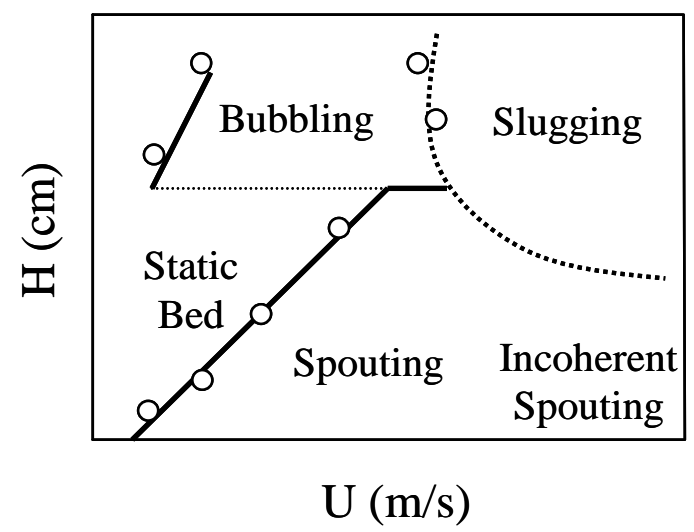

Figure 2.6. Example of a regime map with the different transitions occurring in SBR

Different transitions can be described with the aid of the regime maps. First of all, from the figure it can be seen that there is a maximum spoutable bed depth (dotted grey lines) beyond which spouting does not occur, obtaining instead a poor-fluidisation behaviour. It can also be observed that a high inlet velocity, results in slugging problems affecting the stability of the system.

From a design point of view, parameters like the minimum spouting velocity of the system and the height of the fountain will be necessary to define the specifications of the blower and the height required for the reactor respectively. Pressure drop will also be an important variable of study as it is closely related to the energy needs of the system. Several correlations have been developed for the prediction (especially useful in scaled-up applications) of the main properties of SBR (Mathur \& Gishler, 1955a), but the high dependence of the process with the involved solids makes them not completely suitable for the whole range of applications. Furthermore, in order to facilitate the scale up, square-based reactors were proposed (Rovero et al. 2012) in which the same phenomena occurring for the case of cylindrical bases were demonstrated to define their overall performance, enabling the use of existing correlations with slight adaptations.

Both experimental and modelling activities have been performed on two different scales spouted bed reactors. The fluid dynamic behaviour of the system has been studied in Chapter 4 by means of a conical square-based SBR to characterise the multiphase flow and its main properties. Most predictions of the main parameters of SBR are based on empirical correlations that tend to fall beyond the testing range of application and a careful study is needed prior any scale-up of the process. Successively, the suitability of these devices to perform high temperature reactions has

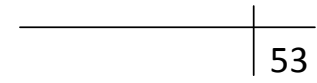


been evaluated in Chapter 5 where the gasification of agricultural residues with a scaled-up plant of the conical squared-based SBR has been discussed in detail.

\subsubsection{Properties of Spouted Bed Reactors}

SBR are sensitive to the geometrical properties of the device and the physical properties of the solids, mainly the diameter of particle. For this reason, it is necessary to delimit the operating conditions that allow a stable spouting regime. The initial design parameters for a SBR are:

-Fluid inlet diameter, $D_{i}$ : two different geometrical conditions need to be satisfied in order to obtain a stable spouting regime. The first condition is described in Eq. 2.1 as:

$$
\frac{D_{i}}{D_{C}} \leq 0.35 \text { (big particles) or } 0.1 \text { (thin particles) }
$$

with $\mathrm{D}_{\mathrm{i}}$ the inlet diameter and $\mathrm{D}_{\mathrm{C}}$ the diameter of the column (Becker condition, Mathur and Gishler, 1974). The second geometrical constraint associated to the inlet diameter is the spoutability condition by Chanddnami and Epstein (Mathur and Gishler, 1974) (Eq. 4):

$$
\frac{D_{i}}{d}<25 \div 30 \text { (cylindrical) or } 60 \text { (conical) }
$$

with $\mathrm{d}$ the diameter of particle.

This last condition is based purely on empirical findings and is irrespective of the particle density.

-Static initial bed height, $H_{b}: \mathrm{H}_{\mathrm{b}}$ is defined as the initial bed depth of particles calculated from the solid bulk density and the column diameter. Its more accurate measurement is calculated after strongly agitagiting the bed and gradually stopping the air flow.

-Maximum spoutable bed height, $H_{m}: \mathrm{H}_{\mathrm{m}}$ is directly related to the maximum quantity of solids that can be processed. The bed enters into the bubbling and slugging regime above that value and compromises the stability of the system. $\mathrm{H}_{\mathrm{m}}$ increases as the particle diameter and the ratio $D_{C} / D_{i}$ decreases. Several correlations have been proposed to calculate $H_{m}$ :

McNab and Bridgwater, 1977

$$
H_{m}=\frac{D_{C}^{2}}{d_{p}}\left(\frac{D_{C}}{D_{i}}\right)^{2 / 3} \frac{700}{A r}\left(\sqrt{1+35.9 \cdot 10^{-6} \cdot A r}-1\right)^{2}
$$

Thorley et al, 1959

$$
H_{m}=U_{m f}^{2}\left(\frac{D_{C}}{d_{p}}\right)^{2}\left(\frac{D_{C}}{D_{i}}\right)^{2 / 3} \frac{\rho_{g}}{2 g\left(\rho_{s}-\rho_{g}\right)} \quad \text { Eq. } 2.4
$$


-Cone angle, $\alpha_{c}$ : angles above $60^{\circ}$ are not recommended, as the solid recirculation rate becomes very poor. On the other limit, values below $28^{\circ}$ result in unstable operating conditions.

-Spout diameter, $D_{s}$ : the spout diameter and shape are important parameters affecting the gas and solid flow, mainly at the gas inlet zone. For simplicity, the value is taken independently of the longitudinal position along the bed. Bridgwater and Mathur (1972) proposed the following expression to predict their values.

$$
D_{s}=\frac{0.0071 \cdot G^{1 / 3} \cdot D_{c}^{3 / 4}}{\rho_{s}^{1 / 4}}
$$

The fluid dynamic parameters that need to be evaluated to obtain stable spouting and that define the operating conditions are:

-Minimum spouting velocity, $U_{m s}: \mathrm{U}_{\mathrm{ms}}$ is defined as the lowest gas velocity required to maintain the fountain. It can be calculated from the gas feed rate referred either to the inlet, or to the column section. However, the diameter of cylindrical sections should not be used for conical reactors as the velocity will not vary if the bed remains in the conical section. When the air inlet is slightly decreased, the fountain collapses and the pressure drop rises dramatically. Ums increases with increasing $\mathrm{H}_{\mathrm{b}}$ and takes its maximum value at the $\mathrm{H}_{\mathrm{m}}$. Besides, for a given air inlet area and bed height, $\mathrm{U}_{\mathrm{ms}}$ increases with bigger particles as a result of a higher porosity of the bed. The prediction of its value has been widely studied and several correlations have been proposed:

Mathur and

Gishler, 1955b

$$
U_{m s}=\frac{d_{p}}{D_{C}}\left(\frac{D_{i}}{D_{C}}\right)^{1 / 3}\left(\frac{2 g H\left(\rho_{s}-\rho_{g}\right)}{\rho_{g}}\right)^{1 / 2}
$$

Wu et al, 1987

$$
U_{m s}=10.6(2 g H)^{1 / 2}\left(\frac{d_{p}}{D_{C}}\right)^{1.05}\left(\frac{D_{i}}{D_{C}}\right)^{0.266}\left(\frac{H}{D_{C}}\right)^{-0.095}\left(\frac{\left(\rho_{s}-\rho_{g}\right)}{\rho_{g}}\right)^{0.256}
$$

Olazar et al,

1994

$$
U_{m s}=\frac{d_{p}}{D_{C}}\left(\frac{D_{i}}{D_{C}}\right)^{0.1}\left(\frac{2 g H\left(\rho_{s}-\rho_{g}\right)}{\rho_{g}}\right)^{1 / 2}
$$

-Average void fraction, $\varepsilon_{0}$ : the average void fraction of a bed under given conditions is defined as the relation between the volume of the bed $\left(\mathrm{V}_{\mathrm{b}}\right)$, the weight of the material in it $(\mathrm{W})$ and the particle density $\left(\rho_{\mathrm{s}}\right)$.

$$
\varepsilon_{0}=1-\frac{W}{V_{b} \cdot \rho_{s}}
$$

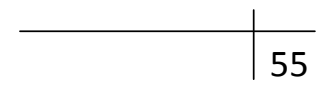


-Stable pressure drop, $\Delta P_{s}$ : it is defined as the necessary gas pressure drop along the bed of particles in stationary regime condition of spouting.

Mamuro and

Hattori, 1968

$$
-\Delta P s=\frac{3}{4} H_{m}\left(\rho_{s}-\rho_{g}\right)\left(1-\varepsilon_{m f}\right) g
$$

-Maximum pressure drop, $\Delta P_{\max }: \Delta \mathrm{P}_{\max }$ is defined as the gas pressure drop required to start the spout.

Malek and

Lu, 1965

$$
-\Delta P_{\max }=H\left(\rho_{s}-\rho_{g}\right)(1-\varepsilon) g
$$

-Bed expansion, E: due to the presence of small bubbles moving upwards through the bed of particles, the bed shows an expansion modifying its height.

Gorshtein and

Mukhlenov, 1964

$$
E=2.17(\operatorname{Re} / A r)^{0.33}\left(H / D_{i}\right)^{0.5}(\tan (\alpha / 2))^{-0.6}
$$

\subsubsection{Segregation phenomena}

Segregation is an important aspect to take into account in thermal processes, as the reacting phase is generally drowned in a stationary and inert phase, generally different in shape and density. In a standard fluidised system, the two phases tend to migrate at different bed levels, compromising the global behaviour. Conversely, conical spouted beds tend to perform well when the system is composed of particles of different sizes and densities obtaining low segregation phenomena. Figure 2.7 shows an example of this phenomenon where the result of a standard fluidisation process (a) and a spouting condition (b) using a mixture of rice straw-silica as bed material is shown.

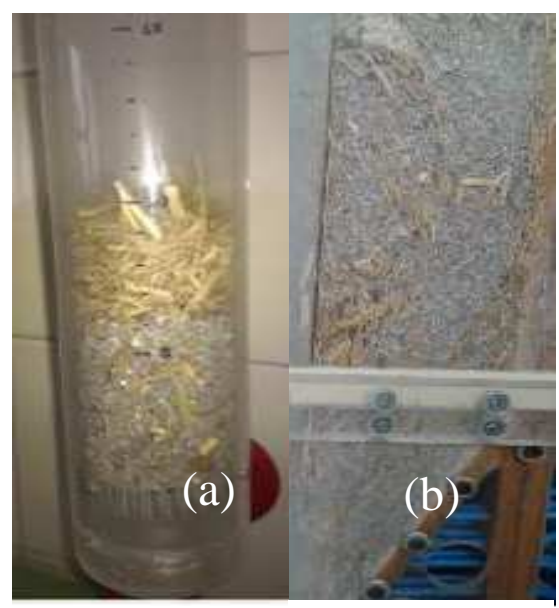

Figure 2.7. Segregation in a standard fluidisation reactor (a) and in a spouting bed reactor (b) 
As can be seen, a prominent segregation phenomenon is observed when a standard fluidisation regime is applied, obtaining an accumulation of the lighter component at the top of the bed. In contrast, a spouted regime leads to a uniform mix of materials as shown in Figure 2.5 (b). A complete study of these phenomena is presented in Chapter 4 with different bed mixtures.

\subsubsection{Additional devices}

The fluid dynamic performance of a SBR can be significantly improved by the addition of different devices which help to maintain stability conditions: draft tubes and additional fluidisation (spout-fluid reactors).

An impermeable draft tube is a vertically placed pipe, a few centimeters above the inlet of air and its main aim is to create a "forced" channel for the air to go through the bed of particles. As a result of this, more controlled solid circulation rates and residence times are obtained. An important parameter to take into account when designing these devices is the ratio $\mathrm{H}_{d} / \mathrm{H}$, with $\mathrm{H}_{\mathrm{d}}$ being the gap from the base to the bottom location of the draft tube (Figure 2.8a).

The secondary fluidisation, rather than a real device, is a structural configuration in which an auxiliary fluid flows through a series of holes and enters tangentially in respect to the main stream (Figure 2.8b). This configuration makes a hybrid reactor that shares some characteristics of both spouting and fluidisation, which is especially useful for coarse, sticky or agglomerating solids (Epstein and Grace, 2011). Often, the auxiliary fluidisation works together with a draft tube since it allows a fine regulation of fluid in the annulus.
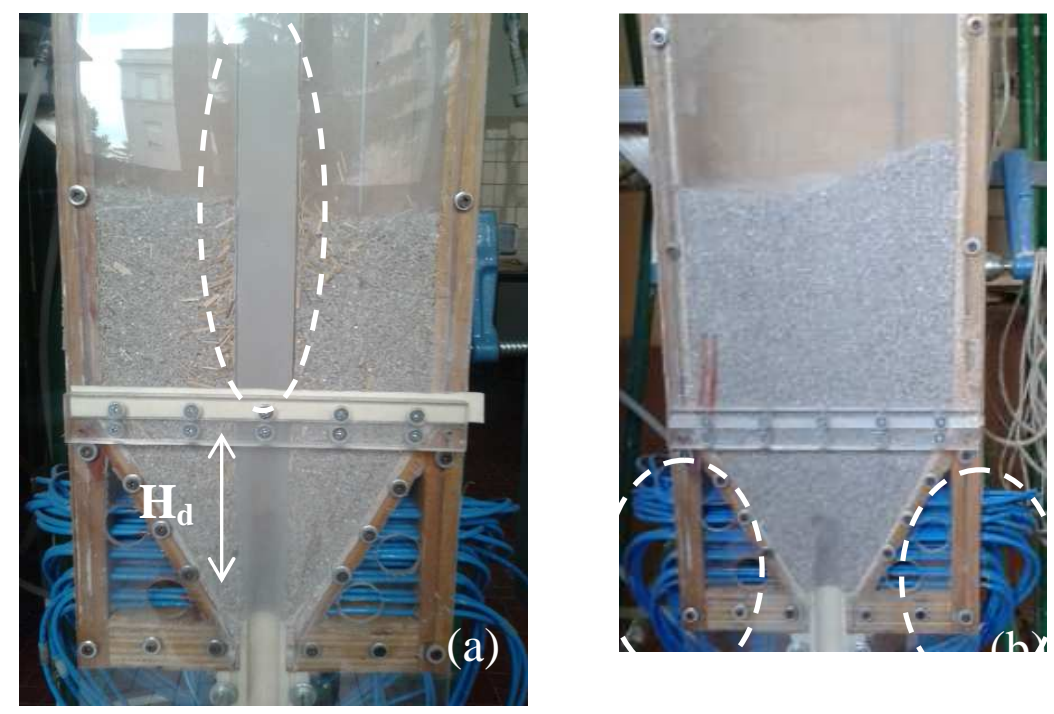

Figure 2.8. Draft tube (a) and secondary fluidisation (b)

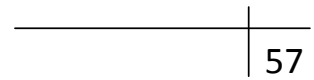




\subsubsection{State of the art in gasification reactions within SBR}

Watkinson and Lisboa (2011) provided a comprehensive presentation on the state of the art about the use of spouted bed reactors for gasification processes. Spouted beds have been used to treat several feedstocks, namely coal, coke, sludge and municipal wastes. The reactors are usually operated at atmospheric pressure and the agent used for gasification is a mixture of air and steam.

The extensive increase in gasification research has been mainly focused on biomass feedstock. Solid waste was gasified at $538-870^{\circ} \mathrm{C}$ by highly super-heated steam to produce a syngas product and an inert granular solid. A unit of 1 meter diameter using silica as bed material treated up to $680 \mathrm{~kg}$ waste/h and produced 12 to $18 \mathrm{MJ} / \mathrm{m}^{3}$ and ash containing $2 \%$ carbon (Zak and Nutcher, 1987). Gasification of wood charcoal was reported by Salam and Bhattacharya (2006). The reactor was tested with a normal circular gas inlet orifice and a novel circular slit orifice. Hoque and Bhattacharya (2001) compared fluidised and spouted bed gasification of coconut shells. Lopez et al used a SBR for the steam gasification of waste plastics (2013b) and more recently, Bernocco (2013) studied the feasibility of the application of SBR in high temperature biomass conversion technologies.

The scale to which gasification in SB has been demonstrated is of crucial interest to evaluate the potential for industrial implementation. Table 2.1 shows different studies in SB units with feed ranging from $0.16 \mathrm{~kg} \mathrm{coal} / \mathrm{h}$ to $700 \mathrm{~kg} / \mathrm{h}$ and reactors diameters between 0.16 and $1 \mathrm{~m}$.

Table 2.1. Summary of SB gasification studies

$\begin{array}{ccccccc}\text { Feed } & \text { Dc }(\mathbf{m}) & \text { Feed rate }(\mathbf{k g} / \mathbf{h}) & \text { Oxidant } & \mathbf{P}(\mathbf{M P a}) & \mathbf{T}\left({ }^{\circ} \mathbf{C}\right) & \text { Ref. } \\ \text { Coal } & 0.028 & 0.16 & \text { Air } & 1.3 & 850-900 & \text { Zhuo et al, 2002 } \\ \text { Coal } & 0.150 & 2.5-12 & \text { Air+steam } & 0.1 & 750-930 & \text { Foong et al, 1980 } \\ \text { Biomass } & 0.09 & 4.2 & \text { Air } & 0.1 & 607-842 & \text { Hoque et al, 2001 } \\ \text { Coal } & 0.4 & 50-100 & \mathrm{O}_{2} \text { +steam } & 0.1 & 1050-1170 & \text { Kikuchi et al, 1985 } \\ \text { MSW } & 1 & 700 & \mathrm{O}_{2} \text { +steam } & 0.1 & 540-870 & \text { EPA/540F, 1993 }\end{array}$




\subsection{Modelling activities}

The obtainment of the optimum operational conditions for a given process is the major goal of pilot and, once scaled, industrial units. Optimal conversion of chemical energy from biomass depends on many factors, like for example the choice of the gasifier, its sizing or the temperature or gasifying medium applied among others. Experimental trial and error tests provide the most reliable data to evaluate these units, even though they are expensive both in time and economic terms. There is, however, a major drawback: the change of one of the parameters of the process may lead to different optimum conditions. This is the case in processes that are size-dependent where the most adequate parameters found for the pilot plant might be no longer valid for the scaled-up unit. It is here where simulation activities play an important role for a reliable design. Achieving the right balance between experimental and modeled results will be the key to success.

The modelling of a gasifier will provide an accurate prediction of its performance (always depending on the degree of detail of the model) and will give quality parameters for the initial design and operating conditions that will allow the designer to sketch a solution and, with the available experimental data, adequately achieve the optimised solution. Modelling can also help in defining technical limits of the process, as well as identifying and preventing potential hazardous or undesired processes.

In conclusion, modelling can help in the assessment of a chemical process but it will never be a substitute for good experimental data. In this sense, the modelling activities of this thesis are validated and evaluated against experimental when possible data obtained from different pilot plants.

The modelling of the Spouted Bed Reactor under study was performed following two complementary methodologies: Computational Fluid Dynamics (CFD) for the study of the fluid dynamic properties of the system and Thermodynamic Equilibrium (and its further modifications to include the decomposition kinetics of the specific materials).

In this thesis, the fluid dynamic properties of the system (cold experiments) studied in Chapter 4 have been simulated with the aid of Fluent ${ }^{\circledR}$, a CFD commercial software. The assessment of the gasification itself (hot experiments) and the main operational conditions have been evaluated

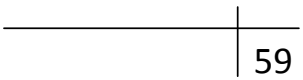


with different models framed in the thermodynamic equilibrium approach and further modifications including the specification of the calculated kinetic rates (Chapter 5).

An explanation of the main concepts and features of each modeling approach is presented in the following sections.

\subsubsection{Computational Fluid Dynamic modelling (CFD)}

CFD modelling has become a powerful tool for the study of multiphase flows thanks to the development of computational power and the advance of numerical algorithms. Currently, there are two different approaches: the Eulerian-Eulerian approach (Two Fluid Model, TFM) and the Eulerian-Lagrangian approach (Discrete Element Method, DEM). This thesis develops a TFM, but the following sections describe the fundamentals and applications for both cases.

A CFD code is based on the solution of the equations of conservation of mass, momentum, species and energy over a specific domain with suitable boundary conditions. The fluid dynamic phenomenon for a laminar flow is well defined by the Navier-Stokes equation. Moreover, the Reynolds-averaged Navier-Stoke $(\mathrm{k}-\varepsilon)$ model is usually applied when the turbulent situation needs to be taken into account.

Several computational methods have been developed and successfully applied to model reactions of fluidisation. Finite difference, finite element and finite volume are the three most common methods used for discretization prior the solution algorithm. Commercial softwares like ANSYS, ASPEN, Fluent, Phoenics, or CFD2000 provide reliable solutions in the field. The main aim at the moment, is to achieve a high degree of accuracy when these models are coupled with reaction kinetics and complex particle-particle interactions, among other situations, that would increase the level of accuracy between the simulated and the real solution.

\subsubsection{Eulerian-Eulerian approach}

Spouted Bed Reactors can be modelled by the Eulerian-Eulerian approach where the fluid and solids are treated as interpenetrating continua for mathematical purposes. Because the volume occupied by one cannot be occupied by the other, the concept of volume fraction is introduced where the sum must be equal to 1 . Moreover, additional closure equations are needed to describe the particle-particle and particle-fluid interactions. To sum up, the Eulerian-Eulerian approach accounts for: (a) conservation equations for mass and momentum for each phase with an interphase momentum transfer term; (b) closure of equations with a complete definition of interfacial forces, solids stress and turbulence in both phases; and (c) meshing of the domain, 
discretisation of equations and solution of the algorithm. A complete definition of all the components of the model is described in the following paragraphs.

Based on the general Eulerian multiphase model, the governing equations can be obtained assuming that there is no mass transfer between the spouting gas and the particles in the bed, the bed pressure gradient for stable spouting is constant and the densities of both phases are constant. Provided these assumptions, the volume fraction equation can be written as:

$\sum_{q=1}^{n} \varepsilon_{q}=1$

with $\mathrm{q}=\mathrm{g}$ (gas) or $\mathrm{s}$ (solid)

The mass conservation equation for each phase $\mathrm{q}(\mathrm{q}=\mathrm{g}, \mathrm{s})$ is:

$\frac{\partial}{\partial t}\left(\varepsilon_{q} \rho_{q}\right)+\nabla\left(\varepsilon_{q} \rho_{q} \vec{u}_{q}\right)=0$

where $\rho_{q}$ and $\bar{u}_{q}$ are the density and velocity of phase q respectively

Similarly, the momentum conservation equation for each phase $\mathrm{q}(\mathrm{q}=\mathrm{g}, \mathrm{s})$ is:

$\frac{\partial}{\partial t}\left(\varepsilon_{q} \rho_{q} \vec{u}_{q}\right)+\nabla\left(\varepsilon_{q} \rho_{q} \vec{u}_{q} \vec{u}_{q}\right)=-\varepsilon_{q} \nabla p+\varepsilon_{q} \rho_{q}\left(\vec{F}_{q}+\vec{F}_{l i f t, q}+\vec{F}_{v m, q}\right)+\nabla \tau_{q}+\sum_{q=1}^{n} \vec{R}_{p q}$

where $\mathrm{p}$ is the fluid pressure, $\vec{F}_{q}$ is the external body force, $\vec{F}_{l i f t, q}$ is the lift force and $\vec{F}_{v m, q}$ is the virtual mass force, $\tau_{\mathrm{q}}$ is the stress tensor and $\vec{R}_{p q}$ is the interaction force between phases. In most cases, only drag and gravity are considered, with lift force and virtual mass neglected.

The closure equations are represented by the term $\vec{R}_{p q}$ and define the drag force exerted on particles in fluid-solid systems. They are usually expressed by the product of a momentum transfer coefficient, $\beta$, and the relative velocity $\left(\vec{u}_{g}-\vec{u}_{s}\right)$ between the two phases.

The drag model most widely applied is that proposed by Gidaspow (2003) in which the dense phase is calculated by the Ergun equation (1952) whereas the dilute phase calculations are performed using the Wen-Yu (1966) expression:

$\left.\beta\right|_{\text {Ergun }}=150 \frac{\left(1-\varepsilon_{g}\right)^{2} \mu_{g}}{\varepsilon_{g}^{2} d^{2}}+1.75 \frac{\left(1-\varepsilon_{g}\right) \rho_{g}}{\varepsilon_{g} d}\left|\vec{u}_{g}-\vec{u}_{s}\right| ;$ forthe range $\varepsilon_{g}<0.8$

Eq. 2.16

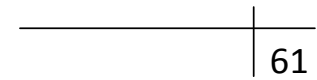


$\left.\beta\right|_{\text {Wen\&Yu }}=\frac{3}{4} \frac{\left(1-\varepsilon_{g}\right)}{d} \rho_{g} C_{D} \varepsilon_{g}^{-2.65}\left|\vec{u}_{g}-\vec{u}_{s}\right| ;$ for the range $\varepsilon_{g} \geq 0.8$

where $\mu_{\mathrm{g}}$ is the air viscosity, $\mathrm{d}$ is the particle diameter, $\vec{u}_{g}$ is the gas velocity, $\vec{u}_{s}$ is the particle velocity and $\mathrm{C}_{\mathrm{D}}$ the drag coefficient, expressed as:

$$
\begin{aligned}
& C_{D}=\frac{24}{\varepsilon_{g} \operatorname{Re}}\left(1+0.15\left(\varepsilon_{g} \operatorname{Re}\right)^{0.687}\right) ; \operatorname{Re}<1000 \\
& C_{D}=0.44 ; \operatorname{Re} \geq 1000
\end{aligned}
$$

With Re representing the Reynolds number:

$$
\operatorname{Re}=\frac{\rho_{g} d}{\mu_{g}}\left|\vec{u}_{g}-\vec{u}_{s}\right|
$$

To avoid the discontinuity at the boundary condition $\left(\varepsilon_{g}=0.8 ; \varepsilon_{s}=0.2\right)$ between the two equations, a switch function was introduced by Lu et al (2003) to obtain a rapid transition from one regime to the other one:

$$
\varphi_{g s}=\frac{\operatorname{arctg}\left[150 \cdot 1.75\left(0.2-\varepsilon_{s}\right)\right]}{\pi}+0.5
$$

Thus, the interaction between fluid and particles defining the drag force can be summarised as:

$$
\beta=\left.\varphi_{g s} \beta\right|_{\text {Wen\&Yu }}+\left.\left(1-\varphi_{g s}\right) \beta\right|_{\text {Ergun }}
$$

The second set of closure equations will be those representing the interfacial forces, solids stress and turbulence in both phases. For this purpose, the kinetic theory of granular flow (Lun et al, 1984) will be applied, considering it as an analogy to the well-established kinetic theory of gases. Analogous to the thermodynamic temperature for gases, a granular temperature $\Theta_{s}$ is introduced as a measure of particle velocity fluctuations:

$$
\Theta_{s}=\frac{u_{s}{ }^{2}}{3}
$$

The granular temperature conservation equation is:

$$
\left.\frac{3}{2}\left[\frac{\partial}{\partial t}\left(\varepsilon_{s} \rho_{s} \Theta_{s}\right)+\nabla\left(\varepsilon_{s} \rho_{s} \Theta_{s}\right) \vec{u}_{s}\right)\right]=\left(-P_{s} \cdot \vec{I}+\tau_{s}\right): \nabla \vec{u}_{s}-\nabla\left(k_{\Theta_{s}} \nabla \Theta_{s}\right)-\gamma \Theta_{s}+\phi_{s}
$$


where $\left(-P_{s} \cdot \vec{I}+\tau_{s}\right): \nabla \vec{u}_{s}$ is the generation of energy by the solid stress tensor, $k_{\Theta_{s}} \nabla \Theta_{s}$ is the diffusion of energy, $\Theta_{s}$ is the collisional dissipation of energy (defined by Eq. 2.25) and $\phi_{s}$ is the energy exchange between the fluid and solid phases $\left(\phi_{s}=-3 \beta \Theta_{s}\right)$.

$\mathcal{\Theta}_{s}=\frac{12\left(1-e_{s s}^{2}\right) \varepsilon_{s}^{2} \rho_{s} g_{0} \Theta_{s}^{3 / 2}}{d \sqrt{\pi}}$

where $e_{s s}$ is the interparticle coefficient of restitution and $g_{0}$ the radial distribution function, defined as (Bagnold, 1954):

$g_{0}=\left[1-\left(\frac{\varepsilon_{s}}{\varepsilon_{s, \max }}\right)^{1 / 3}\right]^{-1}$

where $\varepsilon_{s, \max }$ is the maximum particle volume fraction.

Figure 2.9 shows an schematic representation of the two flow regimes that can be distinguished in granular flows. At high particle concentrations (bed of the reactor) individual particles interact with the multiple neighbours and the normal forces and associated tangential frictional forces are the major contributions on the particle stresses. On the other hand, at low particle concentrations, stresses are mainly caused by particle-particle collisions or translational transfer of momentum (Campbell, 2006). The kinetic theory takes both approaches and considers the process as the sum of a rapidly shearing flow regime in which kinetic contributions are dominant, and a quasistatic flow regime in which friction is the dominant phenomenon. As a result, the estimation of the solid stress is defined by the concepts of solid "pressure" and "viscosity", included in the general conservation equation (Eq 2.24).

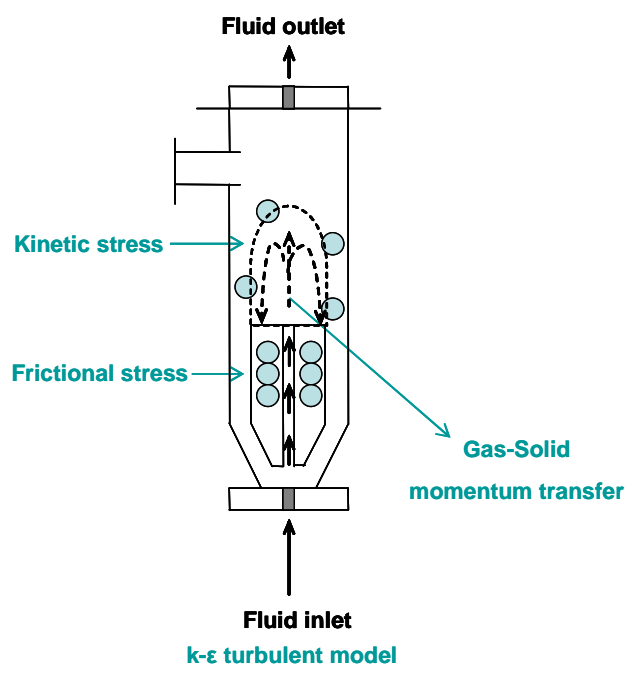

Figure 2.9. Schematic representation of the flow regimes in granular flows

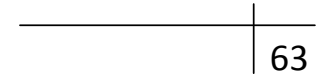


The kinetic solid pressure is given by (Lun et al, 1984):

$$
p_{s, k}=\varepsilon_{s} \rho_{s} \Theta_{s}\left[1+2 g_{0} \varepsilon_{s}\left(1+e_{s s}\right)\right]
$$

And the solid shear viscosity (Ding and Gidaspow, 1990):

$$
\mu_{s, k}=\frac{4}{5} \varepsilon_{s}^{2} \rho_{s} d g_{0}\left(1+e_{s s}\right) \sqrt{\frac{\Theta_{s}}{\pi}}+\frac{10 \rho_{s} d \sqrt{\pi \Theta_{s}}}{96\left(1+e_{s s}\right) g_{0}}\left[1+\frac{4}{5} g_{0} \varepsilon_{s}\left(1+e_{s s}\right)\right]^{2}
$$

The solid bulk viscosity is described using the definition by Lun et al (1984):

$$
\lambda_{s}=\frac{4}{3} \varepsilon_{s}^{2} \rho_{s} d g_{0}\left(1+e_{s s}\right) \sqrt{\frac{\Theta_{s s}}{\pi}}
$$

Finally, the dissipation fluctuation energy is (Jenkins and Savage, 1983):

$$
\gamma_{s}=3\left(1-e_{s s}^{2}\right) \varepsilon_{s}^{2} \rho_{s} g_{0} \Theta_{s}\left(\frac{4}{d} \sqrt{\frac{\Theta_{s}}{\pi}}-\nabla \vec{u}_{s}\right)
$$

Owing to the continuum description of the particle phase, the TFM approach also requires the description of the particle-particle interactions (Syamal, 1987):

$$
\varsigma=\frac{3\left(1+e_{s s}\right)\left(\frac{\pi}{2}+C_{f r} \frac{\pi^{2}}{8}\right) \varepsilon_{s 1} \rho_{s 1} \varepsilon_{s 2} \rho_{s 2}\left(d_{1}+d_{2}\right)^{2} g_{0}}{2 \pi\left(\rho_{s 1} d_{1}^{3}+\rho_{s 2} d_{2}^{3}\right)}\left|\vec{u}_{s 1}-\vec{u}_{s 2}\right|
$$

\begin{tabular}{|c|c|c|}
\hline Authors & Sofware used & Main contribution \\
\hline $\begin{array}{l}\text { Du et al, 2006a, } \\
\qquad 2006 b\end{array}$ & FLUENT & $\begin{array}{l}\text { Importance of the inclusion of interfacial forces and } \\
\text { solid stress }\end{array}$ \\
\hline Gryczka et al, 2008 & FLUENT & Comparison of different drag models \\
\hline Bettega et al, 2009 & FLUENT & Numerical scale-up study of SBR \\
\hline Santos et al, 2009 & FLUENT & $\begin{array}{l}\text { Obtaining of better results with 3D solution instead of } \\
\text { 2D }\end{array}$ \\
\hline Duarte et al, 2009 & FLUENT & $\begin{array}{l}\text { Good agreement in the prediction of particle } \\
\text { velocities and pressure drops }\end{array}$ \\
\hline Olazar et al, 2009 & MATLAB & Accurate flow patterns of solid and air inside the SBR \\
\hline
\end{tabular}

where $C_{f r}$ is the coefficient of friction between the two solid phases $(1,2)$.

Table 2.1 gathers the most significant scientific contributions following the Eulerian-Eulerian approach in the field of SBR.

Table 2.2. Contributions using the Eulerian-Eulerian approach for the simulation of SBR 


\subsubsection{Eulerian-Lagrangian approach}

In the Discrete Element Method (DEM), the fluid phase is treated as continuum by solving the time-averaged Navier-Stoke equations whereas the dispersed phase is solved by tracking the individual particles through the established domain. In this case, no closure laws are required to obtain the solution. The two phases are coupled by interphase forces as the dispersed phase can exchange mass, momentum and energy with the fluid phase. It is obvious that this type of modelling is more realistic and offers more accurate solutions. It is, however, more computationally demanding as a result of the large amounts of particles, and as a consequence, equations that need to be simultaneously solved.

There are also several disadvantages when DEM models are used to simulate SBR. First of all, it is difficult to establish the stable spouting condition, regardless of parameters like particle diameter or gas velocity. Furthermore, convergence of the fluid phase is extremely difficult to achieve as well as the right selection of the turbulence model to describe the central jet (Epstein and Grace, 2010).

Several models have been proposed following the DEM methodology. Kawaguchi et al (2000) obtained the typical flow patterns for SBR and Takeuchi et al (2005) obtained a 3D solution in cylindrical coordinate systems in quite good agreement with experimental results. In a further publication (2008) they also proposed a new method to treat boundary conditions in 3D. Finally, the application of SBR as chemical devices is of increasing interest from both experimental and modelling views. One of these studies was carried out by Limtrakul et al (2004) and their simulated solution based on the combination of DEM and mass transfer models were in close agreement with experimental results previously provided by Rovero et al (1983).

In conclusion, the characteristic parameters of SBR can be correctly reproduced by the EulerianEulerian and the Eulerian-Lagrangian approaches, with fairly close agreement to experimental results. This indicates that CFD modelling can result in being a useful tool to predict the behaviour of both the gas and the solids in a SBR. The initial choice of the adequate approach should be the TFM, due to its lower use of computational resources, whereas, the DEM modelling should be applied when a more physical and reliable solution is required. However, the main challenge continues to be the correct description of the turbulence in the fluid and solid phases, especially in the spout region. 


\subsubsection{Thermodynamic equilibrium models}

Thermodynamic equilibrium models are the most convenient tools when the aim of the simulation is the evaluation of different process parameters and feeds. They are independent of the gasifier design and for that reason, they cannot predict (at least in the first instance, without inserting additional equations) fluid dynamic parameters like fluidising velocity or design variables, such as the gasifier height. Even though they are called equilibrium models, as they are based on the achievement of thermo-chemical equilibrium, this situation may not be achieved mainly due to the relatively low operation temperatures (product gas outlet temperatures range from 750 to $1000^{\circ} \mathrm{C}$ ) (Bridgwater, 1995). Modified models are developed in these cases to take into account the potential deviations of behaviour respect to ideal conditions.

Equilibrium models have two general approaches: stoichiometric and non-stoichiometric. The stoichiometric approach requires a clearly defined reaction mechanism that incorporates all chemical reactions and species involved. In contrast, in the non-stoichiometric approach, no particular reaction mechanisms or species are involved in the numerical simulation. The only input needed to specify the feed is its elemental composition, which can be readily obtained from ultimate analysis data ( $\mathrm{Li}$ et al, 2004). The non-stoichiometric equilibrium model (Mathieu and Dubuisson, 2002) is based on minimising Gibbs free energy in the system without specifying the possible reactions taking place.

As shown by various authors (Smith and Wissen, 1982, Jarungthammachote and Dutta, 2007), the two approaches (stoichiometric and non-stoichiometric) are essentially equivalent. A stoichiometric model may also use free energy data to determine the equilibrium constants of a proposed set of reactions.

Equilibrium models are considered to be effective at high temperatures $(\mathrm{T}>1500 \mathrm{~K})$ when the system can be successfully described by its equilibrium condition with no variations in time occurring (Li et al, 2001).

\subsubsection{Stoichiometric approach}

The stoichiometric method is developed using the chemical reactions and species involved by applying atomic and chemical equilibrium (through the kinetic constant) balances. Desrosiers (1979) showed that under gasification conditions (with temperatures between 600 and 1500K) the only species present at concentrations higher than $10^{-4}$ (\%mol) are $\mathrm{CO}, \mathrm{CO}_{2}, \mathrm{CH}_{4}, \mathrm{H}_{2}, \mathrm{~N}_{2}$, $\mathrm{H}_{2} \mathrm{O}$ and solid carbon (graphite).

As a result, for a reaction of 1 mol of biomass being gasified with d moles of steam and e moles of air following the scheme: 
$\mathrm{CH}_{a} \mathrm{O}_{b} \mathrm{~N}_{c}+d \mathrm{H}_{2} \mathrm{O}+e\left(\mathrm{O}_{2}+3.76 \mathrm{~N}_{2}\right) \rightarrow n_{1} \mathrm{C}+n_{2} \mathrm{H}_{2}+n_{3} \mathrm{CO}+n_{4} \mathrm{H}_{2} \mathrm{O}+n_{5} \mathrm{CO}_{2}+n_{6} \mathrm{CH}_{4}+n_{7} \mathrm{~N}_{2}$

Eq. 2.32

where $n_{i}$ are the stoichiometric coefficients giving the distribution of products, the heterogeneous system of equations is described by:

Atomic balance of C: $\mathrm{n}_{1}+\mathrm{n}_{3}+\mathrm{n}_{5}+\mathrm{n}_{6}=1$

Atomic balance of $\mathrm{H}: 2 \mathrm{n}_{2}+2 \mathrm{n}_{4}+4 \mathrm{n}_{6}=\mathrm{a}+2 \mathrm{~d}$

Eq. 2.34

Atomic balance of O: $n_{3}+n_{4}+2 n_{5}=b+d+2 e$

Eq. 2.35

Atomic balance of $\mathrm{N}: \mathrm{n}_{7}=\mathrm{c}+7.52 \mathrm{e}$

Eq. 2.36

with $\mathrm{a}, \mathrm{b}$ and $\mathrm{c}$ the mole ratios $(\mathrm{H} / \mathrm{C}, \mathrm{O} / \mathrm{C}$ and N/C) determined by the ultimate analysis of the biomass.

Together with the atomic balance equations, the equilibrium constants (defined as Eq. 2.37) for the reactions of water-gas, Boudouard, and methanation (R4, R5 and R6 respectively from Table 1.3 in Chapter 1) complete the set of equations as follows:

$$
K=\prod_{i}\left(x_{i}\right)^{v i}\left(\frac{P}{P^{0}}\right)^{\sum_{i} v i}
$$

where $\mathrm{x}_{\mathrm{i}}$ is the mole fraction of species I in the ideal gas mixture, $v_{\mathrm{i}}$ is the stoichiometric coefficient and $\mathrm{P}^{0}$ is the standard pressure.

The whole set of equations (stoichiometric and equilibrium) are solved simultaneously to find the coefficients $n_{i}$ and hence, the composition of the product gas. It is clear that the complexity of the model (and its calculations) increases with the increasing number of species and equations considered. Given a reaction mechanism, the model predicts the maximum achievable yield of products as well as limiting thermodynamic conditions.

Some authors have reported results on the application of the stoichiometric approach to the study of the gasification of biomass. Zainal et al. (2001) modelled the biomass gasification process on the basis of stoichiometric thermodynamic equilibrium. Jarungthammachote and Dutta (2007) developed a thermodynamic equilibrium model based on the equilibrium constant for predicting the composition of a producer gas in a downdraft gasifier. They used coefficients for correcting the equilibrium constant of the water-gas shift reaction and the methane reaction in order to improve the results from the model. Those coefficients were obtained from the comparison between the model and the results of other researchers' experiments. The predicted results from the modified model satisfactorily agree with experimental results reported by Jayah et al. (2003).

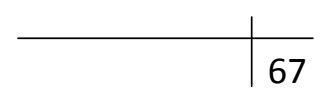




\subsubsection{Non-stoichiometric approach - Minimisation of Gibbs free energy}

The main advantage of these models is that no knowledge of the specific mechanism of reaction is required to solve the problem. By definition, a reacting system reaches stable equilibrium conditions when the Gibbs free energy of the system is at its minimum. The only necessary input for the calculation of this value is the elemental composition of the feedstock, given by its ultimate analysis.

The Gibbs free energy $(\mathrm{G})$ of a system with $\mathrm{N}$ species $(\mathrm{i}=1 \ldots \mathrm{N})$ can be defined as:

$$
G=\sum_{i=1}^{N} n_{i} \Delta G_{f, i}^{0}+\sum_{i=1}^{N} n_{i} R T \ln \left(\frac{n_{i}}{\sum n_{i}}\right)
$$

where $\Delta G_{f, i}^{0}$ is the Gibbs free energy of formation of species i at the standard pressure of $1 \mathrm{bar}$.

The equation is solved for all the unknown $n_{i}$ to minimise $G$ with the constraints of the overall mass balances of the individual elements.

Jarungthammachote and Dutta (2008) applied the non-stoichiometric equilibrium model to three types of gasifiers: a central jet spouted bed, a circular split spouted bed and a spout-fluid bed. The simulation results showed a significant deviation from the experimental data, especially for $\mathrm{CO}$ and $\mathrm{CO}_{2}$. One important factor was the carbon conversion and so, the model was modified to consider its effect. The results improved and were closer to the experimental data. However, a high accuracy could not be achieved for the spouted-bed gasification process. The heating value was also discussed as it is an important parameter for the estimation of energy content in the producer gas. The modified model predicted heating values that were generally higher than those from experiments because of the over-prediction of the $\mathrm{CO}$ content in the producer gas.

\subsubsection{Quasi-Equilibrium Temperatures approach}

Finally, another approach is the use of Quasi Equilibrium Temperatures (QET), whereby the equilibria of the reactions defined in the model are evaluated at a lower temperature than the actual process temperature. This approach was introduced by Gumz (1950). For fluidised-bed gasifiers, the average bed temperature can be used as the process temperature, whereas for downdraft gasifiers, the outlet temperature at the throat exit should be used. Li et al. (2001) found out that the kinetic carbon conversion for pressurised gasification of sub-bituminous coal in the temperature range $747-877^{\circ} \mathrm{C}$ is seen to be comparable to equilibrium predictions for a temperature about $250^{\circ} \mathrm{C}$ lower. Bacon et al. (1982) defined QETs for each independent chemical reaction. Based on 75 operational data points measured in circulating fluidised-bed (CFB) gasifiers operated on biomass, Kersten et al. (2002) showed that, for operating 
temperatures in the range $740-910^{\circ} \mathrm{C}$, the equilibrium corresponding to the reactions of watergas (R4 in Table 1.3), Boudouard (R5 in Table 1.3) and methanation (R6 in Table 1.3) should be evaluated at much lower temperatures $\left(531 \pm 25^{\circ} \mathrm{C}, 583 \pm 25^{\circ} \mathrm{C}\right.$ and $457 \pm 29^{\circ} \mathrm{C}$ respectively). These QETs appeared to be independent of the process temperature in this range. 


\section{References Chapter 2}

Bacon DW, Downie J, Hsu JC, Peters J. Modeling of fluidized bed wood gasifiers. In: Overend P, Milne TA, Mudge LK, editors. Fundamentals of thermochemical biomass conversion. London: Elsevier; p. 71732 (1982).

Bagnold R.A. Enxperiments on a gravity-free dispersion of large solid spheres in a Newtonian fluid under shear. Proc. Royal Soc. London Ser. A, Math and Physics Science A225, 49-63 (1954).

Bernocco, D., Innovative application of spouted bed technology to the high temperature conversion of biomass into energy. PhD Thesis, University of Genova (2013).

Béttega R., Correa R.G., Freire J.T. Scale-up study of spouted beds using computational fluid dynamics. Canadian Journal Chemistry Engineering 87, 193-203 (2009).

Bridgwater J., Mathur K.B. Prediction of spout diameter in a spouted bed - a theoretical model. Powder Technology 6, 183-187 (1972).

Bridgwater AV. The technical and economic feasibility of biomass gasification for power generation. Fuel 74:631-53 (1995).

Campbell C.S. Granular material flows - an overview, Powder Technology 162, 208-229 (2006).

Desrosiers R. Thermodynamics of gas-char reactions. In: Reed TB, editor. A survey of biomass gasification. Colorado: Solar Energy Research Institute (1979).

Ding J., Gidaspow D. A bubbling fluidisation model using kinetic theory of granular flow. AlChE J. 36, 523-538 (1990).

Du W., Bao X., Wei W. Computational fluid dynamics (CFD) modeling of spouted bed: Assessment of drag coefficient correlations. Chemical Engineering Science 61, 1401-1420 (2006a).

Du W., Wei W., Fan Y., Bao X. Computational fluid dynamics (CFD) modeling of fine particle spouting. International Journal of Chemical Reactors Engineering 4, A21 (2006b).

Duarte C.R., Olazar M., Murata V.V., Barrozo M.A.S. Numerical simulation and experimental study of fluid-particle flows in a spouted bed. Powder Technology 188, 195-205 (2009).

Erkiaga A., Lopez G., Amutio M., Bilbao J., Olazar M. Influence of operating conditions on the steam gasification of biomass in a conical spouted bed reactor. Chemical Engineering Journal 237, 259-267 (2014).

EPA/540/F-93/XXX. US Environmental Protection Agency Report. Energy Technology Bulletin Spouted Bed Reactor. Energy and Environmental Research Coorporation (Irvine, CA) (1993)

Epstein N., Grace J.R., Spouted and spout-fluid beds: fundamentals and applications. Cambridge University Press (2011). 
Fernandez-Akarregu A., Makibar J., Lopez G., Amutio M., Olazar M., 2013. Design and operation of a conical spouted bed reactor pilot plant $(25 \mathrm{~kg} / \mathrm{h})$ for biomass fast pyrolysis. Fuel Processing Technology $112,48-56$

Foong S.K., Lim C.J., Watkinson A.P. Coal gasification in a spouted bed. Canadian Journal of Chemical Engineering 59, 625-630 (1980)

Gomez-Barea A., Leckner B.. Modelling of biomass gasification in fluidised bed. Progress in Energy and Combustion Science 36, 444-509 (2010).

Gorshtein A.E., Mukhlenov I.P. Hydraulic resistance of a fluidized bed in a cyclone without a grate: critical gas rate corresponding to the beginning of the jet formation. Zh. Prikl. Khim. 37, 1887-1893 (1964).

Gryczka O., Heinrich S., Tomas J. CFD-modeling of the fluid dynamics in spouted beds. In MicroMacro-Interactions, 265-275. Ed. A. Bertram and J. Tomas. Berlin-Springer (2008).

Gumz W. Gas producers and blast furnaces. New York: Wiley (1950).

Hoque M.M. Bhattacharya S.C . Fuel characteristics of gasified coconut shell in a fluidised and a spouted bed reactor. Energy 26, 101-110 (2001).

Jarungthammachote S, Dutta A. Thermodynamic equilibrium model and second law analysis of a downdraft waste gasifier. Energy 32, 1660-1669 (2007).

Jarungthammachote S, Dutta A. Equilibrium modeling of gasification: Gibbs free energy minimisation approach and its application to spouted bed and spout-fluid bed gasifiers. Energy Convers Manage 49, 1345-1356 (2008).

Jayah TH, Aye L, Fuller RJ, Stewart DF. Computer simulation of a downdraft wood gasifier for tea drying. Biomass Bioenergy 25,459-69 (2003).

Jenkins J.T., Savage S.B. A theory for rapid flow of identical, smooth, nearly elastic spherical particles. J. Fluid Mechanics 140, 223-256 (1983).

Kawaguchi T., Sakamoto M., Tanaka T., Tsuji Y. Quasi-three-dimensional numerical simulation of spouted beds in cylinder. Powder Technology 109, 3-12 (2000).

Kikuchi K., Suzuki A., Mochizuki T., Endo S., Imai E., Tanji Y. Ash-agglomeration gasification of coal in spouted bed reactor. Fuel 64, 368-372 (1985)

Li X, Grace JR, Watkinson AP, Lim CJ, Ergu“ denler A. Equilibrium modeling of gasification: a free energy minimization approach and its application to circulating fluidized bed coal gasifier. Fuel 80, 195207 (2001).

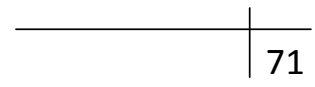


Li XT, Grace JR, Lim CJ, Watkinson AP, Chen HP, Kim JR. Biomass gasification in a circulating fluidized bed. Biomass Bioenergy 26, 171-193 (2004).

Limtrakul S., Boonsritat A., Vatanatham T. DEM modelling and simulation of a catalytic gas-solid fluidised bed reactor: a spouted bed as a case study. Chemical Engineering Science 59, 5225-5231 (2004).

Lopez G., Erkiaga A., Amutio M., Alvarez J., Barbarias I., Bilbao J., Olazar M.. Steam Gasification of Waste Plastics in a Conical Spouted Bed Reactor. The 14th International Conference on Fluidization From Fundamentals to Products, Eds, ECI Symposium Series (2013a).

Lopez G., Erkiaga A., Amutio M., Bilbao J., Olazar M. Steam gasification of biomass in a conical spouted bed reactor with olivine and g-alumina as primary catalysts. Fuel Processing Technology 116, 292-299 (2013b).

Lu H.L., Gidaspow D., Jacques B., Liu W. Hydrodynamic simulation of gas-solid flow in a riser using kinetic theory of granular flow. Chem. Eng. Journal, 95, 1 (2003).

Lun C.K.K., Savage S.B., Jeffrey D.J., Chepurniy N. Kinetic theories for granular flow: Inelastic particles in Couette flow and slightly inelastic particles in a general flow field. Journal of Fluid Mechanics 140, 223-256 (1984).

Malek M.A., Lu B.C.Y. Pressure drop and spoutable bed height in spouted beds. Ind. Eng. Chem. Process Des. Dev 4, 123-128 (1965).

Mamuro T., Hattori H. Flow pattern of fluid in spouted beds. J. Chem. Eng. Japan 1, 1-5 (1968).

Mathieu P, Dubuisson R. Performance analysis of a biomass gasifier. Energy Convers Manage 43, 12911299 (2002).

Mathur K.B. and Gishler P.E. A Study of the Application of the Spouted Bed Technique to Wheat Drying, J. Appl. Chemic., 5, 11, 624-636 (1955a).

Mathur K.B. and Gishler P.E. A technique for contacting gases with coarse solid particles. AIChE J. 1, 157-164 (1955b).

Mathur K.B., Epstein N., Developments in spouted bed technology. The Canadian Journal of Chemical Engineering, 52, 2, 129-144 (1974).

McNab G.S., Bridgwater J. Spouted-beds - estimation of spouting pressure drop and the particle size for deepest bed. Proceedings of the European Congress on Particle Technology (Nuremberg, Germany) (1977).

Olazar M., San José M.J., Aguayo A.T. Arandes J.M., Bilbao J. Hydrodynamics of nearly flat base spouted bed beds. Chemical Engineering Journal 55, 27-37 (1994). 
Olazar M., Lopez G., Altzibar H., Barona A., Bilbao J. One-dimensional modeling of conical spouted beds. Chem. Eng. Process, 48, 1264-1269 (2009).

Rovero G., Epstein N., Grace J.R., Piccini N., Brereton C.M.H. Gas phase solid-catalysed chemical reaction in spouted beds. Chemical Engineering Science 38, 557-566 (1983).

Salam P.A., Bhattacharya S.C. A comparative study of charcoal gasification in two types of spouted bed reactors. Energy 31, 228-243 (2006).

San Jose M., Alvarez S., Garcia I., Peñas F. Conical spouted bed combustor for clean valorization of sludge wastes from paper industry to generate energy. Chemical Engineering Research and Design, http://dx.doi.org/10.1016/j.cherd.2014.01.008 (2014).

Santos K.G., Murata V.V., Barrozo A.S. Three-dimensional computational fluid dynamics modelling of spouted bed. Canadian Journal Chemistry Engineering 87, 211-219 (2009).

Smith WR, Missen RW. Chemical reaction equilibrium analysis: theory and algorithms. New York, USA: Wiley (1982).

Syamal M. The particle-particle drag term in a multiparticle model of fluidization, C National Technical Information Service, Springfield, VA (1987).

Takeuchi S., Wang S., Rhodes J. Discrete element study of particle circulation in a 3-D spouted bed. Chemical Engineering Science 60, 1267-1276 (2005).

Takeuchi S., Wang S., Rhodes J. Discrete element method simulation of three-dimensional conical-base spouted beds. Powder Technology 184, 141-150 (2008).

Thorley B., Saunby J.B., Mathur K.B., Osberg G.L. An analysis of air and solid flow in a spouted wheat bed. Canadian Journal of Chemical Engineering 37, 184-192 (1959).

Watkinson P.A, Lisboa A.C. Chapter 15. Gasification, pyrolysis and combustion. Spouted and spout-fluid beds: fundamentals and applications. Cambridge University Press (2011).

Wu S. W. M., Lim C. J., Epstein N. Hydrodynamics of spouted beds at elevated temperatures. Chemical Engineering Communications, 62, 251-268 (1987).

Zainal ZA, Ali R, Lean CH, Seetharamu KN. Prediction of performance of a downdraft gasifier using equilibrium modeling for different biomass materials. Energy Convers Manage 42, 1499-1515 (2001).

Zak C., Nutcher P.B. Spouted fluid-bed gasification of biomass and chemical wastes-some pilot plant results. Energy from biomass and wastes X. Ed. D.K. Klass (London:Elsevier and Chicago: Institute of Gas Technology) 643-653 (1987).

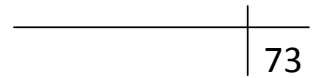


Zhuo Y., Paterson N., Avid B., Dugwell D.R. Kandiyoti R. Investigation of ammonia formation during gasification in an air blown spouted bed: the effect of the operating conditions on ammonia formation and the identification of ways of minimizing its formation. Energy and Fuels 16, 742-751 (2002) 


\section{BIOMASS AND ITS CHARACTERISATION}

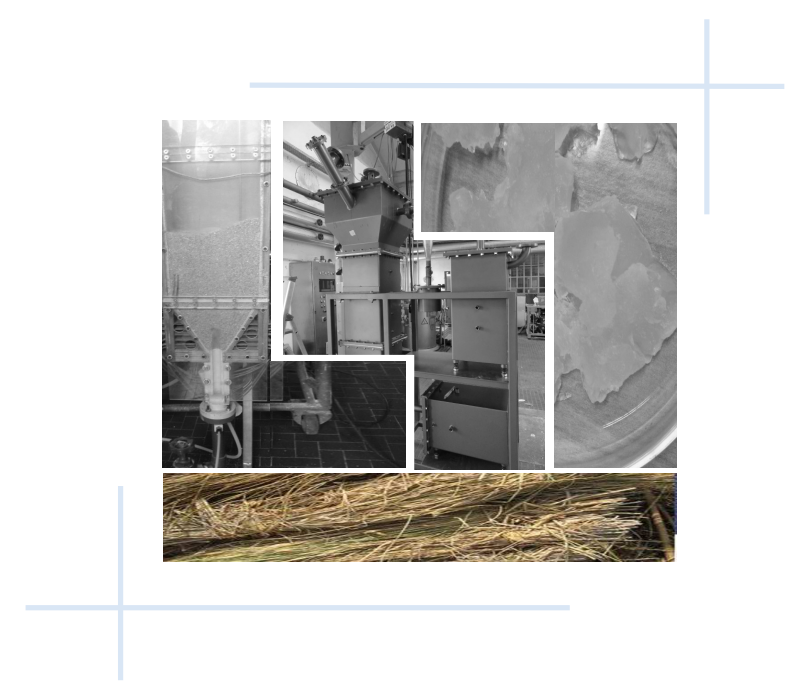

I. Summary $\quad$...... 77

3.1 Physical characterisation of biomass $\quad$...... 78

3.2 Chemical characterisation of biomass $\quad$....... 82

3.3 Thermal characterisation of biomass $\quad$....... 91

3.4 Main results $\quad$....... 102

References in this chapter $\quad$....... 104

Communications ....... 106 



\section{Summary}

The scope of this chapter is to describe the methodology of characterisation of the materials studied in detail for the present thesis. The applied techniques involve the physical, chemical and thermal descriptions of the biomass under study.

The chapter is devoted to the description of the characterisation techniques, including a theoretical background, a description of the instrumental equipment used, procedure carried out and relevant information about the experiments performed.

The main results obtained from this chapter are presented in the following communications:

Communication 3I: C. Moliner, B. Bosio, E. Arato, A. Ribes. Comparative study for the energy valorisation of rice straw. Chemical Engineering Transactions, 37, 2014,241-246 DOI: 10.3303/CET1437041

Communication 3II: C. Moliner, B. Bosio, E. Arato, A. Ribes. Thermal and thermo-oxidative characterisation of rice straw for its use in energy valorisation processes. Fuel 180 (2016) 71-79 


\subsection{Physical characterisation of the biomass}

Physical properties vary greatly among the different types of biomass. Properties such as density, porosity, and internal surface area are closely related to the materials, whereas bulk density, particle size, and shape distribution are more related to their preparation methods. Dimensions and shape of feeds have great influence on the fluid dynamic properties of the system and need to be investigated.

\subsubsection{Density}

Density is an important parameter of the biomass that directly influences the costs of feedstock delivery, transportation, design and dimensioning of the storage and operational units. Two different densities can be calculated for granular solids:

- apparent density: is determined by measuring the volume of a known mass of sample into a graduated cylinder:

$$
\rho_{\text {apparent }}=\frac{\text { TotalMassOfBiomass }}{\text { ApparentVolumeOfBiomass }}
$$

- bulk density: is obtained by a pycnometric analysis, measuring the mass of the sample and its volume, given by the mass of solvent displacement due to the material itself:

$\rho_{\text {bulk }}=\frac{\text { TotalMassOfBiomass }}{\text { BulkVolumeOccupiedByBiomass }}$

Table 3.1 presents some values of bulk density for several types of biomass, important for the design of the fuel storage requirements (volume of containers/deposits). 
Table 3.1 Dry bulk volumes and densities of several types of biomass (McKendry, 2001)

\begin{tabular}{lcc}
\multicolumn{1}{c}{ Material } & Bulk volume $\left(\mathrm{m}^{3} / \mathbf{t}\right)^{*}$ & Bulk density $\left(\mathbf{t} / \mathbf{m}^{3}\right) *$ \\
Wood & & \\
Hardwood & 4.4 & 0.23 \\
Softwood & $5.2-5.6$ & $0.18-0.19$ \\
Pellets & $1.6-1.8$ & $0.56-0.63$ \\
Sawdust & 6.2 & 0.12 \\
Straw & & \\
Loose & $24.7-49.5$ & $0.02-0.04$ \\
Chopped & $12.0-49.5$ & $0.02-0.08$ \\
Baled & $4.9-9.0$ & $0.11-0.20$ \\
Cubed & $1.5-3.1$ & $0.32-0.67$ \\
Pelleted & $1.4-1.8$ & $0.56-0.71$ \\
*Dy, ash-free basis & &
\end{tabular}

The two density values are related by the porosity, $\varepsilon$, defined as:

$\mathcal{E}=1-\frac{\rho_{\text {bulk }}}{\rho_{\text {apparent }}}$

Eq. 3.3

Besides the tested biomass (rice straw), several bed materials were investigated: PET, sand and glass beads. Their densities and porosities were calculated following the previously described procedure. All the measurements were repeated three times and their averaged values are reported in Table 3.2.

Table 3.2. Density values for the tested materials

\begin{tabular}{cccc} 
Sample & $\boldsymbol{\rho}_{\text {apparent }}(\mathbf{g} / \mathbf{l})$ & $\boldsymbol{\rho}_{\text {bulk }}(\mathbf{g} / \mathbf{l})$ & $\boldsymbol{\varepsilon}$ \\
\hline Rice straw & 238.6 & 56.0 & 0.76 \\
PET & 856.7 & 689.0 & 0.19 \\
Glass beads & 2400.0 & 1620.0 & 0.33 \\
Sand & 2632.0 & 1485.0 & 0.43
\end{tabular}

\subsubsection{Shape and dimension of samples}

The irregular shape of biomass and its relatively large dimensions respect to other solid fuels have a great influence in the process, from the design of the feeding system, to the performance of the device itself. An adequate handling of feedstock can become a potential increase in costs

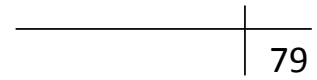


if, for example, straw needs to be baled or processed into a cubed/pelleted form prior to its utilisation

Rice straw was used to study the influence of the shape and dimension of biomass on the fluid dynamic properties of the system. The samples were chopped and considered as cylinders with a constant diameter. Two different average lengths $(1$ and $3.7 \mathrm{~cm}$ ) obtained from the size distribution on a representative sample (obtained by measuring 100 random samples) were evaluated. Due to the nature of the straw, length was taken as its characteristic dimension (Figure 3.1).

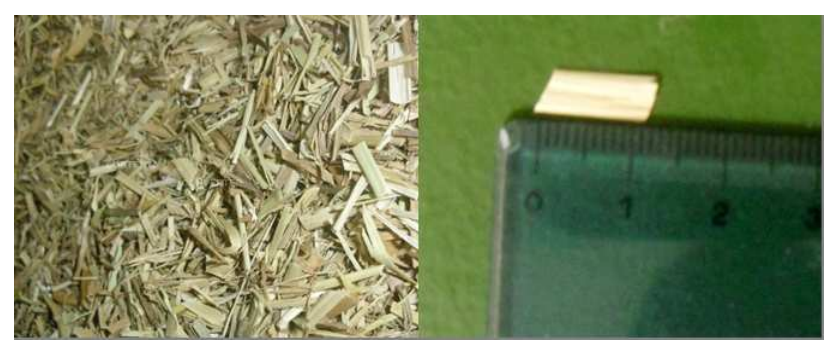

Figure 3.1. Rice straw and main dimensions of sample

The sphericity $\left(\Phi_{\mathrm{S}}\right)$, defined as the ratio of the surface area of an equi-volume sphere to the surface area of a particle (Eq. 3.4), was also calculated for the rice straw samples and all the tested bed materials.

$\Phi_{\mathrm{s}}=\frac{6 \mathrm{~V}_{\mathrm{p}}}{\mathrm{D}_{\mathrm{p}} \mathrm{A}_{\mathrm{p}}}$

where $V_{p}$ is the volume of the object, $A_{p}$ is its surface area, and $D_{p}$ is the diameter of a sphere with the same volume $\left(\pi \mathrm{D}_{\mathrm{p}}{ }^{3} / 6\right)$.

The values of diameter of particle (d) and sphericity $\left(\Phi_{\mathrm{S}}\right)$ of the rice straw and bed materials under study are presented in Table 3.3.

Table 3.3. Dimensions and characteristics of samples

\begin{tabular}{|c|cc|}
\hline Sample & $\mathbf{d}(\mathbf{m m})$ & $\boldsymbol{\Phi}_{\mathrm{S}}$ \\
\hline Rice straw & $10-37$ & 0.82 \\
PET & 2.5 & 0.87 \\
Sand & 1.4 & 0.88 \\
Glass & 1.5 & 1 \\
\hline
\end{tabular}


These values will be of particular interest and the object of study in Section 4.2 where the phenomenon of segregation will be widely discussed.

\subsubsection{Influence of the moisture content on the samples}

The moisture content is defined as the ratio of water in a kilogram of dry sample. Most of the energy production processes require values below $30 \%$ to be technologically adequate. Unfortunately, moisture values usually present high values, and pre-treatment actions are needed to lower it before entering into the conversion system. On the other hand, too low values should also be avoided as they could prompt auto-ignition of the material. The moisture content of rice straw was calculated following standard procedures (UNE-EN 14774-3:2009) and its value was found to be $9.1 \%$. 


\subsection{Chemical characterisation of the biomass}

The design of any type of thermal device, whether it is a gasifier or combustor, requires the definition of the composition of the feed, as well as the calculation of its energy content.

For this reason, the primary properties of the biomass under study were determined by means of the ultimate analysis, proximate analysis and obtainment of the heating values. The composition in terms of hemicellulose, cellulose and lignin contents was also calculated. All the experimental studies were performed according to the standard legislation as indicated in each case.

\subsubsection{Composition of biomass}

Biomass is considered as a lignocellulosic material due to its chemical composition mainly based on cellulose, hemicellulose, lignin and small percentages of extractives. The highest proportion of each of these will determine the properties of the biomass: high proportions of lignin will result in hard external surfaces and higher times of decomposition while high percentages of hemicellulose and cellulose provides more loosely bound fibres easier to be degraded. The relative amount of cellulose and lignin and the control of their decomposition are one of the determining factors when identifying the suitability of a type of biomass for its use in energy conversion technologies.

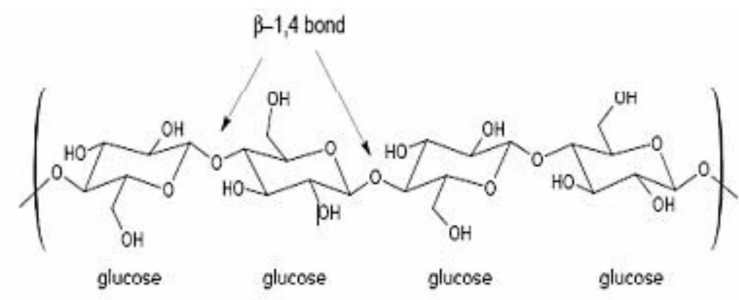

Figure 3.2. Chemical structure of cellulose
Cellulose is a major structural component in plant cell walls and it is responsible for its mechanical strength. The molecule is a highly stable glucose polymer composed by linear chains of $(1,4)-\mathrm{D}$ glucopyranose units attached by $\beta-1,4$ linkages. The chemical formula is $\left(\mathrm{C}_{6} \mathrm{H}_{10} \mathrm{O}_{5}\right)_{n}$ with an average molecular weight of around 100.000. The structure of one chain of the polymer is presented in Figure 3.2.

Biomasses contain $40-50 \%$ of cellulose molecules which are held together by intermolecular hydrogen bonds. They also have a strong tendency to form intra-molecular hydrogen bonds. This tendency increases its rigidity and makes it highly insoluble and resistant to most organic 
solvents. At higher temperatures it becomes soluble, as the energy provided is enough to break the hydrogen bonds that hold the crystalline structure of the molecule. Cellulose is also soluble in concentrated acids, but it causes severe degradation of the polymer by hydrolysis. In alkaline solutions extensive swelling of cellulose takes place as well as dissolution of the low molecular weight fractions of the polymer (Degree of Polimerisation < 200) (Krassig and Schurz, 2002).

Hemicellulose is the second most abundant heterogeneous polymer formed by a mixture of polysaccharides mostly formed by sugars as glucose, mannose, xylose and arabinose. Methylglucuronic and galaturonic acids are also present in the molecule. Hemicellulosic biomass contains $25-35 \%$ of hemicellulose, its chemical formula is $\left(\mathrm{C}_{5} \mathrm{H}_{8} \mathrm{O}_{4}\right)_{n}$ with an average molecular weight of $<30,000$. Hemicellulose is most commonly represented by xylan. The molecule involves 1->4 linkages of xylopyranosyl units with $\alpha$-(4- O)-methyl-Dglucuronopyranosyl units attached to anhydroxylose units.

The result is a branched polymer chain that is mainly composed of five carbon sugar monomers, xylose, and, to a lesser extent, six carbon sugar monomers such as glucose (Figure 3.3). Hemicellulose is insoluble in water at low temperature. However, its hydrolysis starts at a temperature lower than that of cellulose, which renders it soluble at elevated temperatures.

Lignin is an amorphous, high molecular weight compound. The main structure is formed by a three carbon chain attached to rings of six carbon atoms (i.e. phenyl-propanes). These may have zero, one or two methoxyl groups attached to the rings giving rise to three possible

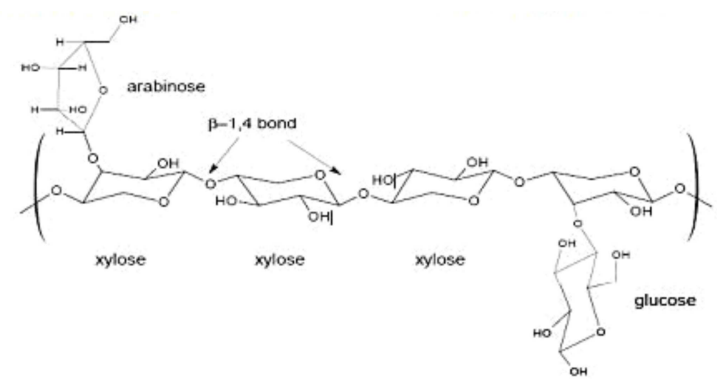

Figure 3.3. Chemical structure of hemicellulose structures, depending on the source of the polymer (Figure 3.4).

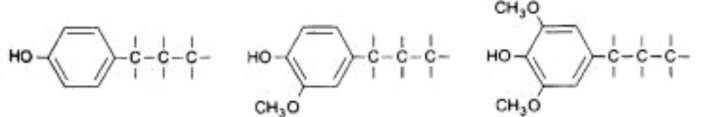

Figure 3.4. Structural units of lignin
Lignin is generally the most complex and smallest fraction, representing about 10 $25 \%$ of the biomass by weight. Lignin acts like a glue by filling the gap between and around the cellulose and hemicellulose complexion with the polymers and forms a protective seal around them (Figure 3.5). It behaves as an insoluble three-dimensional network and plays an important role in the cell's endurance and development, as it affects the transport of water, nutrients and metabolites in the plant cell. It acts as a binder between cells creating a composite material that has a remarkable resistance to impact, compression and bending. 

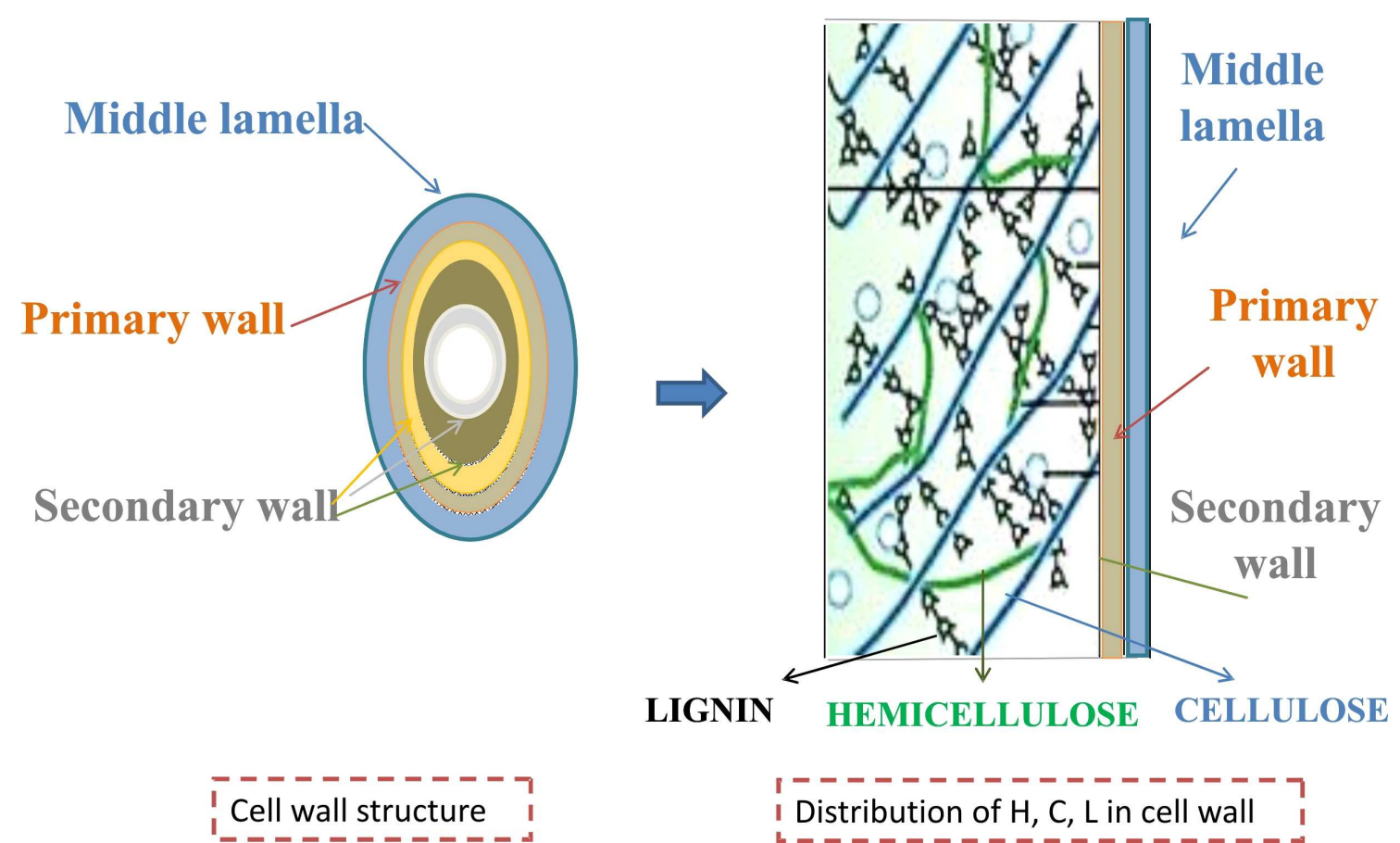

Figure 3.5. Cell wall structure and distribution of pseudo-components within it

Table 3.4 reports the chemical composition of several types of biomass.

Table 3.4 Chemical composition of several types of biomass (Anwar et al, 2014)

\begin{tabular}{lccc}
\multicolumn{1}{c}{ Material } & Cellulose (\%) & Hemicellulose (\%) & Lignin ( $)$ \\
\hline Sugar cane bagasse & 20 & 25 & 42 \\
Sweet sorghum & 21 & 27 & 45 \\
Hardwood & $18-25$ & $24-40$ & $40-55$ \\
Softwood & $25-35$ & $25-35$ & $45-50$ \\
Corn cobs & 15 & 35 & 45 \\
Corn stover & 19 & 26 & 38 \\
Rice straw & 18 & 24 & 32.1 \\
Nut shells & $30-40$ & $25-30$ & $25-30$ \\
Newspaper & $18-30$ & $25-40$ & $40-55$ \\
Grasses & $10-30$ & $25-50$ & $25-40$ \\
Wheat straw & $16-21$ & $26-32$ & $29-35$ \\
Banana waste & 14 & 14.8 & 13.2
\end{tabular}




\subsubsection{Ultimate analysis}

The elemental analysis provides the chemical composition of the biomass in terms of its main elements: $\mathrm{C}, \mathrm{H}, \mathrm{N}, \mathrm{O}$ and $\mathrm{S}$ and, together with the ash content, defines the ultimate analysis of a sample. The importance of the $\mathrm{O} / \mathrm{C}$ and $\mathrm{H} / \mathrm{C}$ ratios of solid fuels can be explained using the Van Krevelen (Van Krevelen, 1950) diagram (Figure 3.6).

This diagram relates the Lower Heating Value (LHV) with the composition of a sample defined by its $\mathrm{H} / \mathrm{C}$ and $\mathrm{O} / \mathrm{C}$ ratios. As it can be seen in the figure, low values of $\mathrm{H} / \mathrm{C}$ and $\mathrm{O} / \mathrm{C}$ (coal) assure high heating values. This is due to the lower energy contained in carbon-oxygen and carbonhydrogen bonds respect to that in carbon-carbon bonds. Biomass, however, presents higher reactivity respect to coal that, together with its

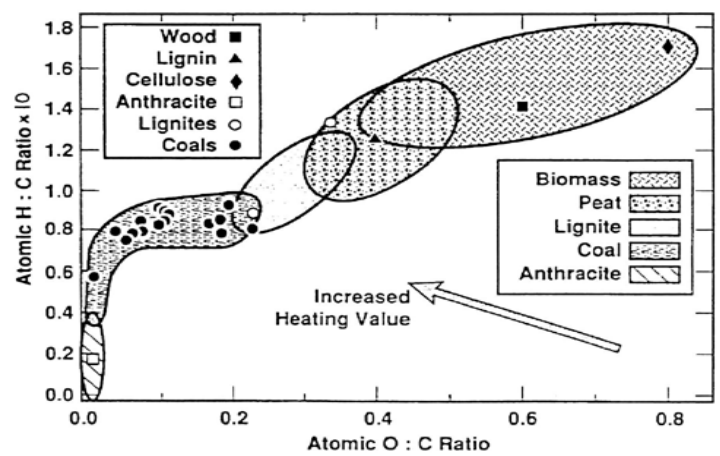
wide availability, makes it suitable for energy recovery purposes.

Figure 3.6. Van Krevelen diagram

The composition of the biomass is expressed in function of its basic elements:

$\mathrm{C}+\mathrm{H}+\mathrm{O}+\mathrm{N}+\mathrm{S}+\mathrm{Ash}=100 \%$

Eq. 3.5

where $\mathrm{C}, \mathrm{H}, \mathrm{O}, \mathrm{N}, \mathrm{S}$ and Ash are the weight percentages of carbon, hydrogen, oxygen, nitrogen, sulphur and ash contained in the sample. The moisture is expressed separately as $\mathrm{M}$ and does not contribute to the previous final sum.

The experiments for this thesis were carried out with an Eurovector EuroEA Elemental Analyser (Figure 3.7) at the facilities of Universitat Politècnica de València (UPV).

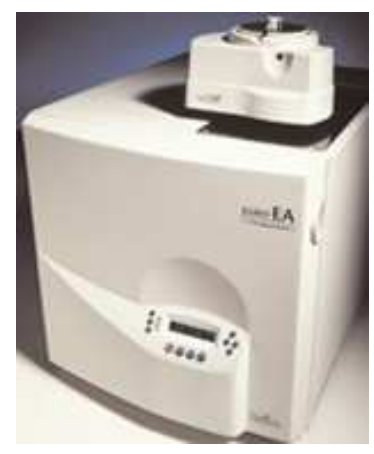

Figure 3.7. Eurovector EuroEA Elemental Analyser 
The results for the samples of rice straw are presented in Table 3.5.

Table 3.5. Ultimate analysis of rice straw

\begin{tabular}{|ccccccc} 
Material & $\mathbf{C}(\mathbf{w t} \%)$ & $\mathbf{H}(\mathbf{w t} \%)$ & $\mathbf{O}(\mathbf{w t} \%)^{*}$ & $\mathbf{N}(\mathbf{w t} \%)$ & $\mathbf{S}(\mathbf{w t} \%)$ & Ash (wt \%) \\
\hline Rice straw & 35.1 & 4.5 & 57.8 & 2.3 & 0.3 & 20.6 \\
${ }^{*}$ Determined by difference & & & & &
\end{tabular}

As can be seen from the table, biomass contains relatively high amounts of oxygen and hydrogen, resulting in relatively low heating values. On the other hand, the remarkably low sulphur content (sometimes equal to zero) provides a major environmental advantage for the use of biomass as energy vector instead of coal.

\subsubsection{Proximate analysis}

It indicates the content of water, fixed carbon, volatiles and ash in the sample. Typical values of moisture content (MC) can vary within the range of 10-90\%wt, depending on the samples and the weather conditions where they were preserved. High values affect negatively to thermal processes, as water removal requires energy as input. However, a small amount of water in the sample is found to be beneficial helping in preserving the sample and also from a thermochemical point of view, as gasification reactions are boosted in presence of water. Water is supplied as \%wt on wet basis whereas the other contents are usually supplied on dry basis.

Chemical energy is stored in two forms: volatiles (VM) and fixed carbon (FC). VM is defined as the portion driven off as a gas by heating and $\mathrm{FC}$ is the mass remaining after the volatiles release, excluding the ash and moisture contents.

Ashes also play an important part in high temperature conversions due to their tendency to melt as a consequence of the presence of oxides $\left(\mathrm{SiO}_{2}, \mathrm{~K}_{2} \mathrm{O}\right)$ that lower their melting point. A measure of the potential for deposition is the ratio alkali metal oxides to silica in the ash. If this ratio exceeds 2 , fouling reactions may occur and special attention must be paid to control and prevent operational difficulties. It is necessary to highlight the enhanced importance of ashes for the case of rice straw. Their high silica content offers a new source of silica if extracted from the ashes produced after an energy valorisation process. This way, if operational conditions are well controlled, a potential hazardous compound during the thermal conversion, becomes the source of renewable silica, closing this way a re-use cycle: all the generated waste is used for recovery purposes to obtain new valuable materials, promoting the zero-waste methodology. 
Normalised laboratory tests are used to determine MC, VM, FC and ash contents where moisture, volatiles and ash are experimentally obtained and fixed carbon is calculated by difference. Table 3.6 gives the values of proximate analyses of different types of biomass where also coal is provided as a reference.

Table 3.6. Proximate analyses of different types of biomass (\%wt dry basis). Coal is reported as a reference (Gaur and Reed, 1998)

$\begin{array}{lccc}\text { Material } & \text { Fixed Carbon (\%) } & \text { Volatiles (\%) } & \text { Ash (\%) } \\ \text { Western Hemlock } & 15.20 & 84.80 & 2.20 \\ \text { Peach Pits } & 19.85 & 79.12 & 1.03 \\ \text { Walnut Shells } & 21.16 & 78.28 & 0.56 \\ \text { Almond Pruning } & 21.54 & 76.83 & 1.63 \\ \text { Black Walnut Pruning } & 18.56 & 80.69 & 0.78 \\ \text { Corncobs } & 18.54 & 80.10 & 1.36 \\ \text { Wheat Straw } & 19.80 & 71.30 & 8.90 \\ \text { Cotton Stalk } & 22.43 & 70.89 & 6.68 \\ \text { Corn Stover } & 19.25 & 75.17 & 5.58 \\ \text { Sugarcane Bagasse } & 14.95 & 73.78 & 11.27 \\ \text { Rice Hulls } & 15.80 & 63.60 & 20.60 \\ \text { Pine needles } & 26.12 & 72.38 & 1.50 \\ \text { Cotton gin trash } & 15.10 & 67.30 & 17.60 \\ \text { Coal - Pittsburgh Seam } & 55.80 & 33.90 & 10.30\end{array}$

The following standard procedures were followed for the determination of the composition of biomass:

- $\quad$ M: UNE-EN 14774-2:2010

- VM: UNE-EN 15148:2010

- Ash: UNE-EN 14775:2010

Finally, FC was obtained by difference of weight respect to the initial sample. The experiments were carried out with a muffle furnace (Figure 3.8) at the Degradacion y reciclaje de materiales plasticos (DREMAP) facilities at Universitat Politècnica de València (UPV). All the methods were repeated three times and the average value was taken as valid. 


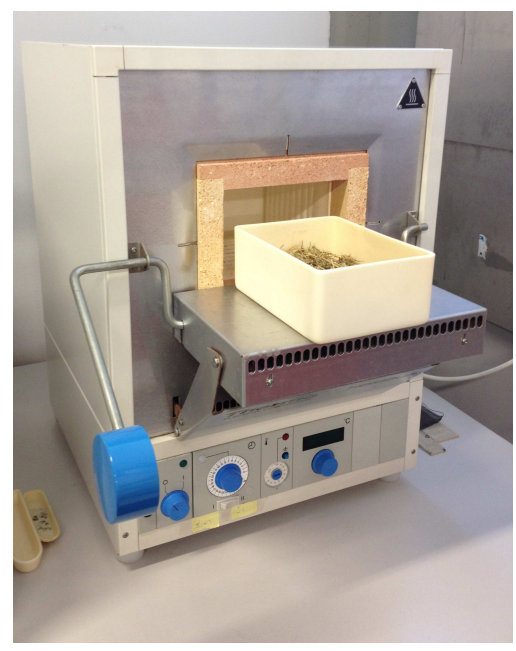

Figure 3.8. Muffle furnace used for the determination of the proximate analysis

Table 3.7 gathers the averaged values for the tested samples of rice straw.

Table 3.7. Proximate analysis of rice straw

\begin{tabular}{ccccc} 
Sample & \multicolumn{4}{c}{ Averaged values (wt\%) } \\
\hline M & VM & FC $^{*}$ & Ash \\
Rice straw & 9.1 & 63.3 & 16.1 & 20.6 \\
${ }^{*}$ Determined by difference & & & &
\end{tabular}

\subsubsection{Calorific value}

The heating value of a substance is defined as the heat released during combustion of $1 \mathrm{~kg}$ of it, assuming that the combustion products are cooled down to the initial temperature. This parameter is called Higher Heating Value (HHV) The expression includes the latent heat of vaporisation of water. It can be measured with a bomb calorimeter (ASTM standard D-2015). In the case where the experimental data cannot be obtained, several correlations estimate its value in basis to the ultimate or proximate analysis. For this thesis, the values of HHV were calculated with the expression provided by Channiwala and Parikh (2002) widely used for biomass feedstock:

$H H V(M J / \mathrm{kg})=0.3491 \cdot C+1.1783 \cdot H-0.1034 \cdot O-0.0211 \cdot A s h+0.1005 \cdot S-0.0151 \cdot N$

with $\mathrm{C}, \mathrm{H}, \mathrm{O}$, Ash, $\mathrm{S}$ and $\mathrm{N}$ the percentages of Carbon, Hydrogen and Oxygen, Ash, Sulfur and Nitrogen content according to the ultimate analysis (\%wt dry basis). 
When data about ultimate analyses are not available, the heating value can be obtained from the proximate analysis according to the expression (Eq.3.7) by Parikh (Parikh, 2005):

$$
H H V(M J / \mathrm{kg})=0.3536 \cdot F C+0.1559 \cdot V M-0.0078 \cdot A s h ; R^{2}=0.617
$$

However, the products of combustion are rarely cooled to the initial temperature of $25^{\circ} \mathrm{C}$ and for that reason, the heat of vaporisation of water is not recovered. Therefore, the effective heat available is lower than the actual chemical energy stored in the fuel. In this situation, the Lower Heating Value $(L H V)$ is defined as the amount of heat released by full combustion of a fuel, minus the heat of vaporisation of water in the combustion product:

$L H V=H H V-h_{g}\left(\frac{9 H}{100}+\frac{M}{100}\right)$ Eq. 3.8

where $\mathrm{h}_{\mathrm{g}}$ is the latent heat of steam (i.e. $2260 \mathrm{~kJ} / \mathrm{kg}$ or $540 \mathrm{kcal} / \mathrm{kg}$ )

On average, the heating value of biomasses is in the interval $14-20 \mathrm{MJ} / \mathrm{Nm}^{3}$. Table 3.8 gathers the ultimate analyses of different types of biomass and their HHV. Coal is provided as a reference.

Table 3.8. Ultimate analyses of different types of biomass (\%wt dry and ash free basis). Coal is reported as a reference. (Gaur and Reed, 1998)

$\begin{array}{lcccccc}\text { Material } & \mathbf{C}(\%) & \mathbf{H}(\%) & \mathbf{O}(\%) & \mathbf{N}(\%) & \mathbf{S}(\%) & \text { HHV(MJ/kg) } \\ \text { Western Hemlock } & 51.64 & 6.26 & 41.45 & 0.00 & 0.00 & 21.10 \\ \text { Peach Pits } & 53.00 & 5.90 & 39.14 & 0.32 & 0.05 & 21.39 \\ \text { Walnut Shells } & 49.98 & 5.71 & 43.35 & 0.21 & 0.01 & 19.68 \\ \text { Almond Pruning } & 51.30 & 5.29 & 40.90 & 0.66 & 0.01 & 19.87 \\ \text { Black Walnut Pruning } & 49.80 & 5.82 & 43.25 & 0.22 & 0.01 & 19.75 \\ \text { Corncobs } & 46.58 & 5.87 & 45.46 & 0.47 & 0.01 & 18.44 \\ \text { Wheat Straw } & 43.20 & 5.00 & 39.40 & 0.61 & 0.11 & 16.71 \\ \text { Cotton Stalk } & 43.64 & 5.81 & 43.87 & 0.00 & 0.00 & 17.40 \\ \text { Corn Stover } & 43.65 & 5.56 & 43.31 & 0.61 & 0.01 & 17.19 \\ \text { Sugarcane Bagasse } & 44.80 & 5.35 & 39.55 & 0.38 & 0.01 & 17.61 \\ \text { Rice Hulls } & 38.30 & 4.36 & 35.45 & 0.83 & 0.06 & 14.40 \\ \text { Pine needles } & 48.21 & 6.57 & 43.72 & 0.00 & 0.00 & 20.02 \\ \text { Cotton gin trash } & 39.59 & 5.26 & 36.38 & 2.09 & 0.00 & 15.85 \\ \text { Coal - Pittsburgh Seam } & 75.50 & 5.00 & 4.90 & 1.20 & 3.10 & 31.82\end{array}$


Finally, Table 3.9 presents the values of HHV and LHV for rice straw based on its ultimate analysis.

Table 3.9. Calorific value of rice straw

\begin{tabular}{c|cc} 
Sample & \multicolumn{2}{c}{ Heating value } \\
\hline & HHV $(\mathrm{MJ} / \mathrm{kg})$ & $\mathrm{LHV}(\mathrm{MJ} / \mathrm{kg})$ \\
\hline Rice straw & 11.1 & 10.0
\end{tabular}




\subsection{Thermal characterisation of the biomass}

The development of thermo-chemical processes for biomass conversion technologies, and a proper design of the equipment to carry out these reactions, requires a good understanding of the involved governing mechanisms, the determination of the most significant thermal parameters and their effect on the kinetics of reaction.

The characterisation of the thermal and thermo-oxidative behaviour of the feedstock and the further study of their kinetics was carried out by Thermogravimetric Analysis (TGA). TGA is a widely used technique to assess the thermal stability and decomposition kinetics of biomass. Few works have studied the thermal properties of rice straw by means of thermal analysis (Calvo et al, 2004, Garcia Barneto et al, 2010, Mishra and Bhaskar, 2014) or the residues of the kaki fruit. The composition of the raw material can be determined by thermal studies as a result of the quantification of the different processes of mass loss observed during the heating process. Valuable parameters related to the thermo-chemical process can be obtained from a detailed kinetic analysis such as the activation energy (Ea), pre-exponential factor (A) and mechanism and order of reaction.

The following sections describe the fundamentals of TGA, the description of the equipment used for the present thesis, the methodology followed during the study and the main parameters under consideration. After this descriptive part, the main results related to the thermal characterisation of the feedstock are gathered in two communications at the end of the chapter.

\subsubsection{Fundamentals of the TGA}

Thermogravimetric Analysis is defined according to the International Conference of Thermal Analysis, a technique in which the mass of a substance is subjected to a controlled temperature programme. The weight loss rate in function of the increasing temperature (dynamic analysis) or time (isothermal analysis), either directly related to the elimination of volatiles or through chemical processes, is registered.

High precision balances are used to carry out TGA experiments. The sample and the reference masses are measured inside aluminium oxide pans which have a small aperture to evacuate possible outlet gases generated in the reactions. The balances are placed inside a high

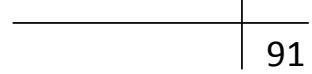


temperature oven that heats the sample and the reference, according to the programme temperature. The oven chamber is fed with a gas to provide a controlled atmosphere during the decomposition reactions. Inert atmospheres are simulated when $\mathrm{N}_{2}$ or argon are used as carrier gas, whereas oxidising atmospheres are obtained when $\mathrm{O}_{2}$ is applied. For this reason, TGA can be used as a reactor to simulate either pyrolysis reactions (inert conditions) or combustion reactions (oxidative conditions) within the framework of the energy valorisation of biomass.

The result of a TGA experiment is known as the thermogravimetric curve (TG) or thermogram. The first derivative of TG is the differential thermogravimetric curve (DTG) in which the presence of a peak corresponds to the maximum falling slope in the TG.

Figure 3.9 shows a typical TG curve for rice straw. A sign of decomposition for almost every type of biomass consists of a sigmoidal curve like the figure. In general, the evolution of the thermal decomposition with temperature can be described as:

- $\mathrm{T}<150^{\circ} \mathrm{C}$ - drying: it corresponds to the loss of volatile compounds in the system as water, organic solvents or low molecular weight gases.

- $150^{\circ} \mathrm{C}<\mathrm{T}<350^{\circ} \mathrm{C}$ - devolatilisation: two major peaks are observed in this zone which can be attributed to the decomposition of hemicellulose and cellulose. Depending on the applied conditions, these peaks will be shown merged as one single peak, or they will appear as a main peak (cellulose) accompanied by a shoulder at a slightly lower temperature (hemicellulose).

- $\quad \mathrm{T}>400^{\circ} \mathrm{C}$ - lignin devolatilisation and combustion of char: a tail is usually found at high temperatures which is associated to lignin volatilisation even though the compound is decomposed all through the heating process at a slow velocity. At higher temperatures, the remaining char goes under combustion, which results in an increase of $\mathrm{CO}_{2}$ production.

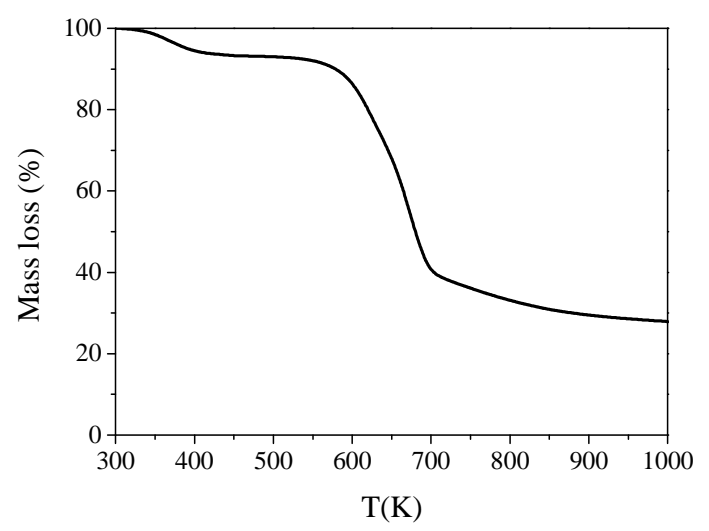

Figure 3.9. $\mathrm{TG}$ of rice straw $\left(20^{\circ} \mathrm{C} / \mathrm{min}\right.$ and inert atmosphere $)$ 
In order to obtain more accurate information regarding the different decomposition processes, a DTG curve like the one represented in Figure 3.10 is usually obtained.

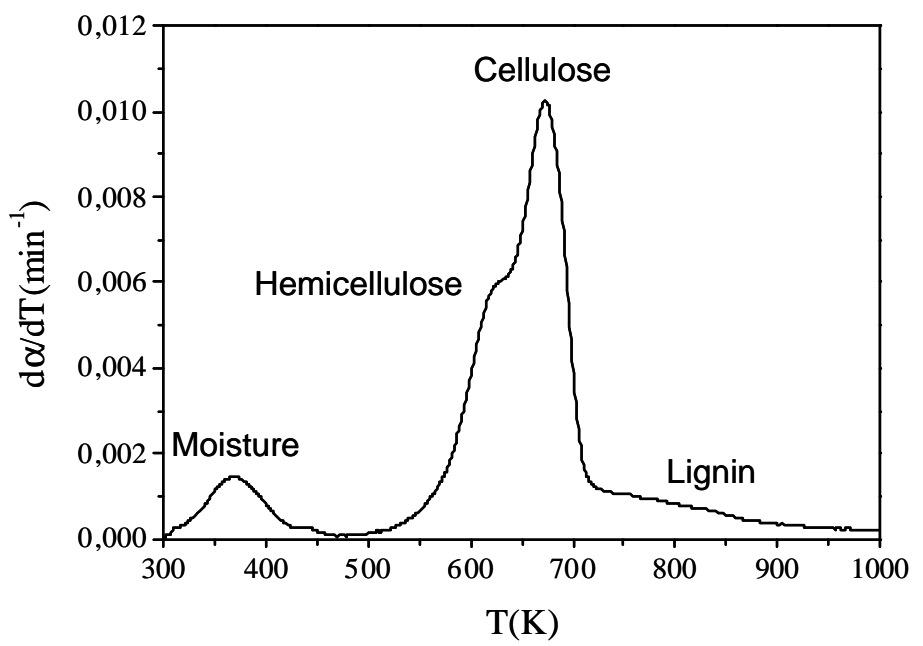

Figure 3.10. DTG of rice straw $\left(20^{\circ} \mathrm{C} / \mathrm{min}\right.$ and inert atmosphere $)$

TGA can also be used coupled with other techniques such as mass spectroscopy (MS) or infrared spectroscopy (FTIR) to analyse the products of decomposition as a function of temperature.

\subsubsection{Equipment}

All the thermogravimetric analysis were performed with a Mettler Toledo TGA/SDTA 851 (Columbus OH) modulus at the Degradacion y reciclaje de Materiales Polimericos (DREMAP) facilities at the Universitat Politècnica de València (UPV). A picture of the TGA module used in this thesis is shown in Figure 3.11.

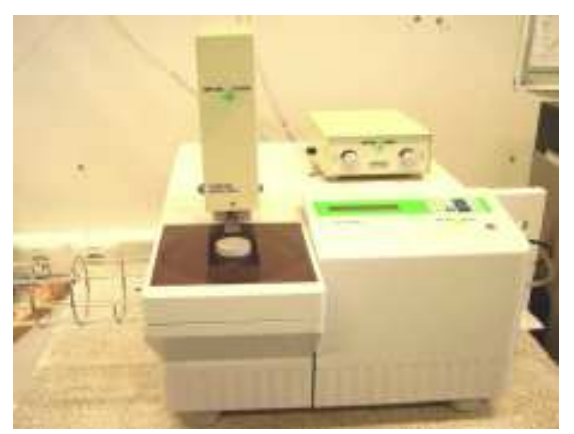

Figure 3.11. TGA equipment used in this thesis 
Samples weighing approximately $7 \mathrm{mg}$ were heated in an alumina holder with the capacity of 70 $\mu \mathrm{L}$. Experiments were performed from $25^{\circ} \mathrm{C}$ to $800^{\circ} \mathrm{C}$ at different heating rates $(\beta=2,5,10,15$, $20^{\circ} \mathrm{C} / \mathrm{min}$ ) under a constant flow of $50 \mathrm{ml} / \mathrm{min}$ of gas of analysis. All samples were analysed under inert $(\mathrm{Ar})$ and oxidative $\left(\mathrm{O}_{2}\right)$ atmospheres to characterise the thermal and thermooxidative processes respectively. Experiments were repeated three times and the average values were considered as representative values. Assessment was performed with the aid of the software Stare 9.10 from Mettler Toledo.

\subsubsection{Analysis of the TGA experimental results}

All the TG and DTG curves were obtained as previously described in Section 3.3.2. A blank was used prior to each series of experiments. Relevant information about the different stages of mass loss was obtained including:

- The onset temperature $\left(\mathrm{T}_{0}\right)$ : indicator of the start of the decomposition process. It is considered as the key parameter describing the thermal stability

- The temperature of maximum decomposition rate $\left(\mathrm{T}_{\text {peak }}\right)$ : this point corresponds to the inflexion point in the TG curve

- The endset temperature $\left(\mathrm{T}_{\text {endset }}\right)$ : temperature at which the process is considered finished

- The mass loss $(\Delta \mathrm{m})$ : the amount of sample that it is degraded in the decomposition step

- The residue: fraction of sample that remains non reacted after the experiment finishes

The presence of shoulders in the curve indicates that more than one decomposition process is occurring. In order to define the individual contributions of each of the pseudo-components of the sample, the DTG curve was fitted to a sum of contributions by means of the tool Advance Fitting Tool from the Origin Lab Software. The results were fitted to the following expression (Gaussian type):

$$
y=\sum_{i=1}^{n} A_{i} \cdot \exp \left(-0.5 \cdot \frac{\left(x-x_{c i}\right)^{2}}{w_{i}^{2}}\right)
$$

with $\mathrm{A}, \mathrm{x}_{\mathrm{ci}}$ and $\mathrm{w}_{\mathrm{i}}$ being the fitting parameters.

Only fits with high $R^{2}$ values were accepted $\left(R^{2}>0.99\right)$. The baseline was substracted before any deconvolution process. Figure 3.12 shows an example of the deconvolution procedure for the leaves of kaki at $10^{\circ} \mathrm{C} / \mathrm{min}$ and oxidative ambient. The deconvoluted peaks were assigned to 
different species according to literature and were analysed separately in the kinetic analysis (See Section 3.3.4).

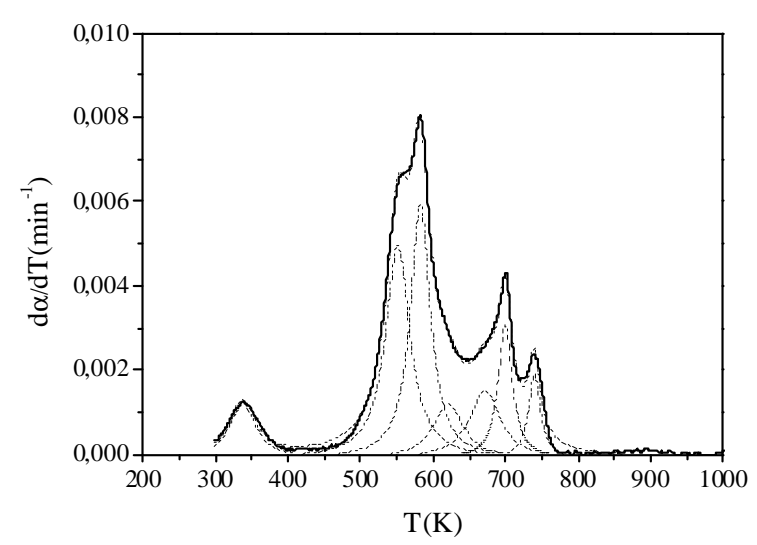

Figure 3.12. Example of deconvoluted curves for leaves of kaki $\left(10^{\circ} \mathrm{C} / \mathrm{min}\right.$; oxidative ambient $)$

\subsubsection{Kinetic analysis methodology}

The behaviour of the biomass during the thermal and thermo-oxidative decompositions was studied through the calculation of their related kinetic expressions. It is widely known that the decomposition of any solid material can be described as:

$$
\mathrm{A}_{\text {solid }} \rightarrow \mathrm{B}_{\text {solid }}+\mathrm{C}_{\text {gas }}
$$

In the case of biomass, this single degradation step can be considered as one step global model lumping all the decomposition processes taking place during the heating process (single component method). However, this approach results in an extremely simplified solution and becomes unsuitable to predict the complex biomass behaviour. Solutions expressed as the sum of the different processes of decomposition of the main pseudo-components of the initial sample provide a more accurate description of the process (multi component method).

In both cases, the kinetics of decomposition are the result of two main contributions: the reaction rate which depends on the concentration of reactants (considered either as the initial sample itself or as its main pseudo-components) and the dependence of the rate constants with temperature. Therefore, the general kinetic law can be expressed as:

$$
\frac{d \alpha}{d t}=f(\alpha) \cdot k(T)
$$

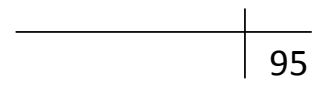


In which the first term represents the dependence of the conversion degree of the reactants $(\alpha)$ and the second term the dependence with temperature $(\mathrm{T})$.

The conversion degree of the reactant $(\alpha)$ can be defined as the mass fraction that has reacted at a time $t$ respect to the final mass loss of the experiment:

$$
\alpha=\frac{m_{0}-m_{t}}{m_{0}-m_{\infty}}
$$

where $\mathrm{m}$ is the mass with the subscripts $0, \mathrm{t}$ and $\infty$ standing for initial, instant and final mass respectively.

The dependence on temperature can be expressed with an Arrhenius model $n$ the form of:

$$
k(T)=A \cdot \exp \left(-E_{a} / R \cdot T\right)
$$

where $\mathrm{A}$ is the pre-exponential factor, $\mathrm{E}_{\mathrm{a}}$ is the activation energy, $\mathrm{R}$ is the gas constant and $\mathrm{T}$ the absolute temperature.

Merging Eq. 3.12 with Eq. 3.10, the rate expression may be expressed as:

$$
\frac{d \alpha}{d t}=f(\alpha) \cdot A \cdot \exp \left(-E_{a} / R \cdot T\right)
$$

If non-isothermal analysis are carried out, the previous law can be expressed as a function of the heating rate $(\beta)$ as follows:

$$
\frac{d \alpha}{d t} \equiv \beta \cdot \frac{d \alpha}{d T}=f(\alpha) \cdot A \cdot \exp \left(-E_{a} / R \cdot T\right)
$$

The correct description of the kinetic law therefore involves the obtaining of the so-called kinetic triplet $\left(\mathrm{E}_{\mathrm{a}}, \mathrm{A}, \mathrm{f}(\alpha)\right)$. The following sections provide a theoretical background of the methods applied in this thesis to obtain these parameters.

\subsubsection{Obtaining of the Activation Energy}

If the experimental TGA data are fitted to the previous expression (with the appropriate selection for $f(\alpha)$ ), it is possible to calculate the kinetic parameters describing the degradation of the sample. However, since Eq. 3.14 cannot be directly integrated, numerical approximations are required to calculate its solution. 
Solid-state kinetics (developed from homogeneous systems) assume that the activation energy and pre-exponential factor remain constant all through the degradation. However, it has been proven that they can vary with the degree of conversion. For this reason, isoconversional methods were applied in this thesis in which no modelistic assumptions were made, with data coming from different multi-linear non-isothermal experiments.

These methods can be classified as integrated or derived methods, depending on whether the rate expression is integrated or derived. The most used isoconversional methods are:

\section{- $\quad$ Linear integral methods:}

$$
\begin{aligned}
& \text { Flynn-Wall-Ozawa } \quad[\log \beta]_{y}=\log \left(\frac{A_{\alpha} \cdot E_{a \alpha}}{R \cdot g(\alpha)}\right)-2.315-\frac{0.457 \cdot E_{a \alpha}}{R} \cdot\left[\frac{1}{T_{\alpha}}\right]_{x} \\
& \quad(\text { FWO) (1966) }
\end{aligned}
$$

Kissinger-Akahira-

Sunose (KAS) (1971)

$$
\left[\ln \left(\frac{\beta}{T^{2}}\right)\right]_{y}=\ln \left(\frac{A_{\alpha} \cdot R}{E_{a \alpha} \cdot g(\alpha)}\right)-\frac{E_{a \alpha}}{R} \cdot\left[\frac{1}{T_{\alpha}}\right]_{x}
$$

with $\mathrm{g}(\alpha)$ is the inverse integral kinetic model: $g(\alpha)=\int_{0}^{\alpha}(f(\alpha))^{-1} \cdot d \alpha$

\section{- Linear differential methods:}

Friedman $(\mathrm{F})$

$$
\left[\ln \left(\frac{d \alpha}{d t}\right)_{\alpha}\right]_{y}=\ln \left(A_{\alpha} \cdot f(\alpha)\right)-\frac{E_{a \alpha}}{R} \cdot\left[\frac{1}{T_{\alpha}}\right]_{x}
$$

- Non- linear integral methods: the activation energy $\mathrm{E}_{\mathrm{a} \alpha}$ is the value that minimises $\Omega$ in Eq. 3.17 for any $\alpha$

$$
\begin{aligned}
& \text { Vyazovkin - Dollimore } \\
& \quad \text { (VYZ) (1997) }
\end{aligned} \quad\left|\sum_{i=1}^{h} \sum_{j \neq 1}^{h} \frac{\beta_{j} \cdot I\left(E_{a \alpha}, T_{\alpha}^{i}\right)}{\beta_{i} \cdot I\left(E_{a \alpha}, T_{\alpha}^{j}\right)}\right|, I\left(E_{a \alpha}, T_{\alpha}^{i, j}\right)=p_{i, j}\left(\frac{E_{a \alpha}}{R \cdot T_{\alpha}}\right)
$$

with $i$ and $j$ the counters though the experiments $h$ at different heating rates.

The value of $\mathrm{p}(\mathrm{x})$ was calculated with the approximation of Senum-Yang truncated to the fifth term: 
Chapter 3. Biomass and its characterization

Senum and Yang

$$
p(x)=\frac{e^{-x}}{x^{2}} \cdot \sum_{n} \frac{n \cdot(1-n)}{x+2 \cdot(n+1)}, x=\frac{E_{a}}{R \cdot T}
$$

Figure 3.13 shows an example of the application of isoconversional methods to rice straw: (a) $\mathrm{E}_{\mathrm{a}}$ evolution with conversion degree evaluated by Friedman, FWO, VYZ and the averaged value; (b) application of FWO under $\mathrm{O}_{2}$ considering the degradation of the sample as a single step, and the corresponding graphs taking the straw as a multi-component sample ((c) and (d)).
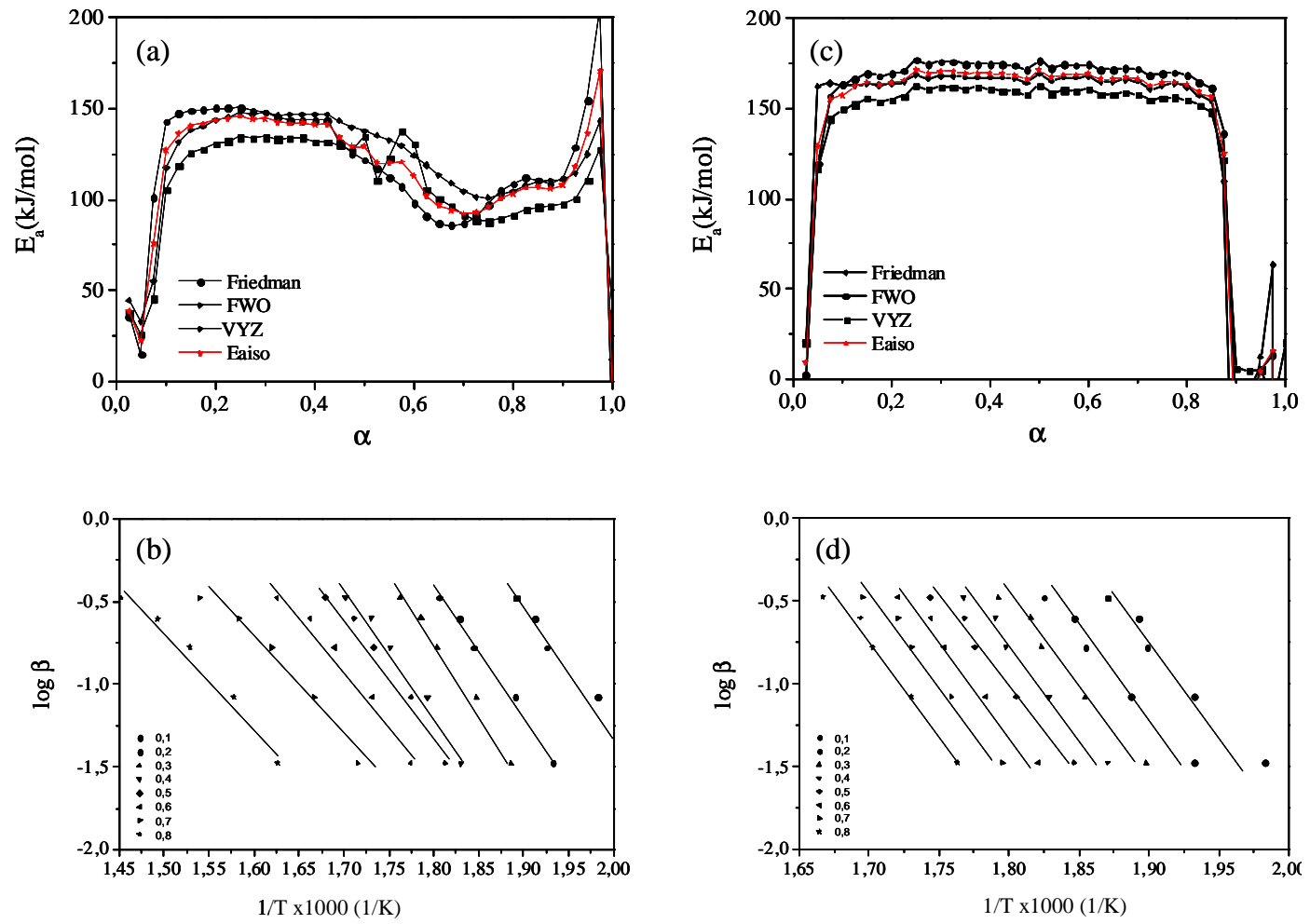

Figure 3.13. Example of application of isoconversional methods to rice straw: (a) evolution of Ea with $\alpha$ considering it as single component under $\mathrm{O}_{2}$; (b) Application of FWO method under $\mathrm{O}_{2}$ (single component); (c) evolution of Ea for the first DTG peak with $\alpha$; (d) Application of FWO method under $\mathrm{O}_{2}$ (multicomponent)

The figure shows the non constant trend of $E_{a}$ with $\alpha$ as a result of the complex mechanism of reaction. This behaviour is also confirmed by the application of the different analytical methods and the lack of parallel lines for all the range $\alpha$. In contrast, if the multicomponent approach is applied, $\mathrm{E}_{\mathrm{a}}$ presents a constant value, also confirmed by the parallel lines for all the studied range. 


\subsubsection{Obtaining of the mechanism and order of reaction}

The reaction models can be classified as: nucleation and nuclei growth, phase boundary conditions, diffusion or chemical reactions. A list of the expressions defining the most common models, $f(\alpha)$ for biomass is given in Table 3.10. The table also shows the values of the integrated function $\mathrm{g}(\alpha)$ in each case (Gotor et al, 2000).

Table 3.10. Summary of models used in the description of thermal degradation processes

\section{Model Differential form $-\mathbf{f}(\alpha) \quad$ Integral form $-\mathbf{g}(\alpha)$}

\section{Chemical reaction control}

\begin{tabular}{ccc}
\hline $\mathbf{n}=\mathbf{0}$ & 1 & $\alpha$ \\
$\mathbf{n}=\mathbf{1}$ & $(1-\alpha)$ & $-\ln (1-\alpha)$ \\
$\mathbf{n}=\mathbf{1 . 5}$ & $(1-\alpha)^{1.5}$ & $2 \cdot\left(-1+(1-\alpha)^{-1 / 2}\right)$ \\
$\mathbf{n}=\mathbf{2}$ & $(1-\alpha)^{2}$ & $-1+(1-\alpha)^{-1}$ \\
\hline Diffusion control & & $\alpha^{2}$ \\
\hline D1 & $1 / 2 \cdot(1-\alpha)-1$ & $(1-\alpha) \cdot \ln (1-\alpha)+\alpha$ \\
D2 & $-\ln (1-\alpha)$ & $\left(1-(1-\alpha)^{1 / 3}\right)^{2}$ \\
D3 & $3 / 2 \cdot(1-\alpha)^{2 / 3}\left(1-(1-\alpha)^{1 / 3}\right)^{-1}$ & $(1-2 / 3 \alpha)(1-\alpha)^{2 / 3}$ \\
D4 & $3 / 2 \cdot(1-\alpha)^{1 / 3}\left(1-(1-\alpha)^{1 / 3}\right)^{-1}$ &
\end{tabular}

\section{Nucleation models}

$\begin{array}{lll}\mathbf{n}=\mathbf{1 . 5} ; \mathbf{m}=\mathbf{0 . 5} & \alpha^{0.5}(1-\alpha)^{1.5} & ((1-\alpha) / \alpha)^{-0.5}\left(0.5^{-1}\right) \\ \mathbf{n}=\mathbf{1 . 9} ; \mathbf{m}=\mathbf{0 . 5} & \alpha^{0.1}(1-\alpha)^{1.9} & ((1-\alpha) / \alpha)^{-0.9}\left(0.9^{-1}\right)\end{array}$

\section{Other}

$\begin{array}{lcc}\text { R2 } & 2 \cdot(1-\alpha)^{1 / 2} & 1-(1-\alpha)^{1 / 2} \\ \text { R3 } & 3 \cdot(1-\alpha)^{2 / 3} & 1-(1-\alpha)^{1 / 3} \\ \text { A2 } & 2 \cdot(1-\alpha)(-\ln (1-\alpha))^{1 / 2} & (-\ln (1-\alpha))^{1 / 2} \\ \text { A3 } & 3 \cdot(1-\alpha)(-\ln (1-\alpha))^{2 / 3} & (-\ln (1-\alpha))^{1 / 3} \\ \text { F1 } & 1-\alpha & -\ln (1-\alpha) \\ \text { Power } & 2 \alpha^{1 / 2} & \alpha^{1 / 2}\end{array}$

"being $\mathrm{n}$ and $\mathrm{m}$ the orders of reaction 
Master Plots (MP) are widely used to determine the mechanism of reaction and calculate its order. MP are defined as the theoretical reference curves $\left(\mathrm{MP}_{\mathrm{t}}\right)$ dependent on the kinetic model and, generally, independent of the kinetic parameters of the process. The comparison between the experimental values $\left(\mathrm{MP}_{\mathrm{e}}\right)$ and these theoretical curves permits the selection of the appropriate kinetic model according to the better fitting of the experimental data on the $\mathrm{MP}_{\mathrm{t}}$.

The three main types of $\mathrm{MP}_{\mathrm{t}}$ are those based on the differential form $\left(\mathrm{MP}_{\mathrm{f}}\right)$ of the general kinetic equation as expressed in Eq. 3.14, the integral form $\left(\mathrm{MP}_{\mathrm{g}}\right)$ as in Eq. 3.20 and the combination of both $\mathrm{MP}_{\mathrm{fg}}$, usually reduced at $\alpha=0.5$ for better visualisation.

$M P_{g}(\alpha)=\int_{0}^{\alpha} \frac{d \alpha}{f(\alpha)}=\frac{A \cdot E_{a}}{\beta \cdot R} \cdot \int_{0}^{\infty} \frac{e^{-x}}{x^{2}}=\frac{A \cdot E_{a}}{R \cdot T} \cdot p(x), x=\frac{E_{a}}{R \cdot T}$

The advantage of using $\mathrm{MP}_{\mathrm{f}}$ and $\mathrm{MP}_{\mathrm{g}}$ instead of $\mathrm{MP}_{\mathrm{fg}}$ is the clear dispersion among models of the formers in the ranges $\alpha<0.5$ and $\alpha>0.5$ which permits a straightforward initial identification.

Figure 3.14 shows an example of $\mathrm{MP}_{\mathrm{g}}$ obtained in the kinetic study of rice straw at $10^{\circ} \mathrm{C}$ under inert (a) and oxidative (b) conditions.
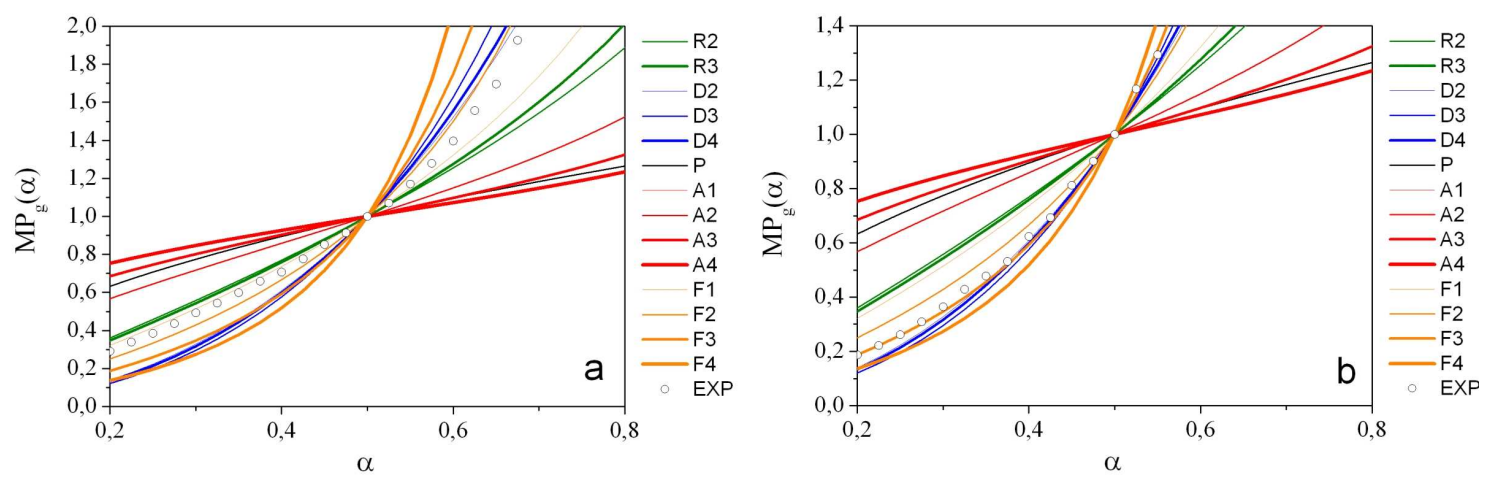

Figure 3.14. Master plots based on the integral $(\operatorname{MPg}(\alpha))$ form of the general law compared to the experimental data obtained by the thermal process applied (circles). Kinetic Models: $\mathrm{D}_{\mathrm{n}}$ : diffusion controlled, blue lines, $A_{n}$ : nucleation and growth, red lines, $F_{n}$ : n-order reaction, orange lines, $\mathrm{R}_{\mathrm{n}}$ : reaction controlled, green lines. 


\subsubsection{Obtaining of the pre-exponential factor: independence of the heating rate}

The pre-exponential factor A must be calculated to complete the kinetic triplet. According to the Perez-Maqueda criterion (Perez-Maqueda et al, 2002), the parameters $\mathrm{A}$ and $\mathrm{E}_{\mathrm{a}}$ should be independent of the applied heating rate $\beta$. This criterion is usually employed with the aid of the Coats-Redfern equation (Eq. 3.21) maintaining $\mathrm{E}_{\mathrm{a}}$ and $\mathrm{A}$ invariable.

Coats-Redfern,

$$
\left[\ln \left(\frac{\beta \cdot g(\alpha)}{T^{2}}\right)\right]_{y}=\ln \left(\frac{A \cdot R}{E_{a}}\right)+\frac{E_{a}}{R} \cdot\left[\frac{1}{T_{\alpha}}\right]_{x}
$$

The representation of each of the points $[\mathrm{x}, \mathrm{y}]$ should lie on a straight line common to all heating rates. Figure 3.15 shows an example of the application of the Coats-Redfern criterion in the case of rice straw under inert (a) and oxidative (b) ambient.
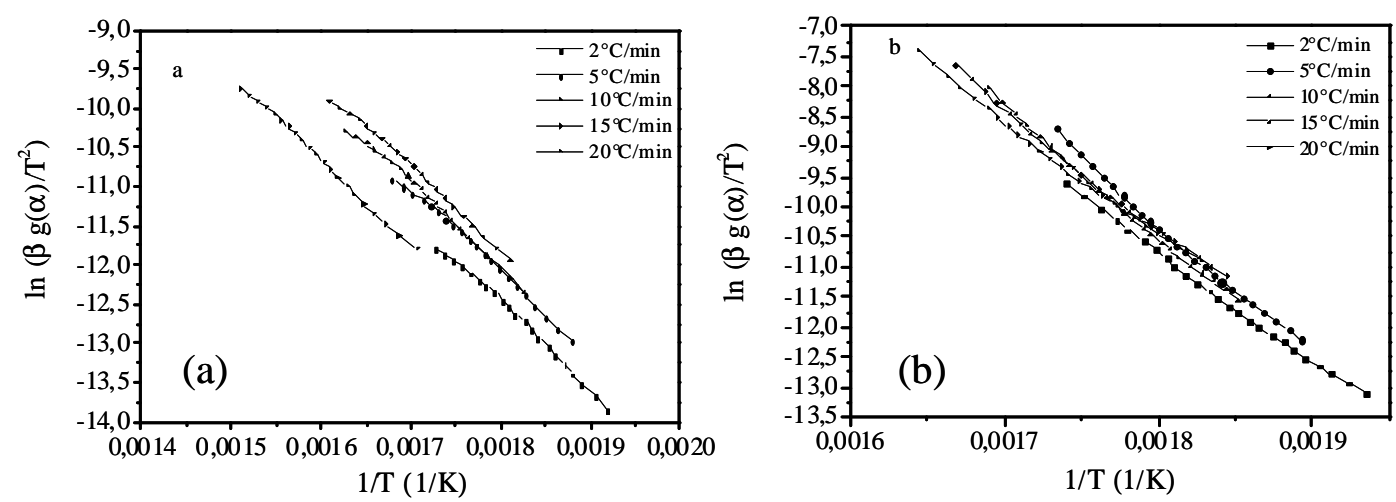

Figure 3.15. Example of the application of the Coats-Redfern criterion for the case of rice straw under inert (a) and oxidative (b) conditions 


\subsection{Main results}

The importance of an accurate definition of the main properties of the biomass was demonstrated crucial for the application of the adequate conversion technology. Specifically, the following characteristics of the biomass were investigated.

The physical properties of the tested biomass were calculated according to standard procedures. The density, dimensions and characteristic shapes of all samples were calculated.

The chemical properties of the tested biomass were evaluated in terms of their constituting elements (ultimate analysis) and gross components (proximate analysis). The energy content was also calculated using existing correlations. More precisely, as a result of a higher relative amount of oxygen, rice straw was a more reactive feed respect to coal. It also resulted in relatively low heating values. The low sulphur content provided a major environmental advantage for the use of biomass as energy vector instead of coal. High percentages of ash were found and the operational temperature was limited to $1000^{\circ} \mathrm{C}$ to prevent their melting.

The characterisation of the thermal and thermo-oxidative behaviour of the feedstock and the further study of their kinetics was carried out by Thermogravimetric Analysis (TGA). All the tested biomass samples exhibited several degradation stages corresponding to the main pseudocomponents (hemicellulose, cellulose and lignin) and successive combustion of the remaining char. The residual values were higher under inert conditions (20\%) than oxidative ambient (5\%) as a result of a less reactive ambient.

The thermal performance of all samples under any linear heating rate was predicted by the function Thermal Decomposition Behaviour (TDB). The values of $\mathrm{ZDT}_{0}$ provided the thermal stability of the samples and the use of $\mathrm{ZDT}_{\text {peak }}$ was useful to monitor the pseudo-components decomposition. A minimum of $\mathrm{T}=273^{\circ} \mathrm{C}$ (inert conditions) and $\mathrm{T}=264^{\circ} \mathrm{C}$ (oxidative conditions) will be necessary to start yielding volatile compounds. The use of $\mathrm{ZDT}_{\text {peak }}$ was useful to monitor the decomposition of each pseudo-component.

The application of isoconversional methods (Friedman, Flynn-Wall-Ozawa, KissingerAkashira-Sunose, Vyazovkin, Master Curves and Perez-Maqueda criterion along with CoatsRedfern equation) permitted the obtainment of the kinetic parameters (Ea, $\ln \mathrm{A}$ and $\mathrm{n}$ ) of the 
biomass for both inert and oxidative conditions. The kinetic law defining the decomposition rate of all samples was thus obtained. 


\section{References Chapter 3}

Akahira T., Sunose Trans.Joint Convention of Four Electrical Institutes, Paper N.246, Research Report/Chiba Institute of Technology. Scientific Technology, 16, 22-31 (1971).

Anwar Z., Gulfraz M., Irshad M. Agro-industrial lignocellulosic biomass a key to unlock the future bioenergy: A brief review. Journal of Radiation Research and Applied Sciences 7, Issue 2, 163-173 (2014).

Calvo L.F., Otero M., Jenkins B.M., Moran A., Garcia A.I. Heating process characteristics and kinetics of rice straw in different atmospheres. Fuel Processing Technology 85, 279-291 (2004).

Channiwala S.A. and Parikh P.P. A unified correlation for estimating HHV of solid, liquid and gaseous fuels. Fuel 81, 1051-1063 (2002).

Coats A.W., Redfern J.P., Kinetic parameters from thermogravimetric data. Nature, 201, 68-69 (1964).

Garcia Barneto A., Ariza J., Martin J.E., Sanchez R. Simulation of the thermogravimetry analysis of three non-wood pulps. Bioresource Technology 101, 3220-3229 (2010).

Gaur S., Reed T., Thermal Data for Natural and Synthetic Fuels. CRC Press New York: Marcel Dekker (1998).

Gotor F.J..Criado J.M, Malek J., Koga N., Kinetic analysis of solid-state reactions: the universatility of master plots for analysing isothermal and non-isothermal experiments. Journal of Physical Chemistry A, 104, 10777-10782 (2000).

Flynn J.H., Wall L.A., A quick, direct method for the determination of activation energy from thermogravimetric data. Journal of Polymer Science, 4, 323-342 (1966).

Friedman H., Kinetics of thermal degradation of char-forming plastics from thermogravimetry. Application to a phenol plastic., J. Polymer. Science, 6, 183-195 (1964).

Mishra G., Bhaskar T. Non isothermal model free kinetics for pyrolysis of rice straw. Bioresource Technology 169, 614-621 (2014).

Ozawa T., Kinetic analysis of derivative curves in thermal analysis. Journal of Thermal Analysis, 2, 301324 (1970).

Parikh P.P., Channiwala S.A. Ghosal G.K. A correlation for calculating HHV from proximate analysis of solid fuels. Fuel 84 (5), 487-494 (2005).

Perez-Maqueda L.A., Criado J.M., Gotor F.J., Malek J., Advantages of combined kinetic analysis of experimental data obtained under any heating rate profile, Journal of Physical Chemistry A, 106, 28622868 (2002).

Senum G.I., Yang R.T. Rational approximations of the integral of the Arrhenius function. Journal of Thermal Analysis and Calorimetry, 11, 446 (1977). 
Van Krevelen D.W. Graphical-statistical method for the study of structure and reaction processes of coal. Fuel 29, 269-284 (1950).

Vyazovkin S., Advanced isoconversional method, Journal of thermal analysis, 49, 1493-1499 (1997). 


\section{Communications}

The following communications related to the chapter Biomass and its characterisation are presented.

Communication 3I: C. Moliner, B. Bosio, E. Arato, A. Ribes. Comparative study for the energy valorisation of rice straw. Chemical Engineering Transactions, 37, 2014, 241-246. DOI: 10.3303/CET1437041

Communication 3II: C. Moliner, B. Bosio, E. Arato, A. Ribes. Thermal and thermo-oxidative characterisation of rice straw for its use in energy valorisation processes. Fuel 180 (2016) 71-79

The first contribution is devoted to the kinetic analysis of the rice straw applying the singlecomponent method, that is, considering the decomposition of the sample as a single compound.

The second contribution, on the contrary, provides a study of the thermal and thermo-oxidative behaviour of the sample according to the individual contribution of the main pseudocomponents present in the straw (ie. hemicellulose, cellulose and lignin). 
Comparative study for the energy valorisation of rice straw

C. Moliner, B. Bosio, E. Arato, A. Ribes

Chemical Engineering Transactions, 37, 2014,241-246

DOI: $10.3303 / C E T 1437041$ 



\title{
Comparative Study for the Energy Valorisation of Rice Straw
}

\author{
Cristina Moliner ${ }^{a *}$, Barbara Bosio $^{a}$, Elisabetta Arato ${ }^{a}$, Amparo Ribes-Greus $^{b}$ \\ a Dipartimento di Ingegneria Civile, Chimica e Ambientale (DICCA). Università degli Studi di Genova, Via Opera Pia 15, \\ 16145 Genova (Italy) \\ ${ }^{\mathrm{b}}$ Departamento de Maquinas y Motores Termicos (CMT). Universidad Politècnica de València, Camino de Vera s/n, \\ 46022. Valencia (Spain) \\ cristina.moliner@edu.unige.it
}

The processes of pyrolysis and combustion of rice straw were simulated by multi-rate linear nonisothermal thermogravimetric experiments under $\mathrm{Ar}$ and $\mathrm{O}_{2}$ respectively. The kinetic parameters and thermal stability of both thermo-chemical processes were assessed and compared under different linear heating rates.

From the results obtained from TGA, the kinetic methodology (combination of Friedman, KissingerAkahira-Sunose, Vyazovkin and Master-Curves methods) permitted to describe mathematically the decomposition processes of rice straw. The use of all the applied atmospheres showed 4 different decomposition stages, corresponding to the main degradation processes (drying and cellulose, hemicellulose and lignin decomposition). Reactions were faster when increasing the content of $\mathrm{O}_{2}$ in the carrying gas as a result of a higher reactive atmosphere and the percentage of ashes decreased, as well as the final temperature of each degradation stage.

\section{Introduction}

As a result of the world industrial development and the advent of new energy needs, a rapid increase in the use of fossil fuels has been encountered by all economic and social sectors. This high demand has led to a huge overuse of coal and oil based fuels, which has consequently resulted in a vast negative impact on the environment. Problems like global warming and the rapid exhaustion of provisions desperately need to be tackled; therefore renewable energy is now receiving increasing attention (Peres et al.).

Additionally, the rise in population has also changed consumption patterns and waste generation has grown dramatically. Inefficient management of this waste can result in large waste dumps which can cause health problems and environmental damage. Rice is one of the most cultivated crop worldwide, with an annual production of $700 \mathrm{Mt}$ according to the Food and Agriculture Organization of the United Nations (FAOSTAT) database resulting in a generation of $3.4 \mathrm{Mt}$ of rice straw in Europe. Open field burning is still the most popular way of eliminating rice straw (30\%). This results in a large increase in $\mathrm{CO}_{2}$ emissions and the inconvenience caused by the resulting smoke. The other common procedure is the disposal of rice straw on the field. This affects the ecosystem as its decomposition damages the quality of water increasing fish and aquatic fauna mortality in the wetland protected areas and producing disturbing odours in the affected areas.

Thermo-chemical conversions of rice straw have been purposed as an alternative to these management strategies taking profit of its capacity for energy production (HHV=15 MJ/Kg). Among the different available techniques, spouted bed reactors have emerged as a promising technology to carry out these processes due to its main working characteristics such as regular and continuous recirculation of particles and possibility of handling particles of different sizes and morphologies and initial difficulties encountered by conventional fluidisation when applied to agricultural residues are overcome.

However, as a consequence of the main properties of the feedstock like its high ash content and the low conversion efficiency, an exhaustive control of the process in terms of thermal conversions will be crucial 
to obtain higher efficiencies. Thermal studies including decomposition profiles, reaction kinetics and thermal stability of the raw material will be used to model the performance of the spouted bed reactor.

Thermogravimetric Analysis (TGA) is a widely used technique to assess the thermal behaviour and decomposition kinetics of biomass (Kirubakaran et al, 2009). Several works have studied the thermal properties of rice straw by means of thermal analysis (White et al, 2011). For the purpose of this work, rice straw samples were submitted to non-isothermal thermogravimetric experiments, under both inert ( $\mathrm{Ar}$ ) and oxidative $\left(\mathrm{O}_{2}\right)$ atmospheres with the aim to simulate different thermo chemical processes from pyrolysis (using $\mathrm{Ar}$ as carrier gas) to combustion (with $\mathrm{O}_{2}$ as carrier gas). The decomposition profiles were obtained and a kinetic analysis was performed to obtain the characteristic parameters during the degradation process. All the studies were carried out following an accurate methodology defined by Badia et al in previous works.

\section{Experimental procedure}

2.1 Thermogravimetric analyses

Multi-rate non-isothermal thermogravimetric experiments (TGA) were carried out in a Mettler Toledo TGA/SDTA 851 (Columbus, OH). Samples weighting $6 \mathrm{mg}$ were heated in an alumina holder with capacity for $70 \mu \mathrm{L}$. Experiments were performed from $25^{\circ} \mathrm{C}$ to $800^{\circ} \mathrm{C}$ at different heating rates $(\beta=2,5,10$, $15,20^{\circ} \mathrm{C} / \mathrm{min}$ ) under a constant flow of $50 \mathrm{~mL} / \mathrm{min}$ of gas of analysis. All samples were analysed under inert $(\mathrm{Ar})$ and oxidative $\left(\mathrm{O}_{2}\right)$ atmospheres to characterise the thermal and thermo-oxidative processes respectively. Experiments were repeated three times and the average values were considered as representative values. Assessment was performed with the aid of the software Star 9.10 from Mettler Toledo.

\subsection{Composition of the rice straw}

The composition of the rice straw was obtained according standard procedures ((UNE-EN 14774-3:2009, UNE-EN 15148 and UNE-EN 14775). The results (in dry basis) are reported in Table 1. The moisture content was $9.1 \%$.

Table 1: Composition of rice straw (dry basis)

\begin{tabular}{lll}
\hline Volatiles & Fixed Carbon & Ash \\
\hline 63.3 & 16.1 & 20.6 \\
\hline
\end{tabular}

\section{Results and conclusions}

\subsection{Thermal and thermo-oxidative decomposition profiles}

The thermal performance of the rice straw was initially addressed. The thermogravimetric curves (TG) and their first derivative curves (DTG) were obtained at all heating rates $\beta$ and compared between them. Figure 1 represents both TG (inset) and DTG curves at all $\beta$ (inert (a) and oxidative (b) ambient). As expected according to previous works by Amutio et al. with different types of biomass, higher $\beta$ led the thermograms to shift to higher temperatures, showing the dependence of the process with temperature.

As shown in Figure 1, the thermal degradation of the rice straw occurred through four different decomposition steps, regardless the atmosphere and the heating rate employed during the analysis. The material started to decompose at $\mathrm{T}_{0} \sim 25^{\circ} \mathrm{C}$ with the evaporation of moisture and light volatiles. The majority of the initial mass was consumed during the second degradation process at the range $\mathrm{T}=200{ }^{\circ} \mathrm{C}$ $400{ }^{\circ} \mathrm{C}$, where the presence of shoulders/double peaks indicates that more than one reaction is being involved at the same time. This step is assigned to the decomposition of hemicellulose and cellulose in line with previous studies by Yang et al. The last stage is assigned to the degradation of lignin whose decomposition occurs in a slow velocity, especially when using Ar. The value of the final residue reached up to the $20 \%$ for the case of samples under inert atmosphere while values around $5 \%$ were found at oxidative conditions.

All the characteristic parameters $\left(T_{0}, T_{p i}\right.$ with $i=1 \ldots 4$ representing the different pseudo-components of the straw: moisture, hemicellulose, cellulose and lignin) for each atmosphere and heating rate are gathered in Table 2. 


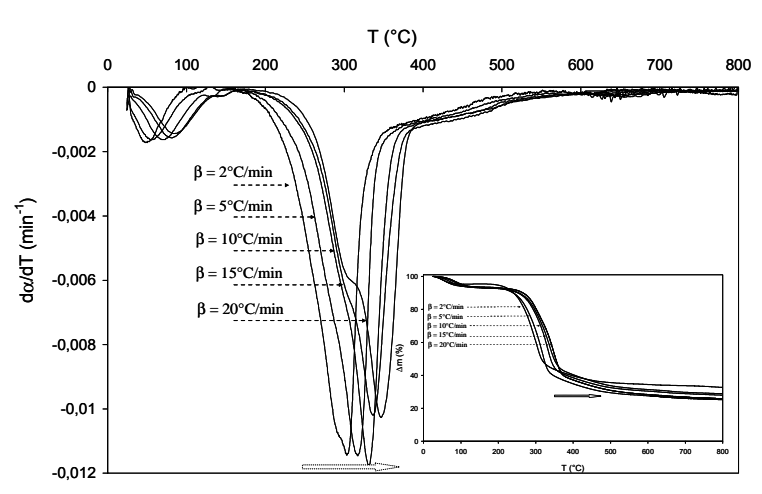

(a)

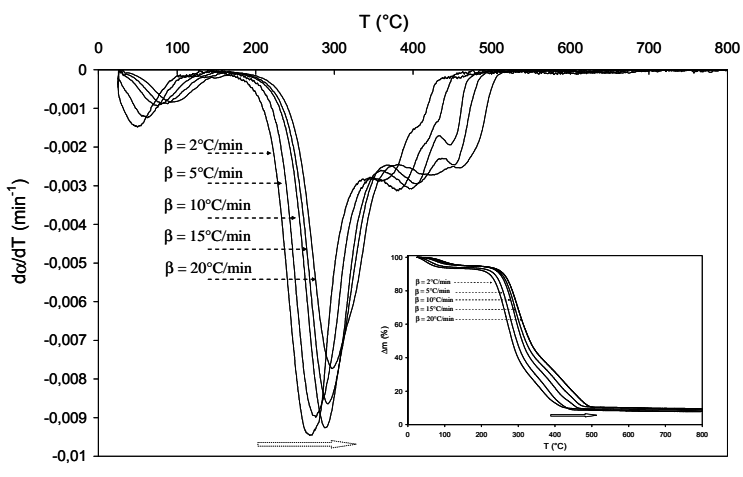

(b)

Figure 1. TG (inset) and DTG curves for rice straw under inert $\left(0 \% \mathrm{O}_{2}\right)(\mathrm{a})$ and oxidative $\left(100 \% \mathrm{O}_{2}\right)(\mathrm{b})$ atmospheres

Table 2: Characteristic temperatures $\left(T_{0}, T_{p i}\right)$ for each $\beta$ and ambient of study

\begin{tabular}{|c|c|c|c|c|c|c|c|c|c|c|c|c|c|}
\hline $\mathrm{Ar}$ & $\begin{array}{l}\beta \\
\left({ }^{\circ} \mathrm{C} / \mathrm{min}\right)\end{array}$ & $\begin{array}{l}\mathrm{T}_{0} \\
\left({ }^{\circ} \mathrm{C}\right)\end{array}$ & $\begin{array}{l}\mathrm{T}_{\mathrm{p} 1} \\
\left({ }^{\circ} \mathrm{C}\right)\end{array}$ & $\begin{array}{l}\mathrm{T}_{\mathrm{p} 2} \\
\left({ }^{\circ} \mathrm{C}\right)\end{array}$ & $\begin{array}{l}\mathrm{T}_{\mathrm{p} 3} \\
\left({ }^{\circ} \mathrm{C}\right)\end{array}$ & $\begin{array}{l}\mathrm{T}_{\mathrm{p} 4} \\
\left({ }^{\circ} \mathrm{C}\right)\end{array}$ & $\mathrm{O}_{2} \beta$ & $\begin{array}{l}\beta \\
\left({ }^{\circ} \mathrm{C} / \mathrm{min}\right.\end{array}$ & $\begin{array}{l}\mathrm{T}_{0} \\
\left({ }^{\circ} \mathrm{C}\right)\end{array}$ & $\begin{array}{l}\mathrm{T}_{\mathrm{p} 1} \\
\left({ }^{\circ} \mathrm{C}\right)\end{array}$ & $\begin{array}{l}\mathrm{T}_{\mathrm{p} 2} \\
\left({ }^{\circ} \mathrm{C}\right)\end{array}$ & $\begin{array}{l}\mathrm{T}_{\mathrm{p} 3} \\
\left({ }^{\circ} \mathrm{C}\right)\end{array}$ & $\begin{array}{l}\mathrm{T}_{\mathrm{p} 4} \\
\left({ }^{\circ} \mathrm{C}\right)\end{array}$ \\
\hline & 2 & 25.0 & 34.9 & 289.2 & 299.8 & 430.0 & 2 & 2 & 25.0 & 51.4 & 270.5 & 378.3 & 407.2 \\
\hline & 5 & 25.0 & 57.3 & 290.8 & 316.9 & 445.0 & 5 & 5 & 28.0 & 62.9 & 273.0 & 387.4 & 425.7 \\
\hline & 10 & 25.0 & 71.5 & 291.4 & 330.6 & 462.0 & & 10 & 25.0 & 74.6 & 287.7 & 402.3 & 452.9 \\
\hline & 15 & 25.0 & 81.6 & 301.4 & 335.6 & 465.0 & & 15 & 30.0 & 83.8 & 291.6 & 408.9 & 457.5 \\
\hline & 20 & 25.0 & 86.1 & 313.6 & 346.6 & 470.0 & & 20 & 30.0 & 95.4 & 297.1 & 419.8 & 473.1 \\
\hline
\end{tabular}

The use of a reactive ambient fastened the decomposition of the material, shifting the TG curves to lower temperatures in comparison with the results obtained under inert conditions, as shown in Figure 2 (a). These values provide valuable information for the design of the spouted bed reactor in terms of temperature of work and resulting decomposition processes of the main constituents of rice straw. A deconvolution procedure was applied to individually characterise and quantify each decomposition stage, as shown in Figure 2 (b).

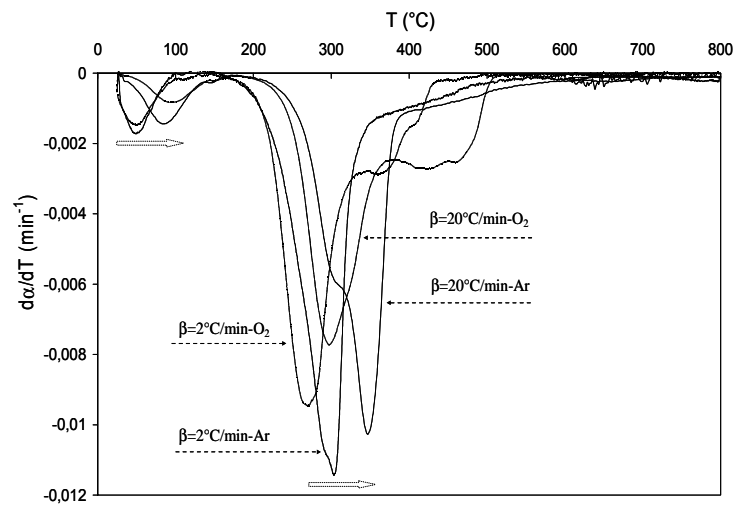

(a)

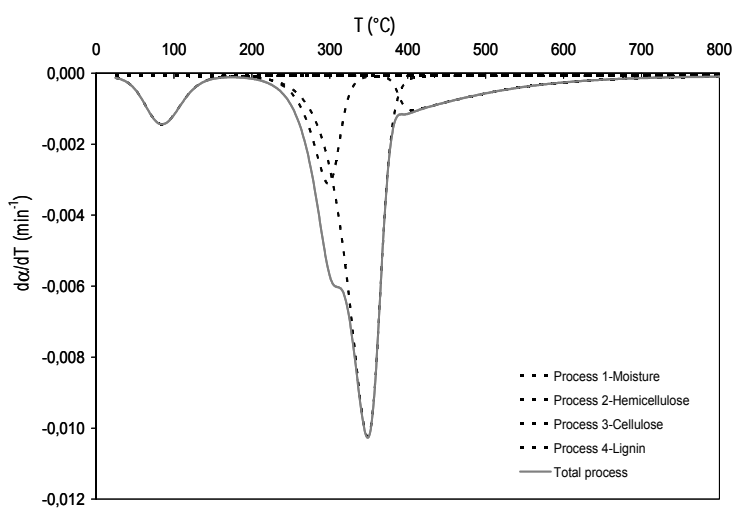

(b)

Figure 2. Comparison of DTG curves for rice straw at different atmospheres and heating rates (a) Deconvolution curves for rice straw at $20^{\circ} \mathrm{C} / \mathrm{min}$ using $\mathrm{Ar}$ as carrier gas (b)

Table 3 gathers the values of mass loss of the different degradation processes for all atmospheres and heating rates. 
Table 3. Mass loss of each decomposition process at every ambient and $\beta$ of study

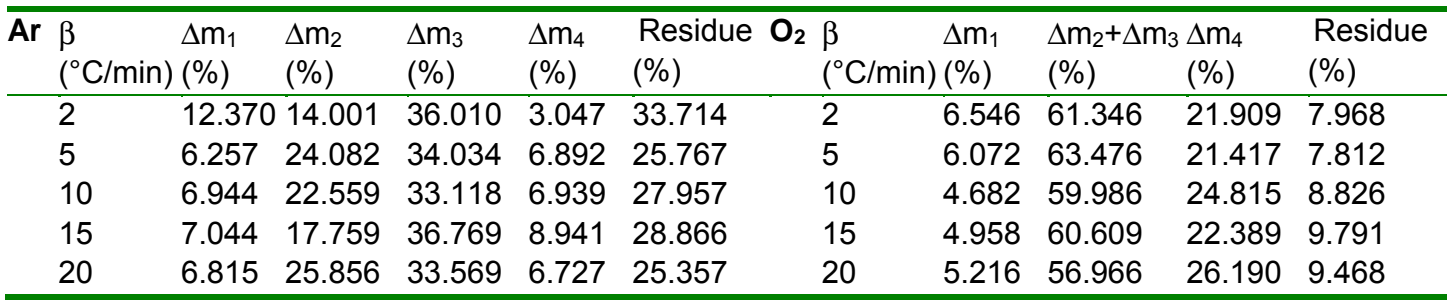

As shown in Table 3, the major mass loss corresponds to the hemicellulose and cellulose decompositions where the presence of a shoulder indicates that both processes are overlapped for inert conditions whereas a single peak is observed for oxidative conditions. The values corresponding to the remaining residue are highly influenced by the atmosphere of work. Higher values were obtained for inert conditions as a result of a less reactive atmosphere. This parameter will be of high interest for the design of the spouted bed reactor, as high percentages of residue could lead to slagging and fouling problems in it due to the high content of silica in the rice straw and so, an exhaustive control of the oxygen content in the carrier gas will be required.

\subsection{Activation energies}

The isoconversional methods by Friedman et al., Kissinger et al. and Vyazovkin et al. were applied to evaluate the dependence of the apparent activation energy (Ea) with the conversion degree $(\alpha)$ of the reaction as shown in Figure 3 for the case of rice straw under inert conditions. All the kinetic analysis were carried out in the range $\alpha=0.2-0.8$, where the main reactions occur. In order to assure that Ea remains constant during the whole process, the average values were obtained for each of the mentioned methods. Relatively low error values were obtained, validating thus the initial hypothesis. The activation energy for rice straw was calculated from the average of the three different methods $\left(E a_{i}\right)$. This value is lower than the calculated $\mathrm{Ea}=197.6 \mathrm{KJ} / \mathrm{mol}$ obtained by Yao et al. in previous works. All the values corresponding to the different methods are presented in Table 3.

Table 3: Apparent activation energy (Ea) for rice straw (Ar)

\begin{tabular}{lllllll}
\hline Ea $_{\text {Friedman }}(\mathrm{KJ} / \mathrm{mol})$ & Error $_{\text {Friedman }}(\%)$ & Ea $_{\text {KAS }}(\mathrm{KJ} / \mathrm{mol})$ & Error $_{\mathrm{KAS}}(\%) \mathrm{Ea}_{\mathrm{VYZ}}(\mathrm{KJ} / \mathrm{mol})$ Error $_{V Y Z}(\%)$ & $\mathrm{Ea}_{\mathrm{i}}(\mathrm{KJ} / \mathrm{mol})$ \\
\hline 144.98 & 12.3 & 144.17 & 6.2 & 134.06 & 19.6 & 141.07 \\
\hline
\end{tabular}

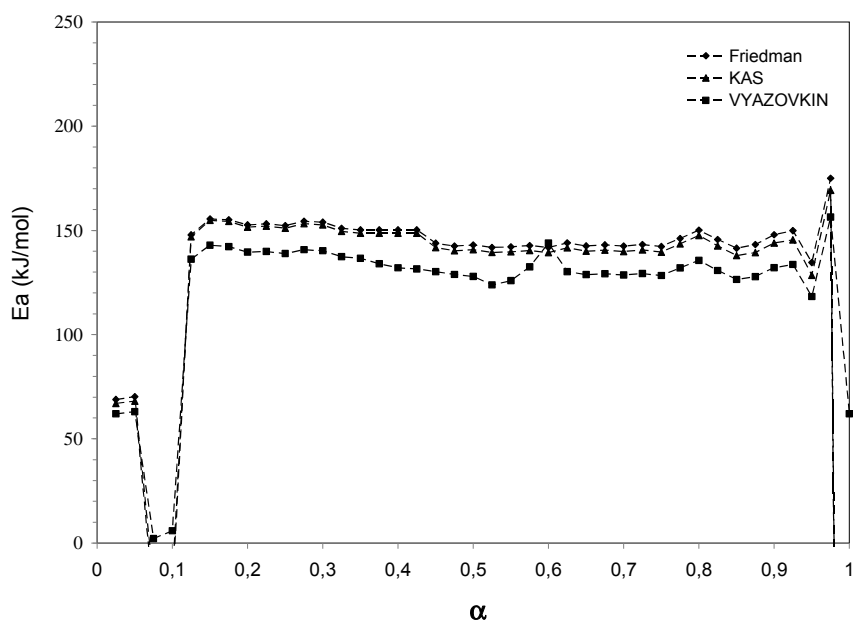

Figure 3. Evolution of Activation Energies with conversion for rice straw under inert conditions

On the contrary, a strong dependence of Ea with the conversion was observed for oxidative conditions and so, the average values in the range of study were not calculated. 
3.3 Decomposition kinetics

The kinetic model was evaluated from the kinetic analysis of the composites and the Master Plot reduced curves (MP). Master plots are defined as the theoretical reference curves dependent on the kinetic model and, generally, independent of the kinetic parameters of the process. The comparison between the experimental values and these theoretical curves permits the calculation of the appropriate kinetic model according to the better fitting obtained on the master plot as described by Gotor et al. The three main types of master plots are the ones based on the differential form $\left(\mathrm{MP}_{\mathrm{f}}\right)$ of the general kinetic equation as expressed in $\mathrm{Eq}(1)$, the integral form $\left(\mathrm{MP}_{\mathrm{g}}\right)$ as in $\mathrm{Eq}(2)$ or the combination of both $\left(\mathrm{MP}_{\mathrm{fg}}\right)$. The theoretical master plots of the different kinetic models can be clearly distinguished for $\alpha<0.5$ (in the case of the differential curves) and $\alpha>0.5$ (for the integral curves) and therefore a straightforward identification can be done. The theoretical curves coincide at $\alpha=0.5$ and so, this point is taken as a reference and all the curves are reduced to it for a better visualisation.

$$
\begin{aligned}
& \frac{d \alpha}{d t} \equiv \beta \cdot \frac{d \alpha}{d t}=A \cdot f(\alpha) \cdot k(T)=A \cdot f(\alpha) \cdot e^{\frac{-E_{a}}{R \cdot T}} \\
& g(\alpha)=\int_{0}^{\alpha} \frac{d \alpha}{f(\alpha)}=\frac{A \cdot E_{a}}{\beta \cdot R} \cdot \int_{0}^{\infty} \frac{e^{-x}}{x^{2}}=\frac{A \cdot E_{a}}{R \cdot T} \cdot p(x), x=\frac{E_{a}}{R \cdot T}
\end{aligned}
$$

Figure 4 shows the theoretical curves in the differential-MP $\mathrm{P}_{\mathrm{f}}(\mathrm{a})$ and integral-MPg $(\mathrm{b})$ along with the experimental data corresponding to rice straw at $5^{\circ} \mathrm{C} / \mathrm{min}$ under inert environment. The kinetic models represented are: Dn: diffusion controlled (dashed lines), An: nucleation and growth (solid black lines), Fn: $\mathrm{n}$-order reactions (solid grey lines) and $\mathrm{Rn}$ : reaction controlled (pointed lines).

By comparison of the experimental data on the theoretical curves as shown in Figure 4, it can be suggested that the sample follows a $4^{\text {th }}$-order chemical reaction mechanism, as the best fitting of the experimental data corresponds to the curve $\mathrm{F} 4$ on both $\mathrm{MP}_{\mathrm{f}}$ and $\mathrm{MP}_{\mathrm{g}}$ representations and therefore the function defining the mechanism will be $f(\alpha)=(1-\alpha)^{4}$.

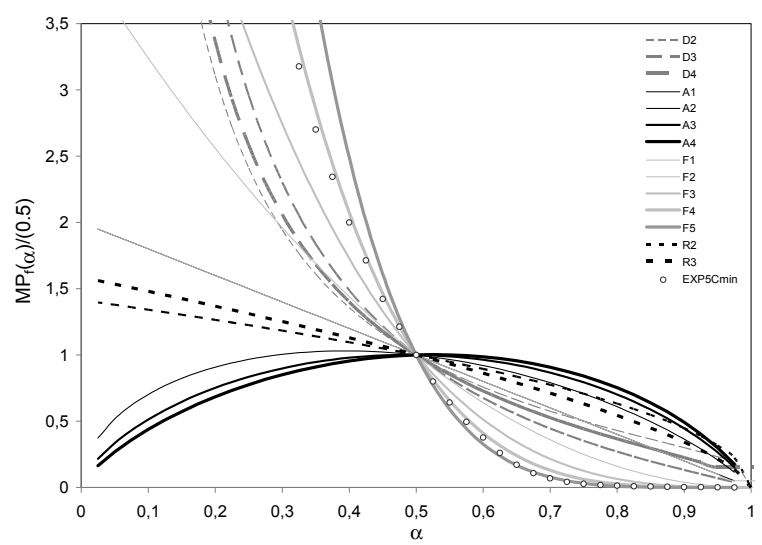

(a)

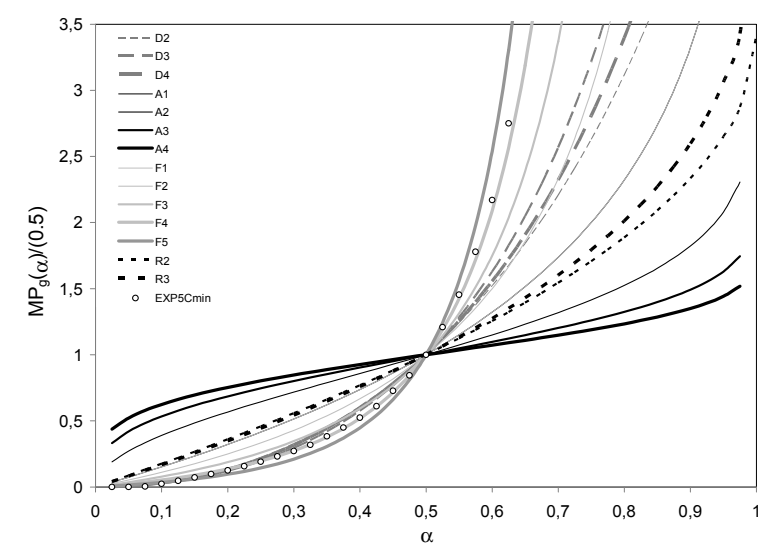

(b)

Figure 4. Master Plots based on the differential-MP $P_{f}(a)$ and integral-MP $P_{g}(b)$ form of the general law compared to the experimental data obtained by the thermal process applied (circles). Kinetic models: Dn: diffusion controlled, dashed lines, An: nucleation and growth, solid black lines, Fn: $n$-order reactor, solid grey lines, Rn: reaction controlled, pointed lines)

\section{Conclusions}

The thermal behaviour of rice straw when submitted to combustion and pyrolysis reactions was studied for the present work. Every sample presented four main steps during the decomposition process, two of them overlapped in the case of inert conditions. The major loss mass was obtained in the range of $\mathrm{T}=200{ }^{\circ} \mathrm{C}$ $400{ }^{\circ} \mathrm{C}$, regardless the atmosphere of work and the values of residue were higher when using $\mathrm{Ar}$ as carrier gas.

The characteristic peak temperatures of the thermal decomposition process $\left(T_{0}, T_{p 1}, T_{p 2}, T_{p 3}, T_{p 4}\right)$ increased when increasing the heating rate and when applying inert conditions. 
The total average activation energy of the process for each sample was calculated. After the kinetic analysis, it was concluded that $E_{a}$ can be assumed as constant for the range of study $(\alpha=0.2-0.8)$ only for inert atmosphere. The average value in this case was $E a=141.07 \mathrm{KJ} / \mathrm{mol}$.

The kinetic model was evaluated with the aid of master plots, obtaining the best fitting for the $4^{\text {th }}$-order chemical reaction mechanism.

\section{References}

Akahira T., Sunose T., 1971, Trans. Joint Convention of Four Electrical Institutes, Paper N.246, Research Report/Chiba Institute of Technology. Scientific Technology, 16, 22-31.

Amutio M., Lopez G., Aguado R., Artetxe M., Bilbao J., Olazar M., 2012, Kinetic study of lignocellulosic biomass oxidative pyrolysis, Fuel 95, 305-311.

Badia J.D, Santonja-Blasco L., Martinez-Felipe A., Ribes-Greus A, 2012, A methodology to assess the energetic valorization of bio-based polymers from the packaging industry: pyrolysis of reprocessed polylactide, Bioresource Technology, 111, 468-475.

Epstein N., Grace J.R., 2011, Spouted and Spout-fluid beds. Fundamentals and applications. Ed. Cambridge university Press.

FAOSTAT (Food and Agriculture Organization of the United Nations), 2013, Production crops $<$ faostat3.fao.org>, Accessed 12.12.2013.

Friedman H.L., 1967, Kinetics and gaseous products of thermal decomposition of polymers. Journal of Macromolecular Science Part A, 1 (1), 57-79.

Gotor F.J., Criado J.M., Malek J., Koga N., 2000, Kinetic analysis of solid-state reactions: the universatility of master plots for analysing isothermal and non-isothermal experiments. Journal of Physical Chemistry A 104, 10777-10782.

Kirubakaran V., Sivaramakrishnan V., Nalini R., Sekar T., Premalatha M., Subramanian P., 2009, A review on gasification of biomass, Renewable and Sustainable Energy reviews 13, 179-186.

Lim J.S., Manan Z.A., Alwi W., Hashim H., 2012, A review on utilisation of biomass from rice industry as a source of renewable energy, Renewable and sustainable energy reviews 16, 3084-3094.

Peres A.P.G., Lunelli B.H., Filho R.B., 2013, Applications of biomass to hydrogen and syngas production, Chemical Engineering Transactions 32, DOI: 10.3303/CET1332099.

Yang H., Yan R., Chen H., Ho Lee D., Zheng C., 2007, Characteristics of hemicellulose, cellulose and lignin pyrolysis, Fuel 86, 1781-1788.

Yao F., Wu Q., Lei Y., Wuo W., Xu Y., 2008, Thermal decomposition kinetics of natural fibers: Activation energy with dynamic thermogravimetric analysis, Polymer Degradation and Stability 93, 90-98.

Vyazovkin S., Dollimore D., 1996, Linear and non-linear procedures in isoconversional computations of the activation energy of non-isothermal reactions in solids. Journal of Chemical Information and Modelling $36,42-45$.

White J.E., Catallo W.J., Legendre B.L., 2011, Biomass pyrolysis kinetics: A comparative critical review with relevant agricultural residue case studies, Journal of Analytical and Applied Pyrolysis 91, Issue 1, $1-33$. 


\section{Communication 3.II}

Thermal and thermo-oxidative characterisation of rice straw for its use in energy valorisation processes

C.Moliner, B.Bosio, E.Arato, A.Ribes

Fuel 180 (2016) 71-79 

Full Length Article

\title{
Thermal and thermo-oxidative characterisation of rice straw for its use in energy valorisation processes
}

\author{
C. Moliner ${ }^{\mathrm{a}, *}$, B. Bosio ${ }^{\mathrm{a}}$, E. Arato ${ }^{\mathrm{a}}$, A. Ribes ${ }^{\mathrm{b}}$ \\ a Dipartimento di Ingegneria Civile, Chimica e Ambientale (DICCA), Università degli Studi di Genova, Via Opera Pia 15, 16145 Genova, Italy \\ ${ }^{\mathrm{b}}$ Instituto de Tecnologia de Materiales (ITM), Universitat Politècnica de València, Camino de Vera s/n, 46022 Valencia, Spain
}

\section{H I G H L I G H T S}

- The thermal behaviour of rice straw under pyrolysis and combustion was compared.

- A simplified kinetic triplet and the mechanism of reaction were obtained.

- The initial design parameters of a spouted bed reactor were discussed.

\section{A R T I C L E I N F O}

\section{Article history:}

Received 4 March 2015

Received in revised form 8 March 2016

Accepted 6 April 2016

\section{Keywords:}

Rice straw

Thermogravimetric analysis

Thermal decomposition

Thermo-oxidative decomposition

Apparent activation energy

Kinetic triplet

\begin{abstract}
A B S T R A C T
The processes of pyrolysis and combustion of rice straw will be carried out in a spouted bed reactor. Both thermo-chemical processes were simulated in the first stage by multi-rate linear non-isothermal thermogravimetric (TGA) experiments using $\mathrm{Ar}$ and $\mathrm{O}_{2}$ as carrier gas respectively. The results obtained from the TGA measurements, the kinetic methodology based on the combination of the iso-conversional methods Friedman, Flynn-Wall-Ozawa, Kissinger-Akahira-Sunose, Vyazovkin and the use of Master Plots assessed by Perez-Maqueda criterion have permitted to describe mathematically both thermochemical reactions. Lower operational temperatures and higher kinetic parameters $(E a, n, A)$ were required to carry out combustion reactions respect to those for pyrolysis. These results will be the initial parameters that will define both thermo-chemical processes in a spouted bed reactor.
\end{abstract}

(c) 2016 Elsevier Ltd. All rights reserved.

\section{Introduction}

Rice is one of the most consumed crops worldwide, with an annual production of 700 million tons according to the Food and Agriculture Organization of the United Nations [1] database resulting in a generation of 3.4 million tons of rice straw in Europe. Inefficient management of this waste can result in large waste dumps which can cause health problems and environmental damage. Open field burning is vastly used to eliminate these residues nowadays (30\%) while the rest is left in the fields with the consequent associated environmental problems that both procedures can generate.

Thermo-chemical conversions of rice straw have been proposed as an alternative to these management strategies taking profit of its capacity for energy production, with high heating values around $15 \mathrm{MJ} / \mathrm{Kg}$ as stated by Lim et al. [2]. Among the different available

\footnotetext{
* Corresponding author.

E-mail address: cristina.moliner@edu.unige.it (C. Moliner).
}

techniques, Spouted Bed Reactors (SBR) has emerged as an adequate technology to carry out pyrolysis [3], gasification [4] and combustion [5] of different waste materials or reforming reactions [6]. Rice straw will constitute the main feedstock of a thermochemical process carried out in a SBR, obtained by replacing the perforated plate of a standard fluidised reactor with a simple orifice, normally in a central position. As a result, the solid circulation is enhanced and stagnant zones are avoided improving the mass and heat transfer phenomena. This behaviour provides the system with important advantages as fuel flexibility with the possibility of handling particles of different sizes and morphologies and low operating temperature conditions. The initial difficulties encountered by conventional fluidisation when applied to agricultural residues can thus be overcome.

However, as a consequence of the main properties of the feedstock like its high ash content and the low conversion efficiency, an exhaustive control of the process in terms of thermal conversions will be crucial to obtain higher efficiencies. 


\section{Nomenclature}

$\alpha \quad$ conversion degree

$\beta \quad$ heating rate of thermogravimetric analysis $\left({ }^{\circ} \mathrm{C} / \mathrm{min}\right)$

DTG first-derivative thermogravimetric curve

$\mathrm{Ea} \quad$ apparent activation energy $(\mathrm{J} / \mathrm{mol})$

$E a_{\text {iso }} \quad$ average apparent activation energy $(\mathrm{J} / \mathrm{mol})$

FWO Flynn-Wall-Ozawa

HHV high heating value $(\mathrm{J} / \mathrm{kg})$

KAS Kissinger-Akahira-Sunose

MP master plots

$\mathrm{MP}_{f, g} \quad$ differential and integral form of MP $n \quad$ order in kinetic functions

SBR spouted bed reactor

$T_{d}(\beta) \quad$ decomposition temperature as function of the heating rate $\left({ }^{\circ} \mathrm{C}\right)$

TG thermogravimetric curve

TGA thermogravimetric analysis

$T_{p i} \quad$ peak temperatures of the pseudo-components of the straw

VYZ Vyazovkin

ZDT zero-decomposition temperature $\left({ }^{\circ} \mathrm{C}\right)$
Thermal studies including decomposition profiles, reaction kinetics and thermal behaviour of the raw material will be crucial to optimise the performance of the SBR. Thermogravimetric Analysis (TGA) is a widely used technique to assess the thermal stability and decomposition kinetics of biomass. Few works have studied the thermal properties of rice straw by means of thermal analysis [7]. From the kinetic analysis, valuable parameters related to the thermo-chemical process can be obtained such as the activation energy $(E a)$ and the pre-exponential factor $(A)$, both highly dependent on the temperature of reaction. Furthermore, the composition of the raw material can also be provided by thermal studies as reported in [8] as a result of the quantification of the different processes of mass loss observed during the heating process.

The main aim addressed in the present work is to characterise and compare the thermo-chemical conversions of rice straw by means of thermogravimetric analysis. The kinetic methodology based on the combination of the iso-conversional methods Friedman, Flynn-Wall-Ozawa, Kissinger-Akahira-Sunose, Vyazovkin and the use of Master Plots assessed by Perez-Maqueda criterion permitted to describe mathematically both thermo-chemical reactions. The results will define the further use of rice straw as feedstock in energy recovery processes. The thermal parameters will be used for the adequate design of pyrolysis and combustion processes in a spouted bed reactor where the thermal recovery reactions will be carried out.

\section{Materials and methods}

\subsection{Materials and sample preparation}

Rice straw was collected from the region of Valencia (Spain). The samples were washed, dried and sized. The diameter of particle was $3.2( \pm 0.8) \mathrm{mm}$.

The composition of the rice straw was obtained according standard procedures (UNE-EN 14774-3:2009, UNE-EN 15148 and UNEEN 14775) to obtain the distribution of products when biomass is heated under specified conditions (proximate analysis) and the composition of the biomass in base of its constituting elements (ultimate analysis). The results are reported in Table 1 . The higher heating value was obtained by application of the relation by Channiwala and Parikh [9]:

$$
\begin{aligned}
\mathrm{HHV}(\mathrm{MJ} / \mathrm{kg})= & 0.3491 \cdot \% \mathrm{C}+1.1783 \cdot \% \mathrm{H}+0.1005 \cdot \% \mathrm{~S} \\
& -0.1034 \cdot \% \mathrm{O}-0.0151 \cdot \% \mathrm{~N}-0.0211 \cdot \% \mathrm{~A}
\end{aligned}
$$

where $\mathrm{C}, \mathrm{H}, \mathrm{S}, \mathrm{O}, \mathrm{N}$ and A are the content (\%w/w) of carbon, hydrogen, sulphur, oxygen, nitrogen and ash in the samples. The calculated $\mathrm{HHV}$ was $11.6 \mathrm{MJ} / \mathrm{kg}$ indicating the suitability of the rice straw for thermo-chemical conversion processes.

\subsection{Thermogravimetric analyses}

Multi-rate non-isothermal thermogravimetric experiments (TGA) were carried out in a Mettler Toledo TGA/SDTA 851 (Columbus, $\mathrm{OH}$ ). Samples weighing about $6 \mathrm{mg}$ were heated in an alumina holder with capacity for $70 \mu \mathrm{l}$.

Experiments were performed from $25^{\circ} \mathrm{C}$ to $800{ }^{\circ} \mathrm{C}$ at different heating rates $\left(\beta=2,5,10,15,20^{\circ} \mathrm{C} / \mathrm{min}\right)$ under a constant flow of $50 \mathrm{ml} / \mathrm{min}$ of gas of analysis. All samples were analysed under inert $(\mathrm{Ar})$ and oxidative $\left(\mathrm{O}_{2}\right)$ atmospheres to characterise the thermal and thermo-oxidative processes respectively. Experiments were repeated three times and the average values were considered as representative values. Assessment was performed with the aid of the software $\operatorname{Star}^{\mathrm{e}}$ 9.10 from Mettler Toledo.

\section{Results and discussion}

\subsection{Thermal and thermo-oxidative decomposition profiles}

The thermal performance of the rice straw was initially addressed. The thermogravimetric curves (TG) and their first derivative curves (DTG) were obtained for each sample at all heating rates $\beta$ and compared between them. Fig. 1 represents the TG (inset) and DTG curves of rice straw for all $\beta$ under inert (a) and oxidative (b) conditions. A visual observation of the thermograms reveals three well differentiated stages, regardless the heating rate and atmosphere employed during the analysis.

\subsubsection{Stage 1. Drying}

The material started to decompose at $T \approx 25^{\circ} \mathrm{C}$ in all cases as a result of the evaporation of moisture and absorbed water due to the hygroscopic nature of the rice straw. This peak was identified as the drying stage and it occurred below $125^{\circ} \mathrm{C}$ in all cases. The process was found to follow the same trend for all the samples.

\subsubsection{Stage 2. Devolatilisation}

Stage 2 is considered to be the step in which most of the devolatilisation reactions take place and therefore, its study will be addressed in great detail. Its complete definition in terms of temperature of degradation and kinetics of decomposition will be the basis for the correct design of the spouted bed reactor to obtain the highest yields.

The majority of the initial mass was consumed during this second degradation process at the range $T \approx 200{ }^{\circ} \mathrm{C}-400^{\circ} \mathrm{C}$. Two different behaviours were observed depending on the applied conditions: a single peak was obtained under oxidative conditions whereas two overlapped peaks, a shoulder together with the main peak, were observed for the case of inert atmosphere. 
Table 1

Proximate and ultimate analysis of rice straw.

\begin{tabular}{|c|c|c|c|c|c|c|c|c|}
\hline \multicolumn{5}{|c|}{ Ultimate analysis (\%) } & \multicolumn{4}{|c|}{ Proximate analysis (\%) } \\
\hline $\mathrm{C}$ & $\mathrm{H}$ & $\mathrm{N}$ & $S$ & 0 & Moisture & $\operatorname{Ash}^{\mathrm{a}}$ & Volatiles $^{a}$ & Fixed carbon $^{\mathrm{a}}$ \\
\hline 34.803 & 4.986 & 2.191 & 0.204 & 57.816 & 9.1 & 20.6 & 63.3 & 16.1 \\
\hline
\end{tabular}

a Dry basis.
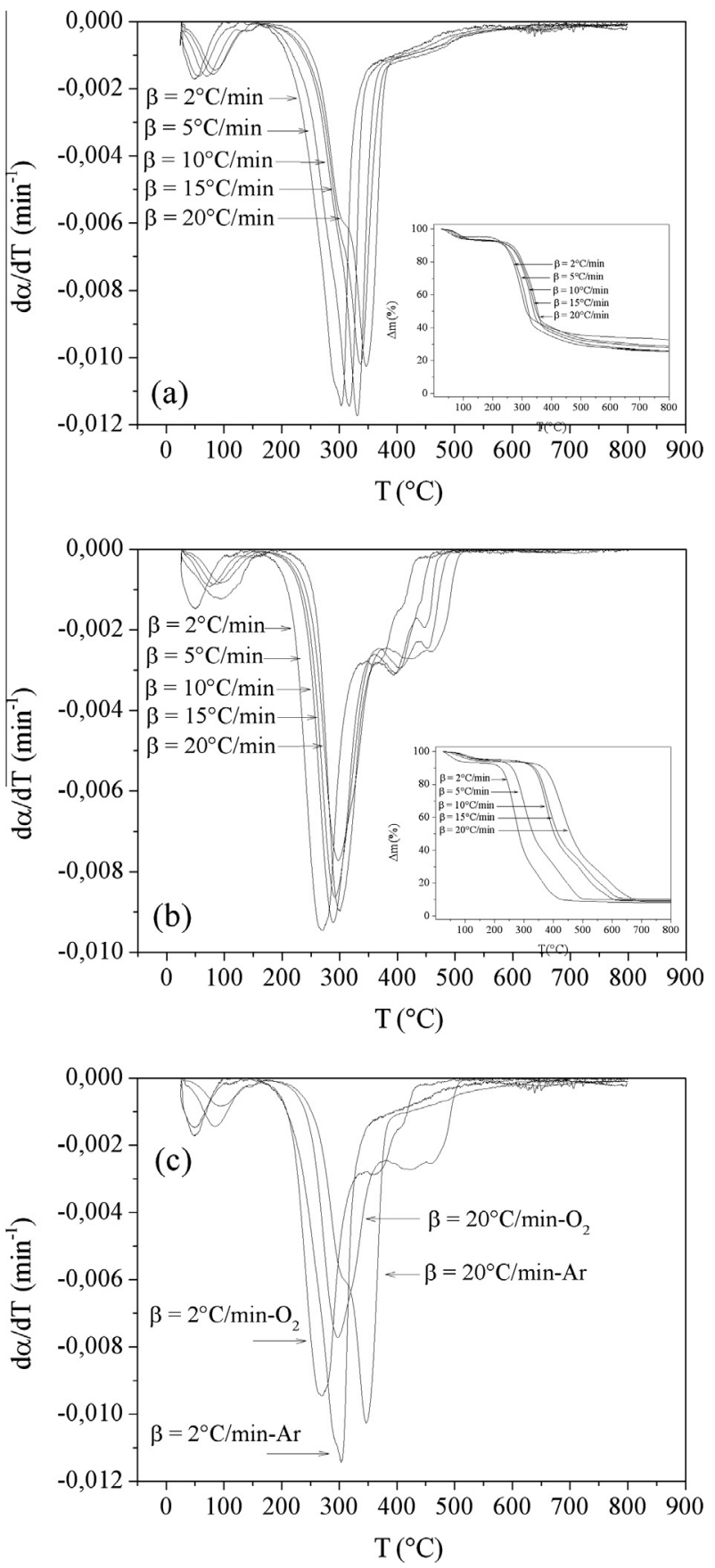

Fig. 1. TG (inset) and DTG curves for rice straw at all $\beta$ at inert (a) and oxidative (b) conditions. Influence of the heating rate and atmosphere of work on the thermal decomposition of rice straw (c).

Moreover, the main peak shifted to lower temperatures in an oxidative ambient respect to that in inert conditions, indicating that heterogeneous oxidation reactions are taking place, together with the those of pyrolysis.
The presence of this shoulder indicated that more than one reaction was being involved with a higher mechanism complexity. In both cases, the molecular origin of this step is the same and it is related to the emissions of volatiles and low molecular weight compounds mainly associated to the decomposition of hemicellulose and cellulose and, in smaller amounts, lignin.

\subsubsection{Stage 3. Combustion}

The last stage $\left(T>400^{\circ} \mathrm{C}\right)$ is mainly assigned to the rapid thermo-oxidation of the remaining combustible components which are more resistant to the thermo-degradation as lignin, whose decomposition occurs in a slow velocity and a wide range of temperatures resulting in high char yields that also burn in this stage. The presence of two peaks indicates a more complex mechanism of reaction. Its higher resistance to thermal decomposition compared to hemicellulose and cellulose is due its complex structure and it is favored in the presence of oxygen. However, due to the difficulty to properly separate these two peaks and, for the purpose of this work, they will be mathematically treated as a single process.

The value of the final residue reached values over $20 \%$ for the case of samples under inert atmosphere whereas values around $5 \%$ were found at oxidative conditions. The whole decomposition scheme is in agreement with previous works on lignocellulosic materials [10].

Fig. 1(c) shows the dependence of the thermal process with the factors of study (heating rate and atmosphere of work) with selected previous curves.

As expected according to previous works with different types of biomass [11], when the heating rate $\beta$ increases the thermograms shift to higher temperatures as a result of a delay in the degradation process and the sharp gradients of temperature obtained between the particle and surroundings which postpone the decomposition of biomass.

In addition, the use of an oxidative atmosphere fastened the decomposition of the material, shifting the TG curves to lower temperatures in comparison with the results obtained under inert conditions. This fact indicates a higher stability of these materials under non-reactive atmosphere due to a decrease on the reactivity in the system, as it occurred for different types of biomass in previous works $[7,12]$.

The presence of shoulders/double peaks in the decomposition profiles shown in Fig. 1 indicates that more than one reaction is being involved at the same time. With the aim of individually characterise and quantify each decomposition process, a deconvolution procedure was applied to all samples. The deconvoluted curves and their fitting on the original data are represented in Fig. 2 for inert (a) and oxidative (b) conditions.

All the characteristic peak temperatures $\left(T_{p i}\right.$ with $i=1 \ldots 4$ representing the different pseudo-components of the straw: moisture, hemicellulose, cellulose and lignin) for all heating rates and atmospheres are gathered in Table 2 together with the associated errors of the averaged value respect to each repetition.

The choice of the adequate temperature of work for the reactor will define the characteristics of the final product of the reaction and its correct assessment will be necessary for achieving the optimised working conditions. 

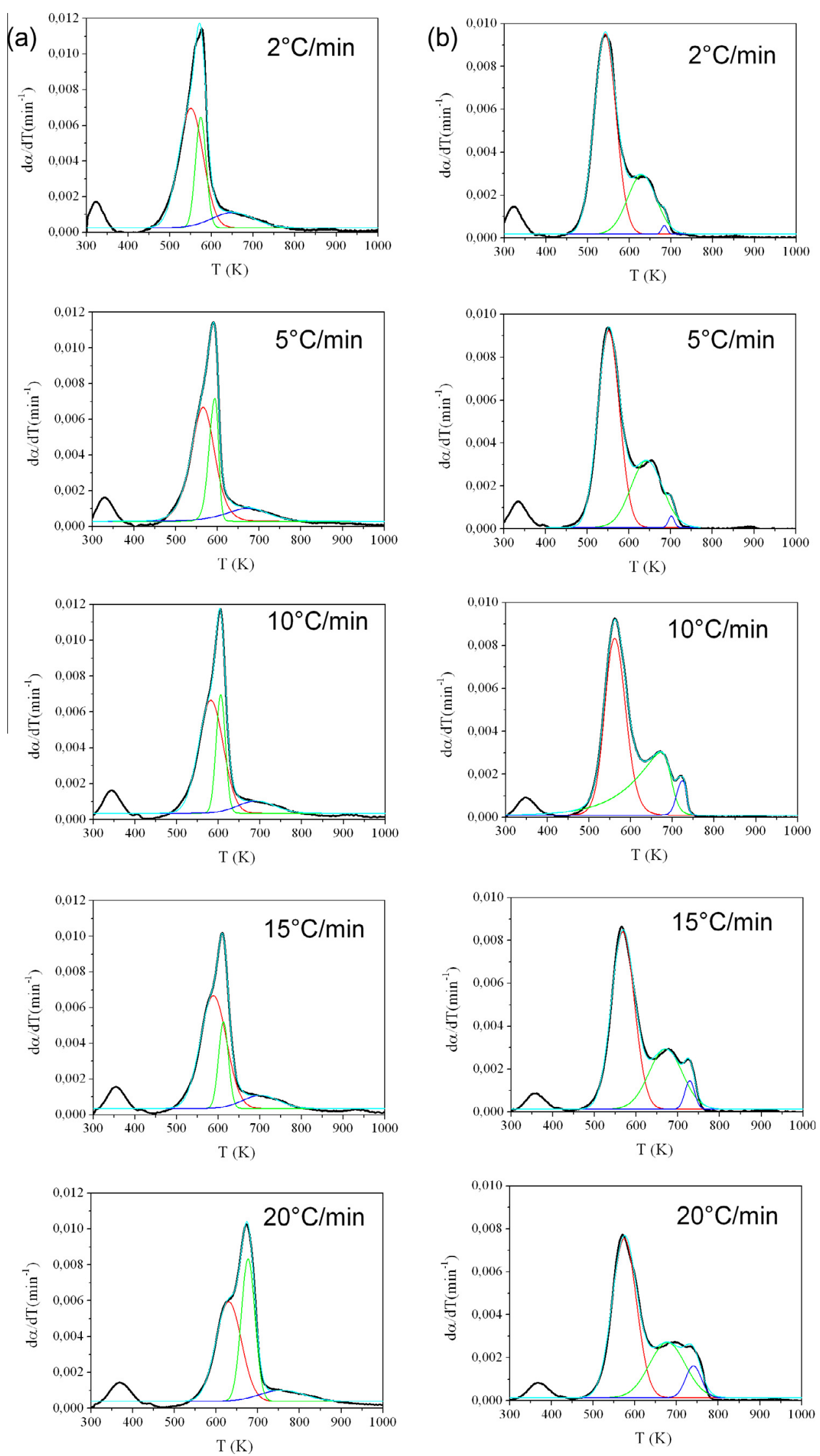

Fig. 2. Deconvolution of all the pseudo-components of rice straw at all heating rates under inert (a) and oxidative (b) conditions. 
Table 2

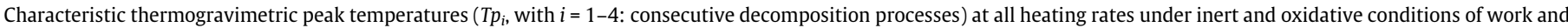
associated error values.

\begin{tabular}{|c|c|c|c|c|c|c|c|c|c|c|}
\hline $\mathrm{Ar}$ & $\beta\left({ }^{\circ} \mathrm{C} / \mathrm{min}\right)$ & $T_{p 1}\left({ }^{\circ} \mathrm{C}\right)$ & $e(\%)$ & $T_{p 2}\left({ }^{\circ} \mathrm{C}\right)$ & $e(\%)$ & $T_{p 3}\left({ }^{\circ} \mathrm{C}\right)$ & & $e(\%)$ & $T_{p 4}\left({ }^{\circ} \mathrm{C}\right)$ & $e(\%)$ \\
\hline & 2 & 50 & 1.1 & 289 & 2.6 & 304 & & 1.0 & 430 & 3.7 \\
\hline & 5 & 57 & 0.8 & 291 & 2.4 & 317 & & 1.2 & 445 & 4.5 \\
\hline & 10 & 71 & 1.4 & 291 & 1.8 & 331 & & 0.9 & 462 & 2.4 \\
\hline & 15 & 82 & 0.9 & 301 & 2.5 & 336 & & 4.3 & 465 & 3.3 \\
\hline & 20 & 86 & 1.6 & 314 & 3.3 & 347 & & 2.1 & 470 & 5.1 \\
\hline \multirow[t]{6}{*}{$\mathrm{O}_{2}$} & $\beta\left({ }^{\circ} \mathrm{C} / \mathrm{min}\right)$ & & & $e(\%)$ & $T_{p 2}\left({ }^{\circ} \mathrm{C}\right)-T_{p 3}\left({ }^{\circ} \mathrm{C}\right)$ & & $e(\%)$ & & $T_{p 4}\left({ }^{\circ} \mathrm{C}\right)$ & $e(\%)$ \\
\hline & 2 & & & 4.1 & 270 & & 5.0 & & 378 & 2.3 \\
\hline & 5 & & & 5.3 & 273 & & 5.2 & & 387 & 4.0 \\
\hline & 10 & & & 2.8 & 288 & & 4.1 & & 402 & 4.6 \\
\hline & 15 & & & 5.6 & 292 & & 6.8 & & 409 & 5.9 \\
\hline & 20 & & & 5.1 & 297 & & 5.7 & & 420 & 4.4 \\
\hline
\end{tabular}

Table 3

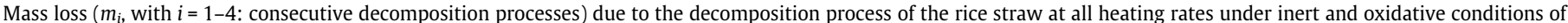
work and associated error values.

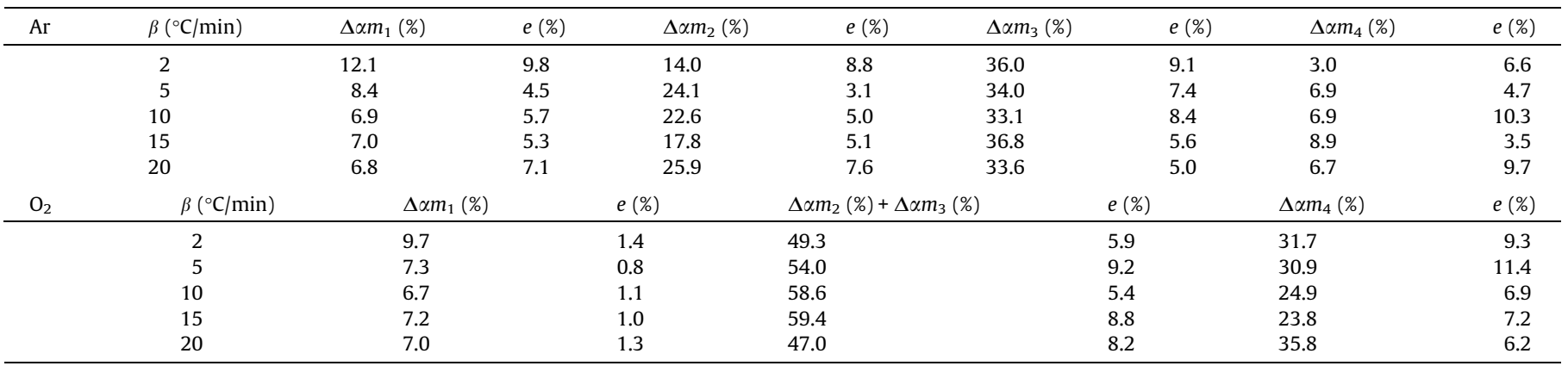

Table 3 gathers the values of mass loss associated to each of the previously calculated $T_{p i}$ corresponding to the different degradation processes for all heating rates and atmospheres and the obtained errors of the averaged value respect to each repetition. These variables were calculated as the area under the deconvoluted $d \alpha / d T$ curves and so, represent the advancement of reaction in terms of conversion degree.

As stated before, the major mass loss occurs in the range of $T \approx 200{ }^{\circ} \mathrm{C}-400{ }^{\circ} \mathrm{C}$, mainly corresponding to hemicellulose and cellulose decompositions. The two peaks corresponding to both compounds are well defined in the case of reactions of pyrolysis and their deconvolution provided the individual mass loss for decompositions each process labelled $\Delta \alpha m_{2}$ for hemicellulose and $\Delta \alpha m_{3}$ for cellulose.

From the results in Table 3 , in order to achieve the highest gas yields, a temperature of work of $T=600^{\circ} \mathrm{C}$ and high heating rates were initially set as the most adequate operational parameters for pyrolysis, obtaining the highest quantity of volatiles $\left(\Delta \alpha m_{2}+\Delta \alpha m_{3}+\Delta \alpha m_{4} \approx 70 \%\right)$ together with the lowest residue (around 25\%), where $\Delta \alpha m_{i}=2,3,4$ is the loss mass of the hemicellulose cellulose and lignin respectively.

Table 3 also presents the equivalent results for the case of oxidative conditions. An only peak was obtained and the calculated mass loss was taken as the total of both hemicellulose and cellulose decompositions processes $\left(\Delta \alpha m_{2}+\Delta \alpha m_{3}\right)$.

In this case, a $T=550{ }^{\circ} \mathrm{C}$ and low heating rates were defined as the most appropriate operational parameters for the case of combustion, obtaining the highest yields in produced gas $\left(\Delta \alpha m_{2}+\Delta \alpha m_{3}+\Delta \alpha m_{4} \approx 85 \%\right)$ and the lowest values of residue (around 10\%).

In summary, the definition of the operational conditions will be determinant for the characteristics of the final product. Lower temperatures of work will be necessary to carry out combustion reac- tions, yielding higher percentages of volatile compounds and lower quantities of final residue respect to pyrolysis reactions.

These parameters are the initial design values of the spouted bed reactor that will carry out the thermo-chemical conversions. However, a deep insight on the process with the aid of the modelled solution validated with experimental results will be necessary to achieve the optimised solution. The values corresponding to the remaining residue are highly influenced by the atmosphere of work, with higher values for inert conditions as a result of a less reactive atmosphere. In the thermo-oxidation of rice straw, this parameter has special interest to design the spouted bed reactor as high percentages of residue could lead to slagging and fouling problems due to the high content of silica in the rice straw. Moreover, residue values are also dependent on the heating rate of the process and so, the scaled up processes within the SBR will require an exhaustive control of the oxygen content in the carrier gas as well as an accurate control of the maximum temperature of work in order to ensure a good performance of the spouted bed reactor.

\subsection{Thermal behaviour of rice straw}

With the aim to evaluate the thermal behaviour of the rice straw and to predict the decomposition temperatures $\left(T_{d}\right)$ of all the processes undergone by the samples when submitted to thermo-chemical reactions, an accurate methodology by Badia et al. $[13,14]$ was applied. Fig. 3 shows the evolution of the previously calculated $T_{p i}$ at all heating rates under inert (a) and reactive (b) ambient and their associated error values in form of error bars.

As shown in the figure, the trend was almost linear at high heating rate $\beta$, but it slightly bended when $\beta$ approached lower values.

For design purposes, it would be interesting to functionalise the thermal behaviour of rice straw under any $\beta$. In this sense, $T_{d}(\beta)$ was obtained as: 

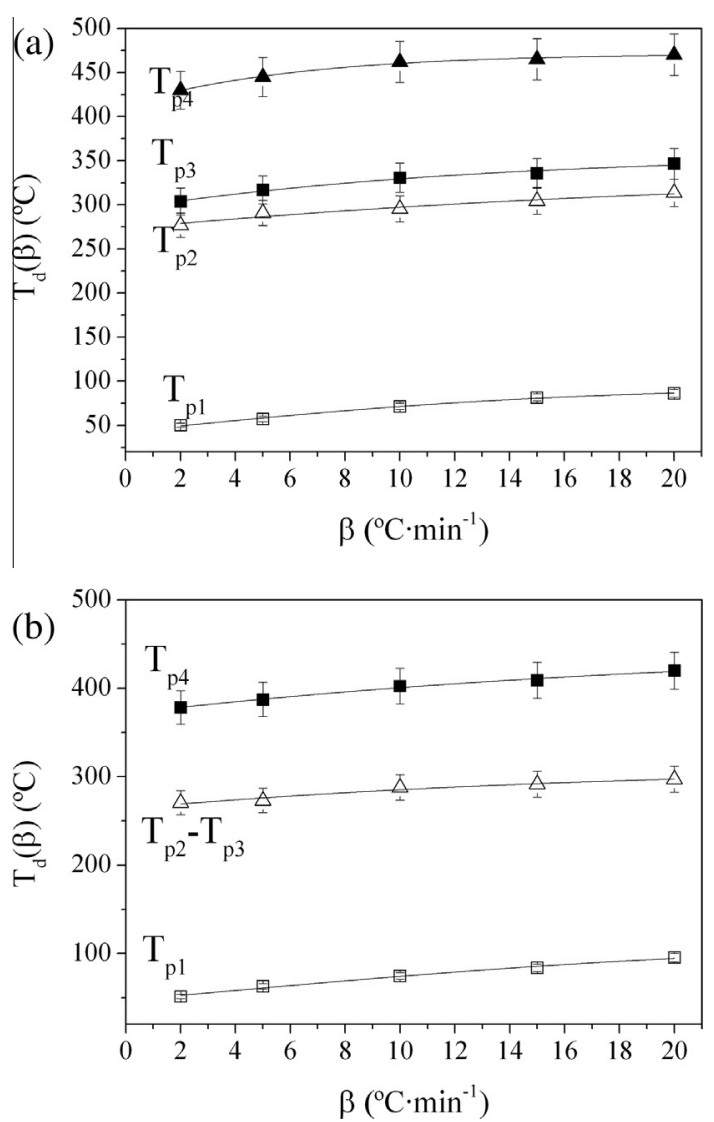

Fig. 3. Application of the $T_{d}(\beta)$ model to assess the evolution of the peak temperatures of rice straw during the thermogravimetric analysis under inert (a) and oxidative (b) ambient and associated error bars ( $T_{p 1}$ : peak of the first decomposition process, $T_{p 2}$ : peak of the second decomposition process, $T_{p 3}$ : peak of the third decomposition process, $T_{p 4}$ : peak of the fourth decomposition process) and associated error bars.

$T_{d}(\beta)=\frac{a}{1+\exp (-b \cdot(\beta-c))}$

with $a, b$ and $c$ being the fitting parameters

As it was shown before, higher heating rates led to higher characteristic temperatures. In order to avoid this influence of linear heating procedures in the evaluation of the characteristic temperatures, the so called Zero-Decomposition Temperature (ZDT) was calculated as the value obtained when the heating rate tends to zero $\left(T_{d}(\beta \rightarrow 0)\right)$.

Table 4 reports the values of the fitting parameters for all temperatures at inert and oxidative atmospheres together with their standard associated error and the resulting ZDT values. The high

Table 4

Results of fitting to Eq. (1) along with ZDT for all decomposition processes as a result of the extrapolation of Eq. (1) to $\beta \rightarrow 0$ and associated error values.

\begin{tabular}{|c|c|c|c|c|c|c|c|c|c|c|c|c|}
\hline $\mathrm{Ar}$ & \multicolumn{2}{|l|}{$a$} & \multicolumn{2}{|c|}{$e(\%)$} & $b$ & $e(\%)$ & & $c$ & \multicolumn{2}{|c|}{$e(\%)$} & $R^{2}$ & ZDT $\left({ }^{\circ} \mathrm{C}\right)$ \\
\hline$T p_{1}$ & & & 3 & & 0.13 & 0.02 & & 1.2 & & & 0.9943 & 43.3 \\
\hline$T p_{2}$ & 334 & & 39 & & 0.06 & 0.06 & & -25.8 & 16 & & 0.9271 & 273.4 \\
\hline$T p_{3}$ & 355 & & 11 & & 0.09 & 0.04 & & -17.0 & & & 0.9695 & 295.8 \\
\hline $\mathrm{Tp}_{4}$ & 471 & & 2 & & 0.18 & 0.03 & & -11.3 & & & 0.9863 & 414.3 \\
\hline $\mathrm{O}_{2}$ & & $a$ & & $\begin{array}{l}e \\
(\%)\end{array}$ & $b$ & & $\begin{array}{l}e \\
(\%)\end{array}$ & $c$ & & $\begin{array}{l}e \\
(\%)\end{array}$ & $R^{2}$ & $\begin{array}{l}\text { ZDT } \\
\left({ }^{\circ} \mathrm{C}\right)\end{array}$ \\
\hline$T p_{1}$ & & 113 & & 14.8 & & 42 & 2.63 & & 10 & 0.03 & 0.9838 & 45.4 \\
\hline$T p_{2}+T_{1}$ & & 310 & & 0.9 & & 16 & 0.00 & & 07 & 0.00 & 0.9367 & 264.0 \\
\hline $\mathrm{Tp}_{4}$ & & 44 & & 19.8 & & .06 & 0.02 & & & 7.86 & 0.9862 & 371.6 \\
\hline
\end{tabular}

values of $R^{2}$ in all fitting parameters indicate the suitability of $T_{d}(\beta)$ to represent the thermal behaviour of the rice straw.

The dependence of the thermal behaviour of the straw with the atmosphere of work is also evidenced from the evolution of the previously calculated ZDT for all the pseudo-components of the straw (moisture-ZDT ${ }_{p 1}$, hemicellulose-ZDT ${ }_{p 2}$, cellulose-ZDT ${ }_{p 3}$, lignin-ZDT ${ }_{p 4}$ ), which followed the same trend as described in Section 3.1.

The values corresponding to the drying process $\left(Z_{p D}\right)$ were very similar under both atmospheres of work, confirming the independence of the process with the used carrier gas. The rest of the calculated ZDT $\left(\mathrm{ZDT}_{p 2}, \mathrm{ZDT}_{p 3}, \mathrm{ZDT}_{p 4}\right)$ presented lower values when $\mathrm{O}_{2}$ was used as the reaction gas respect to those in inert ambient, confirming therefore the higher reactivity of the system when an oxidative atmosphere is applied.

In terms of design of the reactor, $\mathrm{ZDT}_{p 2}$ will provide the minimum temperature of work required inside the reactor to start the devolatilisation stage. For the case of rice straw, a minimum of $T=273^{\circ} \mathrm{C}$ (inert conditions) and $T=264{ }^{\circ} \mathrm{C}$ (oxidative conditions) will be necessary to start yielding volatile compounds. These values represent the minimum operational temperature needed to start the thermo-chemical processes and therefore, the minimum initial energy requirements of the system.

\subsection{Decomposition kinetics}

\subsubsection{Apparent activation energies}

The kinetics of decomposition is a essential parameter in the correct design of a device for thermal conversion processes. They will define the apparent activation energy ( $E a)$ to be applied to the system to start the thermal process and will also provide
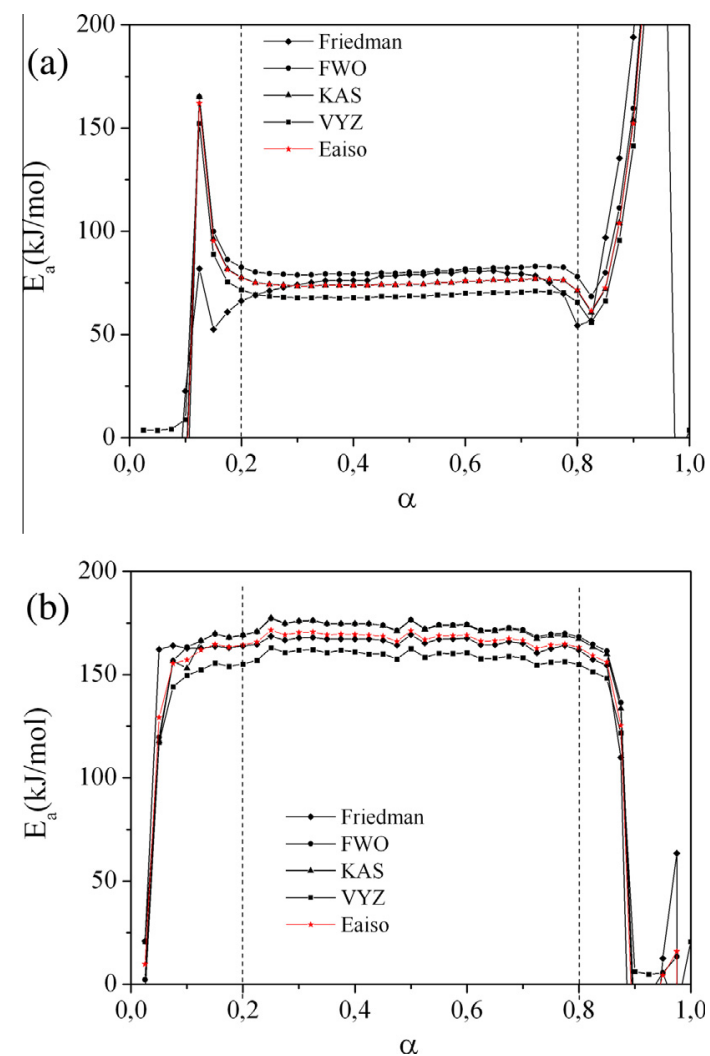

Fig. 4. Evolution of $E a_{\mathrm{FRIEDMAN}}, E a_{\mathrm{FWO}}, E a_{\mathrm{KAS}}, E a_{\mathrm{VYZ}}, E a_{\text {iso }}$ for the main decomposition process of rice straw (range $\alpha=0.2-0.8$ ) at inert (a) and oxidative (b) conditions. 
Table 5

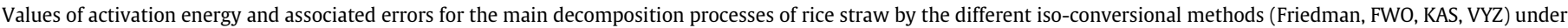
inert and oxidative conditions.

\begin{tabular}{|c|c|c|c|c|c|c|c|c|c|}
\hline & & $E a_{\text {Friedman }}(\mathrm{kJ} / \mathrm{mol})$ & $e(\%)$ & $E a_{\mathrm{FWo}}(\mathrm{kJ} / \mathrm{mol})$ & $e(\%)$ & $E a_{\mathrm{KAS}}(\mathrm{kJ} / \mathrm{mol})$ & $e(\%)$ & $E a_{\mathrm{VYZ}}(\mathrm{kJ} / \mathrm{mol})$ & $e(\%)$ \\
\hline \multirow[t]{3}{*}{$\mathrm{Ar}$} & Process 1 & 75 & 18.0 & 81 & 5.4 & 75 & 5.0 & 69 & 4.8 \\
\hline & Process 2 & 167 & 18.5 & 161 & 6.2 & 154 & 7.3 & 151 & 6.0 \\
\hline & Process 3 & 119 & 11.1 & 127 & 7.9 & 123 & 6.7 & 114 & 4.7 \\
\hline \multirow[t]{2}{*}{$\mathrm{O}_{2}$} & Process $1+2$ & 166 & 5.1 & 173 & 2.6 & 172 & 2.9 & 159 & 2.8 \\
\hline & Process 3 & 135 & 12.3 & 125 & 7.6 & 123 & 5.8 & 111 & 7.3 \\
\hline
\end{tabular}

information on the reaction times to complete the thermochemical conversions.

The isoconversional methods Friedman [15], Flynn-WallOzawa (FWO) [16], Ozawa [17], Kissinger-Akahira-Sunose (KAS) [18] and Vyazovkin (VYZ) [19] were applied to evaluate the dependence of the apparent activation energy $(\mathrm{Ea})$ with the conversion degree $\alpha$ defined as $\alpha=\left(m_{0}-m_{i}\right) /\left(m_{0}-m_{\infty}\right)$, where $m$ is the mass with the subscripts $0, i$ and $\infty$ standing for initial, instant and final respectively.

The temperature range for all the kinetic studies was taken from $T \sim 150{ }^{\circ} \mathrm{C}$ as, at temperatures below this value, only moisture and absorbed water was removed and its kinetics did not exhibit differences with the change of heating rates.

As an example, Fig. 4 shows the application of the mentioned methods along the conversion degree of each of the previously deconvoluted curves in Stage 2 (Fig. 2) under inert (a) and oxidative conditions (b).

All the kinetic analysis were carried out in the range $\alpha=0.2-0.8$, where the main process takes place. The average values were obtained $\left(\mathrm{Ea}_{\mathrm{iso}}\right)$ from the iso-conversional methods. The regression coefficient at the range of study for the main degradation process of the straw at inert conditions was above $90 \%$ whereas the values obtained for experiments under $\mathrm{O}_{2}$ were not below $95 \%$.

All the calculated values of apparent activation energy and associated errors for all the pseudo-components of rice straw are presented in Table 5. As stated before, the two main peaks corresponding to the decompositions of hemicellulose (Process 1) and cellulose (Process 2 ) were individually calculated for inert conditions whereas a single peak represented both processes during combustion reactions.

A higher value of apparent activation energy $\left(E a_{\text {iso }}\right)$ was obtained for oxidative conditions. This fact has been previously reported [20] and it is attributed to the increase of oxidant reactions as a result of an increase of $\mathrm{O}_{2}$ in the carrier gas. However, this assumption should be fully subscribed by evaluating the quantity of $\mathrm{CO}_{2}$ emitted during the thermo-chemical processes as, due to the increase on oxidant reactions, the concentration of $\mathrm{CO}_{2}$ should also increase.

As reported in Table 5, the apparent activation energy values obtained by Friedman method presented the highest associated error. This might be caused by the differential nature of the method that leads to noisy data after the required numerical differentiation. On the contrary, VYZ method provided the least error values thanks to the application of the Senum-Yang approximation (5th order) which yields most accurate results.

These values are also in agreement with previous works dealing with apparent activation energy for different agricultural residues [21,22] where the obtained results fell within the range 140$180 \mathrm{~kJ} /$ mole in all cases.

From a technological point of view, the apparent activation energy provides the barrier of energy that the system needs to surpass in order to start the thermo-chemical reaction and it defines a value related to the energy requirements of the spouted bed reactor. Finally, for the complete design of the reactor, the complete kinetic expression will be obtained.

\subsubsection{Evaluation of the pre-exponential factor and the order of} reaction. Completing the kinetic triplet

The kinetic model was evaluated and defined from the kinetic analysis of the rice straw and the Master Plot reduced curves (MP) [23]. MP are defined as the theoretical reference curves dependent on the kinetic model and, generally, independent of the kinetic parameters of the process. The comparison between the experimental values and these theoretical curves permits the calculation of the appropriate kinetic model according to the better fitting of the experimental data on the master plots.

The three main types of MP are those based on the differential form $\left(\mathrm{MP}_{f}\right)$ of the general kinetic equation as expressed in (3), the integral form $\left(\mathrm{MP}_{\mathrm{g}}\right)$ as in (4) or the combination of both:

$$
\begin{aligned}
& \operatorname{MP}_{f}(\alpha)=\frac{d \alpha}{d t} \equiv \beta \cdot \frac{d \alpha}{d T}=A \cdot f(\alpha) \cdot k(T)=A \cdot f(\alpha) \cdot e^{\frac{-E_{a}}{R \cdot T}} \\
& \operatorname{MP}_{g}(\alpha)=\int_{0}^{\alpha} \frac{d \alpha}{f(\alpha)}=\frac{A \cdot E_{a}}{\beta \cdot R} \cdot \int_{0}^{\infty} \frac{e^{-x}}{x^{2}}=\frac{A \cdot E_{a}}{R \cdot T} \cdot p(x), \quad x=\frac{E_{a}}{R \cdot T}
\end{aligned}
$$

The theoretical curves coincide at $\alpha=0.5$ and so, this point is taken as a reference and all the curves are reduced to it for a better visualisation. The theoretical master plots of the different kinetic models can be clearly distinguished for $\alpha<0.5$ and $\alpha>0.5$ for the differential and integral curves, respectively, and therefore a straightforward identification can be done.

Fig. 5 shows the theoretical $\mathrm{MP}_{\mathrm{g}}$ curves and the experimental data corresponding to the main decomposition process (Stage 2) at $20^{\circ} \mathrm{C} / \mathrm{min}$ occurring for rice straw under inert (a) and oxidative (b) conditions. The represented kinetic models are: $D_{n}=$ diffusion controlled (blue lines), $A_{n}=$ nucleation and growth (red lines), $F_{n}=n$-order reactions (orange lines) and $R_{n}=$ reactions controlled (green lines).

According to Fig. 5, the model describing the thermal degradation following a reaction order mechanism $\left(F_{m}\right)$. According to this model, the reaction rate is proportional to the fraction remaining of reactant(s) raised to a particular power (reaction order) [24].

The exact order of reaction was analytically obtained by accomplishing Perez-Maqueda criterion [25]; that is, the independence of the kinetic parameters $E a$ and $A$ with the heating rate $\beta$. This criterion is usually employed with $E a$ and $A$ invariable with the aid of the Coats-Redfern equation [26] written in the form:

$\left[\ln \frac{\beta \cdot g(\alpha)}{T^{2}}\right]_{y}=\ln \frac{A_{\beta} \cdot R}{E a_{\beta}}+\frac{E a_{\beta}}{R} \cdot\left[\frac{1}{T}\right]_{x}$

with $g(\alpha)$ being the integral form of the model previously calculated.

A single straight line with slope $\left(E a_{\beta} / R\right)$ and an intercept $\ln \left(A_{\beta} \cdot R / E a_{\beta}\right)$ is obtained when the left hand side of Eq. (4) is plotted against $1 / T$ only if the appropriate $g(\alpha)$ is chosen.

By setting the values of $E a_{\text {iso }}$ as the average value of those previously calculated (Table 5 ) and after applying a regression method (with the aid of the tool SOLVER), the values of $n$ and $\ln A$ were obtained. 

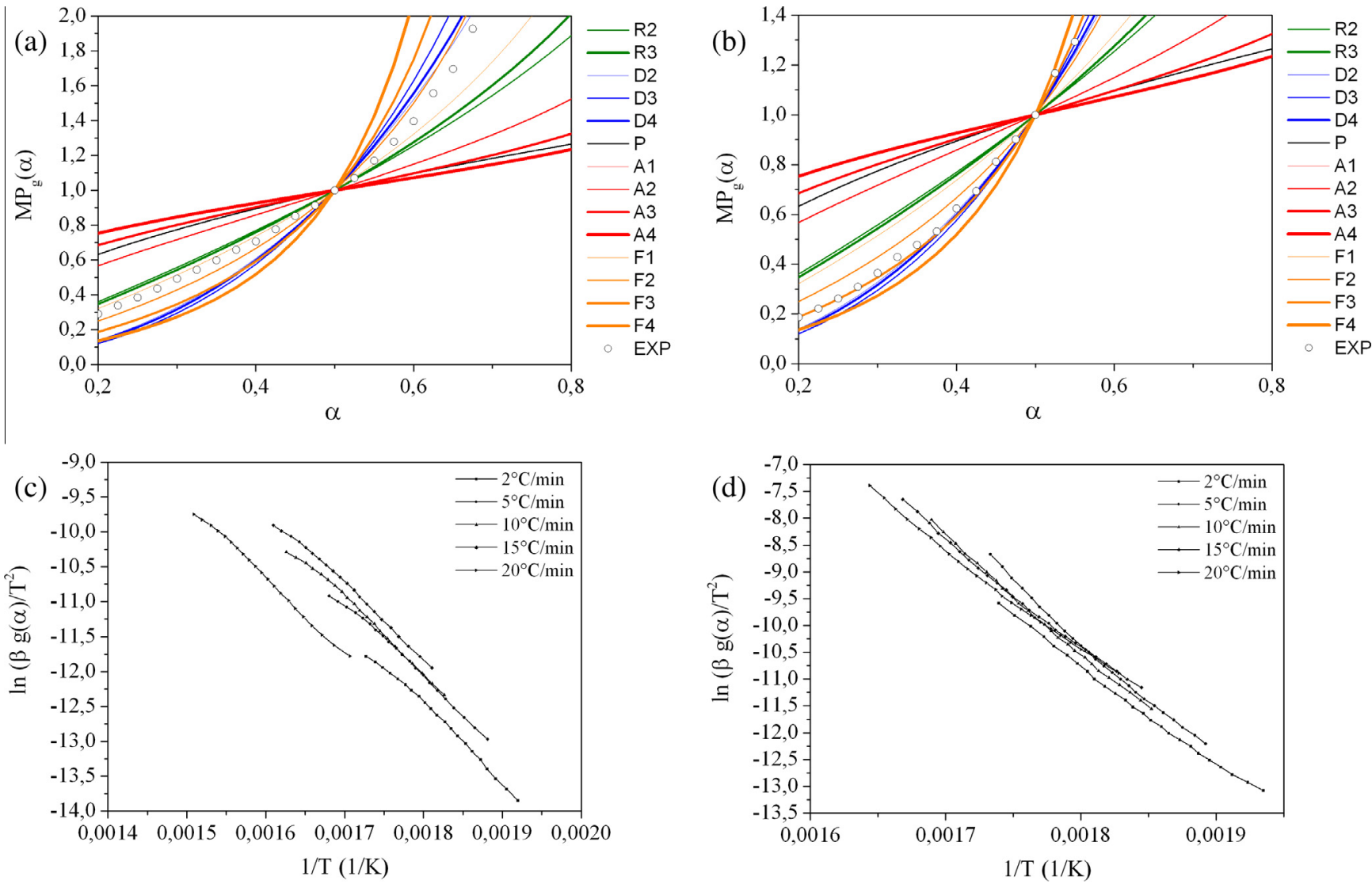

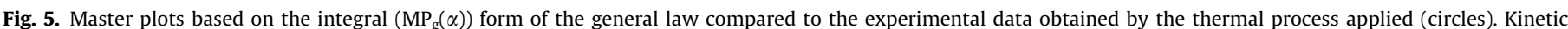

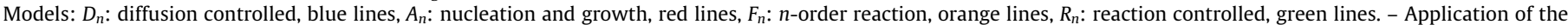

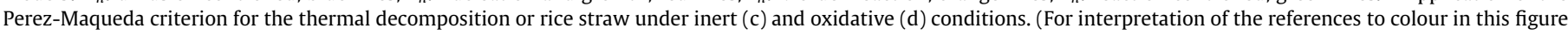
legend, the reader is referred to the web version of this article.)

Table 6

Kinetic triplet for the main decomposition processes of rice straw for thermal and thermo-oxidative reactions.

\begin{tabular}{|c|c|c|c|c|c|c|}
\hline & $E a_{\text {iso }}(\mathrm{kJ} / \mathrm{mol})$ & $e(\%)$ & $n$ (from MP) & $n$ (analytical) & $\ln A\left(\min ^{-1}\right)$ & $e(\%)$ \\
\hline \multirow[t]{3}{*}{$\mathrm{Ar}$} & 75 & 3.8 & $1-2$ & 1.35 & 17.1 & 0.87 \\
\hline & 158 & 7.1 & 1 & 0.89 & 17.1 & 0.98 \\
\hline & 121 & 3.1 & $1-2$ & 1.25 & 15.9 & 5.50 \\
\hline \multirow[t]{2}{*}{$\mathrm{O}_{2}$} & 167 & 6.7 & $2-3$ & 2.95 & 33.2 & 7.40 \\
\hline & 124 & 5.0 & $1-2$ & 1.70 & 13.9 & 5.10 \\
\hline
\end{tabular}

Fig. 5(c) and (d) shows the representation of Eq. (5) after introducing the calculated parameters. The straight lines in the interval of study confirm the goodness of $F_{m}$ (with $\mathrm{m}$ the analytically calculated order of reaction) as the kinetic model describing the main process of degradation for rice straw.

As a summary, the kinetic triplet associated to the main thermal decomposition process of rice straw for thermal and thermooxidative reactions is reported in Table 6. Finally, the following expressions were proposed to define the decomposition of the rice straw, taken as the sum of the individual decompositions of its main components) both for inert (Eq. (6)) and oxidative conditions (Eq. (7)):

$$
\begin{aligned}
\frac{d \alpha_{\mathrm{PYR}}}{d t}= & 13.3 \cdot 10^{6} \cdot(1-\alpha)^{1.35} \cdot e^{-75 / R T}+13.5 \cdot 10^{6} \cdot(1-\alpha)^{0.89} \\
& \cdot e^{-158 / R T}+4.2 \cdot 10^{6} \cdot(1-\alpha)^{1.25} \cdot e^{-121 / R T}
\end{aligned}
$$

$\frac{d \alpha_{O \mathrm{x}}}{d t}=6.8 \cdot 10^{13} \cdot(1-\alpha)^{2.95} \cdot e^{-167 / R T}+6.1 \cdot 10^{5} \cdot(1-\alpha)^{1.7} \cdot e^{-124 / R T}$

In summary, lower activation energies were required to carry out reactions of pyrolysis due to the absence of complex oxidant reactions. For the same reason, a lower order of reaction was found during pyrolysis together with lower values of the pre-exponential factor as a result of a lower reactivity of the system.

These data, together with the peak temperatures calculated in Section 3.2 and the specific fluid dynamic parameters of the spouted bed reactor, will be introduced in a commercial process simulation tool in order to simulate the described processes carried out in a spouted bed reactor and evaluate the optimised operational conditions. 


\section{Conclusions}

An accurate methodology evaluated and compared the initial design parameters of a spouted bed reactor to carry out energy valorisation processes using rice straw as feedstock.

Lower temperatures of work were necessary to carry out combustion reactions, yielding higher percentages of volatiles and lower values of residue respect to pyrolysis reactions. A correct assessment of this parameter will be essential to avoid melting and slagging problems in the reactor and its associated operational problems. A suitable kinetic triplet $(E a, A, n)$ and mechanism of reaction was found for the main devolatilisation process for thermal and thermo-oxidative conditions. Lower activation energies, order of reaction and pre-exponential factor values were required to carry out reactions of pyrolysis due to the absence of complex oxidant reactions.

These parameters, together with the specific fluid dynamics of the system, will be applied as input variables in a theoretical model to describe thermal recovery processes in a spouted bed reactor using rice straw as feedstock. Efforts will be focused then on the optimisation of the working conditions with the aid of the developed model to obtain the highest efficiencies ensuring a good performance of the reactor.

\section{References}

[1] FAOSTAT (Food and Agriculture Organization of the United Nations). Production crops; 2013. <faostat3.fao.org> [accessed 12.11.14]

[2] Lim JS, Manan ZA, Rafidah S, Alwi W, Hashim H. A review on utilisation of biomass from rice industry as a source of renewable energy. Renew Sustain Energy Rev 2012;16:3084-94.

[3] Fernandez-Akarregu A, Makibar J, Lopez G, Amutio M, Olazar M. Design and operation of a conical spouted bed reactor pilot plant $(25 \mathrm{~kg} / \mathrm{h})$ for biomass fast pyrolysis. Fuel Process Technol 2013;112:48-56.

[4] Erkiaga A, Lopez G, Amutio M, Bilbao J, Olazar M. Influence of operating conditions on the steam gasification of biomass in a conical spouted bed reactor. Chem Eng J 2014;237:259-67.

[5] San Jose M, Alvarez S, Garcia I, Peñas F. Conical spouted bed combustor for clean valorization of sludge wastes from paper industry to generate energy. Chem Eng Res Des 2014. http://dx.doi.org/10.1016/i.cherd.2014.01.008.

[6] Lopez G, Erkiaga A, Amutio M, Bilbao J, Olazar M. Steam gasification of biomass in a conical spouted bed reactor with olivine and g-alumina as primary catalysts. Fuel Process Technol 2013;116:292-9.
[7] White JE, Catallo WJ, Legendre BL. Biomass pyrolysis kinetics: a comparative critical review with relevant agricultural residue case studies. J Anal Appl Pyrol 2011;91(1):1-33.

[8] Carrier M, Loppinet-Serani A, Denux D, Lasnier JM, Ham-Pichavant F, Cansell F, et al. Thermogravimetric analysis as a new method to determine the lignocellulosic composition of biomass. Biomass Bioenergy 2011;35:298-307.

[9] Channiwala SA, Parikh PP. A unified correlation for estimating the HHV of solid, liquid and gaseous fuels. Fuel 2002;81(8):1051-63.

[10] Yang H, Yan R, Chen H, Lee D Ho, Zheng C. Characteristics of hemicellulose, cellulose and lignin pyrolysis. Fuel 2007;86:1781-8.

[11] Shen DK, Gu S, Luo KH, Bridgewater AV, Fang MX. Kinetic study on thermal decomposition of woods in oxidative environment. Fuel 2009;88:1024-30.

[12] Amutio M, Lopez G, Aguado R, Artetxe M, Bilbao J, Olazar M. Kinetic study of lignocellulosic biomass oxidative pyrolysis. Fuel 2012;95:305-11.

[13] Badia JD, Santonja-Blasco L, Martinez-Felipe A, Ribes-Greus A. A methodology to assess the energetic valorization of bio-based polymers from the packaging industry: pyrolysis of reprocessed polylactide. Bioresour Technol 2012;111:468-75.

[14] Badia JD, Martinez-Felipe A, Santonja-Blasco L, Ribes-Greus A. Thermal and thermo-oxidative stability of reprocessed poly(ethylene terphthalate). J Anal Appl Pyrol 2013;99:191-202.

[15] Friedman $H$. Kinetics of thermal degradation of char-forming plastics from thermogravimetry. Application to a phenol plastic. J Polym Sci 1964:6:183-95.

[16] Flynn JH, Wall LA. A quick, direct method for the determination of activation energy from thermogravimetric data. J Polym Sci 1966;4:323-42.

[17] Ozawa T. Kinetic analysis of derivative curves in thermal analysis. J Therm Anal 1970;2:301-24.

[18] Akahira T, Sunose Trans. Joint convention of four electrical institutes, paper N.246. Research Report/Chiba Institute of Technology. Scientific Technology, vol. $16 ; 1971$. p. $22-31$.

[19] Vyazovkin S. Advanced isoconversional method. J Therm Anal 1997;49:1493-9.

[20] Zhaosheng Y, Xiaoqian M, Ao L. Kinetic studies on catalytic combustion of rice and wheat straw under air- and oxygen-enriched atmospheres, by using thermogravimetric analysis. Biomass Bioenergy 2008;32(11):1046-55.

[21] Yao F, Wu Q, Lei Y, Guo W, Xu Y. Thermal decomposition kinetics of natural fibers: activation energy with dynamic thermogravimetric analysis. Polym Degrad Sustain 2008;93:90-8.

[22] Mishra G, Bhaskar T. Non isothermal model free kinetics for pyrolysis of rice straw. Bioresour Technol 2014:169:614-21.

[23] Gotor FJ, Criado JM, Malek J, Koga N. Kinetic analysis of solid-state reactions: the universatility of master plots for analysing isothermal and non-isothermal experiments. J Phys Chem A 2000;104:10777-82.

[24] Khawam A, Flanagan DR. Solid-state kinetic models: basics and mathematical fundamentals. J Phys Chem B 2006;110(35):17315-28.

[25] Perez-Maqueda LA, Criado JM, Gotor FJ, Malek J. Advantages of combined kinetic analysis of experimental data obtained under any heating rate profile. J Phys Chem A 2002;106:2862-8.

[26] Coats AW, Redfern JP. Kinetic parameters from thermogravimetric data. Nature 1964;201:68-9. 



\section{4}

\section{CHARACTERISATION}

OF SBR

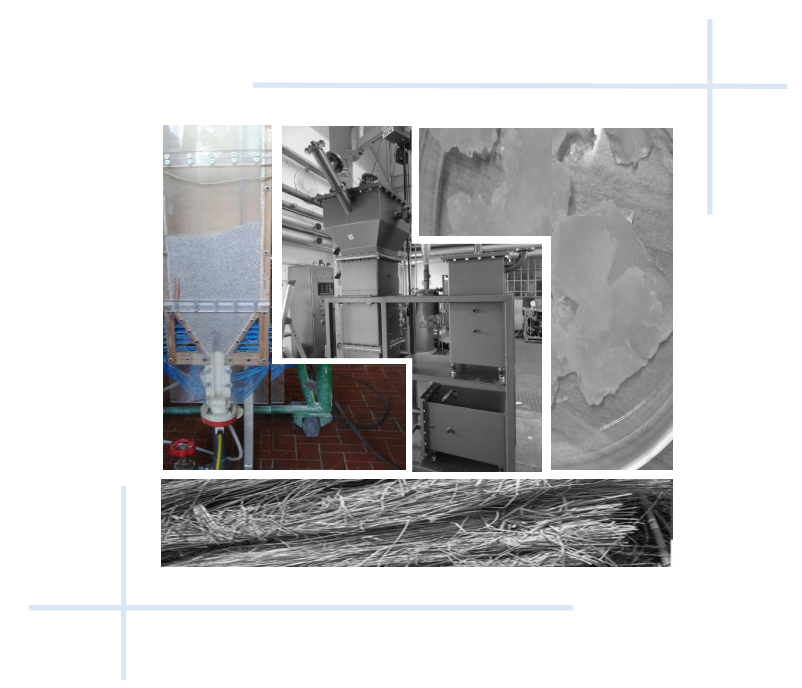

I. Summary

129

4.1 Fluid dynamic characterisation of the SBR

130

4.2 Segregation studies

4.3 CFD modeling 144

4.4 Main results 148

References 

"It is a capital mistake to theorise before one has data. Insensibly one begins to twist facts to suit theories, instead of theories to suit facts. “

Sir Arthur Conan Doyle

\section{Summary}

The scope of this chapter is to describe the methodology of characterisation of the spouted bed reactor that will be used as the key device to carry out the reactions of gasification of agricultural residues.

This chapter is devoted to the description of the unit and the auxiliary equipment, the applied procedure and relevant information about the experiments performed. Studies to prevent potential segregation phenomena are also described. Finally, a computational fluid dynamic model is developed and validated with the obtained experimental results.

The main results obtained from this chapter resulted in the following communications:

Communication 4I: C. Moliner, M. Curti, B. Bosio, E. Arato, G. Rovero. Experimental tests with rice straw on a conical square-based spouted bed reactor. International Journal of Chemical Reactor Engineering 13, 2015, 3, 351-358. DOI 10.1515/ijcre-2014-0172

Communication 4II: C. Moliner, M. Curti, B. Bosio, G. Rovero, E. Arato. Statistical methodology for the assessment of a Spouted Bed Reactor preventing segregation phenomena. Manuscript

Communication 4III: D. Bove, C. Moliner, M. Curti, B. Bosio, G. Rovero, E. Arato. CFD simulations of a square-based spouted bed reactor and validation with experimental tests using rice straw as feedstock. Chemical Engineering Transactions, 43, 2015, 1363-1368. DOI: $10.3303 / \mathrm{CET} 1543228$ 


\subsection{Fluid dynamic characterisation of the SBR}

Gasification has proven to be a convenient technique for thermo-chemical conversions of biomass by means of fluidisation processes. Different devices have been developed to carry out these reactions and, among them, spouted bed reactors (SBRs) have been proposed as a solution to overcome the difficulties that conventional reactors face when treating big and heterogeneous particles.

SBRs are obtained by replacing the perforated plate of a conventional reactor of fluidisation with a plate with a single orifice, normally centred in the base. This modification provides the system an enhanced recirculation of solids, which results in increased mass and energy transfer rates respect to those with conventional techniques. Three different regions (annulus, spout and fountain) can be distinguished in a SBR as shown in Figure 4.1.

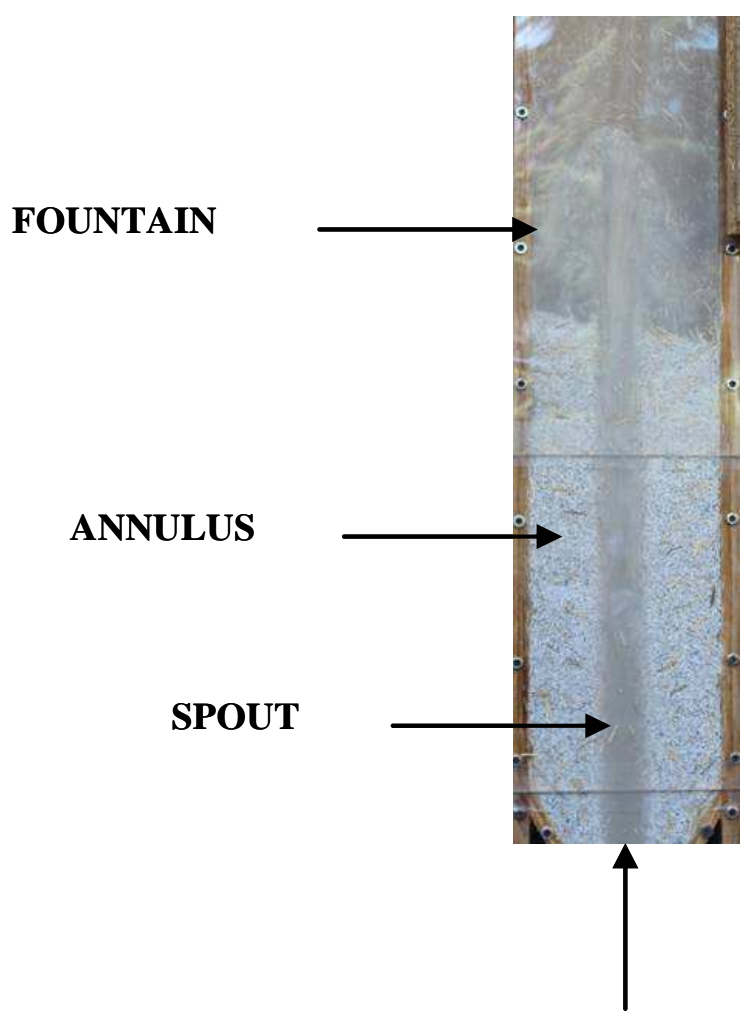

Air inflow

Figure 4.1 Regions within a SBR (System PET/straw 5\%v/v; Initial bed height=50 cm) 
The gas enters the bed through a central orifice of the distributor plate, causing the formation of a central spout in which the particles move upwards in a dilute phase. The annular space between the spout and the vessel wall contains a packed bed of particles which moves slowly downwards and radially inwards. The conical base helps in the recirculation process, enabling the movement of bigger and irregular particles within the device and preventing potential stagnant or dead zones.

The scalability of the device is a key factor for successful development of the technology. With the purpose to optimise geometrical factors and minimise heat losses, investments and operating costs, the reactor was designed with a squared base, in contrast with traditional SBRs provided with circular sections.

The advance of this technology to enable its reliable scale-up resides in a better understanding of its fluid dynamic behaviour. Most empirical and semi-empirical equations already developed are only valid for a certain range of operational conditions. Due to the great influence of the geometric parameters and the properties of the materials on the process, these equations fail to predict most of the design variables when conditions are changed, especially for large devices which tend to be less stable and therefore, harder to control and operate.

For this reason, the present chapter presents a fluid dynamic study of different systems with different solid properties (density, size of particle, irregular shapes ....). The main design properties are evaluated in order to guarantee the stability and correct process performance in all cases. In addition, a CFD model has been developed to simulate and predict the behaviour of the studied systems and validated with experimental data. This model will help in the design of the scaled-up system by providing simulated solutions of parameters that would be time and economically expensive if calculated experimentally.

\subsubsection{Experimental set-up}

All the fluid dynamic experiments were performed at room temperature at the laboratories of the Department of Applied Science and Technology (DISAT) at the Politecnico di Torino. The scheme of the experimental setup used for the present work is shown in Figure 4.2. 

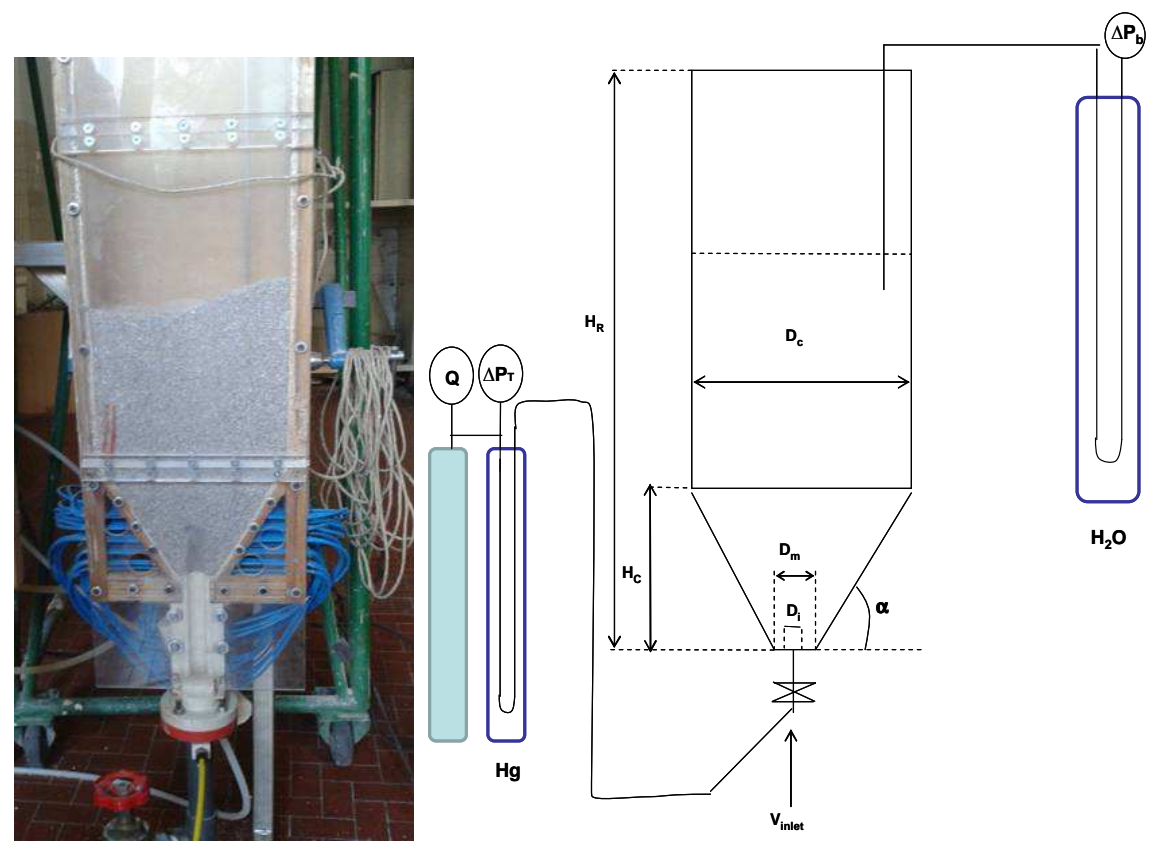

Figure 4.2. Scheme of the experimental set-up used for the present thesis

The main components of the system are:

- air supply: the blower supplies a maximum inlet air flow of $200 \mathrm{Nm}^{3} / \mathrm{h}$ provided by the Department facilities (Figure 4.3a). A regulating valve sets the outlet pressure to a 1.2 bar.

- a flow meter: the air supply is measured by means of a rotameter, tared at 1013 mbar and $20^{\circ} \mathrm{C}$ (Figure $4.3 b$ ).

- two pressure probes: the values of pressure drop across the bed of particles $\left(\Delta \mathrm{P}_{\mathrm{b}}\right)$ were measured for the different set of experiments, by means of a probe located in the intern of the bed at $20 \mathrm{~cm}$ from the bottom and at $4 \mathrm{~cm}$ distance from the wall in the radial direction and connected to a water U-manometer (Figure 4.3c). The pressure drop corresponding to the overall system $\left(\Delta \mathrm{P}_{\mathrm{T}}\right)$ was simultaneously measured with the aid of a mercury $\mathrm{U}$-manometer connected to the flow meter (Figure 4.3d).

- a conical spouted bed reactor. A half-section device of 200x100 mm made in wood with a plexyglass wall was used for the present thesis. The transparent flat wall enables the visualisation of the spouting process and a more accurate evaluation of the fluid dynamic phenomena occurring inside the reactor (Figure 4.3e). As proven by Rovero et al. (1985) the wall has been demonstrated to interfere to a moderate extent with the solids trajectory vectors within the annulus and to not affect the measurement of the fundamental fluid dynamic parameters of SBR. The main dimensions of the reactor are gathered in Table 4.1. 
- draft tube. the half section unit is provided with a removable wall which can be replaced with an equivalent one equipped with a draft tube, in this case an half pipe (Figure 4.3f)

Table 4.1. Main dimensions of the spouted bed reactor

\begin{tabular}{c|ccc|}
\hline Dimension & Value & Dimension & Value \\
\hline Height of reactor $\left(\mathrm{H}_{\mathrm{R}}, \mathrm{cm}\right)$ & 200.0 & Inlet diameter $(\mathrm{Di}, \mathrm{cm})$ & 2.5 \\
Height of cone $\left(\mathrm{H}_{\mathrm{C}}, \mathrm{cm}\right)$ & 17.0 & Bottom diameter $(\mathrm{Dm}, \mathrm{cm})$ & 3.6 \\
Diameter of column $\left(\mathrm{D}_{\mathrm{C}}, \mathrm{cm}\right)$ & 20.0 & Cone angle $\left(\alpha_{\mathrm{c}}\right)$ & $60^{\circ}$
\end{tabular}

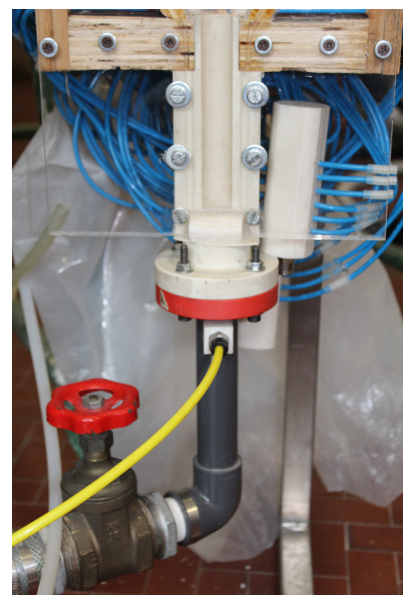

(a)

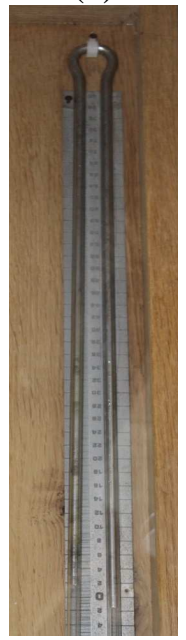

(d)

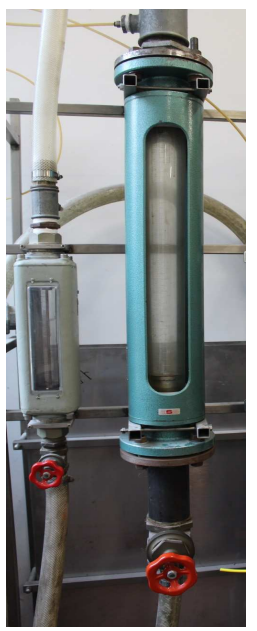

(b)

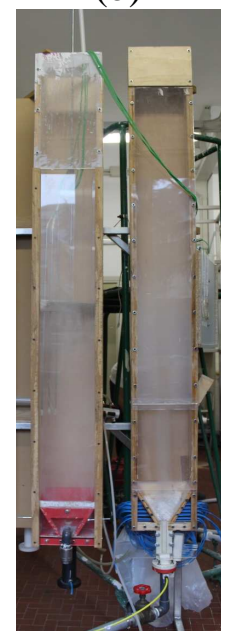

(e)

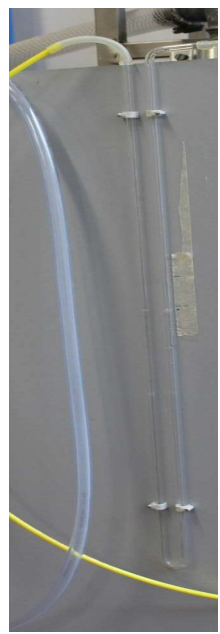

(c)

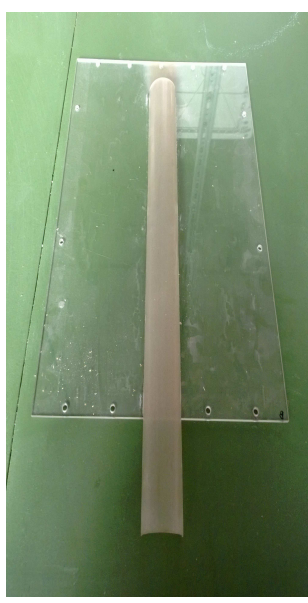

(f)

Figure 4.3. Main components of the experimental set up: air inlet (a); flow meter (b); water Umanometer (c); Hg U-manometer (d); spouted bed reactor (e); draft tube (f) 


\subsubsection{Experimental procedure}

All the experiments were conducted at ambient conditions. A defined quantity of biomass was poured from the top of the reactor into the existing bed of particles (inert solids) until the desired initial bed height was achieved (Figure 4.4). Bed heights were measured visually using a scale along the column height.

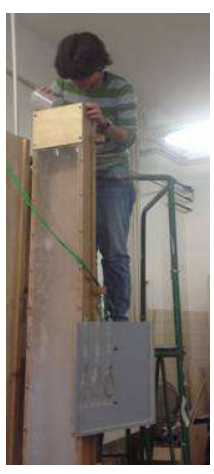

(a)

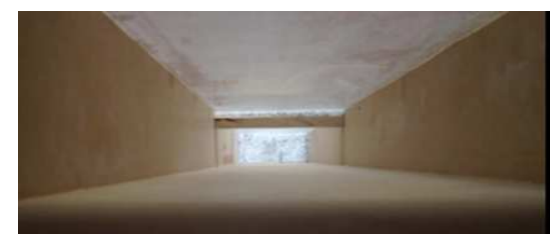

(b)

Figure 4.4. Introduction of biomass (a) and view of the bed of particles from the top of the reactor $(b)$

In order to eliminate the influence of the uncontrolled initial packing state, the conical spouted bed was pre-treated by increasing the superficial gas velocity to obtain full spouting and then decreasing the superficial gas velocity gradually to return to a reproducible initial fixed bed condition. This was completed prior to each experimental run.

The fluid dynamic characterisation was performed on systems containing only bed materials (PET, glass beads, sand) and for mixtures of bed materials and rice straw of different sizes at different volumetric ratios. In the case of working with mixtures, the effective density $\left(\rho_{\text {eff }}\right)$ and effective diameter of particle $\left(d_{\text {peff }}\right)$ were calculated as:

$$
\begin{aligned}
& \rho_{\text {eff }}=\sum_{1}^{n} \frac{W_{i} \cdot \rho_{i}}{W_{i}} \\
& d_{\text {peff }}=\frac{1}{\sum_{1}^{n} \frac{x_{i}}{\phi_{i} \cdot d p_{i}}}
\end{aligned}
$$

where $\mathrm{W}_{\mathrm{i}}$ is the mass of the compounds, $\mathrm{x}_{\mathrm{i}}$ the percentage of the corresponding component in the mixture in volume basis and $\phi_{i}$ the shape factor. 
All the experiments were video-recorded and the following fluid dynamic parameters were measured:

- air flow rate at the start of the spouting $\left(\mathrm{U}_{\text {onset }}\right)$;

- air flow rate at minimum spouting conditions $\left(\mathrm{U}_{\mathrm{ms}}\right)$;

- $\quad$ stable pressure drop along the bed of particles $\left(\Delta \mathrm{P}_{\mathrm{s}}\right)$;

- $\quad$ maximum pressure drop $\left(\Delta \mathrm{P}_{\max }\right)$;

- fountain height and dimensions of the spout.

A visual observation was also performed to evaluate the correct recirculation of solids, the stability of the system and the inexistence of dead or stagnant zones.

A first set of experiments was performed using sand as bed material and rice straw as biomass. The most characteristic fluid dynamic properties were evaluated as described below.

$\mathbf{U}_{\text {onset }}$ and $\mathbf{U}_{\text {ms. }}$ In terms of industrial design, the operational characteristics of the air blower according to the gas inlet requirements are one of the main factors that need to be evaluated as they are closely related to the reliability of the system, as well as to the costs of operation.

$\mathrm{U}_{\text {onset }}$ was experimentally calculated by increasing the air inflow from the static bed condition until the fountain was formed. $\mathrm{U}_{\mathrm{ms}}$ was found by decreasing the air flow from a stable spouting condition until the fountain disappeared.

Figure 4.5 shows the effect of the initial bed height $\left(H_{b}\right)$ for a bed of silica on the $\mathrm{U}_{\mathrm{ms}}$ and $\mathrm{U}_{\text {onset }}$. It is worth noting that $U_{\text {onset }}$ always lays below $U_{m s}$ for any studied $H_{b}$. This trend is observed as a result of the characteristic hysteresis phenomenon previously described in Section 2.2. The air inflow required to induce spouting $\left(\mathrm{U}_{\text {onset }}\right)$ is always greater when the process starts from a packed bed condition than that required to maintain the stable spouting. 


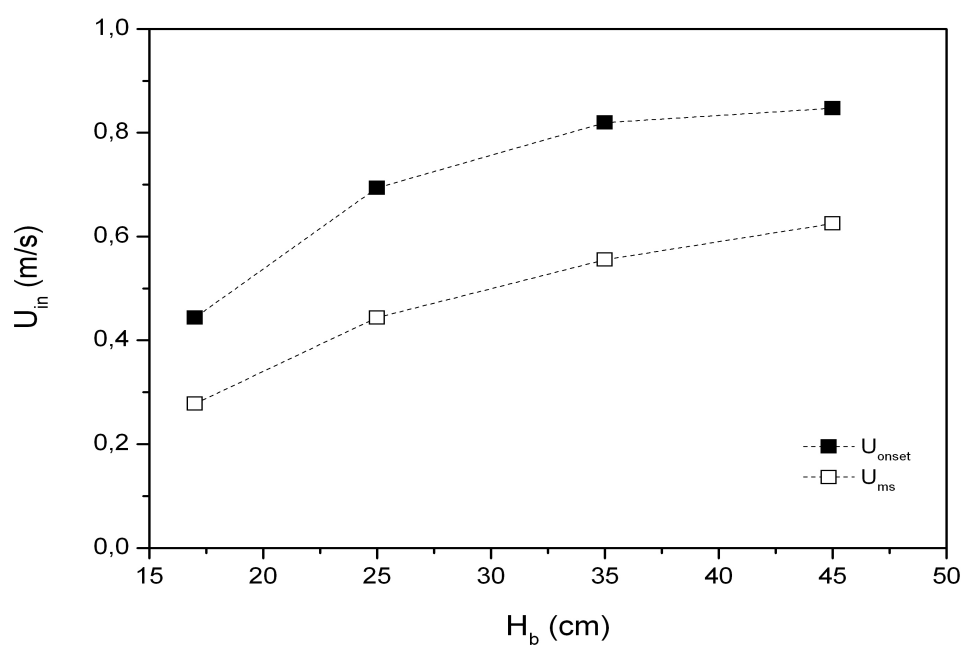

Figure 4.5. Effect of the initial bed height on $U_{m s}$ and $U_{\text {onset }}$ for a bed of silica

Although it is not seen in the figure, these two curves tend to overlap when $\mathrm{H}_{b}$ is further increased. This is a consequence of the increase of the gas velocity in the annulus with the increasing distance from the base approaching the minimum spouting velocity at the top of the bed. At this point, no hysteresis behaviour is produced and so, the two velocities $\left(U_{m s}, U_{\text {onset }}\right)$ coincide. The height at which the two curves overlap defines the maximum spoutable bed depth $\left(H_{m}\right)$.

The same behaviour is found when rice straw is added to the initial bed of silica. Figure 4.6 shows the effect of the initial bed height on $U_{m s}$ and $U_{\text {onset }}$ for a system containing $10 \% \mathrm{v} / \mathrm{v}$ (circles) and $20 \% \mathrm{v} / \mathrm{v}$ of rice straw (triangles).

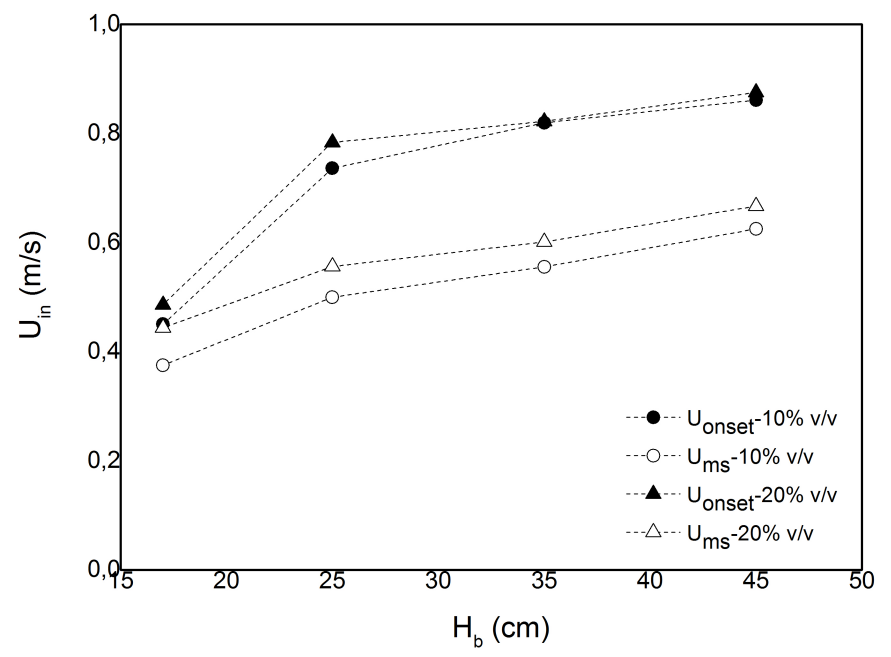

Figure 4.6. Effect of the initial bed height on $U_{m s}$ and $U_{\text {onset }}$ for a system containing $10 \% \mathrm{v} / \mathrm{v}$ (circles) and $20 \% \mathrm{v} / \mathrm{v}$ of rice straw (triangles) 
The figure shows the influence of the addition of coarse particles into the initial bed. This percentage is closely related to the amount of solids that can be processed to ensure a stable spouting condition. An increase in the percentage of coarse particles resulted in an increase of the air inflow requirements in all cases. Moreover, the visual inspection showed that, for percentages above $20 \% \mathrm{v} / \mathrm{v}$ of rice straw, the system became fluid dinamically unstable. For that reason, the maximum percentage added into the system was fixed at this value.

Maximum spoutable bed height. This parameter is also important at the design stage as it defines the amount of material that can be processed for a particular system, i.e. above that value, the spouting regime cannot be achieved. In contrast to cylindrical geometries, conical reactors do not present $\mathrm{H}_{\mathrm{m}}$ for fine particles. Only large particles can lead to instabilities, mainly slugging. This way, $\mathrm{H}_{\mathrm{m}}$ decreases with increasing particle sizes.

$\mathrm{H}_{\mathrm{m}}$ is determined by adding particles to a stable system step by step until this stable spouting regime is no longer achieved. $\mathrm{H}_{\mathrm{m}}$ could not be found experimentally due to lab limitations and so it was theoretically calculated. Table 4.2 gathers the values of $\mathrm{H}_{\mathrm{m}}$ calculated with the aid of the McNab and Bridgewater correlation described in Section 2.1.1.

Table 4.2. Maximum spoutable bed height for the bed materials under study

\begin{tabular}{|c|cc|}
\hline Bed material & $\mathbf{d}_{\text {peff }}(\mathbf{m})$ & McNab and Bridgewater, 1977 (m) \\
\hline Sand & 0.0014 & 1.48 \\
Sand-10\%v/v rice straw & 0.0021 & 1.31 \\
Sand-20\%v/v rice straw & 0.0028 & 1.11 \\
\hline
\end{tabular}

Stable and peak pressure drops. The pressure drop of a system is closely related to its energy requirements. Its correct assessment is crucial to optimise the operational conditions and the associated costs. For the present work, these parameters were experimentally calculated in the following way: the air inlet was increased from the static condition until the fountain was formed. The pressure drop along the bed of particles at that point provided the peak pressure drop $\left(\Delta P_{\max }\right)$. Air was further increased until the pressure drop achieved a constant value which constituted the stable pressure drop $\left(\Delta P_{\text {stable }}\right)$.

Firstly, the pressure drop of a mono-sized particle bed containing only the inert material was measured. The evolution of the pressure drop along the bed of particles $\left(\Delta P_{b}\right)$ with the air inflow $\left(\mathrm{U}_{\text {in }}\right)$ is shown in Figure 4.7, for the initial bed height of $25 \mathrm{~cm}$ (triangle) and $45 \mathrm{~cm}$ (square). 
The curve $U_{\text {onset }}$ represents the increasing direction of velocity whereas $U_{m s}$ shows the decreasing flow.

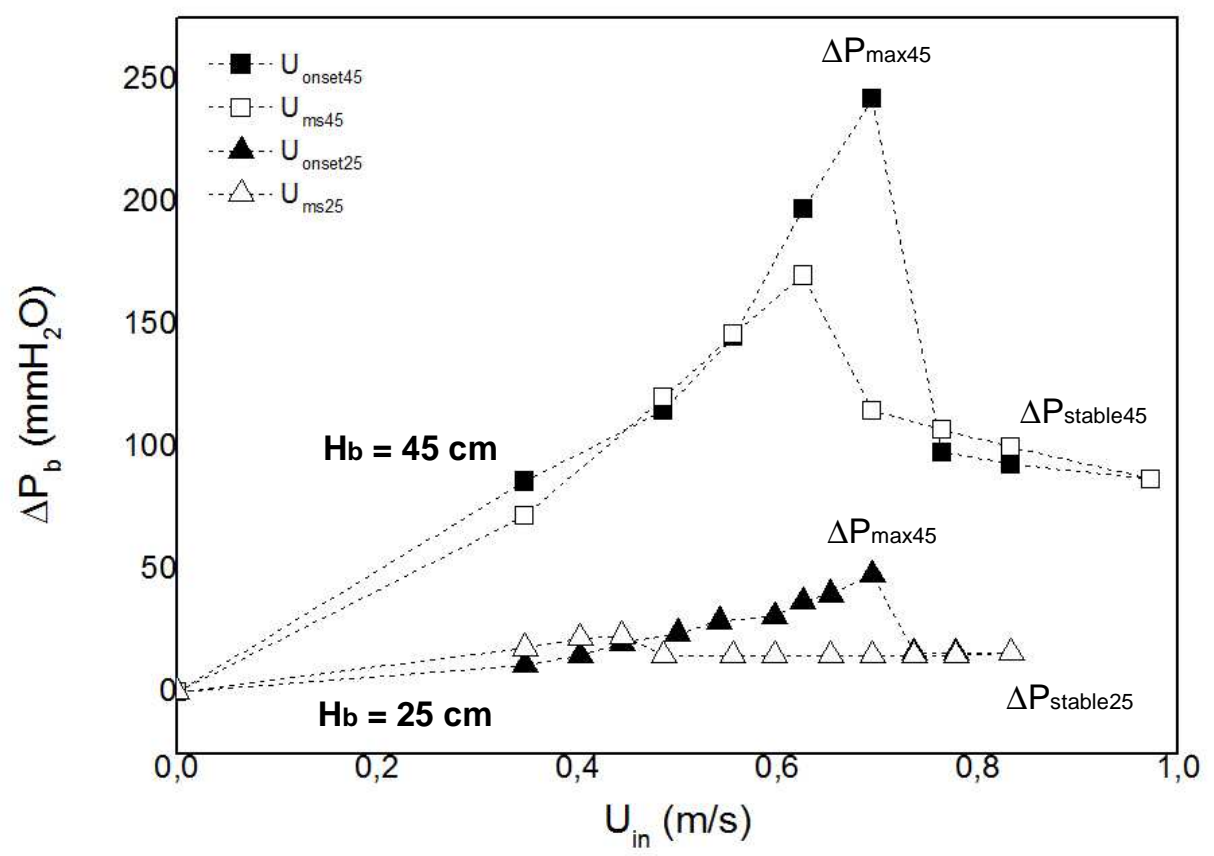

Figure 4.7. Evolution of pressure drop with air inlet for a bed of silica particles (triangle: $25 \mathrm{~cm}$ of initial height; square: $45 \mathrm{~cm}$ of initial bed height).

The more pronounced hysteresis behaviour is shown for higher initial bed heights as a consequence of the need for higher air flows to break the bed containing a higher amount of solids.

Once the inert material was characterised, the effect of the addition of coarse particles on the pressure drop of the system was evaluated. Table 4.3 and Table 4.4 show the variation of the peak and stable pressure drop respectively with the bed height $\left(\mathrm{H}_{\mathrm{b}}\right)$ and the volumetric ratio of rice straw in the system.

Table 4.3. Variation of peak pressure drop with $\mathrm{H}_{\mathrm{b}}$ and biomass volumetric ratio (in $\mathrm{mmH}_{\mathrm{g}}$ )

\begin{tabular}{cccc} 
& $\mathbf{0} \%$ v/v straw & $\mathbf{1 0 \%}$ v/v straw & 20\% v/v straw \\
\hline $\mathrm{H}_{\mathrm{b}}=25 \mathrm{~cm}$ & 68 & 80 & 92 \\
$\mathrm{H}_{\mathrm{b}}=35 \mathrm{~cm}$ & 98 & 102 & 105 \\
$\mathrm{H}_{\mathrm{b}}=45 \mathrm{~cm}$ & 104 & 116 & 122
\end{tabular}


Table 4.4. Variation of stable pressure drop with $\mathrm{H}_{\mathrm{b}}$ and biomass volumetric ratio (in $\mathrm{mmH}_{2} \mathrm{O}$ )

\begin{tabular}{|cccc|} 
& $\mathbf{0} \%$ v/v straw & $\mathbf{1 0 \%}$ v/v straw & $\mathbf{2 0 \%}$ v/v straw \\
\hline $\mathrm{H}_{\mathrm{b}}=25 \mathrm{~cm}$ & 16 & 18 & 21 \\
$\mathrm{H}_{\mathrm{b}}=35 \mathrm{~cm}$ & 40 & 58 & 72 \\
$\mathrm{H}_{\mathrm{b}}=45 \mathrm{~cm}$ & 87 & 90 & 110
\end{tabular}

As can be seen in the table, the values of the operating and peak pressure drop are highly dependent on the experimental system, i.e., on the initial load of solids and on the effective density of the mixture. The same behaviour as that observed for the case of mono-sized particles is observed with the addition of straw: an increase in the peak pressure drop is shown as the stagnant bed height is increased in all cases. This is explained by the higher amount of solids in the bed as the height of the stagnant bed is increased and therefore a higher pressure drop is required to break the bed and open the spout. $\Delta \mathrm{P}_{\max }$ is closely related to the start-up of the system: its value defines the minimum value of electrical power required to achieve the spouting condition from the static situation.

In contrast, the stable pressure drop provides the operational conditions for the stable regime. As shown in Table 4.4, $\Delta \mathrm{P}_{\mathrm{b}}$ follows the same general trend as $\Delta \mathrm{P}_{\max }$ (Table 4.3), presenting the maximum values at the highest height.

Finally, the increase in the percentage of coarse particles in the bed results in an increase of both stable and peak pressure drops in all cases.

Height of the fountain. The region of the reactor where the fountain is formed defines the area of reaction of the system, as it is where the majority of the mass and heat transfer reactions take place. Its evaluation provides useful information for the correct dimensioning of the device. The height of the fountain $\left(\mathrm{H}_{\mathrm{F}}\right)$ was experimentally calculated measuring its value with a scale on the transparent wall of the system. The obtained values were used for the validation of the fluid dynamic model that will be described in Section 4.3.

A more detailed and in-deep study of these parameters for the system sand-rice straw is presented in Communication 4.I. 
Additional tests were carried out with a non-porous draft tube. The dimensions of the tube are depicted in Figure 4.8.

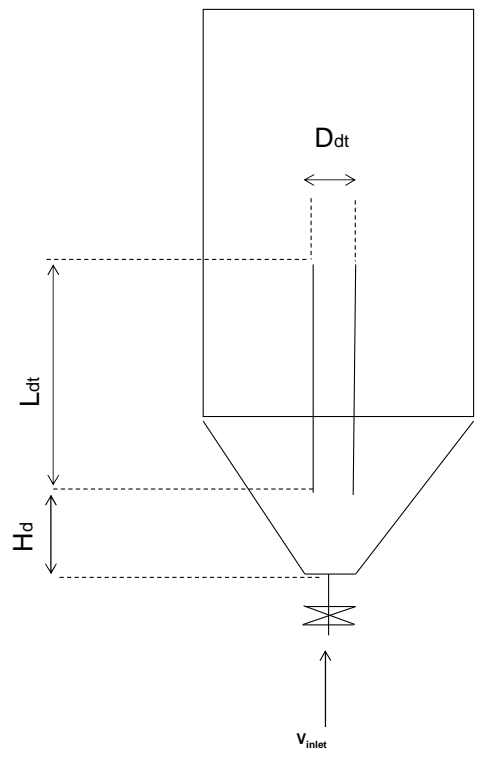

Dimensions $\quad$ Value $(\mathrm{cm})$

Distance from inlet, $\mathrm{H}_{\mathrm{d}}$

6.5

Length of draft tube, $\mathrm{L}_{\mathrm{dt}}$

38.5

Diameter of draft tube, $\mathrm{D}_{\mathrm{dt}}$

3.5

Figure 4.8. Position and dimension of the non-porous draft tube

Table 4.5 shows a comparison of the results obtained for the stable pressure drop with and without the additional device for a system containing sand and rice straw at different initial bed heights $(25$ and $35 \mathrm{~cm}$ ) and volumetric ratios (10 and 20\%v/v of straw). No problems of stability were encountered from the visual inspection and the start-up process was easily performed as a result of a preferential channel for the air thanks to the presence of the tube. From the experimental results it can be affirmed that the draft tube drastically reduces the air consumption. In addition, this decrease is more appreciated for higher initial bed heights achieving savings of up to $80 \%$ in the inflow air. Moreover, these considerably reduced values eventually turn into great energy savings. However, although there are proven benefits to draft tubes for the fluid dynamic stability of the system, their use in high temperature applications is still rather limited.

Table 4.5. Comparison of the stable pressure drop with and without draft tube

\begin{tabular}{|c|c|c|}
\hline $\mathrm{H}_{\mathrm{b}}=25 \mathrm{~cm}$ & $\Delta \mathbf{P}_{\mathrm{s}}\left(\mathrm{mmH}_{2} \mathrm{O}\right)$ without draft tube & $\Delta \mathbf{P}_{\mathrm{s}}\left(\mathrm{mmH}_{2} \mathrm{O}\right)$ with draft tube \\
\hline $10 \%$ v/v straw & 18 & 12 \\
\hline $20 \%$ v/v straw & 21 & 12 \\
\hline$H_{b}=35 \mathrm{~cm}$ & $\Delta \mathbf{P}_{\mathrm{s}}\left(\mathrm{mmH}_{2} \mathrm{O}\right)$ without draft tube & $\Delta \mathbf{P}_{\mathrm{s}}\left(\mathrm{mmH}_{2} \mathrm{O}\right)$ with draft tube \\
\hline $10 \%$ v/v straw & 58 & 14 \\
\hline $20 \%$ v/v straw & 72 & 14 \\
\hline
\end{tabular}




\subsection{Studies of Segregation}

Segregation is an important phenomenon that needs to be evaluated when fluidisation is applied to energy conversion technologies. Due to the mechanism of the process, the reacting phase is generally drowned in an inert phase, normally different in shape and density. In a standard fluidised system, the two phases tend to migrate at different bed levels as a result of their different properties this being the main cause of segregation and compromising the global behaviour of the system.

It is clear that a good mixing of particles is a key feature required when SBR are applied to thermal conversion purposes where a uniform final product is needed to satisfy the energy demand in a regular and continuous way. Even though SBR present improved characteristics such as enhanced recirculation of solids respect to traditional fluidised devices, potential segregation phenomena need to be evaluated in a broader range of conditions in order to ensure the correct functioning of the system in all cases.

With this purpose, a statistical Design of Experiments (DoE) was applied and several cold flow tests were carried out on 6 different systems of solids with very different density, dimension and shape. Afterwards, a full factorial design was used to study the main operational parameters during the three main stages of a spouting regime: start-up, stable spouting and collapse of the fountain. A closer inspection of the statistical results allowed the definition of the range of operational factors for which segregation phenomena are prevented.

DoE stand as a useful and reliable procedure to obtain the best combination of variables for the optimal running of the reactor and also permits the evaluation of the influence of each variable (individually or in combination) on the quality of the response. DoE are based on the study of the multiple input variables (Factors, F) that can be varied (Levels, L) to obtain the response variable (Effect, E). Any combination of $\mathrm{F}$ and $\mathrm{L}$ corresponds to a run in a practical experimentation. F can be quantitative (categorical variable) or qualitative (based on a continuous variable).

The F/L (gathered in Table 4.6) under consideration were (i) sphericity of the inert material; (ii) volumetric ratio of coarse particles in the bed and (iii) type of material. 
Table 4.6 Summary of Factors (F), Levels (L) and general characteristics of the DoE applied for this study

\begin{tabular}{lccc}
\multicolumn{1}{c}{ Factor $(\mathbf{F})$} & Level $(\mathbf{L})$ & Type & Values \\
\hline Sphericity & 3 & Quantitative & $0.82-0.87-1$ \\
Volumetric Ratio & 4 & Quantitative & $0-5-10-20$ \\
Density $\left(\mathrm{kg} / \mathrm{m}^{3}\right)$ & 2 & Quantitative & $56-296$
\end{tabular}

The E chosen for the analysis were:

- $Q_{\text {onset }}$ and $\Delta P_{\text {onset }}$ - to study the influence of the different factors on the start-up of the system

- $Q_{m s}$ and $\Delta P_{m s}$ - to evaluate the influence of the different factors on the stable operational conditions of the system

- $\quad Q^{*}$ and $\Delta P^{*}$ - to establish the factors for which segregation phenomena are prevented

- Existence of visual instabilities and, if so, time until it is appreciated ( $\left.\mathrm{t}_{\text {block }}\right)$

The statistical software Minitab $^{\odot}$ was used to carry out the statistical study, evaluating the significant factors and effects. The individual influence of each $\mathrm{F}$ through the different $\mathrm{L}$ was analysed by means of Main Effect Plots (MEP) whereas the general influence of all factors in combination was studied with the aid of the Interaction Plots (IP).

The device used for this experimental campaign was the same as that used for the previous fluid dynamic characterisation (Section 4.1). The existence of the flat transparent wall enabled the visualisation of the spouting onset, the solid circulation pattern and the potential stability problems encountered by the system. All the experiments were registered by video-recording.

Table 4.7 gathers the physical characteristics of the solids used for the complete experimental campaign. For the purpose of these tests, the influence of the dimension of the second phase was not addressed and so, PVC and straw were sieved to have similar diameters of particle.

Table 4.7 Physical properties of the solids used for the segregation studies

\begin{tabular}{l|ccc}
\hline \multicolumn{1}{|c}{ Material } & $\boldsymbol{\rho}_{\mathbf{p}}\left(\mathbf{k g} / \mathbf{m}^{3}\right)$ & $\mathbf{d}_{\mathbf{p}}(\mathbf{m m})$ & $\boldsymbol{\phi}$ \\
\hline Glass & 1660 & 1.5 & 1.00 \\
PET & 857 & 2.5 & 0.87 \\
Sand & 1485 & 1.4 & 0.82 \\
PVC & 296 & 36 & 0.6 \\
Straw & 56 & 37 & 0.74
\end{tabular}


The same experimental procedure as explained in Section 4.1 was applied. All the tests were performed at an initial bed height of $17 \mathrm{~cm}$ which corresponds to the cone height of the reactor.

\section{Methodology of work}

A defined quantity of solids was poured into the reactor according to the required volumetric ratio in each case and the set bed height of $17 \mathrm{~cm}$. The system was initially mixed vigorously before each run so there was no influence of an uncontrolled initial packing state.

Visual inspections were performed in first instance to evaluate the degree of mixing in the bed and the potential zones where segregation could occur. For every run, three different stages were identified and characterised by their air inflow requirement and the obtained pressure drop along the bed of particles. These values were submitted to the previously described statistical full design of experiments to evaluate their individual and in combination influence on the main parameters of the process.

Once the main operational parameters were obtained, the system was left until block (when possible) to evaluate the preferential segregation phenomena occurring for each mixture.

All the experimental runs were video recorded with the aim to obtain more information regarding the system, such as height of the fountain, shape of the spout, degree of mixing in the bed, etc. These data will be used to validate further modeling activities aimed to predict segregation problems.

All the experimental parameters and discussion of results corresponding to the explained methodology are presented in Communication 4.II. 


\subsection{CFD modelling}

Computational fluid dynamic (CFD) modelling has become a powerful tool for understanding dense gas-solid systems thanks to the advance of numerical algorithms and the deeper understanding of multiphase flow phenomena within the recent years. CFD studies enable the modelling of fluid phenomena that cannot be easily measured experimentally or that are economic and time costly. This way, by applying CFD modelling, the complex multiphase flow and the fluidisation reactions that take place within the Spouted Bed Reactor can be described by a numerical solution that can be further used to optimise all the operational parameters in an effective and quick way.

With this purpose, the Euler-Euler approach was applied to obtain the simulated fluid dynamic solution of the device under study. The fluid and particulate phases are treated mathematically as interpenetrating continua and the volume fractions of the overlapping phases are assumed to be continuous functions of space and time, with their sum always equal to one. Equivalent conservation equations are used for each phase and additional closure laws are applied to describe particle-particle and particle-fluid interactions. The density of each phase is considered constant during the tests.

All the studies were carried out with the aid of the commercial software ANSYS 14.5 workbench (Fluent User's Guide). This software includes a great number of advanced features to make the study of this complex mechanism an easy and efficient task.

The methodology followed for the modelling activities is schematised in Figure 4.9 


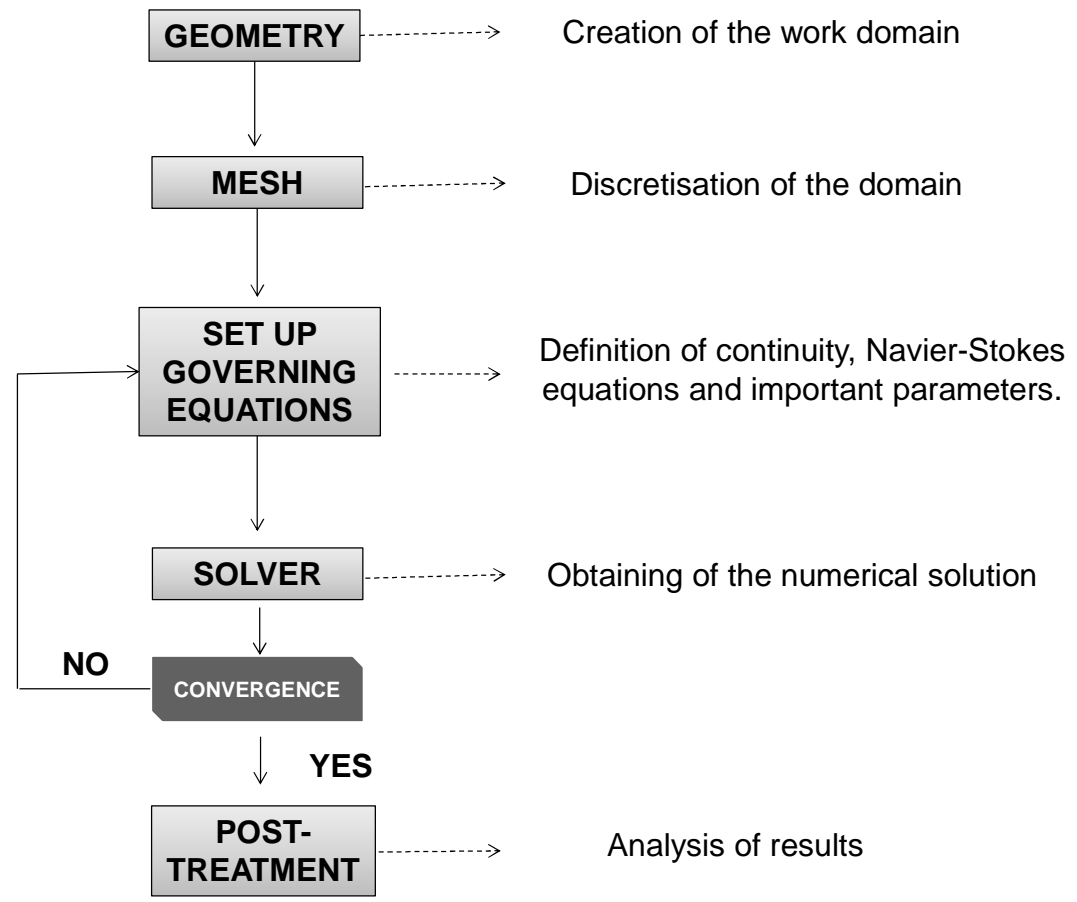

Figure 4.9. Scheme of the modelling methodology using FLUENT

Firstly, the geometry of the reactor was built with the tool Design Modeler provided within FLUENT software. This tool also permits the exportation of the particular geometry from an Autocad file but this feature was not used in this case. Once the work domain is done, this geometry is discretised into a number of computational cells: grids or mesh. This way, the complex governing equations (described in Chapter 2) are approximated by a system of algebraic equations for the variables at discrete locations in space and time. The equations of continuity, Navier-Stokes and energy (when applied) are solved using numerical analysis. For the case of FLUENT software, the discretisation is based on the finite volume method. The discretised algebraic equations are solved at each grid point by iterative methods until a converged solution is achieved. The values at different points are obtained by interpolation of the calculated numerical solution between the grid values. Finally, a post-treatment step is performed to analise the converged solution.

A first CFD model was developed to simulate the fluid dynamic behaviour of the system sandrice straw within the spouted bed reactor under study. The solution was validated with the experimental results described in Section 4.1. The description of the material properties and the simulated operational conditions are presented in Table 4.8. 
Table 4.8. Properties of materials and simulated operational conditions

\begin{tabular}{|c|c|}
\hline Properties of materials & Value \\
\hline Density of sand & $2600 \mathrm{~kg} / \mathrm{m}^{3}$ \\
\hline Density of straw & $238 \mathrm{~kg} / \mathrm{m}^{3}$ \\
\hline Density of air & $1.225 \mathrm{~kg} / \mathrm{m}^{3}$ \\
\hline Diameter of sand & $0.141 \mathrm{~cm}$ \\
\hline Diameter of straw & $0.8 \mathrm{~cm}$ \\
\hline Operational conditions & Value \\
\hline Initial bed height & $25-35-45 \mathrm{~cm}$ \\
\hline Percentage of straw & $0-10 \% \mathrm{v} / \mathrm{v}$ \\
\hline
\end{tabular}

Governing equations and main process parameters. The simulation was carried out in $2 \mathrm{D}$ in unsteady conditions. The governing equations were defined by selecting the Eulerian multiphase model. The dispersed turbulence was taken into account by selecting the standard $\mathrm{k}-$ $\varepsilon$ model. The gravitational acceleration was activated and selected as negative in the y direction. The pressure-velocity coupling was obtained using the SIMPLE algorithm.

Materials and associated interactions. Air was selected as the primary phase and two new materials (sand and straw) were defined as the second phase. Their properties were specified according to Table 4.9. Granular flow was activated and the following interactions were specified: the interaction between sand and air and straw and air was simulated by the Huilin and Gidaspow drag model (2003). In addition, the interaction between the two solids (sandstraw) was simulated by the Syamlal-O'Brien-Symmetric model (Syamal, 1987).

Closure relations. The choice of the correct closure model and parameters is crucial to achieve the most accurate simulation results. For this simulation, the following coefficients were those offering the best fittings: coefficient of restitution for sand particles $=0.85$; coefficient of restitution for sand and straw $=0.3$; coefficient of restitution for straw particles $=0.3$ (See their definitions in Chapter 2).

Computational mesh. The applied mesh generated by the Meshing editor tool. The space between nodes was $5.5 \mathrm{~mm}$, increasing gradually towards the outlet zone. The mesh used quadrilateral cells. Figure 4.10 shows the diagram of the applied mesh and Table 4.9 provides the mesh main characteristics. 


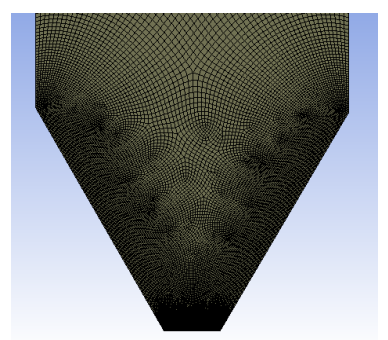

Figure 4.10. Diagram of the mesh
Table 4.9. Mesh characteristics

$\begin{array}{cr}\text { Minimum element quality } & 0.25969 \\ \text { Maximum element quality } & 0.99997 \\ \text { Total number of elements } & 51606 \\ \text { Number of nodes } & 52471\end{array}$

Boundary conditions. The following boundary conditions were selected. For the surface inlet, the air velocity was specified at the minimum spouting velocity at each case $(0.44,0.556,0.625$ $\mathrm{m} / \mathrm{s}$ ). The solids (sand and straw) were kept at $0 \mathrm{~m} / \mathrm{s}$. At the outlet, a pressure equal to 1 atm was applied. The walls were defined as non slip for both air and the solids. Also during this stage, a patch was inserted in order to include the different initial bed heights $(\mathrm{Hb}=25,35$ and $45 \mathrm{~cm})$.

Numerical solution. Once all the set-up is ready, the solution parameters are set by defining an adequate time step size $(0.0008 \mathrm{sec})$, number of time steps for iteration (8000) and interactions for step (20). An adequate setting of these parameters is crucial for achieving the correct solution as it is closely related to the overall convergence. Finally, the solution is initialised and run.

Post-processing. When the convergence is achieved, the post-processing stage permits to analyse the numerical solution obtained.

The calculated solution was validated with the experimental results discussed in Section 4.1. The variables fountain height and pressure drop along the bed of particles were used as validating parameters. The model represents the height of the fountain with good accuracy in all cases with a maximum error below $5 \%$. This result allows the identification of the region where the fountain will develop and so, where the mass and energy transfer reactions between gas and solids will take place. However, the model does not predict, with the same precision, the pressure drop along the bed of particles. This fact could be attributed to inaccuracies in the experimental measure. An upgrade of the model obtaining the 3D solution will be carried out to improve these results.

A complete discussion of results related to the described simulation is presented in Communication 4.III. 


\subsection{Main results}

An initial set of room temperature experiments was performed with sand and rice straw at different operational conditions with the aim to characterise the fluid dynamic behaviour of the system. This characterisation is a key feature for the further design and adequate scale-up of the device: a correct fluidisation regime ensures a stable and reliable process. As a result of these tests, the maximum load of particles susceptible to be spouted without problems was defined $(20 \% \mathrm{v} / \mathrm{v})$ as well as the optimum operational conditions for the whole system. Moreover, a new correlation to calculate the minimum spouting velocity was obtained based on the experimental parameters of the SBR under study.

Statistical studies were applied to the study of mixtures of solids greatly differing in shape, dimension and density. These big differences stand as the main cause of segregation phenomena in SBR. From the results it can be concluded that similar density ratios between the solids in the bed improve the performance of the system. Segregation phenomena do not appear at any situation with a volumetric ratio lower than $5 \%$. However, the increase of the quantity of coarse particles results in increasing instabilities in all cases.

Finally, a computational fluid dynamic model was developed and validated with the experimental results. The values of fountain height were predicted with high accuracy whereas the pressure drop was not in good agreement and further improvements need to be done. The use of a 3D model is expected to improve the accuracy of the results respect to the experimental data. 


\section{References Chapter 4}

ANSYS ${ }^{\odot}$ Fluent Release 14.5 User's manual

Epstein N., Grace J.R., Spouted and spout-fluid beds: fundamentals and applications. Cambridge University Press (2011).

Huilin L., Gidaspow D. Hydrodynamics of binary fluidization in a riser: CFD simulation using two granular temperatures, Chemical Engineering Science, 58, 3777-3792 (2003).

Lu H.L., Gidaspow D., Jacques B., Liu W. Hydrodynamic simulation of gas-solid flow in a riser using kinetic theory of granular flow. Chem. Eng. Journal, 95, 1 (2003).

Malek M.A., Lu B.C.Y. Pressure drop and spoutable bed height in spouted beds. Ind. Eng. Chem. Process Des. Dev 4, 123-128 (1965).

Mathur K.B. and Gishler P.E. A Study of the Application of the Spouted Bed Technique to Wheat Drying, J. Appl. Chemic., 5, 11, 624-636 (1955a).

Mathur K.B. and Gishler P.E. A technique for contacting gases with coarse solid particles. AIChE J. 1, 157-164 (1955b).

Mathur K.B., Epstein N., Developments in spouted bed technology. The Canadian Journal of Chemical Engineering, 52, 2, 129-144 (1974).

McNab G.S., Bridgwater J. Spouted-beds - estimation of spouting pressure drop and the particle size for deepest bed. Proceedings of the European Congress on Particle Technology (Nuremberg, Germany) (1977)

Minitab Inc. Statistical Software Release 16 User's Guide

Rovero G., Epstein N., Grace J.R., Piccini N., Brereton C.M.H. Gas phase solid-catalysed chemical reaction in spouted beds. Chemical Engineering Science 38, 557-566 (1983).

Rovero G, Piccini N, Lupo A. Vitesses des particules dans les lits à jet tridimensional et semicylindriques. Entropie 124: 43-49 (1985).

Syamal M. The particle-particle drag term in a multiparticle model of fluidization, C National Technical Information Service, Springfield, VA (1987). 


\section{Communications}

The main results regarding the Characterisation of the Spouted Bed Reactor are presented in the following communications:

Communication 4I: C. Moliner, M. Curti, B. Bosio, E. Arato, G. Rovero. Experimental tests with rice straw on a conical square-based spouted bed reactor. International Journal of Chemical Reactor Engineering 13, 2015, 3, 351-358. DOI 10.1515/ijcre-2014-0172

Communication 4II: C. Moliner, M. Curti, B. Bosio, G. Rovero, E. Arato. Statistical methodology for the assessment of a Spouted Bed Reactor preventing segregation phenomena. Manuscript

Communication 4III: D. Bove, C. Moliner, M. Curti, B. Bosio, G. Rovero, E. Arato. CFD simulations of a square-based spouted bed reactor and validation with experimental tests using rice straw as feedstock. Chemical Engineering Transactions, 43, 2015, 1363-1368. DOI:10.3303/CET1543228 
Experimental tests with rice straw on a conical square-based spouted bed reactor.

C. Moliner, M. Curti, B. Bosio, E. Arato, G. Rovero

. International Journal of Chemical Reactor Engineering 13, 2015, 3, 351-358.

DOI 10.1515/ijcre-2014-0172 



\section{Cristina Moliner*, Massimo Curti, Barbara Bosio, Elisabetta Arato and Giorgio Rovero Experimental Tests with Rice Straw on a Conical Square-Based Spouted Bed Reactor}

\begin{abstract}
A spouting bed reactor using rice straw as feedstock for further gasification purposes was studied in the present work. Experimental fluid dynamic tests were carried out in a conical square-based spouted bed reactor using a mixture of straw and silica, the latter acting as inert material. The influence of the initial bed of particles and the presence of coarse particles in the mixture on the pressure drop and minimum spouting velocity were evaluated. As a result, lower values of pressure drop along the bed were found compared to conventional fluidisation processes. Higher initial bed heights and higher percentage of straw in the mixture resulted in higher values of pressure drop and minimum spouting velocity. A new correlation for a cross section spouted bed reactor was proposed for the prediction of the minimum spouting velocity.
\end{abstract}

Keywords: spouted bed reactor, fluid dynamics, rice straw

DOI 10.1515/ijcre-2014-0172

\section{Introduction}

The overuse of fossil fuels and the concern over environmental problems have led to an increasing interest on renewable energies worldwide. Biomass and specifically agricultural residues have emerged as suitable materials for its use as feedstock for new energy recovery processes [1]. Among the different agricultural residues, rice straw has been pointed out as an option for its use in thermochemical reactions due to two main factors: its high

\footnotetext{
*Corresponding author: Cristina Moliner, Dipartimento di Ingegneria Civile, Chimica e Ambientale (DICCA), Università degli Studi di Genova (UNIGE), Via Opera Pia 15, 16145, Genova, Liguria, Italy, E-mail: cristina.moliner@edu.unige.it

Massimo Curti, Giorgio Rovero, Dipartimento di Scienza Applicata e Tecnologia (DISAT), Politecnico di Torino (POLITO), Torino, Piemonte, Italy, E-mail: massimo.curti@polito.it, giorgio.rovero@polito.it

Barbara Bosio, Elisabetta Arato, Dipartimento di Ingegneria Civile, Chimica e Ambientale (DICCA), Università degli Studi di Genova (UNIGE), Via Opera Pia 15, 16145, Genova, Liguria, Italy, E-mail: barbara.bosio@unige.it, elisabetta.arato@unige.it
}

production and, as a consequence, the necessity of a sustainable management.

Gasification has been proven a convenient technique for thermo-chemical conversions of biomass [2] by means of fluidisation processes. Different devices have been developed to carry out these reactions and, among them, spouted bed reactors (SBRs) have been proposed as a solution to overcome the difficulties that conventional reactors face when treating big and heterogeneous particles.

SBRs are obtained by replacing the perforated plate of a conventional reactor of fluidisation by a plate with a single orifice, normally centred in the base. This modification provides the system an enhanced recirculation of solids which results in increased mass and energy transfer rates respect to conventional techniques. Three different regions (annulus, spout and fountain) can be distinguished in a SBR. From a hydrodynamic point of view, the spout and fountain behaviours are similar to those in fluidised beds with particles dynamically suspended, whereas the annulus acts more like a packed/ moving bed. The conical base also helps in the recirculation process, enabling the movement of bigger and irregular particles in the device. Figure 1 shows an schematic diagram of the spouting process.

SBRs have found extensive industrial applications, mainly related to drying processes, due to the high fluid-solid contact achieved. Several applications of these devices acting as chemical reactors are being developed and SBR currently stand out as a promising technology to carry out thermo-chemical reactions such as pyrolysis [3], gasification [4] and combustion [5] of different waste materials or for reforming reactions [6].

A successful design and scale-up of these reactors must include a deep study of the fluidynamics of the system. The spouting phenomenon, its stability and the operating conditions depend on many factors such as particle size, flow rate of fluidising agent, bed height or density of particles and, for given materials and fixed geometries, a maximum spoutable bed depth is defined, beyond which the spouting is replaced by poor fluidisation [7]. Previous studies in SBRs at low temperature [8,9] proved the good performance of these devices with solids of big dimensions and heterogeneous profiles. Moreover, lower pressure drops were obtained respect to those for 


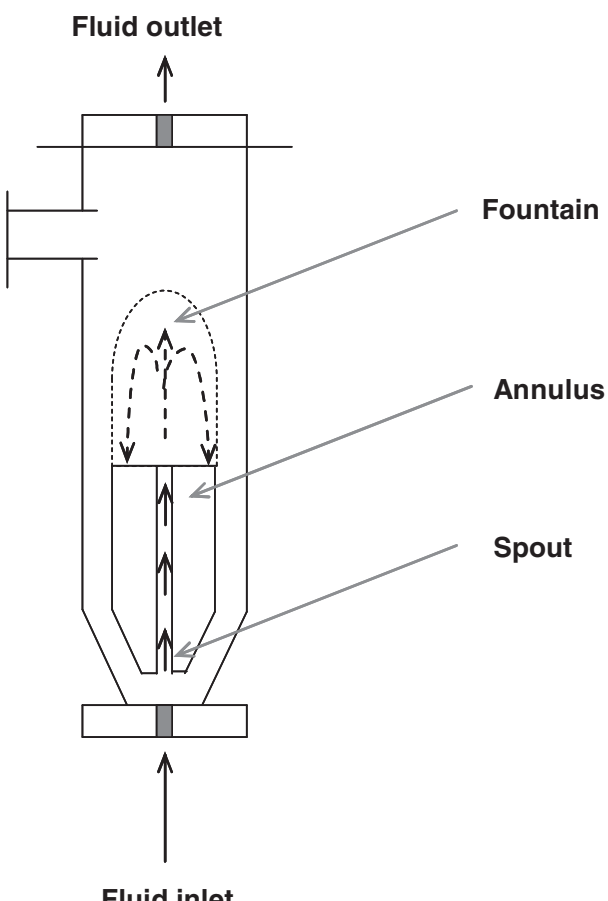

Figure 1: Scheme of a SBR.

conventional fluidization, as well as lower values of the required fluidization agent.

From a design point of view, parameters like the minimum spouting velocity of the system and the height of the fountain will be necessary to define the specifications of the blower and the height required for the reactor respectively. Pressure drop will also be an important variable of study as it is closely related to the energy needs of the system. Several correlations have been developed for the prediction (specially useful in scaled-up applications) of the main properties of SBR [10], but the high dependence of the process with the involved solids makes them not completely suitable for the whole range of applications. Furthermore, in order to facilitate the scale up, square-based reactors were proposed [9] and the same phenomena occurring for the case of cylindrical bases were demonstrated to define the overall performance, enabling the use of existing correlations with slight adaptations.

In the present work, low temperature experimental studies were performed in a conical square-based SBR using rice straw as feedstock and silica as inert bed material to characterise the fluidynamic behaviour of the system in terms of pressure drop and minimum spouting velocity.

\section{Experimental}

The scheme of the experimental setup used for the present work and the definition of the main dimensions of the reactor is shown in Figure 2. The system is composed by an air compressor, a flow meter, two manometers and
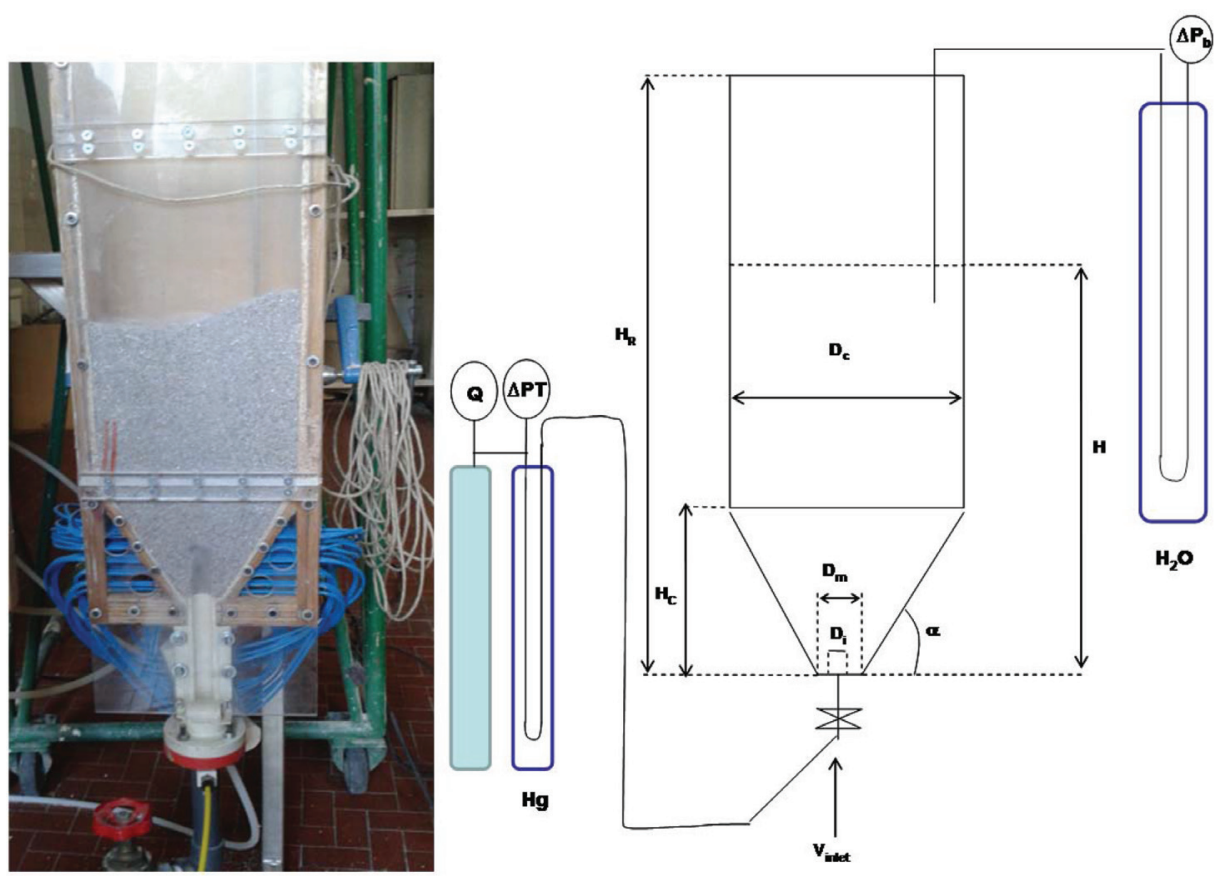

Figure 2: Scheme of the experimental apparatus. 
a conical SBR whose numerical definition is presented in Table 1. A half section device with a plexyglass wall was used for the present work, in order to enable the visualisation of the spouting process and to better evaluate the fluidynamic phenomena occurring inside the reactor. As proven by Rovero et al. [11] the wall has been demonstrated to interfere to a moderate extent with the solids trajectory vectors within the annulus and to not affect the measurement of the fundamental fluidynamic parameters of SBR, such as $\mathrm{U}_{\mathrm{ms}}$. Therefore, the results obtained with this device were taken as valid to describe the behaviour of the whole reactor.

Table 1: Values of the main dimensions of the experimental apparatus.

\begin{tabular}{lrrrrr}
\hline$H_{\mathrm{R}}(\mathrm{cm})$ & $\boldsymbol{H}_{\mathrm{C}}(\mathrm{cm})$ & $\boldsymbol{\alpha}$ & $\boldsymbol{D}_{\mathrm{i}}(\mathrm{cm})$ & $\boldsymbol{D}_{\mathrm{m}}(\mathrm{cm})$ & $\boldsymbol{D}_{\mathrm{C}}(\mathrm{cm})$ \\
\hline 200.0 & 15.5 & $60^{\circ}$ & 2.5 & 3.6 & 20.0 \\
\hline
\end{tabular}

Two different measures of pressure drop $(\Delta \mathrm{P})$ were obtained as represented in Figure 2. The values of pressure drop across the bed of particles $\left(\Delta \mathrm{P}_{\mathrm{b}}\right)$ were measured for the different set of experiments by means of a probe located in the intern of the bed at $20 \mathrm{~cm}$ from the bottom and at $4 \mathrm{~cm}$ distance from the wall in the radial direction and connected to a water U-manometer. The pressure drop corresponding to the overall system $\left(\Delta \mathrm{P}_{\mathrm{T}}\right)$ was simultaneously measured with the aid of a mercury U-manometer connected to the flow meter.

The inlet distributor consists on a single orifice placed in the centre of the base of the reactor with an inlet diameter of $2.5 \mathrm{~cm}$ and Dc represents the length of the square side of the base and corresponds to an equivalent diameter of $23 \mathrm{~cm}$.

The blower supplies a maximum air flow of $200 \mathrm{Nm}^{3} / \mathrm{h}$ measured by means of a rotameter (tared at $1013 \mathrm{mbar}$ and $20^{\circ} \mathrm{C}$ ). A U-tube water manometer is connected to the rectangular column for measuring the pressure drop across

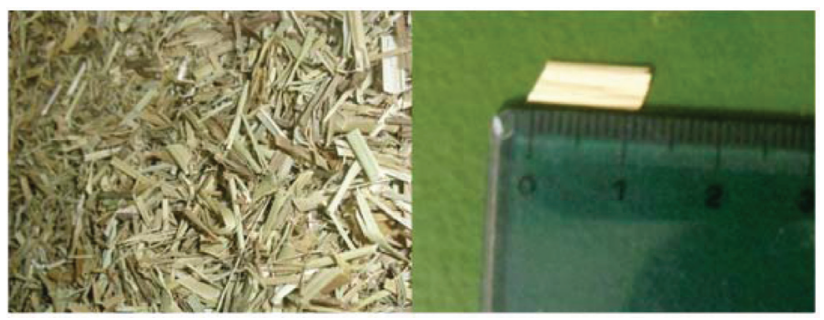

Figure 3: Rice straw employed for the tests.

the bed and a mercury manometer is employed to measure the total pressure drop of the system.

Rice straw was chopped and considered as a cylinder with constant diameter. An averaged length of $1 \mathrm{~cm}$ was obtained from the size distribution performed on a representative sample. Due to the nature of the straw, length was taken as its characteristic dimension (Figure 3).

The reactor also contained particles of silica acting as the inert bed material. Different percentages of rice straw $(10 \% \mathrm{v} / \mathrm{v}, 20 \% \mathrm{v} / \mathrm{v})$ were tested for the present work. The effect of the height of the bed was assessed with values set at 25, 35 and $45 \mathrm{~cm}$ for each experiment. Table 2 gathers the physical properties of the components of the system together with the quantities of silica and rice straw required to reach each height of study.

For the case of the mixtures straw-silica, the effective density and diameter of particle were calculated according to the following expressions:

$$
\begin{gathered}
\rho_{\text {eff }}=\frac{W_{1} \cdot \rho_{\text {silica }}+W_{2} \cdot \rho_{\text {straw }}}{W_{1}+W_{2}} \\
d_{\text {peff }}=\frac{1}{\sum_{1}^{2} \frac{x_{i}}{\phi_{i} \cdot d p_{i}}}
\end{gathered}
$$

With $W_{1}$ and $W_{2}$ the mass of silica and straw respectively, $x_{\mathrm{i}}$ the percentage of the corresponding component in the mixture in volume basis and $\phi_{i}$ the shape factor defined as the ratio of the surface area of equi-volume sphere to the surface area of the particle, with values of $\phi=1$ for spherical particles (silica) and $\phi=0.82$ for the case of the straw.

\begin{tabular}{|c|c|c|c|c|c|c|c|c|}
\hline & \multicolumn{3}{|c|}{$W_{1}-$ Mass Silica (kg) } & \multicolumn{3}{|c|}{$W_{2}-$ Mass Straw $(\mathrm{kg})$} & \multirow[b]{2}{*}{$d_{\text {peff }}(\mathrm{m})$} & \multirow[b]{2}{*}{$\rho_{\text {eff }}\left(\mathrm{kg} / \mathrm{m}^{3}\right)$} \\
\hline & $H=25(\mathrm{~cm})$ & $H=35(\mathrm{~cm})$ & $H=45(\mathrm{~cm})$ & $H=25(\mathrm{~cm})$ & $H=35(\mathrm{~cm})$ & $H=45(\mathrm{~cm})$ & & \\
\hline Straw $0 \% \mathrm{v} / \mathrm{v}$ & 5.357 & 7.730 & 10.250 & 0.000 & 0.000 & 0.000 & $1.4 \cdot 10^{-3}$ & 1485 \\
\hline Straw $10 \% \mathrm{v} / \mathrm{v}$ & 5.280 & 7.690 & 9.930 & 0.021 & 0.032 & 0.043 & $2.1 \cdot 10^{-3}$ & 1479 \\
\hline Straw $20 \% \mathrm{v} / \mathrm{v}$ & 5.280 & 7.690 & 9.930 & 0.047 & 0.071 & 0.091 & $2.8 \cdot 10^{-3}$ & 1470 \\
\hline
\end{tabular}

Table 2: Physical properties of the materials under study at different heights $(H)$. 
From previous experimental measurements, the values of diameter and density of the initial rice straw were $d_{\text {straw }}=0.01 \mathrm{~m}$ and $\rho_{\text {straw }}=56 \mathrm{~kg} / \mathrm{m}^{3}$.

The dimension of particle is fundamental to guarantee a good spouting behaviour. They must belong to group D of Geldart classification [12] and satisfy the condition in eq. (3):

$$
\left(\rho_{\text {eff }}-\rho_{\text {air }}\right) d_{\text {peff }}^{1.24}>0.23
$$

condition satisfied for all tested cases.

\section{Fluidynamic experimental studies}

The behaviour of SBRs is highly influenced by the characteristics of the treated solids and a description of the fluidynamics of the system at low temperatures becomes necessary to characterise the performance of the device. A correct definition will help to choose the most suitable conditions of work according to the available solids and their characteristics. The influence of the bed height and the percentage of coarse particles (rice straw) in the mixture on the pressure drop and spouting velocity of the conical spouted bed are studied in the present work.

\subsection{Study of the pressure drop}

Figure 4 shows the evolution of $\Delta \mathrm{P}_{\mathrm{b}}$ with air velocity $\left(\mathrm{U}_{\text {in }}\right)$ for a mixture with a $10 \% \mathrm{v} / \mathrm{v}$ of rice straw at an initial static bed of $35 \mathrm{~cm}$. The pressure drop along the bed of particles increases as air velocity goes up showing a linear trend $(\diamond)$ and a packed bed behaviour with an increasing cavity being formed in the centre of the spout.

At certain point, $\Delta \mathrm{P}_{\mathrm{b}}$ reaches a peak value when the fountain is formed $\left(\Delta \mathrm{P}_{\mathrm{bmax}}\right)$ from which it decreases sharply when the air velocity is further increased. This fact can be attributed to the lower resistance offered by the solids as a result of the vigorous movement of the fountain. The $\Delta \mathrm{P}_{\mathrm{b}}$ continues going down until a value that remains constant $\left(\Delta \mathrm{P}_{\mathrm{bs}}\right)$ for a wide range of velocities.

Once the stable conditions are achieved, the fluid velocity is decreased ( $\square$ ), and a hysteresis process is observed as the pressure required to break the bed and form the spout is higher than the corresponding peak pressure drop at each point.

For comparison purposes, the theoretical trend that a conventional fluidisation process would show is represented by the grey dashed line. The difference of pressure drop between the two processes is represented by $\Delta \mathrm{P}_{\mathrm{d}}$ proving that lower values should be obtained when applying spouting conditions.

The effect of the initial static bed height is studied in Figure 5 where the evolution of $\Delta \mathrm{P}_{\mathrm{b}}$ at the tested heights $(25,35$ and $45 \mathrm{~cm})$ with increasing $U_{\text {in }}$ are represented for the mixture of particles with a $10 \% \mathrm{v} / \mathrm{v}$ of rice straw.

The values of $\Delta \mathrm{P}_{\mathrm{b}}$ increase with increasing bed heights as well as the required inlet flow necessary to form the fountain $\left(\Delta \mathrm{P}_{\mathrm{bmax}}\right)$ because, as bed increases, the resistance offered by the solids also increases and it makes necessary higher inlet flows to start the spouting process.

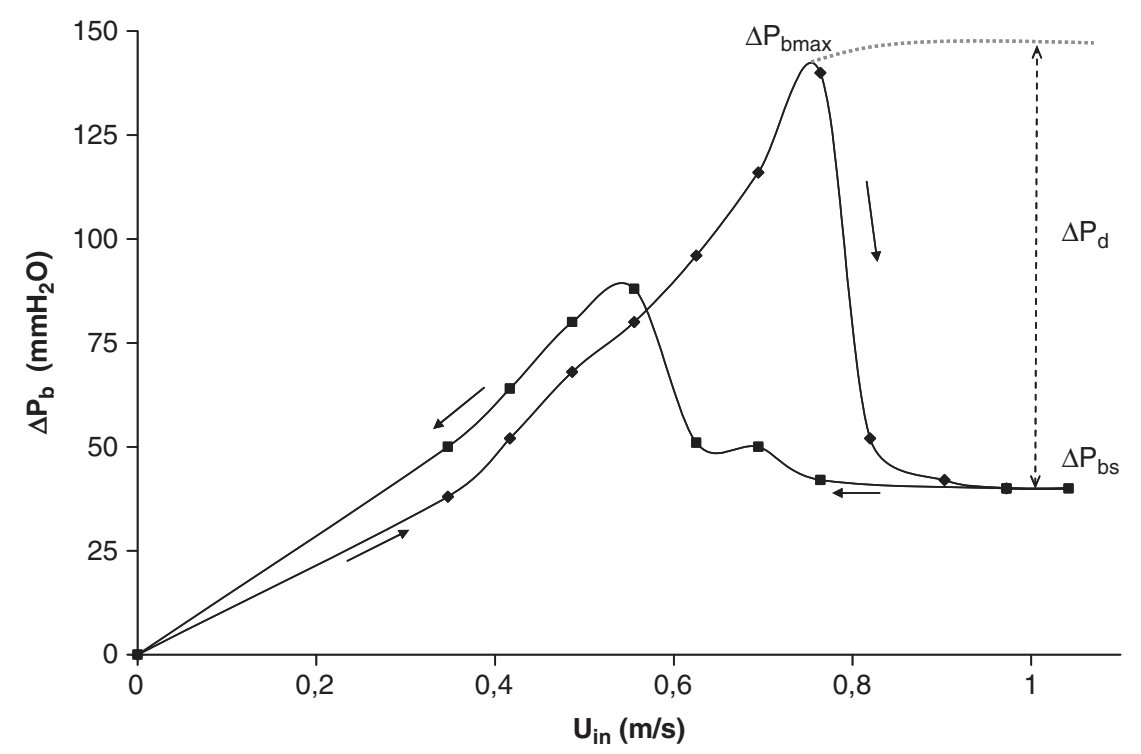

Figure 4: Pressure drop evolution across the bed with the inlet velocity (Rice straw $10 \% \mathrm{v} / \mathrm{v}$ ). 


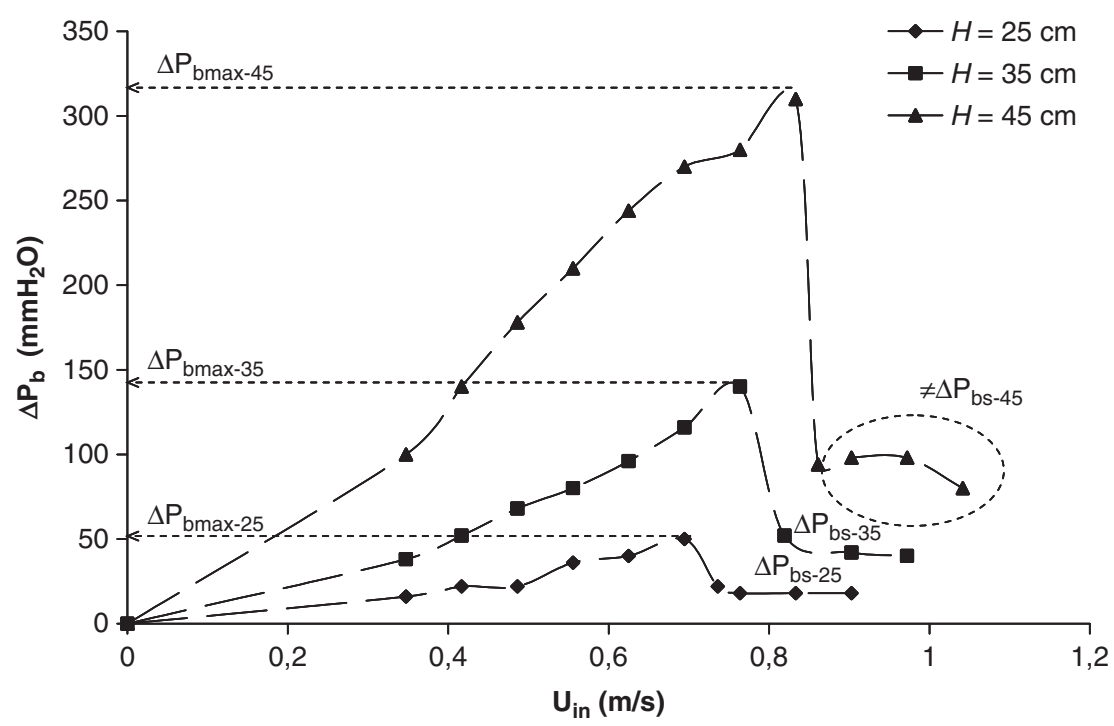

Figure 5: Pressure drop evolution along the bed with the inlet velocity for different initial bed height (rice straw $10 \% \mathrm{v} / \mathrm{v}$ ).

The same trend is shown for the stable pressure drop $\left(\Delta \mathrm{P}_{\mathrm{bs}}\right)$ for the case of the lower heights. However, $H=$ $45 \mathrm{~cm}$ showed incipient instabilities (circle dashed lines) and therefore it was defined as the maximum height value to be tested to ensure stable conditions within the reactor under study.

In order to study the influence of the characteristics of the particles present in the bed, different percentages of rice straw were tested at a constant bed height of 45 $\mathrm{cm}$. Figure 6 represents the pressure drop along the initial bed of $45 \mathrm{~cm}$ with the inflow gas for three different percentages $(0,10$ and $20 \% \mathrm{v} / \mathrm{v}$ of straw). A higher value of $\Delta \mathrm{P}_{\mathrm{b}}$ is found when straw is added to the bed, indicating a higher resistance when coarse particles are present in the mixture. However, the increase in the percentage of straw showed slightly different values of $\Delta \mathrm{P}_{\mathrm{b}}$ compared to those observed respect to the bed containing only silica.

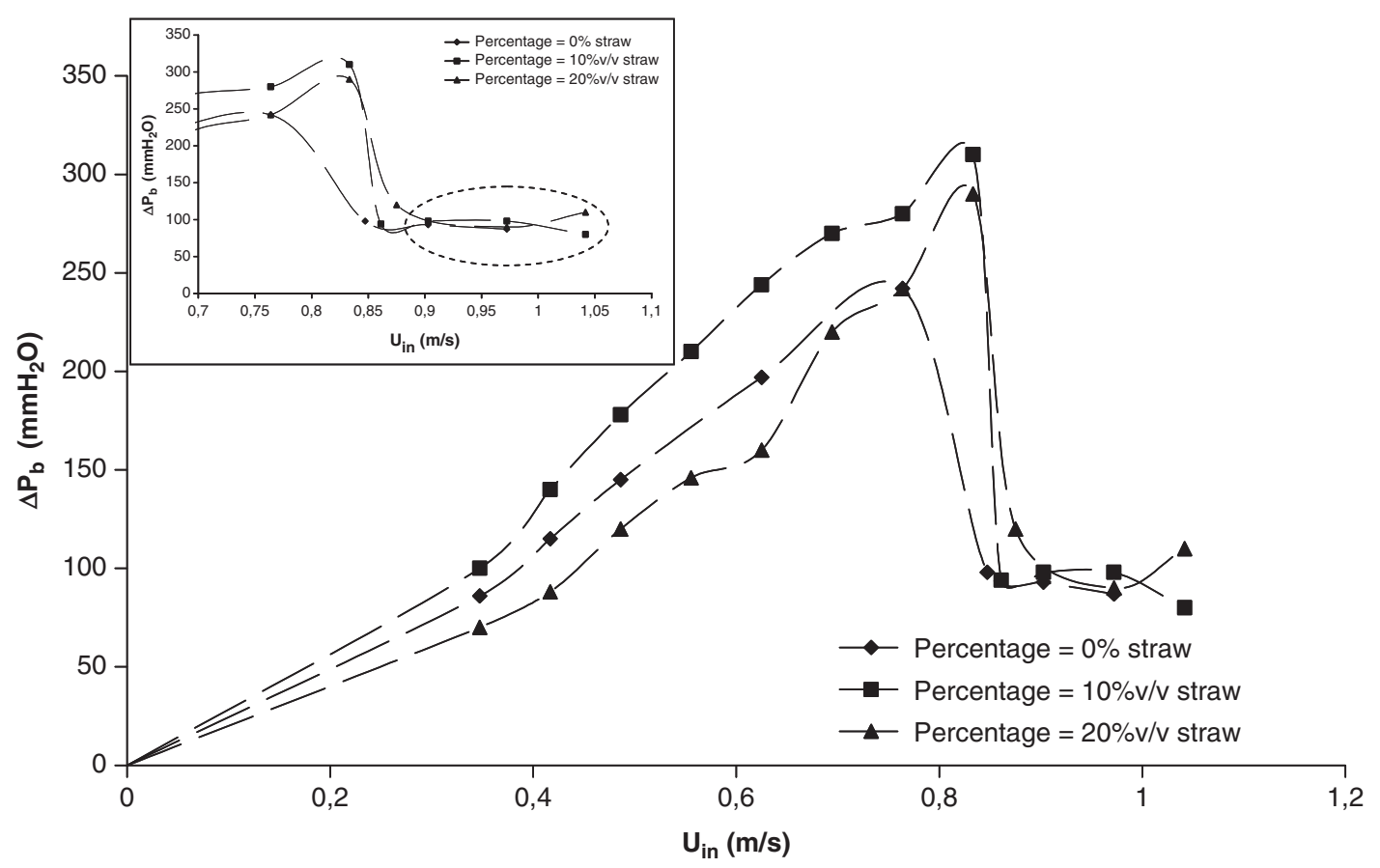

Figure 6: Pressure drop evolution along the bed with the inlet velocity for different percentages of rice straw $(H=45 \mathrm{~cm})$. 
Regarding the study of the stable spouting conditions, the values of stable pressure drop (Figure 6 - inset) are within the same range for all the tested percentages, but higher percentages of coarse particles showed slight incipient instabilities and for that reason, $H=45 \mathrm{~cm}$ was defined as the maximum height of the bed of particles (corresponding to a maximum ratio $H_{b} / D_{c}=2.25$ ) at any percentage of straw to ensure a stable process of the device under study.

\subsection{Study of the spouting velocity}

The second fundamental parameter to define the performance of SBRs is the so-called minimum spouting velocity, $\mathrm{U}_{\mathrm{ms}}$, defined as the minimum rate of gas required to maintain the conditions of spout in the system. For the present work, $\mathrm{U}_{\mathrm{ms}}$ was evaluated experimentally and compared with the existing correlations.

For the experimental evaluation of $\mathrm{U}_{\mathrm{ms}}$, the inflow was decreased from the stable condition and the value at which the fountain collapsed was taken as $\mathrm{U}_{\mathrm{ms}}$. The effect of the bed height on $\mathrm{U}_{\mathrm{ms}}$ (percentage of rice straw $=10 \%$ $\mathrm{v} / \mathrm{v}$ ) can be evaluated from Table 3. The resulting $U_{\mathrm{ms}}$ takes higher values with increasing beds as it was expected from the previous results (Section 3.1). Stable conditions for the further study of the spouting process were set at $1.1 \mathrm{U}_{\mathrm{ms}}$ in order to ensure the spouting and avoid instabilities. From this trend, it can be concluded that the requirements of the inflow equipment will be affected by the height of the static bed with higher gas flows required for higher static beds.

In order to study the influence of the presence of big and irregular particles in the bed, different percentages of rice straw were tested measuring the corresponding $U_{m s}$ in each case, given that the percentage of straw in the sample is closely related to the effective diameter of particles. Table 4 shows that $\mathrm{U}_{\mathrm{ms}}$ is slightly affected by the addition of straw to the system $(H=45 \mathrm{~cm})$. This

Table 3: Influence of bed height on $\mathrm{U}_{\mathrm{ms}}$ (percentage rice straw = $10 \%)$.

\begin{tabular}{lrrr}
\hline$H(\mathrm{~cm})$ & 25 & 35 & 45 \\
$\mathrm{U}_{\mathrm{ms}}(\mathrm{m} / \mathrm{s})$ & 0.500 & 0.556 & 0.625 \\
\hline
\end{tabular}

Table 4: Influence of percentage of rice straw on $U_{m s}(H=45 \mathrm{~cm})$.

\begin{tabular}{lrrr}
\hline Percentage straw $(\% \mathrm{v} / \mathrm{v})$ & 0 & 10 & 20 \\
$\mathrm{U}_{\mathrm{ms}}(\mathrm{m} / \mathrm{s})$ & 0.625 & 0.625 & 0.667 \\
\hline
\end{tabular}

behaviour is also in accordance to previously discussed results (Figure 6) in which the range of stable operational conditions remained constant for the different mixtures under study and also in agreement with previous observations in rectangular spouted reactors [13, 14].

Several correlations have been proposed to predict $\mathrm{U}_{\mathrm{ms}}$. The validity of these correlations for the calculation of the minimum spouting velocity for rice straw with a conical square-based SBR was studied. The following correlations (eq. 4-7) based on empirical considerations were evaluated:

Mathur and Gishler, 1955 [10]

$$
U m s_{M G}=\left(\frac{d_{\text {peff }}}{D_{C}}\right)\left(\frac{\rho_{\text {eff }}-\rho_{\text {air }}}{\rho_{\text {air }}}\right)^{0.5}\left(\frac{D i}{D_{C}}\right)^{1 / 3} \sqrt{2 g H}
$$

Choi and Meisen [15]

$$
\begin{aligned}
\operatorname{Ums}_{C M}= & 18.5\left(\frac{d_{\text {peff }}}{D_{C}}\right)^{1.19}\left(\frac{\rho_{\text {eff }}-\rho_{\text {air }}}{\rho_{\text {air }}}\right)^{0.263}\left(\frac{D i}{D_{C}}\right)^{0.373} \\
& \left(\frac{H}{D_{C}}\right)^{-0.103} \sqrt{2 g H}
\end{aligned}
$$

Olazar et al. [16]

$$
\operatorname{Ums}_{O}=\left(\frac{d_{\text {peff }}}{D_{C}}\right)\left(\frac{\rho_{\text {eff }}-\rho_{\text {air }}}{\rho_{\text {air }}}\right)^{0.5}\left(\frac{D i}{D_{C}}\right)^{0.1} \sqrt{2 g H}
$$

Anabtawi [17]

$$
\begin{aligned}
U^{\prime} s_{A}= & 0.25\left(\frac{d_{\text {peff }}}{D_{C}}\right)^{0.65}\left(\frac{\rho_{\text {eff }}-\rho_{\text {air }}}{\rho_{\text {air }}}\right)^{0.5}\left(\frac{D i}{D_{C}}\right)^{0.312} \\
& \left(\frac{H}{D_{C}}\right)^{0.254} \sqrt{2 g H}
\end{aligned}
$$

Different cases of application were taken into account from the previous correlations: cylindrical reactors-eq. (4), conical reactors-eq. (6), influence of the properties of solids-eq. (5) and square cross section-eq. (7). However, none of them fulfil the exact operational conditions applied to this work.

Table 5 gathers the results for $U_{m s}$ when eq. (4)-(7) are applied to the experimental values and their associated error values $\left(\operatorname{Error}(\%)=\left(\mathrm{Ums}_{\text {correlation }}-\mathrm{Ums}_{\mathrm{exp}}\right) /\right.$ $U m s_{\text {correlation }} \times 100$ ).

As it can be concluded from the table, none of the available correlations predicted well the $U_{\mathrm{ms}}$ associated to the spouting of the mixture silica - straw in a SBR with a square cross section. Moreover, the predictions tended to fail in higher percentage with the increase of rice straw in the bed of particles. This fact can be explained by the complex influence of the geometry of the reactor and the physical properties of solids on the spouting behaviour. 
Table 5: Values of $U_{m s}$ according to correlation methods.

\begin{tabular}{|c|c|c|c|c|c|c|c|c|c|}
\hline Experimental conditions $\left(d_{\text {peff }} / H\right)$ & $U_{m s} \exp (m / s)$ & $\mathrm{U}_{\mathrm{ms} \mathrm{MG}}(\mathrm{m} / \mathrm{s})$ & Error (\%) & $\mathrm{U}_{\mathrm{ms} \mathrm{CM}}(\mathrm{m} / \mathrm{s})$ & Error (\%) & $\mathrm{U}_{\mathrm{ms}} \circ(\mathrm{m} / \mathrm{s})$ & Error (\%) & $\mathrm{U}_{\mathrm{ms} \mathrm{A}}(\mathrm{m} / \mathrm{s})$ & Error (\%) \\
\hline $1.4 \mathrm{~mm} / 25 \mathrm{~cm}$ & 0.444 & 0.366 & $-21 \%$ & 0.382 & $-16 \%$ & 0.594 & $25 \%$ & 0.575 & $23 \%$ \\
\hline $1.4 \mathrm{~mm} / 35 \mathrm{~cm}$ & 0.556 & 0.433 & $-28 \%$ & 0.436 & $-27 \%$ & 0.703 & $21 \%$ & 0.741 & $25 \%$ \\
\hline $1.4 \mathrm{~mm} / 45 \mathrm{~cm}$ & 0.625 & 0.491 & $-27 \%$ & 0.482 & $-30 \%$ & 0.797 & $22 \%$ & 0.895 & $30 \%$ \\
\hline $2.1 \mathrm{~mm} / 45 \mathrm{~cm}$ & 0.625 & 0.735 & $15 \%$ & 0.780 & $20 \%$ & 1.194 & $48 \%$ & 1.163 & $46 \%$ \\
\hline $2.8 \mathrm{~mm} / 45 \mathrm{~cm}$ & 0.667 & 0.978 & $32 \%$ & 1.098 & $39 \%$ & 1.589 & $58 \%$ & 1.399 & $52 \%$ \\
\hline
\end{tabular}

This gives the available correlations a restricted range of dimensions of the reactor and properties of gas and particles involved in which they can be applied with successful results.

In order to obtain a significant relation between the variables of the process and the specific SBR under study, a complex multiple regression analysis was performed by fitting the experimental values to an expression with the form:

$$
\frac{U_{m s}}{\sqrt{2 g H}}=A\left(\frac{d_{p e f f}}{D_{C}}\right)^{a}\left(\frac{H}{D_{C}}\right)^{b}\left(\frac{\rho_{\text {eff }}-\rho_{\text {air }}}{\rho_{\text {air }}}\right)^{c}\left(\frac{D i}{D_{C}}\right)^{d}
$$

As a result of the fitting process, the expression that best described the relation between all the variables involved in the process of spouting for the system silica-rice straw was:

$\frac{U_{m s}}{\sqrt{2 g H}}=0.6\left(\frac{d_{p e f f}}{D_{C}}\right)^{0.524}\left(\frac{H}{D_{C}}\right)^{0.191}\left(\frac{\rho_{\text {eff }}-\rho_{\text {air }}}{\rho_{\text {air }}}\right)^{0.232}\left(\frac{D i}{D_{C}}\right)^{0.158}$

Table 6 shows the values of $U_{m s}$ according to (9) along with their associated error values:

Table 6: Values of $U_{m s}$ according to eq. (9).

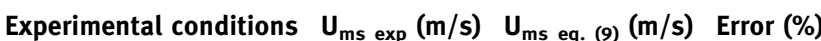
$\left(d_{\text {peff }} / H\right)$

\begin{tabular}{lllr}
\hline $1.4 \mathrm{~mm} / 25 \mathrm{~cm}$ & 0.444 & 0.447 & $1 \%$ \\
$1.4 \mathrm{~mm} / 35 \mathrm{~cm}$ & 0.556 & 0.564 & $1 \%$ \\
$1.4 \mathrm{~mm} / 45 \mathrm{~cm}$ & 0.625 & 0.671 & $7 \%$ \\
$2.1 \mathrm{~mm} / 45 \mathrm{~cm}$ & 0.625 & 0.829 & $25 \%$ \\
$2.8 \mathrm{~mm} / 45 \mathrm{~cm}$ & 0.667 & 0.963 & $31 \%$ \\
\hline
\end{tabular}

The proposed correlation predicts with high level of accuracy the value of $U_{m s}$ for low particle diameters at every height of bed. However, higher percentages of error are obtained as the concentration of coarse particles increases in the sample, but lower than those predicted by the previous correlations (eq. 4-7) in all cases. This fact reinforces the hypothesis that the geometry and physical properties of solids have a great influence on the spouting behaviour and more tests with different values of $d_{\text {peff }}$ will be required to correctly tune the expression for the case of bigger particles $\left(d_{\text {peff }}>2.1 \mathrm{~mm}\right)$.

For validation purposes, the obtained equation was applied to data from other authors (Table 7) whose studies were performed with solids with similar properties as the studied in the present work [18]:

As expected, the best results were obtained for the smallest diameters of particle and the percentage of error was below $30 \%$ in all cases.

\section{Conclusions}

Rice straw was used as feedstock in a conical squarebased spouted bed reactor with silica acting as inert material. The fluidynamic behaviour of the system was studied in order to assess the main defining parameters of the technology for its further scale-up.

Three different initial bed heights were tested $(25,35$ and $45 \mathrm{~cm})$ and the percentage of rice straw was also varied $(0,10 \%$ and $20 \% \mathrm{v} / \mathrm{v})$.

The highest pressure drop values were those with the highest initial bed heights and the increasing percentage

Table 7: Experimental data fitted to eq. (9).

\begin{tabular}{|c|c|c|c|c|c|c|c|c|c|}
\hline Dc (m) & Di (m) & $H(\mathrm{~m})$ & $d_{\text {peff }}(\mathrm{m})$ & $\rho_{\text {eff }}\left(\mathrm{kg} / \mathrm{m}^{3}\right)$ & $\rho_{\text {air }}\left(\mathrm{kg} / \mathrm{m}^{3}\right)$ & $\alpha$ & $U_{m s \exp }(m / s)$ & $U_{\text {ms eq. (9) }}(\mathrm{m} / \mathrm{s})$ & Error (\%) \\
\hline 0.240 & 0.366 & 0.290 & 0.0027 & 1385 & 1.06 & 60 & 0.759 & 0.544 & $28 \%$ \\
\hline 0.240 & 0.308 & 0.370 & 0.0027 & 1385 & 1.04 & 60 & 0.808 & 0.646 & $20 \%$ \\
\hline 0.152 & 0.019 & 0.396 & 0.0011 & 2960 & 1.205 & 60 & 0.580 & 0.670 & $16 \%$ \\
\hline
\end{tabular}


of straw resulted in slight instabilities during the spouting.

The minimum spouting velocity increased with the increase of the bed height. The presence of coarse particles and consequently, a bigger dimension of particle in the bed, resulted in higher minimum spouting velocities. Existing correlations were applied but did not show a good agreement with the experimental data when the percentage of straw was increased. A new correlation for particles of small diameter $\left(d_{\text {peff }}<2.1 \mathrm{~mm}\right)$ was proved valid for the prediction of the minimum spouting velocity in a conical square-based spouted bed reactor.

\section{Nomenclature}

$$
\begin{aligned}
& D_{\mathrm{c}}, D_{\mathrm{i}}, D_{\mathrm{m}} \\
& d_{\text {peff }} \\
& H, H_{\mathrm{C}}, H_{\mathrm{R}} \\
& \mathrm{U}_{\mathrm{in}}, \mathrm{U}_{\mathrm{ms}}
\end{aligned}
$$

column, spout inlet and bed bottom diameter (m) effective particle diameter $(\mathrm{m})$

height of the static bed, conical section and total of

\begin{tabular}{|c|c|}
\hline$\Delta \mathrm{P}_{\mathrm{b}}$ & pressure drop along the bed of particles $\left(\mathrm{mm} \mathrm{H}_{2} \mathrm{O}\right)$ \\
\hline$\Delta \mathrm{P}_{\text {bmax }}, \Delta \mathrm{P}_{\mathrm{s}}$ & $\begin{array}{l}\text { maximum and stable pressure drop along the bed } \\
\text { of particles }\left(\mathrm{mm} \mathrm{H}_{2} \mathrm{O}\right)\end{array}$ \\
\hline$\Delta \mathrm{P}_{\mathrm{d}}$ & $\begin{array}{l}\text { difference between conventional fluidization and } \\
\text { spouting pressure drops }\left(\mathrm{mm} \mathrm{H}_{2} \mathrm{O}\right)\end{array}$ \\
\hline$\Delta \mathrm{P}_{\mathrm{T}}$ & total pressure drop of the system $(\mathrm{mmHg})$ \\
\hline A & base angle \\
\hline & air density $\left(\mathrm{kg} / \mathrm{m}^{3}\right)$ \\
\hline & effective particle density $\left(\mathrm{kg} / \mathrm{m}^{3}\right)$ \\
\hline
\end{tabular}
the reactor $(\mathrm{m})$ fluid inlet and minimum spouting velocity $(\mathrm{m} / \mathrm{s})$

Greek symbols

\section{References}

1. Lim JS, Manan ZA, Rafidah S, Alwi W, Hashim H. A review on utilisation of biomass from rice industry as a source of renewable energy. Renewable Sustainable Energy Rev 2012;16: 3084-94.

2. Tanger P, Field L, Jahn C, DeFoort M, Leach JE. Biomass for thermo-chemical conversion: targets and challenges. Front Plant Sci 2013;4:1-20, Article 218.
3. Fernandez-Akarregu A, Makibar J, Lopez G, Amutio M, Olazar M. Design and operation of a conical spouted bed reactor pilot plant $(25 \mathrm{~kg} / \mathrm{h})$ for biomass fast pyrolysis. Fuel Process Technol 2013;112:48-56.

4. Erkiaga A, Lopez G, Amutio M, Bilbao J, Olazar M. Influence of operating conditions on the steam gasification of biomass in a conical spouted bed reactor. Chem Eng J 2014;237:259-67.

5. San Jose M, Alvarez S, Garcia I, Peñas F. Conical spouted bed combustor for clean valorization of sludge wastes from paper industry to generate energy. Chem Eng Res Des 2014. DOI:10.1016/j.cherd.2014.01.008.

6. Lopez G, Erkiaga A, Amutio M, Bilbao J, Olazar M. Steam gasification of biomass in a conical spouted bed reactor with olivine and g-alumina as primary catalysts. Fuel Process Technol 2013;116:292-9.

7. Epstein N, Grace JR. Spouted and spout-fluid beds. Fundamentals and applications. Cambridge: Cambridge University Press, 2011.

8. Olazar M, San Jose MJ, Aguayo AT, Arandes JM, Bilbao J. Pressure drop in conical spouted beds. Chem Eng J 1993; 51:53-60.

9. Rovero G, Curti M, Cavaglià G. Optimization of spouted bed scale-up by square-based multiple unit design. (Chap. 16). In: Nawaz Z and Naveed S, Editors. Advances in chemical engineering. Croatia: InTech, 2012:405-34.

10. Mathur KB, Gishler PE. A study of the application of the spouted bed technique to wheat drying. J Appl Chem 1955;5:624-36.

11. Rovero G, Piccini N, Lupo A. Vitesses des particules dans les lits à jet tridimensional et semi-cylindriques. Entropie 1985;124: 43-9.

12. Geldart D. Type of gas fluidization. Powder Technol 1973;7: 285-92.

13. Epstein N, Chandnani PP. Gas spouting characteristics of fine particles. Chem Eng Sci 1987;42:2977-81.

14. Epstein N, Grace JR. Handbook of particulate science and technology. New York: Van Nostrand Reinhold, 1997.

15. Choi M, Meisen A. Hydridynamics of shallow, conical spouted beds. Can J Chem Eng 1992;70:916-24.

16. Olazar MS, Jose MJ, Aguayo AT, Arandes JM, Bilbao J. Hydrodynamics of nearly flat base spouted beds. Chem Eng J Biochem Eng J 1994;55:27-37.

17. Anabtawi MZ. Minimum spouting velocity for binary mixture of particles in rectangular spouted beds. Can J Chem Eng 1998;76:132-6.

18. Zhong W, Chen X, Grace JR, Epstein N, Jin B. Intelligent prediction of minimum spouting velocity of spouted bed by back propagation neural network. Powder Technol 2013;247:197-203. 


\section{Communication 4.II}

Statistical methodology for the assessment of a Spouted Bed Reactor preventing segregation phenomena.

C. Moliner, M. Curti, B. Bosio, G. Rovero, E. Arato

Manuscript 



\section{Statistical methodology for the assessment of a Spouted Bed Reactor preventing segregation phenomena}

Cristina Molinera ${ }^{a}$ Massimo Curtib, Barbara Bosioa, Giorgio Rovero ${ }^{b}$ and Elisabetta Arato ${ }^{a}$

a Dipartimento di Ingegneria Civile, Chimica e Ambientale (DICCA), Università degli Studi di Genova (UNIGE).

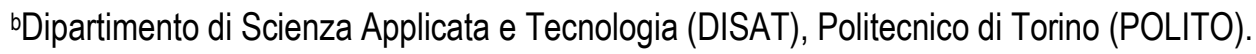

\section{ABSTRACT}

The influence of the physical characteristics of different binary mixtures of solids on the spouting regime of a square based spouted bed reactor was experimentally discussed. A further application of a methodology based on statistical design of experiments permitted to evaluate in a more precise way the effects of the variation of the tested variables (sphericity of inert solids and volumetric ratio and density of the second solid phase) on the response variables (air flow to maintain the spout and associated pressure drop along the bed of particles). For the particular system under study it was observed that similar density ratios between the solids composing the bed of particles improved the performance of the device in all cases. Segregation phenomena became more evident at volumetric ratios above $10 \% \mathrm{v} / \mathrm{v}$ regardless the second solid phase.

In general terms, the application of the described statistical methodology to different case scenarios can lead to the definition of the most adequate operational parameters in each case and can define the technical limits encountered by that specific system when treated in a spouted bed reactor.

Keywords: Design of Experiments, spouted bed reactor, segregation

Highlights

- Design of experiments applied to assessment of performance of Spouted Bed Reactor

- Similar density ratios between solids improved the performance of the system

- Segregation phenomena are present above the $10 \% \mathrm{v} / \mathrm{v}$ of second phase solid

- The described methodology is susceptible to be applied to different case scenarios 


\section{INTRODUCTION}

Spouted bed reactors (SBRs) were initially proposed as a suitable device to carry out the drying [1], granulation [2] and coating [3] of particles. The extensive development of the technology led to the application of SBRs to an increased number of industrial processes as biomass pyrolysis [4-7], biomass and coal gasification [8-11], reactions of polymerisation [12] or reforming of bio-oil [13, 14].

SBRs are obtained by replacing the perforated plate of a conventional reactor of fluidisation by a plate with a single orifice, normally centred in the base. This modification promotes the recirculation of solids within the reactor which results in increased mass and energy transfer rates respect to conventional techniques [15]. In addition, a conical base helps in the recirculation process and enables the movement of bigger and irregular particles in the device and helping overcome the difficulties that conventional reactors face when treating heterogeneous mixtures.

In practical terms, the gas enters the bed through a central orifice of the distributor plate causing the formation of a central spout in which the particles move upwards in a dilute phase. The annular space between the spout and the vessel wall contains a packed bed of particles, moving slowly downwards and radially inwards. According to the mechanism of the process, the reacting phase is drowned in an inert phase, generally different in shape and density. In a standard fluidised system, these two phases tend to migrate at different bed levels, being the main cause of segregation phenomena, and compromising the global behaviour of the system. In general, due to their particular configuration, SBRs have shown improved mixing of solids respect to fluidised beds provided they work in their optimum operational conditions. Nevertheless, segregation must be an important design factor that needs to be evaluated prior the application of SBRs in high temperature processes, where a good mixing is a key feature to obtain a uniform product.

Segregation problems arise mainly due to the difference of properties between the inert material and the second solid phase [16]. It can also occur as an inadequate choice of the applied operational conditions [17]. In this framework, little research has been done on the mixing/segregation behaviour of binary mixtures containing highly irregular shaped solids while presenting great differences in density and dimension between them. Its influence on the main operational parameters of the reactor requires a deep study in order to optimise the performance of the device and, accordingly, the final product yields.

With the objective of evaluating the potential segregation problems that a previously characterised squaredbase SBR may encounter in a defined range of conditions [18], several cold flow tests have been carried out with six different mixtures diverging in density, shape and dimension of particles. The effect of these variables on the operational parameters of the reactor (i.e. start-up, stable regime and prevention of segregation) has been studied in the present work by the application of a methodology based on statistical Design of Experiments $(\mathrm{DoE})$. A closer inspection of the statistical results permitted to define the range of operational factors for which the specific studied system works in optimum conditions while preventing segregation phenomena. The described methodology provides a tool susceptible to be applied to assess the performance of spouted bed reactors in different case scenarios. 


\section{Description of experimental methodology}

\subsection{Materials and methods}

Three different solids were used as inert materials (glass bead-Figure 1a, PET-Figure 1b and sand- Figure 1c) and two types of second phase solids (PVC- Figure $1 \mathrm{~d}$ and rice straw- Figure 1e) were tested.

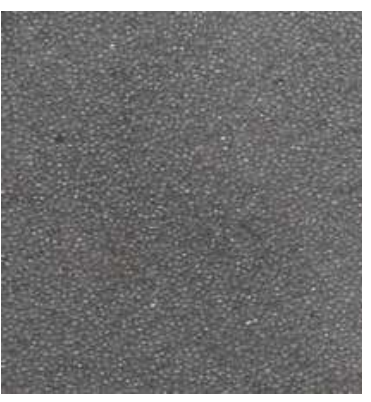

(a)

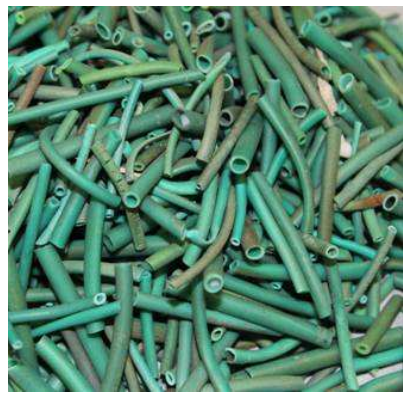

(d)

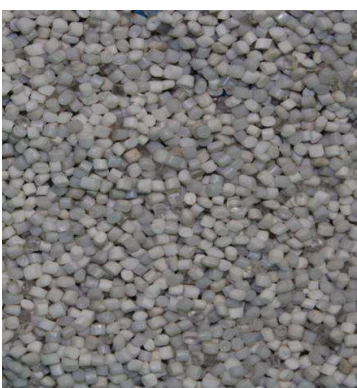

(b)

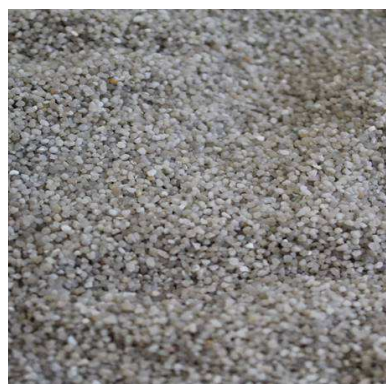

(c)

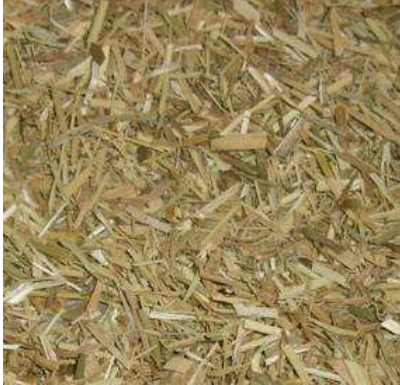

(e)

Figure 1. Solids used for the segregation studies

Table 1 gathers the physical characteristics of the solids used for the complete experimental campaign. For the purpose of these tests, the influence of the dimension of the second phase was beyond the scope of the present work and for that reason, PVC and straw were sieved to have similar diameters of particle.

Table 1 Physical properties of the solids used for the segregation studies

\begin{tabular}{lccc}
\multicolumn{1}{c}{ Material } & $\boldsymbol{\rho}_{\mathrm{p}}\left(\mathrm{kg} / \mathrm{m}^{3}\right)$ & $\mathrm{d}_{\mathrm{p}}(\mathrm{mm})$ & $\boldsymbol{\phi}$ \\
Glass & 1660 & 1.5 & 1.00 \\
PET & 857 & 2.5 & 0.87 \\
Sand & 1485 & 1.4 & 0.82 \\
Straw & 56 & 37 & 0.74 \\
PVC & 296 & 36 & 0.6
\end{tabular}




\subsection{Experimental set-up}

All the fluid dynamic experiments were performed at room temperature at the laboratories of the Department of Applied Science and Technology (DISAT) at the Politecnico di Torino. A previously described [18] lab-scale square-based spouted bed reactor was used for the present experimental campaign. The system is represented in Figure 2. It is composed by: (i) a blower supplying a maximum inlet air flow of $200 \mathrm{Nm}^{3} / \mathrm{h}$ provided by the Department facilities; (ii) a pressure probe located in the intern of the bed at $20 \mathrm{~cm}$ from the bottom and at $4 \mathrm{~cm}$ distance from the wall in the radial direction and connected to a water U-manometer and (iii) a conical squarebased half section device of $200 \times 100 \mathrm{~mm}$ made in wood with a plexyglass wall that enabled the visualisation of the spouting onset, the solid circulation pattern and the potential stability problems encountered by the system. All the experiments were repeated three times and the averaged value was taken as representative. The flow meter had an associated experimental error equal to $\pm 2 \mathrm{~m}^{3} / \mathrm{h}$.
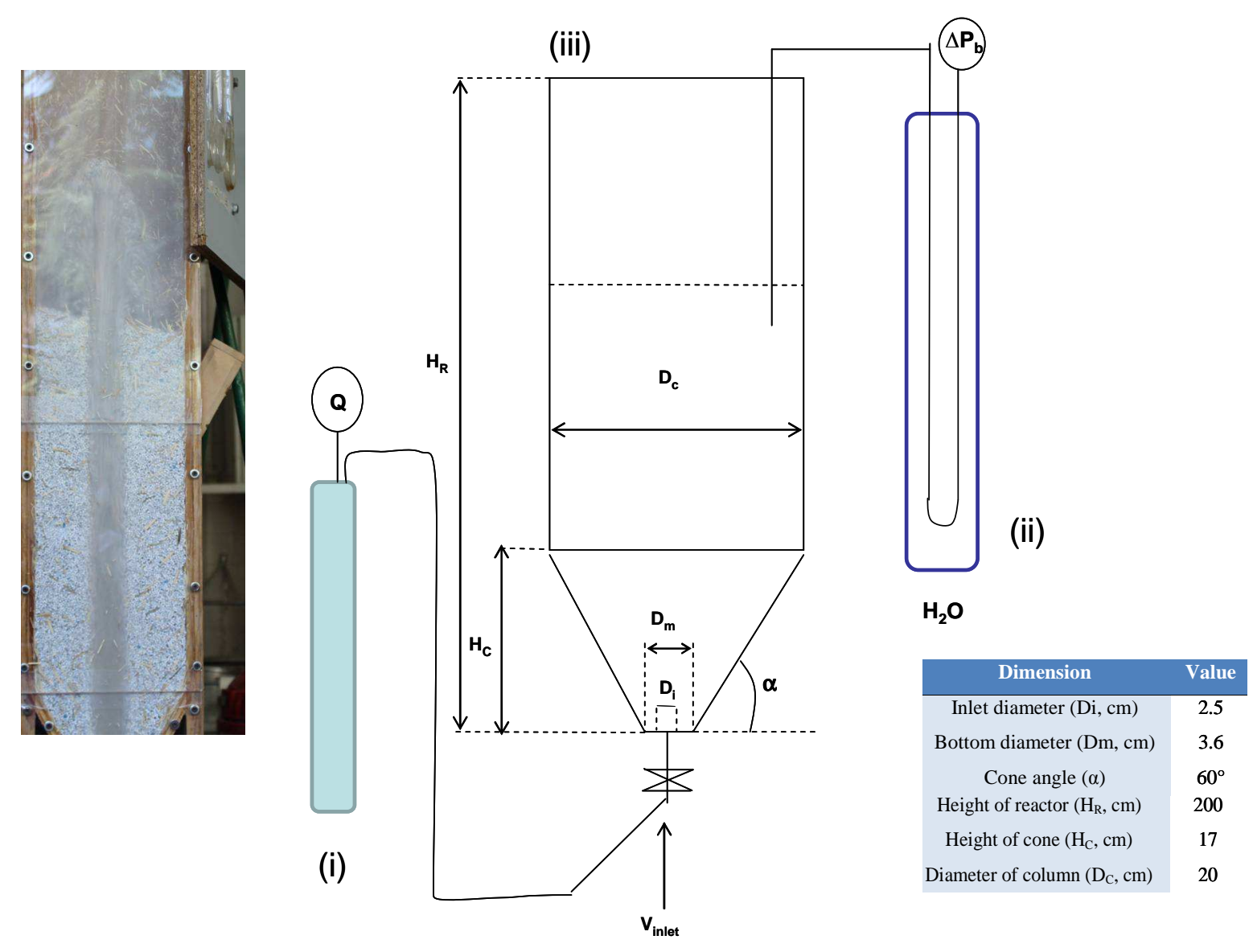

Figure 2. Scheme of the experimental set-up 


\subsection{Experimental procedure}

All the experiments were conducted following the procedure explained in previous works [18]. A desired quantity of second solid (biomass/PVC) was poured from the top of the reactor into the existing bed of particles (inert solids) until the desired initial bed height was achieved. The maximum volumetric ratio added to the inert bed of solids was set at $20 \% \mathrm{v} / \mathrm{v}$ according to previous results obtained on the device [18]. Bed heights were visually measured using a scale along the column height and its value was fixed at an initial bed height of $17 \mathrm{~cm}$ which corresponds to the cone height of the reactor.

In order to eliminate the influence of the uncontrolled initial packing state, prior to each experimental run, the conical spouted bed was pre-treated by increasing the superficial gas velocity to obtain full spouting and then decreasing the superficial gas velocity gradually to return to a reproducible initial fixed bed condition.

\subsection{Statistical approach}

DoE stands as a useful and reliable procedure to obtain the best combination of variables for the optimal running of the reactor and also permits to evaluate the influence of each variable (individually or in combination) on the quality of the response. DoEs are based on the study of the multiple input variables (Factors, F) that can be varied (Levels, $L$ ) to obtain the response variables (Effect, $E$ ). Any combination of $F$ and $L$ corresponds to a run in a practical experimentation. $\mathrm{F}$ can be quantitative (categorical variable) or qualitative (based on a continuous variable) [19]. The F/L (gathered in Table 3) under consideration were: sphericity of the inert material; volumetric ratio of coarse particles in the bed and density of the second solid phase.

Table 3 Summary of Factors $(F)$, Levels $(L)$ and general characteristics of the DoE applied for this study

\begin{tabular}{lccc}
\multicolumn{1}{c}{ Factor (F) } & Level (L) & Type & Values \\
\hline Sphericity & 3 & Quantitative & $0.82-0.87-1$ \\
Volumetric Ratio & 4 & Quantitative & $0-5-10-20$ \\
Density of second solid phase & 2 & Quantitative & $56-296$
\end{tabular}

The individual influence of each $\mathrm{F}$ through the different $\mathrm{L}$ was analysed by means of Main Effect Plots (MEP). The $E$ identified for the analysis were the experimental outputs of air inflow $(Q)$ and pressure drop $(\Delta P)$ at the three main stages of the process: start-up, stable operational conditions and minimum conditions to prevent segregation. More precisely, the studied parameters for each stage were:

- Start-up: $Q_{\text {onset }}$ and $\Delta P_{\text {onset }}$

- $\quad$ stable operational conditions: $Q_{m s}$ and $\Delta P_{m s}$

- conditions for the prevention of segregation: $Q^{*}$ and $\Delta P^{*}$

In addition, a visual characterization was performed to evaluate the existence of visual instabilities and, if so, the time until they were appreciated.

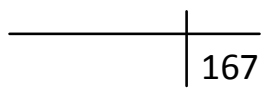




\section{Results and discussion}

\subsection{Overall visual characterisation}

From the visual observation of all the tested scenarios, it was observed that the bed was effectively mixed in a short time after the addition of both PVC and straw at low volumetric ratios, that is below a $5 \% \mathrm{v} / \mathrm{v}$ of the secondary phase. Figure 3 shows the degree of mixing of the bed of particles few seconds after the addition of $5 \% \mathrm{v} / \mathrm{v}$ rice straw. For beds containing ratios above a $10 \% \mathrm{v} / \mathrm{v}$ of second solid, the systems tended to get blocked after some minutes (or even just one minute for the highest tested ratio, $20 \% \mathrm{v} / \mathrm{v}$ ) when working at minimum spouting conditions (Figure 4).

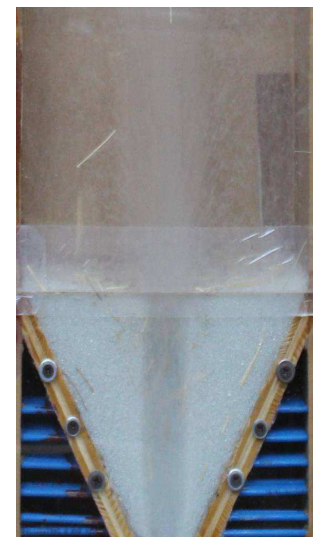

(a)

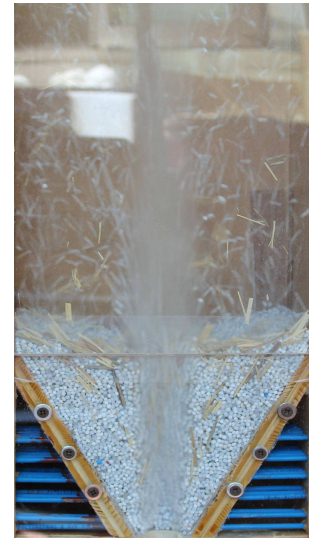

(b)

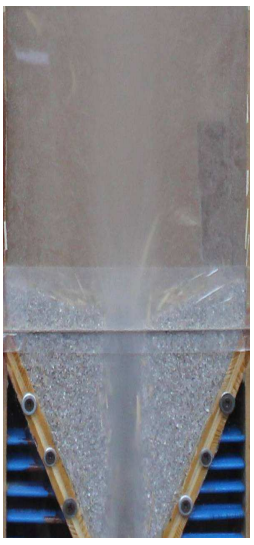

(c)

Figure 3. Degree of bed mixing at $5 \% \mathrm{v} / \mathrm{v}$ of coarse particles for the systems: glass-straw (a); PET-straw (b); sand-straw (c) few seconds after the addition of solids at minimum spouting conditions

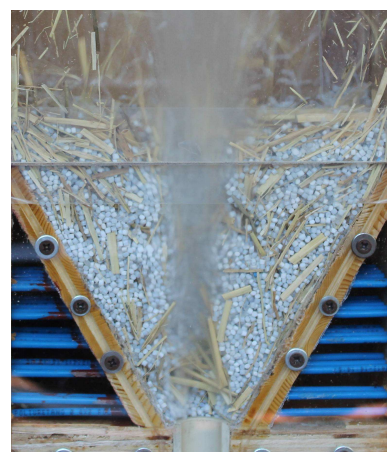

(a)

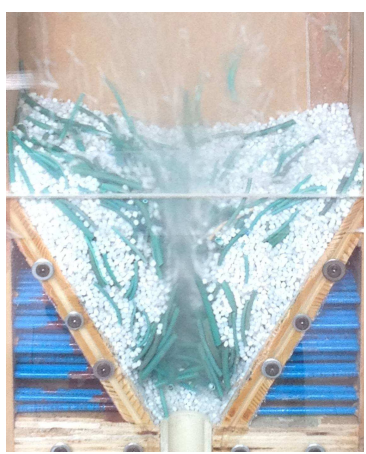

(b)

Figure 4. Degree of bed mixing at $20 \% \mathrm{v} / \mathrm{v}$ of straw (a) and PVC (b) in a bed of PET particles few seconds after the addition of solids at minimum spouting conditions

In this framework, the parameter $Q^{*}$ and its associated pressure drop along the bed of particles, $\Delta P^{*}$, was used to evaluate the potential segregation of the system. As previously mentioned, $Q^{*}$ was defined as the air inflow required to maintain stable spouting conditions for an infinite time while guaranteeing the absence of segregation phenomena. 
Finally, segregation was purposely induced to evaluate the time needed by the system to incur into stability problems and to define the preferential positions of solids in an eventual undesired situation. The system was left until blocked and re-activated afterwards by introducing air until proper conditions were achieved.

All the systems with the inert material and those with the mixtures containing a volumetric ratio below $5 \%$ of both PVC and rice straw were found to be stable in all situations and no segregation phenomena were observed neither in short nor long term.

On the contrary, at ratios above $10 \% \mathrm{v} / \mathrm{v}$ of PVC, the second phase tended to accumulate at the bottom of the reactor causing an eventual block of the inlet after a long time working in minimum spouting conditions (Figure $5 a$ and $5 b$ ). In this situation, the air required to shift from the new static bed into vigorous movement (Figure $5 c$ ) was higher than the initially registered $Q_{\text {onset, }}$ showing that a collapse of the fountain in case of failure can lead to enhanced difficulties for the start-up of the system. Despite this fact, the system achieved a well mixed degree after few seconds of high air flow inlet (Figure $5 \mathrm{~d}$ and $5 \mathrm{e}$ ).

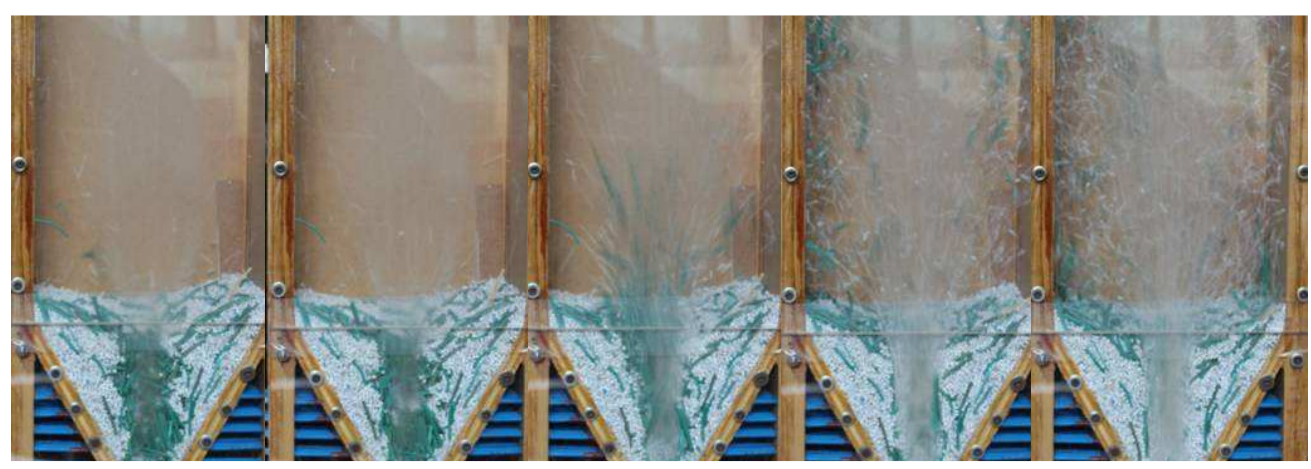

(a)

(b)

(c)

(d)

(e)

Figure 5. Evolution of the bed of particles composed by PET and PVC (at $20 \% \mathrm{v} / \mathrm{v}$ ) from an initial block to a well mixed situation through vigorous movement

The same overall behaviour was encountered when straw was used as the secondary phase. However, the fibrous shape of the straw led to enhanced block problems due to the easiness of the samples to inter-cross between them, especially at high volumetric ratios (10 and 20\%v/v). Those inter-crossed samples created preferential channels where the inert material continued with its regular recirculation and the straw tended to increasingly accumulate at the bottom until no more air was allowed to flow.

From these results it can be concluded that the particular properties of the second phase solid can lead to different operational problems and, for that reason, the definition of these specific difficulties in each case scenario may be crucial to achieve the optimum performance of the device. It is also important to highlight that, in addition to the fluid dynamic considerations evaluated in the present work, further thermo-chemical 
evaluations (beyond the scope of this paper) need to be performed when SBRs are applied with energy recovery purposes.

\subsection{Application of the Design of Experiments (DoE)}

In order to quantitatively characterise the spouting regime of the tested mixtures, a statistical DoE was applied. A full factorial design was used to evaluate the different operational conditions with the aid of the statistical software Minitab ${ }^{\odot}$.

Figure 6 shows the Main Effect Plots (MEP) of the DoE for the response variables $Q_{\text {onset }} / \Delta P_{\text {onset }}(a) Q_{m s} / \Delta P_{m s}$ (b) and $Q^{*} / \Delta P^{*}(c)$. The changes in the level means provided information concerning the factors that influenced the response the most. The horizontal line across the graphs is the grand mean, that is, the average of all data for a specific effect which is the reference value for data interpretation.
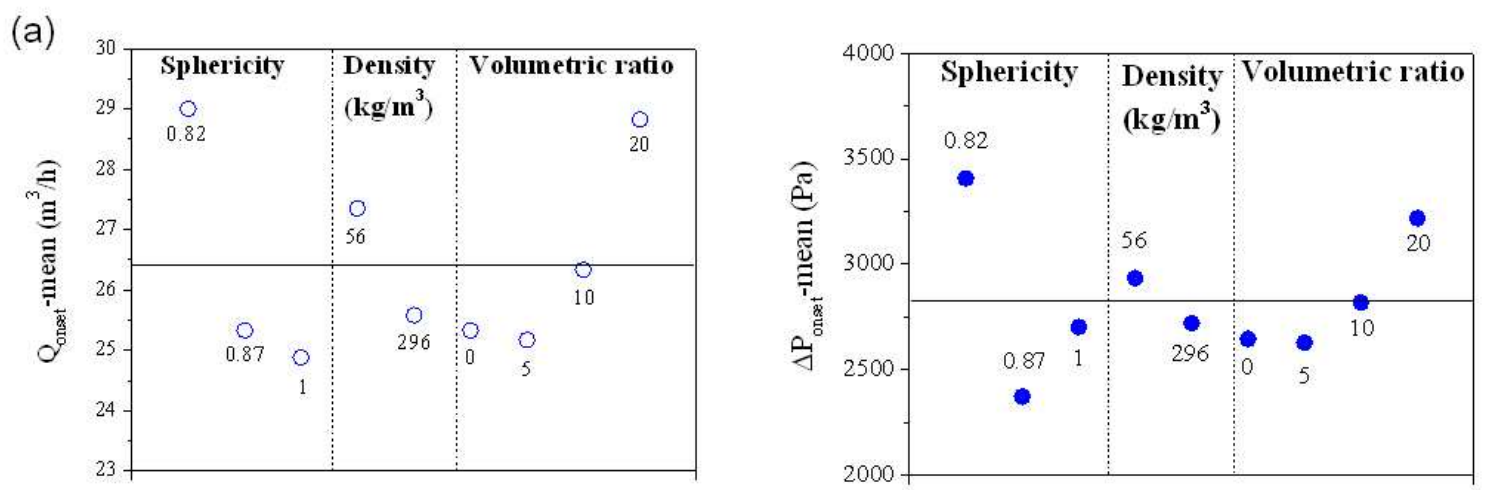

(b)
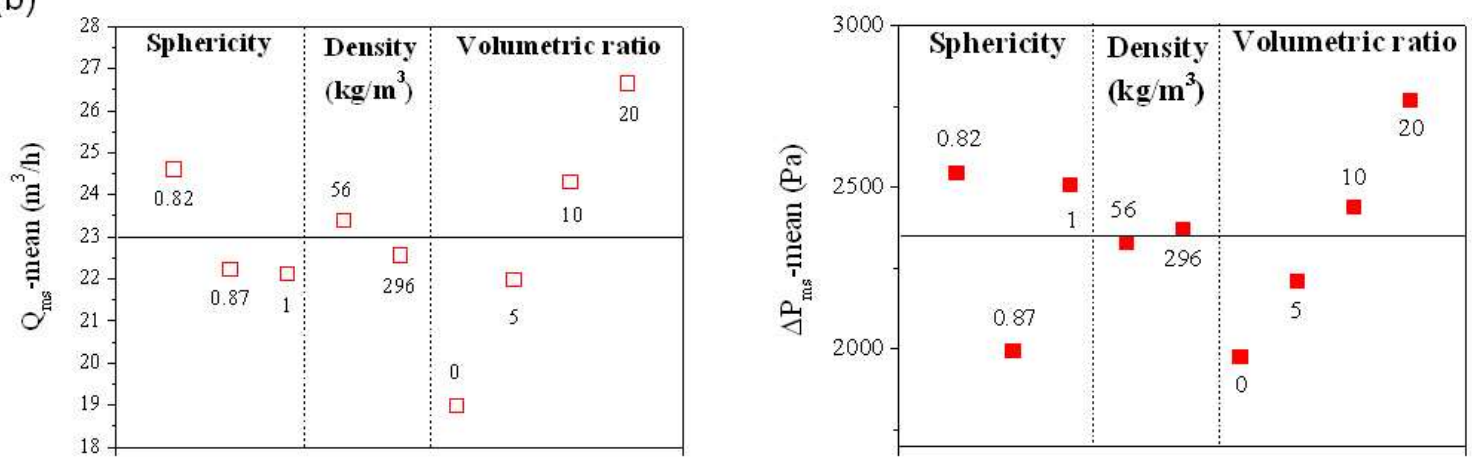

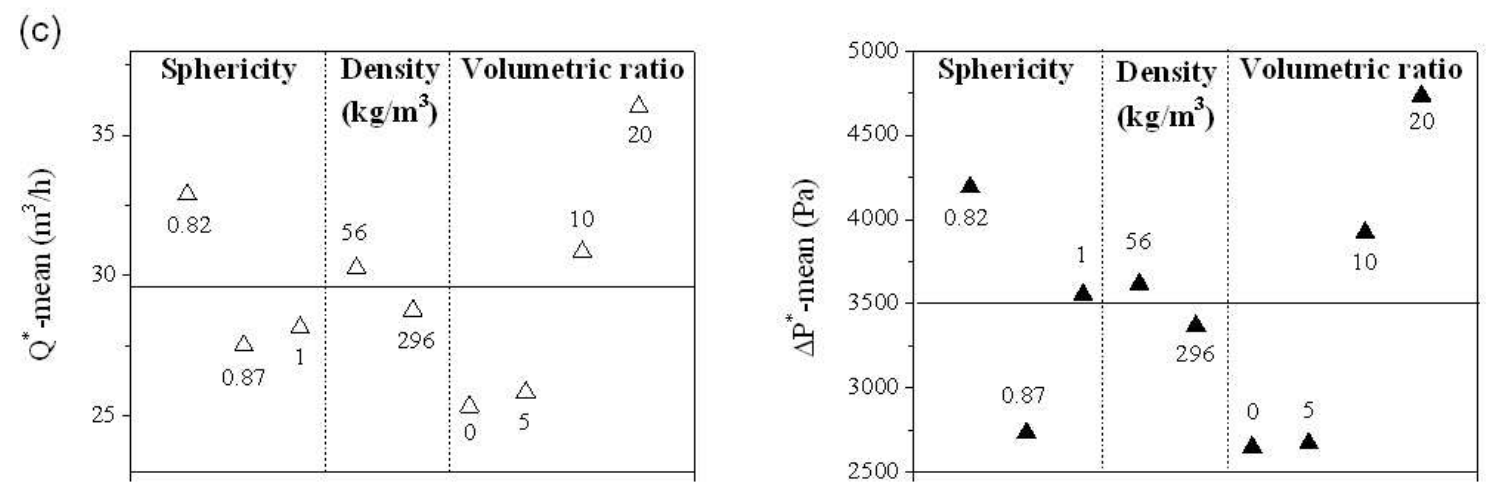

Figure 6. Main Effects Plot for the analysis of the start-up (a), operational (b) and prevention of segregation (c) conditions of the SBR

From the figure, the following interpretations can be drawn. Firstly, the more irregular shape of the solids composing the bed of particles, characterised by a lower sphericity, resulted in higher air requirements to start the spouting in all cases. However, opposed to what it would have been expected, the pressure drop along the bed of particles presented its minimum at 0.87 and not at the lowest sphericity value. This sphericity corresponds to PET which presents a more similar density than the other two inert solids respect to that of the added solid phase. As a result, a more homogeneous bed of particles results in a lower energy loss in the system. This fact also indicates the existence of a possible combined influence of the two variables (sphericity and relative densities) on the main responses under study that will be further discussed with the aid of Interaction Plots.

The difference in the absolute densities of the second phase (Straw: light phase; PVC: dense phase) mainly affected the start-up of the process as it is shown by the bigger deviation from the grand mean among the two materials in Figure $5 \mathrm{a}$.

Finally, it is evident that the required inflow air and its associated pressure drop values are mostly affected by the volumetric ratio of coarse particles in all cases, also in accordance to other authors [20]. Particularly, the conditions for the start-up (a) and the prevention of segregation phenomena (c) are mainly affected by ratios above $5 \% \mathrm{v} / \mathrm{v}$ whereas the operational conditions (b) follow an increasing linear trend within all the studied range. These results are also in accordance with the previous visual observations where the system was in risk of collapsing at the highest tested ratios.

Interaction Plots (IP) provide information about the general influence of all factors in combination. Figure 7 shows the IP for the three factors on the $Q_{\text {onset }}(\mathrm{a}-\mathrm{c})$ and $\Delta \mathrm{P}_{\text {onset }}(\mathrm{d}-\mathrm{f})$. 


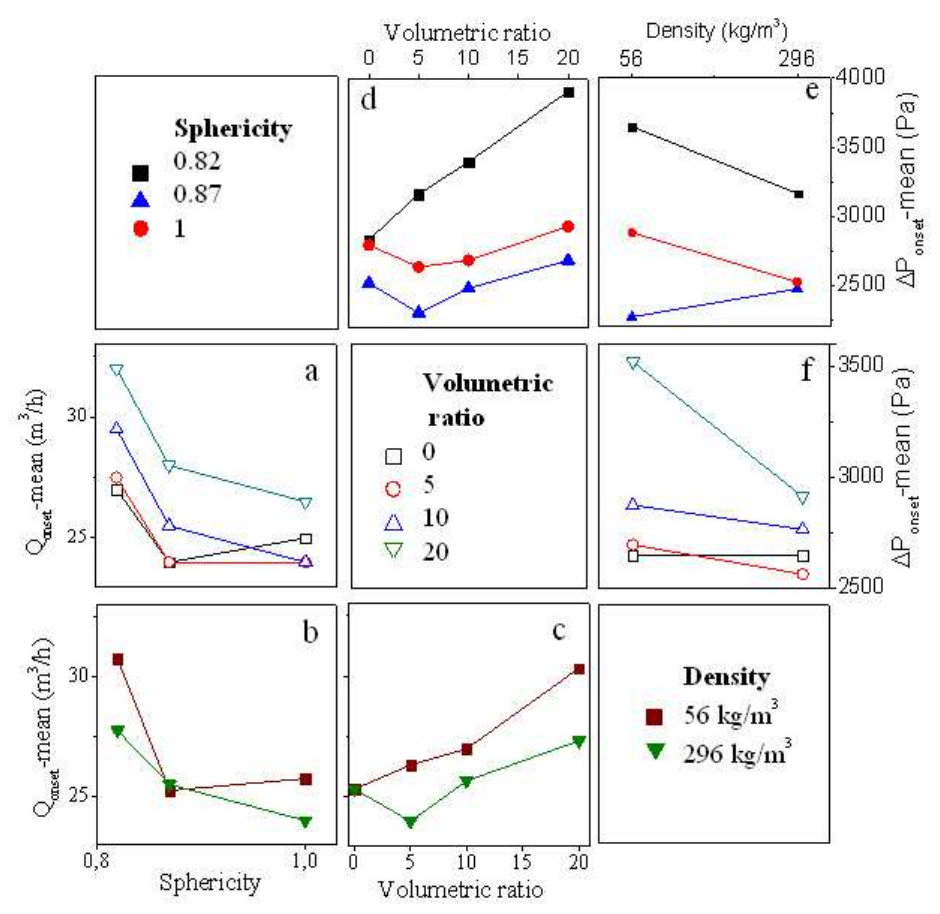

Figure 7. Interaction Plot for the analysis of the start-up conditions

Initially, for all sphericities, an increasing volumetric ratio resulted in an increased general trend for $Q_{\text {onset }}$ (Figure $7 \mathrm{a}$ ) and $\Delta \mathrm{P}_{\text {onset }}$ (Figure $7 \mathrm{~d}$ ) being this effect more appreciable for sphericities $=0.82$. In addition, the light material required more air to start its spouting at all tested ratios as shown in Figure 7c. Interestingly, in Figure $7 f$ the addition of light or dense materials showed little influence on $\Delta \mathrm{P}_{\text {onset }}$ at low volumetric ratios. However, this difference became more evident at ratios equal to $20 \%$ where it was appreciated the maximum difference between materials $(17 \%)$. In this situation, it could be concluded that dense materials improved the performance of the system at high volumetric ratios. Finally, the interaction between the sphericity of the inert material and the density of the added second solid showed different trends, as it was previously mentioned on the initial MEP. Figure $7 \mathrm{~b}$ shows that, at sphericities $=0.87$, the air required to start the spout was insensitive to the use of straw (light solid) or PVC (dense solid). On the contrary, light materials presented higher $Q_{\text {onset }}$ than dense solids for the other two tested sphericities. In this latter case, a positive effect on the $\Delta \mathrm{P}_{\text {onset }}$ was found when dense solids were used instead of light ones (Figure 7e) whereas the opposite trend was observed when PET was used as inert solid where the light material showed an improved spoutability.

From these results it can be concluded that the ratio of densities between the two solids composing the bed of particles has a great effect on the start-up process: similar density ratios improve the performance of the system in terms of energy losses in all cases. In addition, highly irregular inert solids provided the worst conditions of work regardless the quantity and type of second solid phase.

Similarly, the operational conditions (through the study of $Q_{m s}$ Figure $8(a-c)$ and $\Delta P_{m s}$ Figure $8(d-f)$ ) and the minimum requirements to prevent segregation phenomena (by the evaluation of $Q_{s t}$ Figure 9 (a-c) and $\Delta P_{\text {st }}$ Figure 9 (d-f)) were studied with the aid of Interaction Plots. 


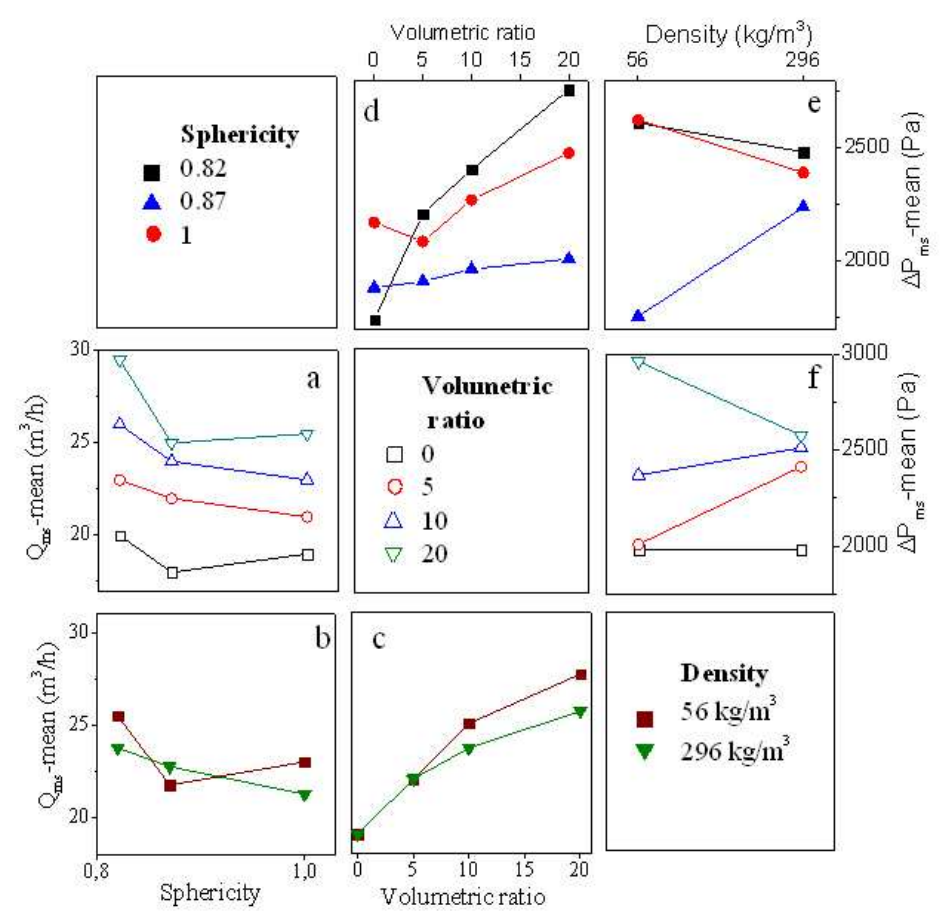

Figure 8. Interaction Plot for the analysis of the stable operational conditions

In general, all the studied effects presented lower values than those obtained in the previous stage confirming the fact that higher air requirements are needed to initiate the spout than to maintain the stable process according to the well- known hysteresis process that SBR present [5].

A deep insight in the figure shows that, as it happened before, an increasing volumetric ratio resulted in an increase general trend for the $Q_{m s}$ (Figure 8a) and $\Delta P_{m s}$ (Figure 8d). This effect was more appreciable for sphericities $=0.82$ whereas almost no variation was observed for sphericities $=0.87$. This fact can be attributed to the fact that the bed is composed by solids with similar densities in the latter case and, as a result, the addition of coarse particles does not modify in the same extent the properties of the bed. No effects on the air required to maintain the spout (Figure $8 \mathrm{c}$ ) were seen for any added solid at low volumetric ratios.

When this ratio was above 5\%, the difference on the flow between straw and PVC presented an increasing trend. Contrary to the observed behaviour during the start-up, the addition of coarse particles at low ratios negatively affected the $\Delta \mathrm{P}_{\mathrm{ms}}$. However, when the light solid was at $20 \%$, this trend reversed dramatically (Figure 8f). Moreover, the variability on $\Delta \mathrm{P}_{\mathrm{ms}}$ when a light solid is added to the bed (32\%) is much higher than that as a result of the addition of coarse particles $(6.3 \%)$ indicating that coarse particles lead to more stable spouting processes. Finally, the same behaviour as that described for the start-up was observed for $Q_{m s}$ (Figure 8b) and $\Delta \mathrm{P}_{\mathrm{ms}}$ (Figure $8 \mathrm{e}$ ) when light and coarse particles were added to the different inert solids. In this case, the differences on $\Delta \mathrm{P}_{\mathrm{ms}}$ for the most homogenous bed were higher $(21 \%)$ respect to the previous stage $(17 \%)$ indicating an enhanced influence of the relative density between solids on the stable spouting conditions.

Lastly, the minimum requirements to ensure the prevention of segregation phenomena are discussed from the results obtained in Figure 9. 


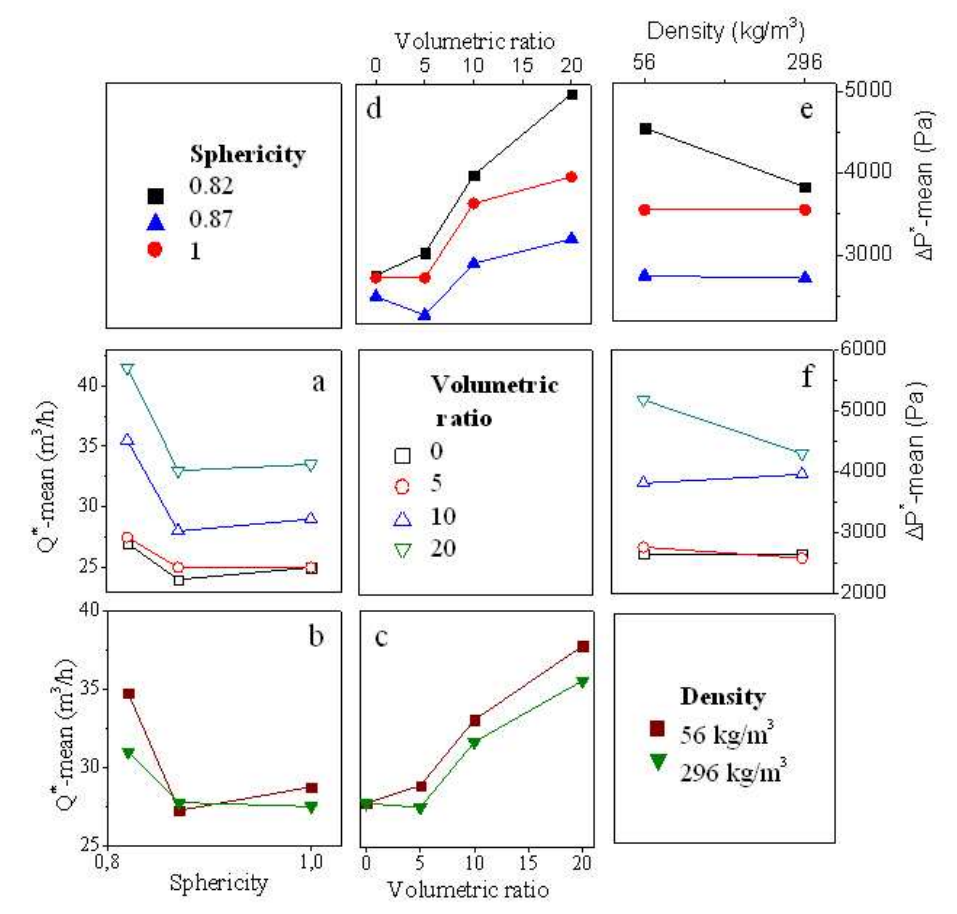

Figure 9. Interaction Plot for the analysis of the conditions to prevent segregation

From the figure it can be stated that the main factor inducing segregation is the volumetric ratio of the second solid in the bed of particles: higher ratios led to higher air requirements and higher pressure drop values in all cases (Figures 9a, c, $d$ and f). Little effect of the nature of the added solid on the $Q^{*}$ was observed (Figure 9c) and only the highest ratio showed a positive effect on the $\Delta \mathrm{P}^{*}$ when coarse particles were added instead of light solids (Figure 9f). The difference on the added solids did not show any influence on the $\Delta \mathrm{P}^{*}$ for high sphericities.

For the case of the most irregular inert solid, the addition of coarse particles resulted in a positive effect on the $\Delta \mathrm{P}^{*}$ respect to that obtained with light solids (Figure 9e). Finally, segregation phenomena were highly influenced by the density ratios between the solids present in the bed as in the previously discussed spouting stages. At similar density ratios, higher sphericity values led to lower air flow requirements to prevent segregation phenomena (Figures 8b).

\section{Conclusions}

Binary mixtures containing solids with very different physical properties were used to study the potential segregation phenomena occurring within a square-based spouted bed reactor. A methodology based on statistical studies permitted to evaluate the influence of the difference in properties between the two solids on the main operational parameters of the device. For the specific case under study, it was found that the most adverse conditions for the start-up of the system were obtained at the highest volumetric ratio of the light phase, limited to $20 \% \mathrm{v} / \mathrm{v}$ according to previous results. Similar density ratios between the solids improved the performance of the system in stable spouting conditions thanks to a higher homogeneity of the bed of particles. 
No segregation phenomena were encountered at low volumetric ratios of added solids whereas increasing values promoted instabilities and segregation phenomena, specially at $20 \% \mathrm{v} / \mathrm{v}$, accentuated by the fibrous nature of the straw that resulted in enhanced blocking problems.

The presented methodology, in general a quick and reliable tool to evaluate different set of experiments, could be applied to assess the performance of a spouted bed reactor in different case scenarios and to define the technological limits that the technology potentially presents for each specific case of study. 


\section{References}

[1] Magalhaes A., Pinho C. Spouted bed drying of cork stoppers- Chemical Engineering Process 47 (2008) 2395-2401

[2] Borini G.B., Andrade T.C., Freitas L.A.P Hot mel granulation of coarse pharmaceutical powders in a spouted bed reactor. Powder Technology 189 (2009) 520-527

[3] Da Rosa G.S., Dos Santos Rocha S.C. Effect of process conditions on particle growth for spouted bed coating of urea. Chemical Engineering Process 49 (2010) 836-842

[4] Fernandez-Akarregu A, Makibar J, Lopez G, Amutio M, Olazar M. Design and operation of a conical spouted bed reactor pilot plant (25 kg/h) for biomass fast pyrolysis. Fuel Process Technology 112 (2013) 48-56

[5] Amutio M., Lopez G., Artetxe M., Elordi G., Olazar M., Bilbao J. Influence of temperature on biomass pyrilysis in a conical spouted bed reactor. Resource Conserv. Recycl. 59 (2012) 23-31

[6] Makibar J., Fernandez-Akarregi A.R., Diaz L., Lopez G., Olazar M. Pilot scale conical spouted bed pyrolysis reactor: draft tube selection and hydrodynamic performance. Powder Technology 219 (2012) 49-58

[7] Lopez G., Olazar M., Aguado R., Bilbao J. Continuous pyrolysis of waste tyres in a conical spouted bed reactor. Fuel 89 (2010) 1946-1952

[8] Erkiaga A, Lopez G, Amutio M, Bilbao J, Olazar M. Influence of operating conditions on the steam gasification of biomass in a conical spouted bed reactor. Chem Eng J 237 (2014) 259-67

[9] Lopez G, Erkiaga A, Amutio M, Bilbao J, Olazar M. Steam gasification of biomass in a conical spouted bed reactor with olivine and g-alumina as primary catalysts. Fuel Process Technol116 (2013) 292-9

[10] Alghurabie I.K., Hasan B.O., Jackson B., Kosminski A., Ashman P.J. Fluidised bed gasification of Kigston coal and marine microalgae in a spouted bed reactor. Chem. Eng. Res.Des. 91 (2013) 1614-1624

[11] Bernocco D., Bosio B., Arato E. Feasibility study of a spouted bed gasification plant. Chem. Eng. Res. Des. 91 (2013) 843-855

[12] Beltramo C., Rovero G., Cavaglià G. Hydrodynamic and thermal experimentation on square-based spouted beds for polymer upgrading and unit scale-up. The Canadian Journal of Chemical Engineering 87 (2009) 394402

[13] Kechagiopoulos P.N., Voutetakis S.S., Lemonidou A.A., Vasalos I.A. Sustainable hydrogen production via reforming of ethylene glycol using a novel spouted bed reactor. Catal. Today 127 (2007) 246-255

[14] Kechagiopoulos P.N., Voutetakis S.S., Lemonidou A.A., Vasalos I.A. Hydrogen production via reforming of the aqueous phase of bio.oil over Ni/olivine catalysts in a spouted bed reactor. Ind. Eng. Chem. Res. 48 (2009) $1400-1408$ 
[15] Epstein N, Grace JR. Spouted and spout-fluid beds. Fundamentals and applications. Cambridge: Cambridge University Press, 2011

[16] J. Gao, X. Lan, Y. Fan, J. Chang, G. Wang, C. Lu, C. Xu. Hydrodynamics of gas-solid fluidized bed of disparately sized binary particles. Chem. Eng. Science 64 (20) (2009) 4302-4316

[17] A. Sahoo, G.K. Roy. Mixing characteristics of homogeneous binary mixture of regular particles in a gassolid fluidized bed. Powder Technology 159 (3) (2005) 150-154

[18] C. Moliner, M. Curti, B. Bosio, E. Arato, G. Rovero. Experimental tests with rice straw on a conical squarebased spouted bed reactor. International Journal of Chemical Reactor Engineering 13 (2015) 3, 351-358

[19] G.E. Box, J.S. Hunter, W.G. Hunter. Statistics for experimenters. Design, Innovation and Discovery. (2005) John Wiley \& Sons, New Jersey

[20] Anabtawi M.Z. Minimum spouting velocity for binary mixture of particles in rectangular spouted beds. The Canadian Journal of Chemical Engineering 76 (1998) 132-136 

CFD simulations of a square-based spouted bed reactor and validation with experimental tests using rice straw as feedstock.

D. Bove, C. Moliner, M. Curti, B. Bosio, G. Rovero, E. Arato.

Chemical Engineering Transactions, 43, 2015, 1363-1368.

DOI:10.3303/CET 1543228 



\title{
CFD Simulations of a Square-Based Spouted Bed Reactor and Validation with Experimental Tests Using Rice Straw as Feedstock
}

\author{
Dario Bove ${ }^{\star a}$, Cristina Moliner ${ }^{b}$, Barbara Bosio ${ }^{b}$ Elisabetta Arato ${ }^{b}$, Massimo Curtic, \\ Giorgio Rovero ${ }^{c}$ \\ ${ }^{\mathrm{a}}$ Faculty of Science and Technology, Free University of Bozen-Bolzano, Piazza Università 5, 39100 Bolzano, Italy \\ ${ }^{b}$ Department of Civil, Chemical and Environmental Engineering, University of Genoa, Via Opera Pia 15, 16145 Genoa, Italy \\ ${ }^{c}$ Department of Applied Science and Technology, Politecnico di Torino, C.so Duca degli Abruzzi 24, 10129 Torino, Italy \\ dario.bove@natec.unibz.it
}

The present work aims to develop a model to simulate the fluid dynamic behavior of processes related to the exploitation of biomass as energy source by means of gasification. In particular, the attention has been focused on a spouted bed reactor with a square base using rice straw as feedstock.

Spouted Bed reactors are attracting particular attention for their use in gasification processes. In these devices, the gas is introduced through a single nozzle at the center of the base and, as a result, a particular fluid dynamic pattern is followed which results in an enhanced solid circulation movement increasing therefore the mass and energy transfer rates.

A Computational Fluid Dynamic (CFD) modeling technique was used to simulate the previously described fluid flow. The Eulerian-Eulerian method was applied to predict the gas-solid flow behavior and the kinetic theory of granular flow was incorporated within the method as closure equation. The gas and particle dynamics were investigated through the simulation of different operational regimes by varying the gas flow rate at the inlet and the amount of initial solids in the initial bed of particles.

The obtained model was validated through experimental activities on a square based-reactor with a pyramidal bottom. Air was used as the gas phase and the particles were a mixture of rice straw and silica. The fluid dynamic parameters (minimum spouting velocity, Ums and pressure drop along the bed of particles, $\Delta \mathrm{P}$ ) of the system were recorded for each case and compared with the values provided by the developed model.

The resulting model will be used to optimize the fluid dynamic parameters defining the process and it will lead to an improvement of the gas-solid mass transfer and the minimisation of the energy requirements of the system.

\section{Introduction}

The first spouted bed was developed in 1954 as an alternative method for drying moist wheat particles with fluidized bed reactors, as they presented serious slugging problems (Gishler, 1983). Nowadays they are widely applied in various physical operations such as gasification, drying, coating and granulation (San José et al., 2010). A Spouted Bed Reactor is a device where gas (or occasionally liquid) is injected vertically upwards through a single central orifice into a bed of solid particles. If the flow rate of the fluid is sufficient and the bed depth is less than the "maximum spouted bed depth", the central jet breaks through the upper surface, resulting in a characteristic flow pattern known as spouting. Three regions can be distinguished in a spouted bed reactor: a dilute central jet, called "spout", in which particles are entrained, a peripheral annular region called "annulus" and a "fountain "region above the bed surface where entrained particles ascend centrally and then return less centrally due to gravity forces to land on the bed surface. In the annulus, fluid percolates outwards and upwards, counter-current to the movement of the particles (Epstein and Grace, 2011). The 


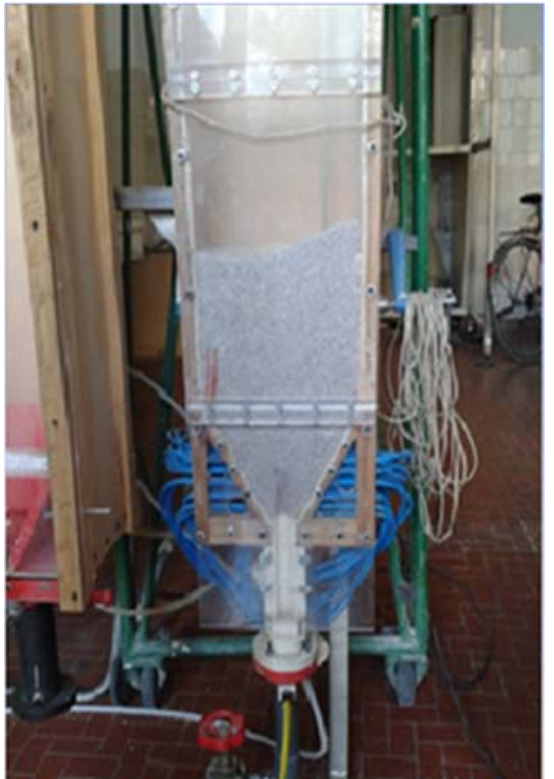

overall bed thereby becomes a composite of a dilute phase central core with upward moving solids entrained by a concurrent flow of fluid and a dense phase annular region with counter-current percolation of the fluid. A systematic cyclic pattern of solid movement is established with effective contact between the gas and the solids. The vessel forming a spouted bed is usually a circular cylinder, but sometimes it may have a square section. To enhance the solid motion and eliminate dead spaces at the bottom of the vessel, it is very common to use a diverging conical (or pyramidal) base (Altzibar et al., 2013).

Simulation activities are used to model the fluid behaviour of Spouted Bed reactors in order to design the equipment as precisely as possible. A deep study in spouted beds using appropriate multiphase models must be performed in order to understand what it is actually happening inside the fluidized bed. Computational fluid dynamic (CFD) modelling has become a powerful tool for understanding dense gas-solid systems thanks to the development of the computing power, the advance of numerical algorithms, and the deeper understanding of multiphase flow phenomena in the recent years.

Figure 1: Experimental system

Currently, there are two main CFD approaches: the Eulerian-Eulerian approach (two fluid model, TFM), and the Eulerian-Lagrangian (discrete element method, DEM) approach. In the Eulerian-Eulerian approach, the fluid and particulate phases are treated mathematically as interpenetrating continua. Several studies (Wang et al., 2006) have shown that this approach is capable of predicting gas-solids behaviour in spouted beds with high accuracy. In this approach, volume fractions of the overlapping phases are assumed to be continuous functions of space and time, with their sum always equal to one. The conservation equations have similar structure for each phase. Owing to the continuum description of the particle phase, two-fluid models require additional closure laws to describe particle-particle and particle-fluid interactions. In the Eulerian-Lagrangian approach, the fluid phase is treated as a continuum medium by solving the time-averaged Navier-Stokes equations, whereas the dispersed phase is solved by tracking a large number of individual particles through the computed flow field, not requiring additional closure equations (Cundall and Strack, 1979). The dispersed phase can exchange momentum, mass, and energy with the fluid phase, and interphase forces couples the two phases. However, it is much more computationally demanding, especially as the number of particles simulated becomes large.

\section{Experimental}

In a previous work (Moliner et al., 2014), low temperature essays were performed in a square-based spouted bed reactor using rice straw as feedstock and silica as inert bed material to characterize the fluid dynamic behaviour of the system in terms of pressure drop and height of the fountain. An air compressor, a flow meter and a conical spouted bed reactor compose the system. A half section device with a Plexiglas wall was used in order to better evaluate the fluid dynamic phenomena occurring inside the reactor. As proven elsewhere (Rovero et al, 1985) the wall did not add extra effects and the results obtained with this device are taken as valid to describe the behaviour of the whole reactor. The inlet distributor consists on a single orifice placed in the center of the base of the reactor. Rice straw was chopped and considered as a cylinder with constant diameter and an average length of $1 \mathrm{~cm}$. Different percentages of rice straw $(0 \% \mathrm{v} / \mathrm{v}, 10 \% \mathrm{v} / \mathrm{v})$ were tested for the present work. The effect of the height of the bed was assessed with values set at 25,35 and $45 \mathrm{~cm}$ for each experiment. Figure 1 shows the experimental system.

\section{Model equations}

In the present work, the TFM approach is adopted to model the complex gas-solid flow in a Spouted Bed reactor. The full Eulerian-Eulerian approach includes conservation equations of mass and momentum for each phase; closure equations, which requires a proper description of interfacial forces, solid stress, and turbulence phenomena of the phases; meshing of the domain, discretization of equations, and finally, solution algorithms. 


\subsection{Conservation equations of mass and momentum}

The volume fraction balance equation is:

$\sum_{q=1}^{n} \alpha_{q}=0$

where $\alpha_{q}$ is the volume fraction of the phase $q(q=g, s, r$ where $g$ is air, $s$ is silica and $r$ is rice)

The mass conservation equation for phase $q$ is:

$\frac{\partial}{\partial t}\left(\alpha_{q} \rho_{q}\right)+\nabla\left(\alpha_{q} \rho_{q} \vec{v}_{q}\right)$

where $\rho_{q}$ and $v_{q}$ are density and velocity of phase $q$ respectively

The momentum conservation equation for phase $q$ is:

$\frac{\partial}{\partial t}\left(\alpha_{q} \rho_{q} \vec{v}_{q}\right)+\nabla\left(\alpha_{q} \rho_{q} \vec{v}_{q} \vec{v}_{q}\right)=-\alpha_{q} \nabla P+\nabla \tau_{q}+\sum_{p=1}^{n} \vec{R}_{p q}+\alpha_{q} \rho_{q} \times\left(\vec{F}_{q}+\vec{F}_{l i f t, q}+\vec{F}_{v m, q}\right)$

where $P$ is the fluid pressure, $T_{q}$ is the Reynolds stress tensor, $R_{p q}$ is the interaction force between phases, $F_{q}$ is the external body force, $F_{\text {lift, } q}$ is the lift force and $F_{v m, q}$ is the virtual mass force.

The drag model chosen for defining the interaction silica-air and interaction rice-air is Huilin and Gidaspow (2003) model. This model uses the Ergun (1952) equation for dense phase calculations and the Wen and Yu (1966) equation for the case of dilute phases.

$\beta_{\text {Ergun }}=150 \frac{\left(1-\alpha_{g}\right)^{2} \mu_{g}}{\alpha_{g}^{2} d_{p}^{2}}+1.75 \frac{\left(1-\alpha_{g}\right) \rho_{g}}{d_{p}}|\vec{v}-\vec{u}| \quad \alpha_{g}<0.8$

$\beta_{W e n-Y u}=\frac{3}{4} \frac{\left(1-\alpha_{g}\right)}{d_{p}} \rho_{g} C_{D} \alpha_{g}^{-2.65}\left|\vec{u}_{g}-\vec{u}_{s}\right| \quad \alpha_{g} \geq 0.8$

where $\mu_{\mathrm{g}}$ is the air viscosity, $d_{p}$ is the particle diameter, $v$ is the particle velocity, $u$ is the gas velocity and the drag coefficient $C_{D}$ is defined as:

$C_{D}= \begin{cases}\frac{24}{\alpha_{g} R e_{p}}\left[1+0.15\left(\alpha_{g} R e_{p}\right)^{0.687}\right] & R e_{p}<1000 \\ 0.44 & R e_{p} \geq 1000\end{cases}$

$R e_{p}=\frac{\rho_{g}|\vec{v}-\vec{u}| d_{p}}{\mu_{g}}$

where $\alpha_{g}$ is the gas volume fraction and $\rho_{g}$ is the gas density.

To avoid the discontinuity of the two equations, a switch function is introduced in this model to give a rapid transition from one regime to the other one:

$\varphi_{g k}=\frac{\operatorname{arctg}\left[150 \times 1.75\left(0.2-\left(1-\alpha_{g}\right)\right)\right]}{\pi}+0.5$

Thus, the fluid-particle interaction coefficient can be expressed as:

$\beta=\left(1-\varphi_{g k}\right) \beta_{\text {Ergun }}+\varphi_{g k} \beta_{W e n-Y u}$

The drag model chosen for the interaction silica-rice is Syamlal-O'Brien-Symmetric (Syamal, 1987). In this model, the silica-rice exchange coefficient has the following form:

$K_{s r}=\frac{3\left(1+e_{s r}\right)\left(\frac{\pi}{2}+C_{f r, s r} \frac{\pi}{8}\right) \alpha_{s} \rho_{s} \alpha_{r} \rho_{r}\left(d_{s}+d_{r}\right)^{2} g_{0, s r}}{2 \pi\left(\rho_{s} d_{s}^{2}+\rho_{r} d_{r}^{2}\right)}\left|\vec{v}_{s}-\vec{v}_{r}\right|$

where $e_{s r}$ is the coefficient of restitution and $C_{f r, s r}$ is the coefficient of friction between the silica and rice phases. 


\subsection{Kinetic theory of granular flow}

The kinetic theory of granular flow is analogous to the kinetic theory of gases. The fluctuations that occur in the solid particle phase were modeled using the kinetic theory of granular flow to account for inelastic collisions between the particles. In this model, this theory is applied for silica and rice. In the following equations, the symbol $k$ is used to indicate phases $k$ ( $k=s, r$ where $s$ is silica and $r$ is rice).

The transport equation for the turbulent fluctuating energy of the phase $k$, also called granular temperature is:

$\frac{3}{2}\left[\frac{\partial}{\partial t}\left(\alpha_{k} \rho_{k} \theta_{k}\right)+\nabla\left(\alpha_{k} \rho_{k} \theta_{k} \vec{v}_{k}\right)\right]=\left(-P_{k} \cdot \vec{I}+\tau_{k}\right): \nabla \vec{v}_{k}+\nabla\left(h_{\theta_{k}} \nabla \theta_{k}\right)-\gamma \theta_{k}+\phi_{g k}$

where $\theta_{k}$ is the granular temperature, $\left(-P_{k} I+T_{k}\right): \operatorname{div}\left(v_{k}\right)$ is the generation of energy by the solid stress tensor, $h_{\theta k} \operatorname{div}\left(\theta_{k}\right)$ is the diffusion of energy, $\gamma \theta_{k}$ is the collisional dissipation of energy and $\phi_{g k}$ is the energy exchange between fluid and $k$ phase.

Granular flows can be classified into two distinct flow regimes: a rapidly shearing regime, in which stresses arise because of collisional or translational transfer of momentum, and a plastic or slowly shearing regime, in which stresses arise because of friction among particles in contact (Campbell 2006). Closure of the solid phase momentum equation requires a description of the solid phase stress that depends on the magnitude of the particle velocity fluctuations. The granular temperature conservative equation of Lun et al. (1984) expresses the kinetic solid pressure as:

$P_{k}=\alpha_{k} \rho_{k} \theta_{k}\left[1+2 g_{0, k k} \alpha_{k}\left(1+e_{k k}\right)\right]$

where $e_{k k}$ is the coefficient of restitution of particles and $g_{0, k k}$ is the radial distribution function.

Lun et al. (1984) defines the solid bulk viscosity as:

$\lambda_{k}=\frac{4}{3} \alpha_{k}^{2} \rho_{k} d_{p} g_{0, k k}\left(1+e_{k k}\right) \sqrt{\frac{\theta_{k}}{\pi}}$

and Ding and Gidaspow (1990) express the solid shear viscosity as:

$\mu_{k}=\frac{3}{5} \lambda_{k}+\frac{10 \rho_{k} d_{p} \sqrt{\pi \theta_{k}}}{90\left(1+e_{k k}\right) g_{0, k k}}\left[1+\frac{4}{5} g_{0, k k} \alpha_{k}\left(1+e_{k k}\right)\right]^{2}$

\subsection{Turbulence model}

The dispersed turbulence model is the appropriate model when the concentrations of the secondary phases are low or when using the granular model. Fluctuating quantities of the secondary phases can be given in terms of the mean characteristics of the primary phase and the ratio of the particle relaxation time and eddyparticle interaction time. The model is applicable when there is clearly one primary continuous phase and the rest are dispersed dilute secondary phases (Launder and Spaulding,1972). Therefore, the dispersed turbulence model is adopted in this study, where the standard $\mathrm{k}-\varepsilon$ model is used to obtain the turbulence predictions for the gas phase.

\section{Simulation procedure}

The commercial CFD simulation package FLUENT® is used to simulate the hydrodynamics of the spouted bed. The set of governing equations are solved by a finite control volume technique. The pressure-velocity coupling is obtained using the SIMPLE algorithm. The physical and numerical parameters of the experimental run and the inputs for the computer run are presented in Table 1.

\section{Results and discussion}

The output variables height of the fountain and pressure drop were studied and compared with the experimental results. Table 2 shows the comparison for the different amount of initial solid with $0 \%$ of rice straw while Table 3 gathers the equivalent results for the case of an initial bed of solids containing $10 \%$ of rice straw. 
Table 1: Physical and numerical parameters of the runs

\begin{tabular}{lll}
\hline Description & Experimental run & Computer run \\
\hline Solids density $\left(\mathrm{kg} / \mathrm{m}^{3}\right)$ & 2,600 & 2,600 \\
Rice straw density $\left(\mathrm{kg} / \mathrm{m}^{3}\right)$ & 238 & 238 \\
Gas density $\left(\mathrm{kg} / \mathrm{m}^{3}\right)$ & 1.225 & 1.225 \\
Diameter of the spout gas inlet $(\mathrm{cm})$ & 2.5 & 2.5 \\
Diameter of the bed $(\mathrm{cm})$ & 20 & 20 \\
Vessel height $(\mathrm{cm})$ & 200 & 200 \\
Particle solids diameter $(\mathrm{cm})$ & 0.141 & 0.141 \\
Particle rice straw diameter & $0.4 \div 1$ & 0.8 \\
Minimum spouting velocity $\mathrm{U}_{\mathrm{ms}}(\mathrm{m} / \mathrm{s})$ & $0.44-0.56-0.625$ & $0.44-0.56-0.625$ \\
\hline
\end{tabular}

Table 2: Fountain height and pressure drop for different heights of initial solids with $0 \% \mathrm{v} / \mathrm{v}$ of rice straw

\begin{tabular}{lllll}
\hline Parameter & Height initial solids & Experimental result & Simulation result & Error \% \\
\hline Fountain height $(\mathrm{cm})$ & $25 \mathrm{~cm}$ & 49.5 & 50.6 & +2.22 \\
Fountain height $(\mathrm{cm})$ & $35 \mathrm{~cm}$ & 64.0 & 64.8 & +1.25 \\
Fountain height $(\mathrm{cm})$ & $45 \mathrm{~cm}$ & 77.7 & 81.4 & +4.76 \\
Pressure drop $(\mathrm{Pa})$ & $25 \mathrm{~cm}$ & 196.1 & 775.7 & +295.77 \\
Pressure drop $(\mathrm{Pa})$ & $35 \mathrm{~cm}$ & 980.6 & 1212.5 & +23.64 \\
Pressure drop $(\mathrm{Pa})$ & $45 \mathrm{~cm}$ & $1,931.7$ & $2,157.4$ & +11.72 \\
\hline
\end{tabular}

Results in table were obtained by setting 0.85 the coefficient of restitution among the silica particles. The inlet gas velocity is set as $u_{x, 0}=0$ and $u_{y, 0}=\sigma U_{m s}$ where $\sigma$ is the geometric factor in the numerical model set as 40.764 .

Table 3: Fountain height and pressure drop for different heights of initial solids with $10 \% \mathrm{v} / \mathrm{v}$ of rice straw

\begin{tabular}{lllll}
\hline Parameter & Height initial solids & Experimental result & Simulation result & Error \% \\
\hline Fountain height $(\mathrm{cm})$ & $25 \mathrm{~cm}$ & 78.0 & 79.9 & +2.43 \\
Fountain height $(\mathrm{cm})$ & $35 \mathrm{~cm}$ & 93.0 & 93.4 & +0.43 \\
Fountain height $(\mathrm{cm})$ & $45 \mathrm{~cm}$ & 107.0 & 102.4 & -4.30 \\
Pressure drop $(\mathrm{Pa})$ & $25 \mathrm{~cm}$ & 294.2 & 894.3 & +203.97 \\
Pressure drop $(\mathrm{Pa})$ & $35 \mathrm{~cm}$ & 784.5 & 1324.3 & +68.67 \\
Pressure drop $(\mathrm{Pa})$ & $45 \mathrm{~cm}$ & $2,392.7$ & $2,559.36$ & +6.96 \\
\hline
\end{tabular}

Results in table were obtained by setting a value of 0.85 to the coefficient of restitution among the silica particles and a value of 0.3 for the case of silica and rice straw particles and among rice straw particles. The inlet gas velocity was set as $u_{x, 0}=0$ and $u_{y, 0}=h \sigma U_{m s}$ where $\sigma$ is the geometric factor and $h$ is the velocity correction coefficient in the numerical model with a value of 0.636 . The diameter of the solid particles was set as $\omega d_{s}$ where $d_{s}$ is the diameter of the solid particle and $\omega$ is the diameter correction coefficient set as 0.313 . The precise determination of the height of the fountain allows the identification of the main zone of the spouted Bed Reactor because in it occurs the main transfers of mass and energy. Moreover, it also permits the optimisation of the initial amount of solid and the velocity of the gas at the inlet in order to minimize the energy requirements of the system. However, the model does not provide good values for the predicted pressure drop especially in the cases with low height of initial solid. This error may be due to interference of the edge of the probe in the experimental measurement because the probe was located in the intern of the bed at $20 \mathrm{~cm}$ from the bottom. A potential solution is to change the position of the probe in the intern of the bed. In addition, an upgraded 3D model of the Spouted Bed Reactor might be necessary in order to obtain a better prediction of the pressure drop. The graphic simulation results are shown in Figure 2.

\section{Conclusions}

In this work, through the combination of experimental data and a numerical model, the fluid dynamic behaviour of a Spouted Bed Reactor was studied. The obtained data show that the model approximates with good results the height of the fountain in all cases with a maximum error of less than $5 \%$. This result allows identifying in advance the region where the fountain will develop, which is very important because in it takes place bulk transfers between gas and solids. However, this model does not provide, with the same precision, the predicted values of pressure drop. It is likely to be necessary an upgrading of the experimental apparatus 
and a setup of the 3D model of the SBR to obtain a correct prediction of the pressure drop. The calibration of the model for pressure drop is left for a future study.

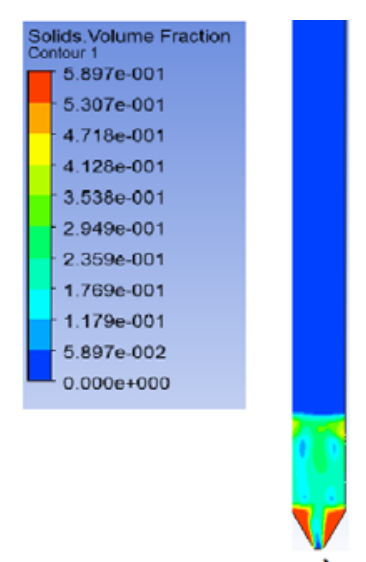

a)

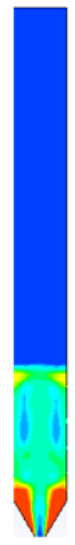

b)

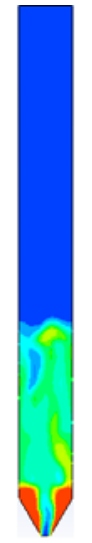

c)

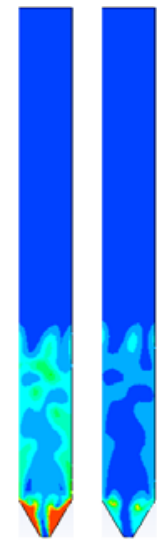

d)

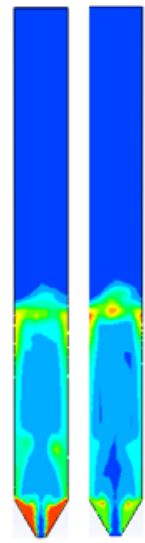

e)

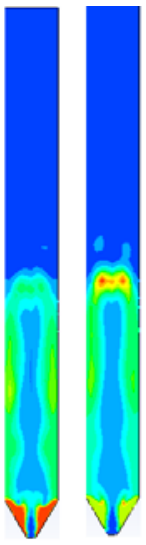

f)

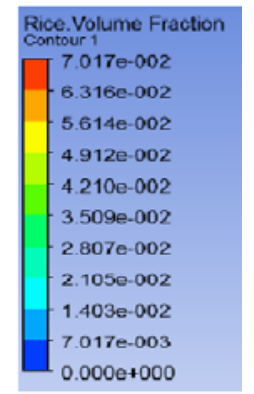

Figure 2: Volume fraction for different heights of initial solids with $0 \% \mathrm{v} / \mathrm{v}$ of rice straw: a) $25 \mathrm{~cm}, b) 35 \mathrm{~cm}, c)$ $45 \mathrm{~cm}$ and with $10 \% \mathrm{v} / \mathrm{v}$ of rice straw (on the right of the figures): d) $25 \mathrm{~cm}$, e) $35 \mathrm{~cm} \mathrm{f}) 45 \mathrm{~cm}$

\section{References}

Altzibar H., Estiati I., Olazar M., 2013, Influence of the geometric factors of conical contactors and draft tubes on the performance of draft tube conical spouted beds, Chemical Engineering Transactions, 32, 15431548

Campbell C.S., 2006 Granular material flows - an overview, Powder Technology, 162, 208-229.

Cundall P.A., Strack O.D.L., 1979, A discrete numerical model for granular assemblies, Geotechnique, 29, 47-65.

Ding J., Gidaspow D., 1990, A bubbling fluidization model using kinetic theory of granular flow, AIChE Journal, $36,523-538$.

Epstein N., Grace J.R., 2011, Spouted and Spout-Fluid Beds. Fundamentals and Applications, Ed. Cambridge University Press, Cambridge, United Kingdom.

Ergun S., 1952, Fluid flow through packed columns, Chemical Engineering Progress, 48, 89-94.

Gishler P.E., 1983, The spouted bed technique - discovery and early studies at N.R.C., The Canadian Journal of Chemical Engineering, 61, 267-268.

Huilin L., Gidaspow D., 2003, Hydrodynamics of binary fluidization in a riser: CFD simulation using two granular temperatures, Chemical Engineering Science, 58, 3777-3792,

Launder B.E., Spaulding D.B., 1972, Mathematical Models of Turbulence, Academic Press, London, England

Lun C.K.K., Savage S.B., Jeffrey D.J., Chepurniy N., 1984, Kinetic theories for granular flow: inelastic particles in Couette flow and slightly inelastic particles in a general flowfield, Journal of Fluid Mechanics, 140, 223256.

Moliner C., Curti M., Bosio B., Arato E., Rovero G., 2014, Experimental tests with rice straw on a squarebased spouted bed reactor, paper presented at the 13th International conference on multiphase flow in industrial plants, Sestri Levante, Italy, 17-19 September, Session 7, Lecture 3.

San José M.J., Alvarez, S., Morales A., López L.B., Ortiz de Salazar A., 2010, Diluted spouted bed at high temperature for the treatment of sludges wastes, Chemical Engineering Transactions, 20, 303-308.

Syamal M., 1987, The particle-particle drag term in a multiparticle model of fluidization, C National Technical Information Service, Springfield, VA, USA.

Rovero G., Piccinini N., Lupo A., 1984, Particles rates in tri-dimensional and semi-cylindrical jet beds (French), Entropie, 124, 43-49.

Wang Z.G., Bi H.T., Lim C.J., 2006, Numerical simulations of hydrodynamic behaviors in conical spouted beds, China Particuology, 4, 194-203.

Wen C.Y., Yu Y.H., 1966, Mechanics of fluidization, Chemical Engineering Progress Symposium Series, 62, $100-111$. 


\section{GASIFICATION IN SBR}

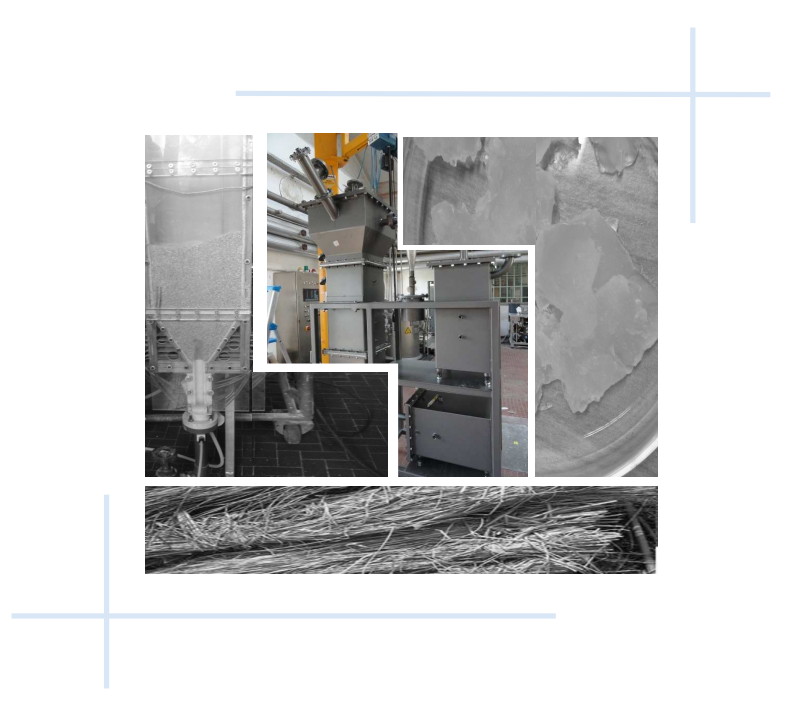

I Summary

5.1 Generalities on gasification reactions

5.2 Experimental studies on a SBR

5.3 Modelling activities

5.4 Main results

207

References in this chapter

208

Communications 

"The fundamental laws of thermodynamics will place fixed limits on technological innovation and human advancement" The 2nd law: unsustainable. Muse

\section{Summary}

The scope of this chapter is to describe the reactions of gasification occurring within a Spouted Bed Reactor.

The chapter is devoted to a brief insight on the reactions of gasification and the main variables influencing the process. After that, the description of the experimental activities carried out in Biella (Politecnico di Torino) including a description of the SBR pilot plant used, the procedure carried out and relevant information about the experiments performed are explained. In addition, modeling activities at several levels of detail are considered, from an ideal situation to a more realistic view of the process.

The main results obtained from this chapter are presented in the following communications:

Communication 5I: C. Moliner, D. Bove, B. Bosio, A. Ribes, E. Arato. Feasibility studies on the energy valorization of agricultural residues using Aspen Plus ${ }^{\circledR}$. Proceedings of the $23 \mathrm{rd}$ European Biomass Conference and Exhibition, 803-809. (Vienna) 2015. DOI: 10.5071/23rdEUBCE2015-2DV.1.24

Communication 5II: C. Moliner, D. Bove, B. Bosio, A. Ribes, E. Arato. Simulation activities for the pseudo-equilibrium modeling of the gasification of agricultural residues. Accepted abstract at the 24th European Biomass Conference and Exhibition. (Amsterdam) 2016 
Communication $5 I I I$ C. Moliner, B. Bosio, A. Ribes, E. Arato. Process simulation of the gasification of rice straw by means of a spouted bed reactor based on its fluid dynamic and kinetic properties. Manuscript

Communication 5IV: C. Moliner, B. Bosio, E. Arato. Comparison and validation with experimental data of different modelling approaches for the gasification of agricultural residues. Abstract submitted to the 19th Conference on Process Integration, Modelling and Optimisation for Energy Saving and Pollution Reduction (Prague) 2016 


\subsection{Generalities on gasification reactions}

\subsubsection{Reactions of gasification}

The gasification of solid fuels is a complex thermo-chemical process comprising a sequence of steps presented in Figure 5.1. In particular, and after a drying process to remove the moisture, the gasification of biomass consists of two stages of physical changes and chemical reactions. The initial stage is the pyrolysis and it accounts for the thermal decomposition of the biomass to produce pyrolysis gases $\left(\mathrm{CO}, \mathrm{CO}_{2}, \mathrm{H}_{2}\right.$ and $\left.\mathrm{CH}_{4}\right)$, tar, char and a minor quantity of oxygenated compounds. The subsequent step consists of the chemical reactions among the pyrolysis gases, the gasification agent and the remaining char, all of them at high temperatures.

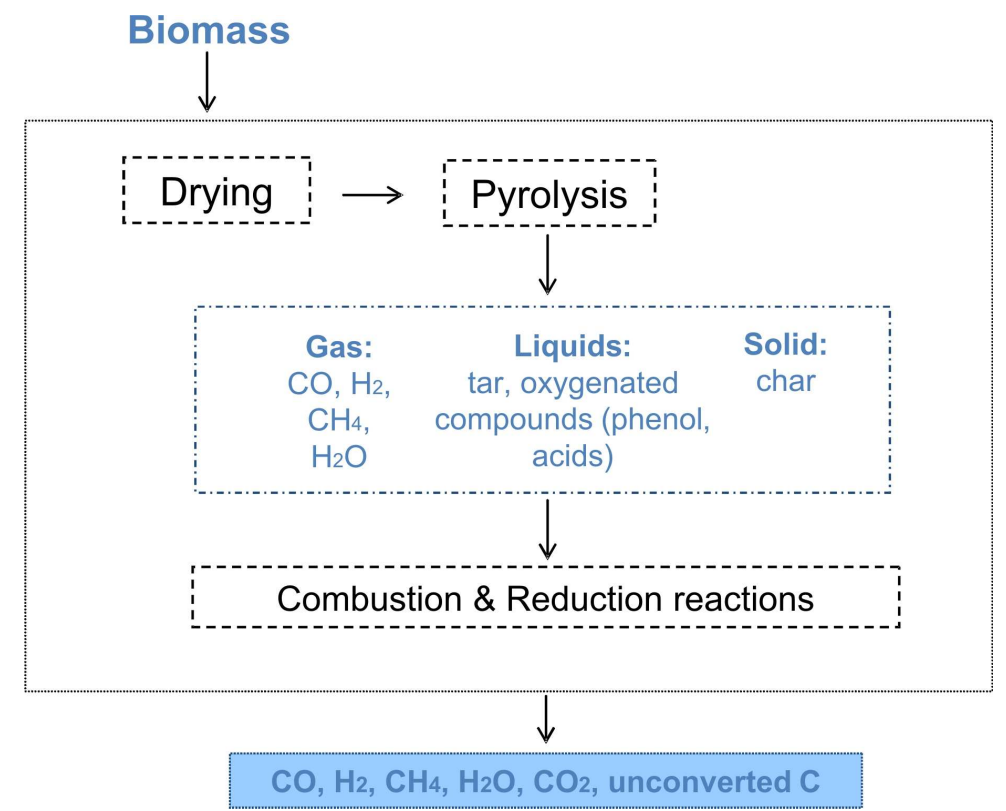

Figure 5.1. Scheme of the gasification of biomass

A more detailed description of each step is described in the following paragraphs.

Drying. Most of the gasification systems use dry biomass with moisture contents ranging between 10-20\%. A higher value results in a decrease of the overall efficiency of the process due to the high amount of energy required to initiate the gasification itself. In the drying step, the material is heated up to evaporate the moisture contained in the structure. This moisture can exist in different manners such as a liquid water in the voids (free water), chemically bonded to hydroxyl groups in the cell walls or vapour in void spaces. The moisture content can also vary

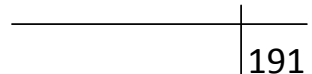


depending on the type of biomass ranging from a possible $30 \%$ in stems to up to $80 \%$ in leaves. With increasing contents of moisture, the heat consumption for drying and heating up the biomass to reach the temperatures of decomposition increases considerably.

The effect of the moisture content on the products distribution and the efficiency of the process has been discussed in Communication 5I.

Pyrolysis or devolatilisation. After drying, and with the increase of temperatures, a series of complex physical and chemical changes occur. The thermally unstable components of the biomass are broken down and evaporate with other volatile compounds. Generally, pyrolysis proceeds at a much quicker rate than the subsequent gasification reactions being the latter the rate controlling step in the overall process.

Combustion of carbon and hydrogen. The control of the oxidation rate of the biomass is one of the most important parameters in the chemical reactions taking place inside a gasifier. After the pyrolysis step, the gasifying agent (air, oxygen or vapour of water) is introduced in substoichiometric conditions into the reactor producing a partial oxidation of the carbon and hydrogen that are present in the biomass These reactions firstly produce CO (R5.1) and in addition, as a consequence of its exothermic character, the necessary heat to carry out the further endothermic reactions. If excess oxygen is supplied to the reactor, the thermo-chemical conversion becomes a complete combustion producing mainly the undesired $\mathrm{CO}_{2}$ and $\mathrm{H}_{2} \mathrm{O}$ (R5.2 and 5.3).

$$
\begin{aligned}
& \mathrm{C}+0.5 \mathrm{O}_{2} \rightarrow \mathrm{CO}+111 \mathrm{KJ} / \mathrm{mol} \\
& \mathrm{C}+\mathrm{O}_{2} \rightarrow \mathrm{CO}_{2}+393.77 \mathrm{KJ} / \mathrm{mol} \\
& 2 \mathrm{H}_{2}+\mathrm{O}_{2} \rightarrow 2 \mathrm{H}_{2} \mathrm{O}+242 \mathrm{KJ} / \mathrm{mol}
\end{aligned}
$$

Reduction reactions. As previously stated, these reactions control the gasification rate and define the producer gas yield and composition. In general, their rates are an order of magnitude longer in time than those of pyrolysis. The main reactions taking place inside the gasifier are described as it follows:

\section{- Water-Gas reaction}

It is the partial oxidation of the char (unreacted part of the carbon in the biomass) by steam. This steam can be directly supplied as the gasifying agent or can be taken from the evaporation of the 
moisture in the biomass, showing the importance of its moderate content in its initial composition. Steam reacts with hot char according to the following heterogeneous endothermic reaction (R5.4):

$$
\mathrm{C}+\mathrm{H}_{2} \mathrm{O} \leftrightarrow \mathrm{CO}+\mathrm{H}_{2}-138.33 \mathrm{KJ} / \mathrm{mol}
$$

\section{- Bouduard reaction}

The $\mathrm{CO}_{2}$ formed in the initial stages of the biomass gasification reacts with char to produce $\mathrm{CO}$ according to the following heterogeneous endothermic reaction (R5.5):

$\mathrm{C}+\mathrm{CO}_{2} \leftrightarrow 2 \mathrm{CO}-170.45 \mathrm{KJ} / \mathrm{mol}$

\section{- Water-Gas shift conversion}

Given the high heating value of the $\mathrm{H}_{2}(142 \mathrm{MJ} / \mathrm{kg}$ ) (Wladheim and Nilsson, 2001), its obtaining is more desirable respect to other possible products. The exothermic reaction takes place between the available steam with $\mathrm{CO}$ (R5.6) and results in an increased ratio $\mathrm{H}_{2} / \mathrm{CO}$, mostly employed in the production of synthesis gas. According to Graboski (1981) this reaction can be prioritised by heterogeneous catalysis on the carbon surface at temperatures below the $1000^{\circ} \mathrm{C}$. At higher temperatures, they may occur as a homogeneous reaction.

$$
\mathrm{CO}+\mathrm{H}_{2} \mathrm{O} \leftrightarrow \mathrm{H}_{2}+\mathrm{CO}_{2}+41.98 \mathrm{KJ} / \mathrm{mol}
$$

\section{- Methanation reaction}

Methane is formed according to the exothermic reaction described in R5.7. It also presents a high heating value $(55.5 \mathrm{MJ} / \mathrm{kg}$ ) (Wladheim and Nilsson, 2001) and its formation is highly desirable. The reaction can be enhanced by nickel-based catalysts at $1100^{\circ} \mathrm{C}$ and high pressure (Graboski, 1981).

$$
\mathrm{C}+2 \mathrm{H}_{2} \leftrightarrow \mathrm{CH}_{4}+93.80 \mathrm{KJ} / \mathrm{mol}
$$

\section{- Steam Methane reforming reaction}

The endothermic reaction (R5.8) produces $\mathrm{H}_{2}$ and $\mathrm{CO}$ and consumes $\mathrm{CH}_{4}$. It is the slowest reaction among the endothermic ones and hence, the net consumption of water below $700^{\circ} \mathrm{C}$ is very low.

$$
\mathrm{CH}_{4}+\mathrm{H}_{2} \mathrm{O} \leftrightarrow \mathrm{CO}+3 \mathrm{H}_{2}-232.78 \mathrm{KJ} / \mathrm{mol}
$$




\subsubsection{Important parameters in gasification reactions}

Several parameters are used as control or quality indicators to define, evaluate and optimise the overall behaviour of the system during the described thermo-chemical conversions.

The two main input parameters influencing the process are the Equivalence Ratio (ER) and the temperature of gasification (T). The $E R$ is defined as the ratio of the amount of oxygen (or air) introduced in the system respect to that necessary to carry out the complete combustion of the biomass (Eq. 5.1).

$$
E R=\frac{\text { ActualAirS upplied }}{\text { StoichiometricAir }}
$$

Depending on its value, the thermo-chemical conversion can be classified as pyrolysis $(E R=0)$, gasification $(\mathrm{ER}<1)$ or combustion $(\mathrm{ER} \geq 1)$.

As it is indicated, the actual air supplied is only a proportion of the required stoichiometric air $\left(\mathrm{ER}_{\text {stoic }}\right.$ ), the latter calculated based on the ultimate analysis of the biomass (Eq. 5.2)

$$
E R_{\text {stoic }}\left(\mathrm{kgO}_{2} / \mathrm{kg}_{\text {fuel }}\right)=\frac{32}{12} \mathrm{C}+8 \mathrm{H}+\mathrm{S}-\mathrm{O}
$$

with $\mathrm{C}, \mathrm{H}, \mathrm{S}$ and $\mathrm{O}$ being the percentages $(\% \mathrm{w} / \mathrm{w})$ of carbon, hydrogen, sulfur and oxygen respectively in the initial biomass composition.

ER is an indicator of the performance of the gasifier. The normal range for biomass gasification lies between 0.2-0.3 to ensure a partial combustion of the fuel rather than the complete reaction. Its value strongly affects the products of reaction: with lower ER, char may not be converted into gases and higher ER can result in incomplete gasification and low heating values for the products.

In addition, the temperature of the process will determine which reactions are thermodynamically preferential influencing the composition and yields of the final product. The temperature of the bed is closely related to ER, presenting an increasing trend with the increasing amount of introduced oxygen as a result of a greater extent of the combustion reactions.

On the other hand, several parameters serve as indicators of the performance of the reactor: Carbon Boundary Layer (CBL), Carbon Conversion Efficiency (CCE), Cold Gas Efficiency (CGE) or the Heating Value (HHV) of the final product are among them. 
The Carbon Boundary Layer (CBL) is defined as the operational condition in which the carbon is totally gasified and the addition of more air leads to a further undesired reaction of combustion. At that moment, a relatively strong increase of temperature is encountered within the reactor as only exothermic reactions are taking place. The overall efficiency of the process is maximum at the CBL.

The CBL is directly related to the other parameters measuring the efficiency of the system: Carbon Conversion Efficiency (CCE) and Cold Gas Efficiency (CGE). In general terms, CGE is defined as the ratio between the energy input and the energy output of reaction (Eq. 5.3) whereas CCE represents the percentage of initial carbon converted into gas (Eq. 5.4).

$$
C G E(\%)=\frac{\dot{m}_{\text {gas }} \cdot H H V_{\text {gas }}}{\dot{m}_{\text {biomass }} \cdot H H V_{\text {biomass }}} \cdot 100
$$

where $\dot{m}_{\text {gas }}$ and $\dot{m}_{\text {biomass }}$ are the mass flow rates of the produced gas and fed biomass respectively and $\mathrm{HHV}_{\text {gas }}$ and $\mathrm{HHV}_{\text {biomass }}$ are the high heating values of the produced gas and fed biomass respectively.

$$
\operatorname{CCE}(\%)=\frac{\dot{m}_{\text {gas }} \cdot C_{\text {gas }}}{\dot{m}_{\text {biomass }} \cdot C_{\text {biomass }}} \cdot 100
$$

where $\mathrm{C}_{\text {gas }}$ and $\mathrm{C}_{\text {biomass }}$ are the percentage of carbon (\%wt) in the produced gas and fed biomass respectively.

Figure 5.2 presents the carbon conversion and efficiency parameters resulting from the simulation of gasification of rice straw considering equilibrium conditions (assuming time of reaction long enough to complete the equilibium conversion). Figure 5.2a shows how carbon increasingly reacts with the increasing quantity of oxygen (ER) until the minimum quantity of unreacted carbon in the outlet is achieved which corresponds to the maximum CGE and CCE values $\left(\mathrm{T}=700^{\circ} \mathrm{C}\right)$. The $\mathrm{ER}$ in which it is found the minimum flow of carbon in the outlet defines the CBL and provides the optimum conditions of work and the maximum efficiencies of process (achieving a $\mathrm{CCE}=100 \%$ in case of models based on the equilibrium).

Temperature has also a great influence on the discussed parameters. Figure 5.2b shows the evolution of unreacted $\mathrm{C}, \mathrm{CGE}$ and $\mathrm{CCE}$ with the increasing temperature for the gasification of rice straw ( $E R=0.15$ ). In the figure it is observed how the increase in $\mathrm{T}$ leads to a decrease on $\mathrm{C}$ due to its consumption during the chemical reactions, and consequently also CGE and CCE present an increasing trend until a maximum point is achieved when all the $\mathrm{C}$ is converted to gas.

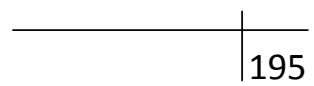



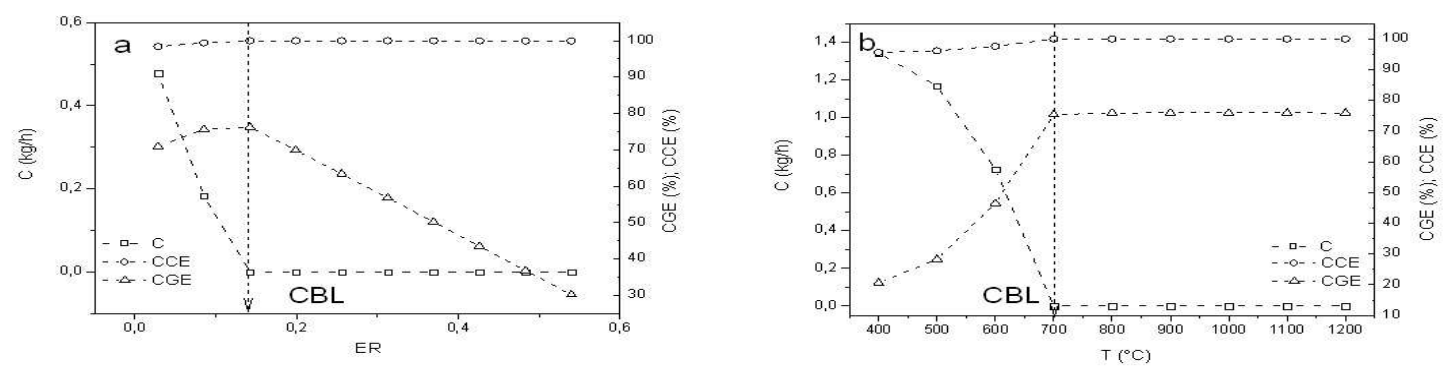

Figure 5.2 Influence of ER at $\mathrm{T}=700^{\circ} \mathrm{C}$ (a) and $\mathrm{T}$ at $\mathrm{ER}=0.15$ (b) on the efficiency of gasification of rice straw

The obtaining of the CBL (and in consequence the CGE and CCE) with the aid of simulated solutions, highly depends on the level of detail applied within the model. Figure 5.3 presents the CGE with the varying $\mathrm{T}$ (Figure 5.3a) and ER (Figure 5.3b) obtained with a model admitting that the gasification of rice straw achieves the equilibrium conditions ( $\square$ ) and a model in which the kinetics of decomposition of the rice straw are included ( $\mathbf{})$. CGE increases with the increasing temperature as seen in Figure 5.3a. However, different predictions are obtained depending on the temperature range: lower values do not provide similar results due to the fact that the assumptions of equilibrium are far from being valid at temperatures below the $850^{\circ} \mathrm{C}$. A notable increase in the CGE is observed around $800^{\circ} \mathrm{C}$ when kinetics are considered which is consistent with the fact that it is the temperature range in which the main gasification reactions take place. At higher temperatures, the equilibrium and kinetic model provide more similar results. On the other hand, the increase of ER results in a general decrease of CGE (Figure 5.3b). Equilibrium conditions again lay above the kinetic solution with the results not differing as much as in the previous case at low ER values.
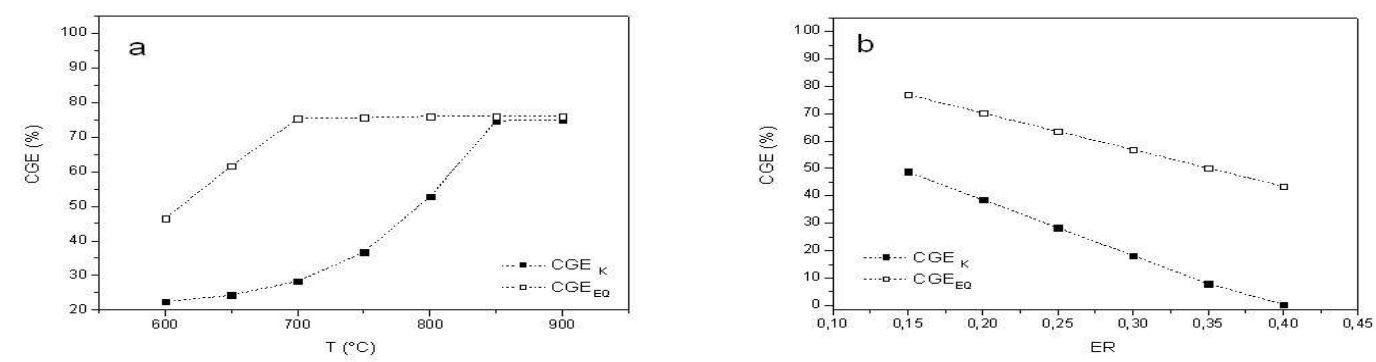

Figure 5.3. CGE with the varying $T$ at $E R=0.15$ (a) and $E R$ at $700^{\circ} \mathrm{C}$ (b) according to equilibrium conditions $(\square)$ and taking into account kinetic expressions ( $\square$ )

A more complete description of the different models developed for the study of gasification reactions is performed in Section 5.3. 
The Higher Heating Value of the produced gas (HHV) measures the quality of the final product of gasification and is obtained as the total contribution of all the constituents of the produced gas according to their corresponding volume fraction. When air is used as gasifying agent, nitrogen dilutes the product gas and lowers the HHV (4-6 $\left.\mathrm{MJ} / \mathrm{Nm}^{3}\right)$ respect to those obtained with pure oxygen $\left(10-15 \mathrm{MJ} / \mathrm{Nm}^{3}\right)$. However, this increase of HHV is normally worth the effort as the production of pure oxygen counterbalances the total energy requirements. HHV represents the quantity of energy that it is produced in the gasification process (per $\mathrm{kg} \mathrm{o} \mathrm{Nm}^{3}$ of product gas) as it follows (Eq. 5.5):

$E_{\text {gasification }}(M W t h)=Q_{\text {product }} \cdot H H V$

with $\mathrm{Q}_{\text {product }}$ the flow of produced gas.

As it is expected from the definition of CGE, the HHV increases with the increasing temperature in the same way as CGE (Figure 5.3a). On the contrary, a decrease of HHV with higher ER values is observed, also presenting the same trend as that of CGE on Figure 5.3b. These behaviours are closely related to the distribution of products in the obtained gas: a higher presence of combustible gases in the mixture increases its HHV value as it will be discussed in detail in Section 5.3. 


\subsection{Experimental studies on a SBR}

\subsubsection{Description of the pilot unit and experimental procedure}

The experimental activity has been carried out in a conical square-based spouted bed reactor (Figure 5.4a). Its main dimensions are: side of $200 \mathrm{~mm}$ and total high of $2 \mathrm{~m}$. The base has an inclined angle of $60^{\circ}$ in order to enhance the recirculation of solids. The air inlet orifice is situated at the center with a diameter of $21 \mathrm{~mm}$.

A burner (Figure 5.4b) is used to preheat the fluidising gas (air) and the exhaust gases go through a cyclone (Figure 5.4c) followed by a water scrubber to cool them and remove fines. The gaseous products $\left(\mathrm{H}_{2}, \mathrm{CO}_{2}, \mathrm{CH}_{4}, \mathrm{CO}, \mathrm{O}_{2}\right.$ and $\mathrm{C}_{2}-\mathrm{C}_{5}$ compounds) are analysed using a gas chromatograph (Figure 5.4d). The remaining percentage of carbon after the gasification of the residues is also quantified. The temperature in the experimental unit is monitored by several thermocouples connected to a data acquisition system.
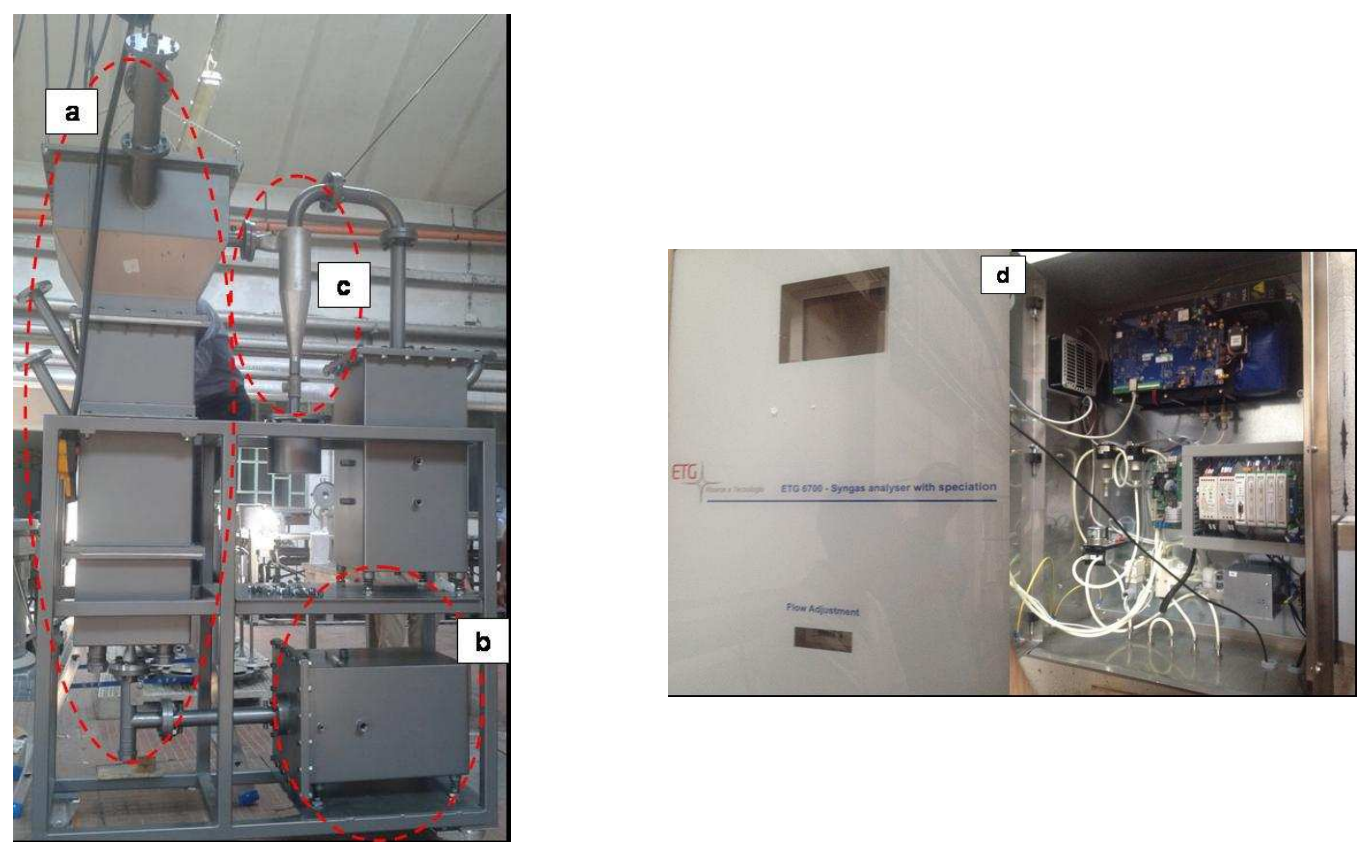

Figure 5.4. Description of the pilot SBR 
The experimental procedure is described through the following steps: the square-based reactor is the core of the unit and it initially contains the inert material (silica sand) that will help in the fluidisation process. The system is preheated until the start-up temperature is achieved. The fluidising gas is mixed in the burner with propane. Steam is also introduced in the system performing the so called "steam-air" gasification.

The reacting biomass is sized and introduced into the reactor at the solids feeding point at the vertical wall of the device. Experimentally, the system does not present technical problems with the feeding system when traditional wood pellets were used as feeding material. However, great difficulties were found when the material had a fibrous nature, as it is the case of the rice straw. The valve easily gets blocked and the whole feeding system collapses within few seconds of functioning. For that reason, the initial system was replaced with a specially designed one (Figure 5.5) that could fulfill the feeding requirements regardless the introduced solid.

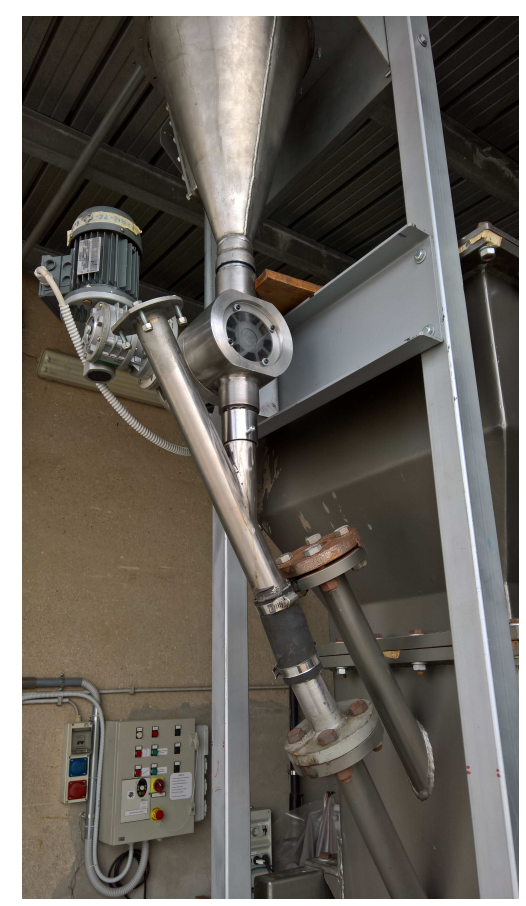

Figure 5.5. Feeding system after the modification on the initial design

The exhausted gases are cleaned from powders in a cyclone followed by a water scrubber to cool them down and remove fines before going to the GC. Experimentally, the obtained gas contained a great quantity of pollutants after going through the cleaning stage and an additional filter had to be included before reaching the GC. 


\subsubsection{Preliminary experimental tests.}

At the moment of writing this thesis, all the encountered technical issues described in the previous section had been solved and combustion reactions to calibrate the GC have been performed. With this purpose, the combustion of air and GPL has been conducted to evaluate the final composition of the produced gas at different GPL flows. Table 5.1 shows the operational conditions at each time step. The temperature of work during the test was $60^{\circ} \mathrm{C}$. An initial regime was required until the desired temperature was achieved and the system was stabilised (time 0:00-1:13). The theoretical percentage (in volume fraction) was calculated according the following reaction, considering GPL as a mix of propane and butane:

$\mathrm{GPL}+6 \mathrm{O}_{2} \rightarrow 3.7 \mathrm{CO}_{2}+4.7 \mathrm{H}_{2} \mathrm{O}$

Eq. 5.6

Table 5.1. Operational conditions for the reaction of combustion air-GPL

\begin{tabular}{|c|cccc|}
\hline Step Number & Time (h:m) & Air flow (l/h) & GPL flow (1/h) & $\mathbf{C O}_{\mathbf{2}}(\% \mathbf{v} / \mathbf{v})$ \\
\hline 1 & $1: 13$ & 20 & 2.1 & 2.32 \\
\hline 2 & $1: 23$ & 20 & 4.5 & 5.19 \\
\hline 3 & $1: 33$ & 20 & 6.0 & 6.96 \\
\hline 5 & $1: 37$ & 20 & 7.0 & 8.16 \\
\hline 6 & $1: 43$ & 20 & 9.5 & 11.25 \\
\hline
\end{tabular}

Figure 5.6 shows the response of the GC and its comparison with the theoretical calculated values. An optimum agreement is observed between the stoichiometric and the experimental curves, with a quick velocity of response of the measuring instrument. Finally, a maximum difference of $1.4 \%$ is observed between all the values, keeping that value as the experimental error associated with the GC. 


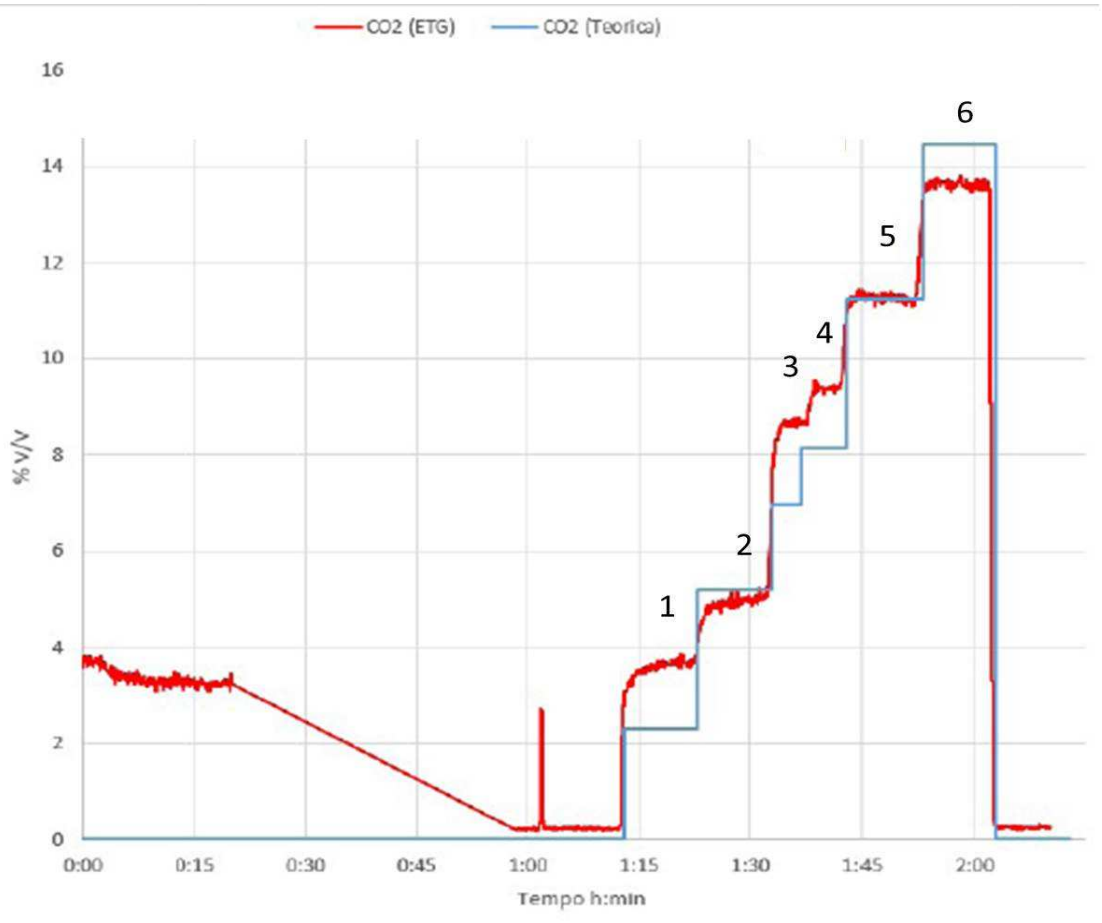

Figure 5.6. Calibration curve for the GC 


\subsection{Modelling activities}

Modelling activities constitute a useful tool to evaluate industrial processes in a costless and non time consuming way respect to experimental activities themselves. They can provide valuable information regarding the feasibility of a process using new feedstock or they can help predicting the behaviour of a system when the operational conditions are modified. Models may be used to evaluate potential hazardous processes or to define the technological limits that a reaction can face due to either thermo-chemical or technical limitations.

For this reason, the importance of modeling activities is crucial for the good development of a technology and for its application to achieve optimum results. In this framework, the gasification of several agricultural residues has been addressed and modeled according to different degrees of detail, from the ideal situation to a more realistic one, but each of them providing essential information about the overall process.

For the present thesis, the gasification of agricultural residues has been performed according three levels of detail: equilibrium models, quasi-equilibrium models and models taking into account the specific kinetic rates of the decomposition of biomass.

\subsubsection{Description of the models}

Equilibrium models. Unlike combustion reactions, gasification reactions do not always reach equilibrium, so only a rough estimate is possible through an equilibrium calculation. Still, this can be a reasonable start for an initial design until detailed kinetic modeling is carried out in the optimisation stage. An equilibrium calculation ideally predicts the product of gasification if the reactants are allowed to react in a fully mixed condition for an infinite period of time. However, these models have limitations as tar not being considered, even though its presence can be a major problem in the gasification process and can affect plant operation. Furthermore, the equilibrium model assumes infinite reaction times resulting in fully completed reactions but these assumptions are not valid for most gasifiers. Finally, they do not offer any information regarding intermediate products or mechanisms of reaction. Nevertheless, equilibrium calculations provide information about the basic process parameters in a quick way and help defining possible thermodynamic limits or potential hazardous situations. In any case, this approximation needs to be upgraded and more specific parameters (kinetic rates, conversion of 
carbon achieved, ...) need to be included in order to simulate the real process. Communication 5I presents an initial feasibility study of the use of rice straw and residues from the kaki fruit following this approach.

Quasi-equilibrium models. In order to describe more accurately the gasification of biomass, several modifications can be performed in the previous models. These modifications are mostly related to empirical parameters that lead to a better agreement between the simulated and the real values. The definition of the actual carbon conversion achieved (Li et al, 2001) or the actual amount of methane in the product gas (Maniatis et al, 2002) are obtained based on experimental data and can be included as extra-inputs in a restricted equilibrium model. It is clear that these models lose much of their predictive capabilities but represent in a more accurate way the described system. Another approach often applied is to use the "quasi-equilibrium temperatures" where the equilibrium of the system is evaluated at a temperature which is lower than the actual process temperature (Gumz, 1950). For example, based on 75 experimental results, Kersten et al (2002) showed that, for operating temperatures in the range a $740-910^{\circ} \mathrm{C}$, part of the reactions achieved equilibrium conditions. However, the specified pseudoequilibrium conditions were found for the following reactions:

$$
\begin{array}{ll}
\mathrm{C}+\mathrm{H}_{2} \mathrm{O} \leftrightarrow \mathrm{CO}+\mathrm{H}_{2} & \mathrm{~T}_{\text {pseudo_eq }}=531 \pm 25^{\circ} \mathrm{C} \\
\mathrm{C}+\mathrm{CO}_{2} \leftrightarrow 2 \mathrm{CO} & \mathrm{T}_{\text {pseudo_eq }}=583 \pm 25^{\circ} \mathrm{C} \\
\mathrm{C}+2 \mathrm{H}_{2} \leftrightarrow \mathrm{CH}_{4} & \mathrm{~T}_{\text {pseudo_eq }}=457 \pm 29^{\circ} \mathrm{C}
\end{array}
$$

An application of this approach is presented in Communication 5II.

Kinetic models. As widely explained, the prediction of the gas composition by equilibrium models can vary significantly from the experimental data. This inadequacy underscores the need of kinetic models to simulate more precisely the behaviour of the gasifier. The inclusion of kinetic laws in a model gives information about the gas yield and product distribution achieved within a gasifier taking into account the reaction rates and mechanisms under a kinetic point of view. These models offer a realistic description and prediction of the gasification process and become a valuable tool during the design, evaluation and improvement of gasifiers. They can be very accurate but heavy in calculations, as well as very specific and each one valid for a certain case of study.

For the present work, the kinetic model was introduced according to the following Eq. 5.7: 
$\frac{d \alpha_{\text {Biomass }}}{d t}=\ln A \cdot\left(1-\alpha_{\text {biomass }}\right)^{n} \cdot e^{-E a / R T}$

being $\alpha_{\text {biomass }}$ the fraction of the converted biomass at each time $t, A$ the pre-exponential factor $\left(\mathrm{s}^{-1}\right), \mathrm{n}$ the order of reaction and Ea the activation energy $(\mathrm{kJ} / \mathrm{mol})$.

The previous general expression was defined as the individual sum of the main pseudocomponents of the biomass, following the methodology described in Chapter 3, and was introduced in Aspen Plus as an external subroutine. The full description of the model and its results are presented in Communication 5III.

All the three modelling approaches were performed with the aid of the commercial software Aspen Plus ${ }^{\odot}$ and were used to simulate the gasification of biomass according to the principles of mass, energy and chemical balances. Aspen Plus ${ }^{\odot}$ contains a large property database for conventional components and provides the possibility of adding built-in expressions to further personalise the model. The methodology that was carried out to obtain the models is described below.

\subsubsection{Description of the methodology}

Setting of main properties. The property method applied for all the simulations was RKSOAVE, cubic equation of state for all thermodynamic properties recommended for gas processing and particularly suitable for high temperature processes (Aspen Guide, 2014): All the components participating in the simulation were introduced in an initial stage and were labelled according to their properties (conventional: $\mathrm{CO}, \mathrm{CO}_{2}, \mathrm{CH}_{4}, \mathrm{H}_{2}, \mathrm{H}_{2} \mathrm{O}, \mathrm{O}_{2}, \mathrm{~N}_{2}$; solids: $\mathrm{C}$; non-conventional: ash and biomass). The enthalpy and density of the non-conventional components were defined as HCOALGEN and DCOALIGT respectively and their compositions (in dry and ash-free basis) were described by their proximate and ultimate analysis. Their high heating values were also specified as initial input (Figure 5.7).

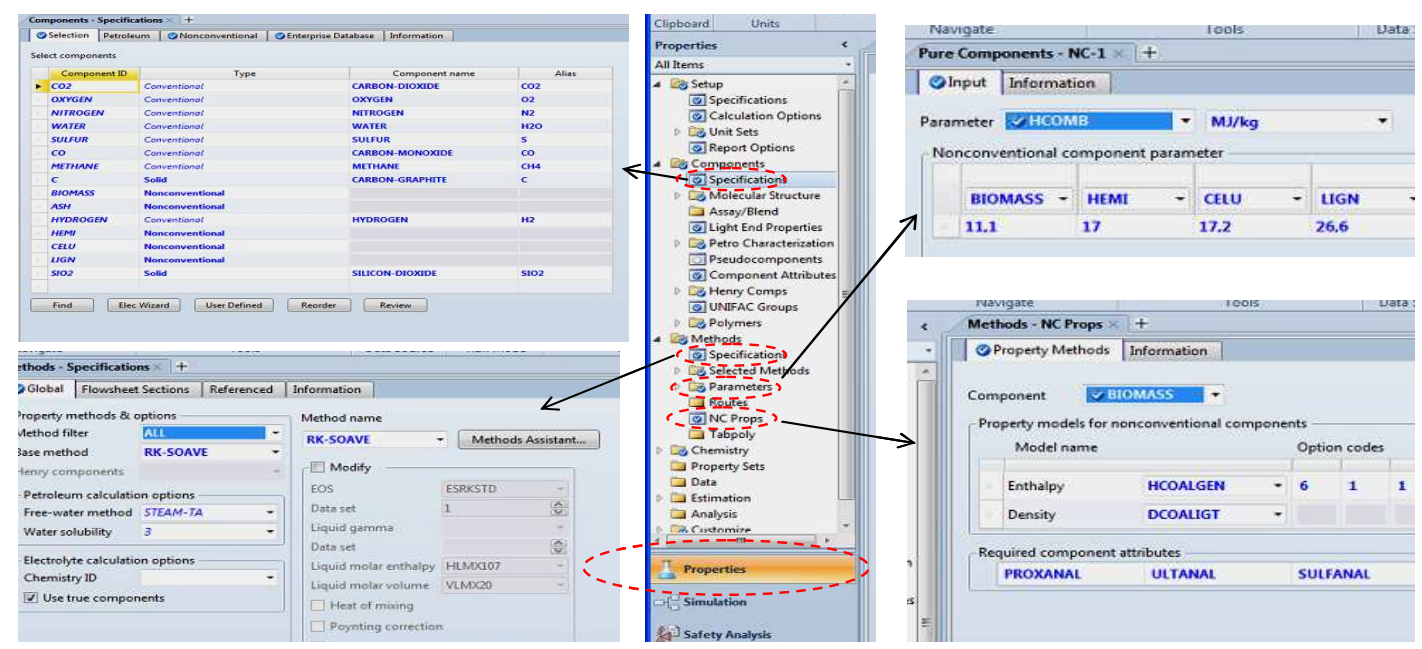

Figure 5.7. Setting of main properties on Aspen Plus ${ }^{\circledR}$ 
Setting of simulation properties. Once the components were introduced and the properties defined, the flow sheet was drawn using streams (material or heat) containing the involved compounds connecting blocks representing the different elemental actions composing the process. In the particular case of the model containing the kinetic description, a block linked to EXCEL was introduced: the input information from Aspen was sent to EXCEL where the specific kinetic calculations were performed by means of a sub-routine. These outputs were sent back to Aspen (Figure 5.8).

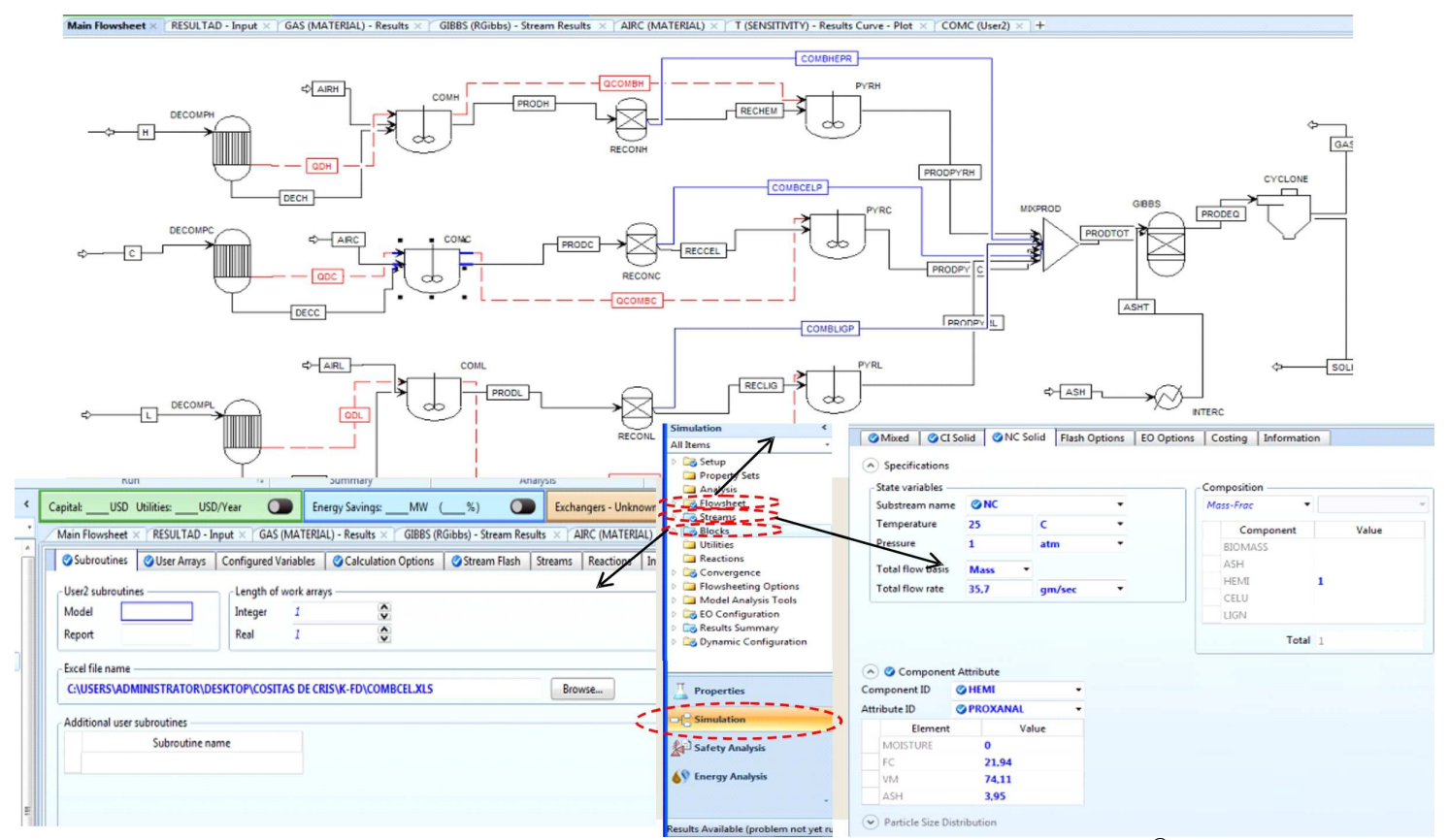

Figure 5.8. Setting of simulation properties on Aspen Plus ${ }^{\odot}$

Setting of calculator block. All the parameters describing the performance of the reactor were introduced in the form of a Calculator Block in Fortran. This way, their calculations were performed automatically in each run (Figure 5.9).

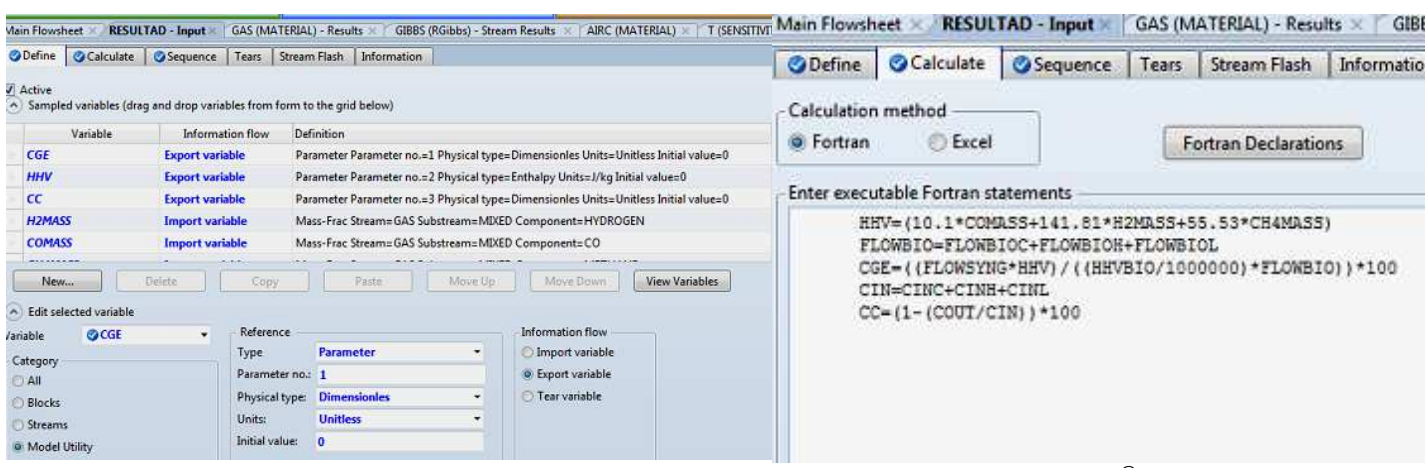

Figure 5.9. Setting of calculator block on Aspen Plus ${ }^{\odot}$ 
Setting of sensitivity analysis. With the aim to study the influence of the main variables affecting the process on the performance of the reactor, several sensitivity analysis were performed and discussed (Figure 5.10).

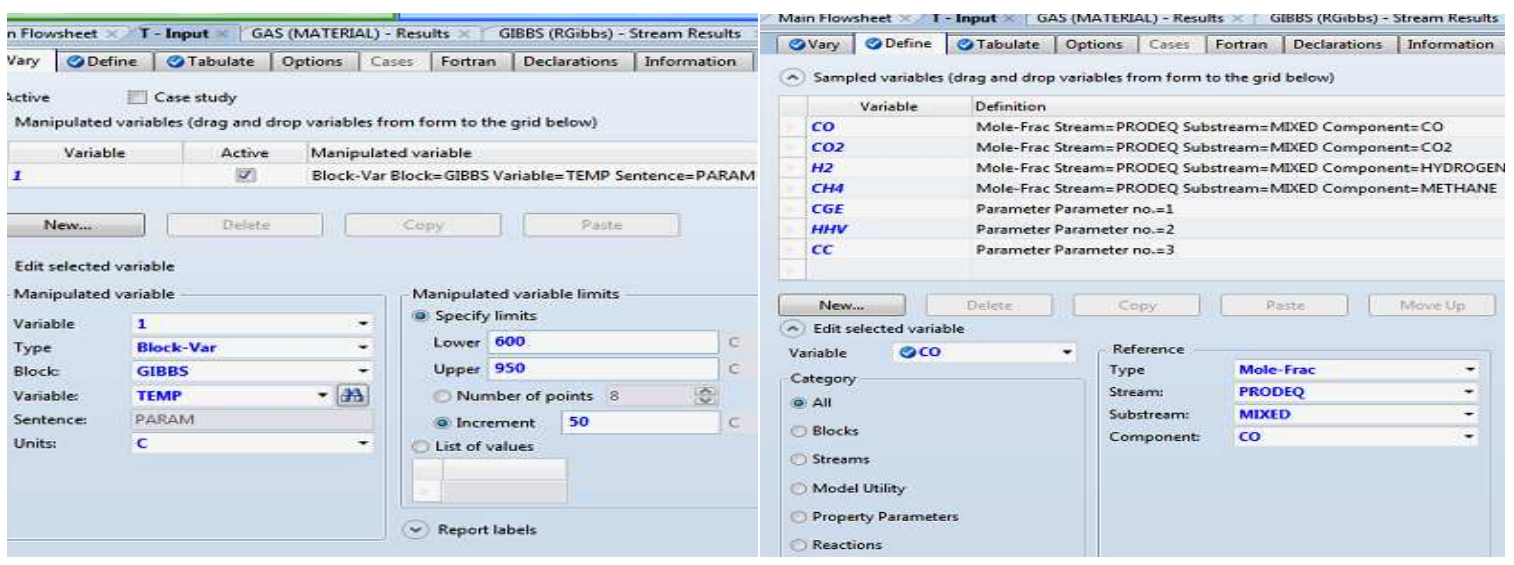

Figure 5.10. Sensitivity analysis on Aspen Plus ${ }^{\circledR}$

Finally, the experimental results obtained with the pilot plant unit (as described in Section 5.2) were used to validate the performance of the developed models. The achieved results and conclusions are described in Communication 5IV. 


\subsection{Main results}

A pilot SBR unit was conditioned to carry out the reactions of gasification of biomass. In particular, several experimental difficulties were encountered regarding the feeding system due to the fibrous nature of the straw. This fact led to the replacement of the original system with a new one able to deal with biomass to prevent blocking problems. Moreover, an extra filter was required before the GC to further depurate the exhausted gas. Finally, the GC was calibrated through comparison among theoretical and experimental results in combustion reactions.

Different models were applied for the study of the reactions of gasification of biomass. Globally, it can be concluded that the ER is one of the most significant parameters in gasification processes. Reduced ER result in high heating values of the syngas but low conversion efficiencies. Temperature also plays an important role on the final gas quality as it is the defining parameter of the thermodynamic behaviour of the system.

Overall, the energy that can be recovered through the gasification of agricultural residues is maximised when the exact quantity of oxygen to convert all the biomass is introduced in the reactor. The overuse of oxygen results in undesired combustion reactions that lower the heating value of the produced gas and, consequently the CGE, even though the actual increase on the syngas flow. High temperatures help in overcoming kinetic limitations. However, important technical problems related to the maintenance of the reactor are encountered at temperatures above $1000^{\circ} \mathrm{C}$ and for that reason, it has been defined as a limiting operational condition. 


\section{References Chapter 5}

Aspen Plus. Cambridge, MA, USA: Aspen Technology, Inc., V.8.4 (2014)

Basu P., Biomass Gasification and Pyrolysis. Practical design and theory. Ed. Elsevier Inc. (2010).

Gumz W. Gas producers and blast furnaces. New York: Wiley; (1950).

Kersten S., Prins R.A., Van der Drift B., Van Swaaij W.P.M. Interpretation of biomass gasification by "quasi" equilibrium models. Proceedings of the 12th European Conference on biomass for energy, industry and climate protection (2002).

Li X, Grace JR, Watkinson AP, Lim CJ, Ergu“ denler A. Equilibrium modeling of gasification: a free energy minimization approach and its application to circulating fluidized bed coal gasifier. Fuel 80, 195-207 (2001).

Li XT, Grace JR, Lim CJ, Watkinson AP, Chen HP, Kim JR. Biomass gasification in a circulating fluidized bed. Biomass Bioenergy 26, 171-193 (2004).

Maniatis K, Guiu G, Riesgo J. The European commission perspective in biomass and waste thermochemical conversion. In: Bridgwater AV, editor. Pyrolysis and gasification of biomass and waste, Proceedings of an Expert Meeting. p. 1-18 (2002).

Waldheim L., Nilsson T. Heating value of gases from biomass gasification. Report prepared for IEA Bioenergy Agreement, Task 20-Thermal gasification process (2001)

Wooley R. J., Putsche V., Development of an ASPEN PLUS Physical Property Database for Biofuels Components, National Renewable Energy Laboratory, Colorado, April 1996

Zhang R., Basu P. A simple model for prediction of solid collection efficiency of a gas-solid separator. Powder Technology 2004, 147, 86-93 


\section{Communications}

The main results obtained from this chapter are presented in the following communications:

Communication 5I: C. Moliner, D. Bove, B. Bosio, A. Ribes, E. Arato. Feasibility studies on the energy valorization of agricultural residues using Aspen Plus ${ }^{\odot}$. Proceedings of the $23 \mathrm{rd}$ European Biomass Conference and Exhibition, 803-809. (Viena) 2015. DOI: 10.5071/23rdEUBCE2015-2DV.1.24

Communication 5II: C. Moliner, D. Bove, B. Bosio, A. Ribes, E. Arato. Simulation activities for the pseudo-equilibrium modeling of the gasification of agricultural residues. Accepted abstract at the 24th European Biomass Conference and Exhibition. (Amsterdam) 2016

Communication 5III: C. Moliner, B. Bosio, A. Ribes, E. Arato. Process simulation of the gasification of rice straw by means of a spouted bed reactor based on its fluid dynamic and kinetic properties. Manuscript

Communication 5IV: C. Moliner, B. Bosio, E. Arato. Comparison and validation with experimental data of different modelling approaches for the gasification of agricultural residues. Abstract submitted to the 19th Conference on Process Integration, Modelling and Optimisation for Energy Saving and Pollution Reduction (Prague) 2016 



\section{Communication 5.I}

Feasibility studies on the energy valorization of agricultural residues using Aspen Plus ${ }^{\mathcal{O}}$.

C. Moliner, D. Bove, B. Bosio, A. Ribes, E. Arato.

Proceedings of the $23^{\text {rd }}$ European Biomass Conference and Exhibition, 803-809. 2015. Viena DOI: 10.5071/23rdEUBCE2015-2DV.1.24 



\title{
FEASIBILITY STUDIES ON THE ENERGY VALORISATION OF AGRICULTURAL RESIDUES USING ASPEN PLUS ${ }^{\circ}$
}

\author{
C. Moliner ${ }^{1}$, D.Bove ${ }^{2}$, B.Bosio ${ }^{1}$, A.Ribes $^{3}$, E.Arato $^{1}$ \\ 1. Dipartimento di Ingegneria Civile, Chimica e Ambientale (DICCA) \\ Università degli Studi di Genova, Via Opera Pia 15, 16145 Genova (Italy) \\ 2. Facoltà di Scienze e Tecnologie. \\ Libera Università di Bolzano, Piazza Università 5, 39100 Bolzano (Italy) \\ 3. Instituto Tecnologico de Materiales (ITM) \\ Universidad Politècnica de València, Camino de Vera s/n, 46022 Valencia (Spain)
}

\begin{abstract}
The gasification of different agricultural residues (rice straw, leaves and stems from kaki fruit) on a spouted bed reactor was studied with the aid of the commercial software Aspen Plus $\odot$. A computational model was used to study the effect of three different operational parameters (initial biomass Moisture Content - MC, Temperature of reaction - $\mathrm{T}$ and Equivalence Ratio - ER) on the final gas composition and on the overall reactor performance. The reactor was assumed to be in steady state and $\mathrm{CO}, \mathrm{CO}_{2}, \mathrm{H}_{2}, \mathrm{CH}_{4}$ and $\mathrm{H}_{2} \mathrm{O}$ were considered in the produced gas. The optimum operational parameters were calculated for all the studied samples. Residues from the kaki stems were found to be those providing the highest overall efficiencies at the optimal conditions of work.

Keywords: Agricultural residues, modeling, renewable energies, syngas, thermo-chemical conversion
\end{abstract}

\section{INTRODUCTION}

The use of biomass as a renewable source of energy has increased in the last decades and it stands out as a promising alternative likely to play an important role in the energy scenario. In particular, the use of agricultural residues like rice straw or fruits by-products as feedstock for energy recovery purposes is currently receiving special attention [1,2]. These lignocellullosic materials are initially considered as waste products with all the negative environmental and economic associated impacts and their correct management would provide not only environmental benefits but also the development of new renewable sources of energy.

Gasification is defined as the thermo-chemical conversion of carbonaceous materials into a combustible fuel, known as syngas. The reactions occur when a controlled quantity of oxygen (or air or steam or the combination of them) reacts at high temperature with the available carbon of the biomass within a gasifier [3]. The basis of gasification is to supply less oxidant than required for a stoichometric combustion of the fuel. As a result, a gas containing a mixture of carbon monoxide (CO) and hydrogen $\left(\mathrm{H}_{2}\right)$ is obtained at high temperatures.

This syngas can be further combusted for example in a turbine to generate electricity or addressed to heating purposes. The main stages involved in gasification are:

- Drying: the moisture content of the biomass is reduced at the temperature range of $100-150^{\circ} \mathrm{C}$. Contents below $10 \%$ are preferable in order to achieve high overall efficiencies.

- Devolatilisation: the biomass is decomposed in absence of oxygen resulting in a reduction of the volatile matter. The biomass is reduced to solid charcoal. This stage is considered to be instantaneous [3].

- Oxidation: the solid carbonised biomass reacts with oxygen to form $\mathrm{CO}_{2}$. The hydrogen is also oxidised producing $\mathrm{H}_{2} \mathrm{O}$. If oxygen is in substoichiometric conditions, the carbon is partially oxidised resulting in the generation of $\mathrm{CO}$. These reactions are highly exothermic releasing a large amount of heat.

- Reduction: in absence (or substoichiometric presence) of oxygen, endothermic reactions of reduction take place above $800^{\circ} \mathrm{C}$. The main reactions describing the whole process of gasification are presented in Table I.
Table I: Main gasification reactions [3]

\begin{tabular}{lll}
\hline \multicolumn{1}{c}{ Reaction } & \\
\hline $\mathrm{C}+0.5 \mathrm{O}_{2} \rightarrow \mathrm{CO}$ & Partial carbon combustion & $\mathrm{R} 1$ \\
$\mathrm{C}+\mathrm{O}_{2} \rightarrow \mathrm{CO}_{2}$ & Carbon combustion & $\mathrm{R} 2$ \\
$\mathrm{H}_{2}+\mathrm{O}_{5} \mathrm{O}_{2} \rightarrow \mathrm{H}_{2} \mathrm{O}$ & Hydrogen combustion & $\mathrm{R} 3$ \\
$\mathrm{C}+\mathrm{H}_{2} \mathrm{O} \rightarrow \mathrm{H}_{2}+\mathrm{CO}$ & Water-gas reaction & $\mathrm{R} 4$ \\
$\mathrm{C}+\mathrm{CO}_{2} \leftrightarrow 2 \mathrm{CO}$ & Boudouard reaction & $\mathrm{R} 5$ \\
$\mathrm{C}+2 \mathrm{H}_{2} \leftrightarrow \mathrm{CH}_{4}$ & Methane reaction & $\mathrm{R} 6$ \\
$\mathrm{CO}+\mathrm{H}_{2} \mathrm{O} \leftrightarrow \mathrm{CO}_{2}+\mathrm{H}_{2}$ & Shift reaction & $\mathrm{R} 7$ \\
$\mathrm{H}_{2}+\mathrm{S} \leftrightarrow \mathrm{H}_{2} \mathrm{~S}$ & $\mathrm{H}_{2} \mathrm{~S}$ formation & $\mathrm{R} 8$ \\
$0.5 \mathrm{~N}_{2}+1.5 \mathrm{H}_{2} \leftrightarrow \mathrm{NH}_{3}$ & $\mathrm{NH}_{3}$ formation & $\mathrm{R} 9$ \\
& &
\end{tabular}

The overall efficiency will be mainly determined by the initial composition of the biomass and also by the technology applied to carry out the conversion process. An initial characterisation of the fuel is necessary to evaluate the suitability of the produced gas as energy carrier. The diagram of Van Krevelen provides a useful tool to assess the energy content of a fuel through the analysis of its atomic ratios $\mathrm{O} / \mathrm{C}$ and $\mathrm{H} / \mathrm{C}$ [4]. The lower the respective ratios are, the greater the energy content of the material is.

On the other hand, the accurate selection of the gasifier and its operational conditions are also key factors in the thermo-chemical conversion of the biomass. Fluidised bed reactors have been proposed as an adequate tool due to the achieved perfect contact between gas and solid and the high level of turbulence [5]. In particular, Spouted Bed Reactors (SBR) are a type of fluidised units in which the perforated base is replaced by one with a single orifice, normally in a central position. This configuration enhances the recirculation of particles providing higher yields and lower energy requirements respect to the traditional fluidised technologies [6].

Moreover, SBR offer the possibility of handling bigger particles with a wide size distribution without problems of segregation which makes this device a flexible and versatile tool for agricultural residues. Figure 1 shows a scheme of the reactor and the definition of the main stages of gasification within it. The high level of mixing of particles due to the constant recirculation inside the reactor ensures high efficiency rates and uniform temperature profiles within the reactor. 


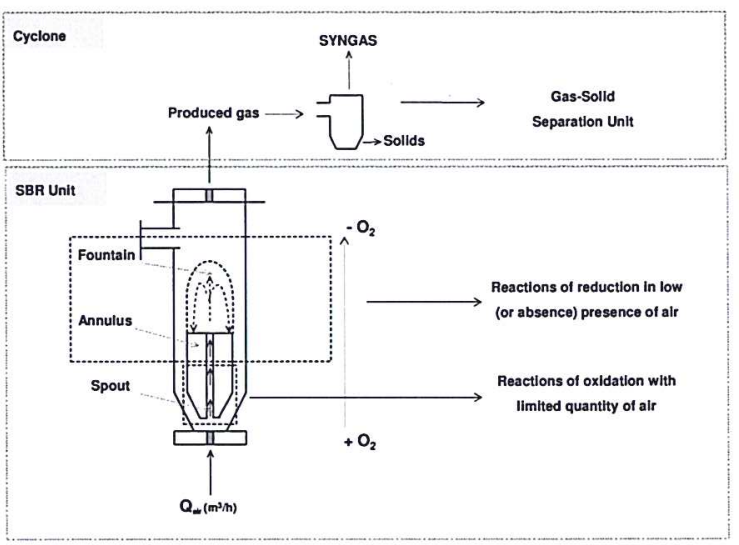

Figure 1: Scheme of a SBR and main reactions of gasification within it

Modelling activities provide a useful tool for the design and assessment of operational conditions for industrial processes. They also help in defining the technological limits and constraints of a certain process and enable the obtaining of the optimum conditions of work in a low time consuming way. The relative novelty of the SBR technology results in a lack of studies focusing on the modelling of these reactors.

Jarungthammachote et al (2008) [7] proposed a nonstoichiometric equilibrium model and applied it to three different SBR configurations: central jet, spout-fluid bed reactor and circular SBR. The model showed significant inaccuracies respect to experimental data, especially in the study of $\mathrm{CO}$ and $\mathrm{CO}_{2}$ concentrations.

It is clear than efforts need to be done for a proper design of the SBR unit that permits the correct development of the technology. For this reason, the aim of this work is to provide a preliminary thermodynamic basis for the gasification of different agricultural residues within a SBR. Kinetic constraints have been also taken into account in the present study. The model will be used to study the influence of the moisture content of the feedstock, the equivalence ratio and the temperature of reaction on the overall gasification process. Finally, the optimised conditions of work will be defined for each of the residues under study and their potential energy supply will be calculated.

\section{ASPEN PLUS $^{\oplus}$ SIMULATION MODELING $^{-10}$}

A computational model was applied for the study of the gasification of agricultural residues using Aspen Plus ${ }^{\Theta}$. The overall process is broken down in three different stages: pyrolysis or devolatilisation of the biomass, main gasification reactions and separation of gases.

\subsection{Assumptions} are:

The main assumptions considered for the modelling

- Steady state conditions

- Pyrolysis is considered as an instantaneous reaction

- The reactor is considered as perfectly mixed and with uniform temperature

- Char is composed by carbon and ash

- Cyclone separation efficiency: $85 \%$

\subsection{Physical property method}

The property method RK-SOAVE has been used to estimate the properties of mixed conventional and inert solid components. HCOALGEN and DCOALIGT models were used to calculate the enthalpy and density of non-conventional components respectively. Ashes were also defined as non-conventional component with an ash content set to $100 \%$ [8].

\subsection{Description of feedstock and properties}

Rice straw (RS), and leaves (KL) and stems (KS) from kaki fruit were used as feedstock for the present simulation. They were specified as non-conventional components in Aspen Plus ${ }^{\odot}$ and defined by their proximate and ultimate analysis. These properties had been previously calculated according to standard procedures as explained in a previous work [9]. The results for each of the studied material are reported in Table II.

Table II: Feedstock properties defined in Aspen Plus ${ }^{(}$

\begin{tabular}{lccc}
\hline Proximate analysis (wt. \%) & RS & KL & KS \\
\hline Moisture content (MC) $^{\mathrm{a}}$ & 9.1 & 9.4 & 9.7 \\
Fixed Carbon (FC) $^{\mathrm{b}}$ & 16.1 & 1.9 & 2.3 \\
Volatile Matter (VM) $^{\mathrm{b}}$ & 63.3 & 84.3 & 91.8 \\
Ash $^{\mathrm{b}}$ & 20.6 & 13.8 & 5.9 \\
\hline Ultimate analysis (wt. \%) $^{\mathrm{n}}$ & $\mathrm{RS}$ & $\mathrm{KL}$ & $\mathrm{KS}$ \\
\hline Ash $^{\mathrm{b}}$ & 20.6 & 13.8 & 5.9 \\
$\mathrm{C}^{\mathrm{c}}$ & 35.1 & 38.1 & 45.7 \\
$\mathrm{H}^{\mathrm{c}}$ & 4.5 & 0.9 & 0.9 \\
$\mathrm{O}^{\mathrm{c}}$ & 57.8 & 56.2 & 48 \\
$\mathrm{~N}^{\mathrm{c}}$ & 2.3 & 4.8 & 5.4 \\
$\mathrm{~S}^{\mathrm{c}}$ & 0.3 & 0.0 & 0.0 \\
$\mathrm{HHV}_{\text {biomass }}{ }^{\mathrm{d}}{ }^{\mathrm{c}}(\mathrm{MJ} / \mathrm{kg})$ & 11.1 & 8.2 & 11.8
\end{tabular}

${ }^{\text {a }}$ wet basis, ${ }^{\text {b }}$ dry basis, ${ }^{\text {c }}$ ash-free basis ${ }^{\mathrm{d}}$ according to [10]

It is worthwhile to highlight the high percentage of ash present in rice straw. This ash plays a determinant role in the design of the gasifier due to its high content of silica that can lead to slagging and fouling problems inside the reactor. To avoid these problems, temperatures below $1000^{\circ} \mathrm{C}$ are recommended and for that reason, the temperature of reaction in this study was limited to $1000^{\circ} \mathrm{C}$.

The reaction mechanisms, kinetic parameters and thermal stability of all samples were previously calculated according to the methodology described elsewhere [9]. The kinetic triplet that defines the main decomposition process for each of the analysed biomass is presented in Table III.

Table III: Kinetic parameters of the main decomposition processes for $\mathrm{RS}, \mathrm{KL}$ and $\mathrm{KS}$

\begin{tabular}{lccc}
\hline Parameter & RS & KL & KS \\
\hline Activation energy $(\mathrm{kJ} / \mathrm{mol})$ & 167 & 145 & 152 \\
Pre-exponential factor $\left(\mathrm{sec}^{-1}\right)$ & 0.55 & 0.49 & 0.57 \\
Order of reaction & 2.95 & 1.80 & 1.40
\end{tabular}

The first order differential equations describing the kinetic equations according to the apparent kinetic law (Eq. 1) were solved for the different temperatures of reaction in MATLAB using the ODE45 function and were used to obtain the time of reaction required to achieve the complete thermo-chemical conversion of the biomass in each case. 


$$
\frac{d \alpha_{\text {Biomass }}}{d t}=\ln A \cdot\left(1-\alpha_{\text {biomass }}\right)^{n} \cdot e^{-E a / R T}
$$

being $\alpha_{\text {biomass }}$ the fraction of the converted biomass at each time $t, \ln A$ the pre-exponential factor, $n$ the order of reaction and $E_{a}$ the activation energy.

\subsection{Model description}

A number of steps described the overall gasification process. Figure 2 shows a scheme with the main stages and their equivalence in Aspen Plus.

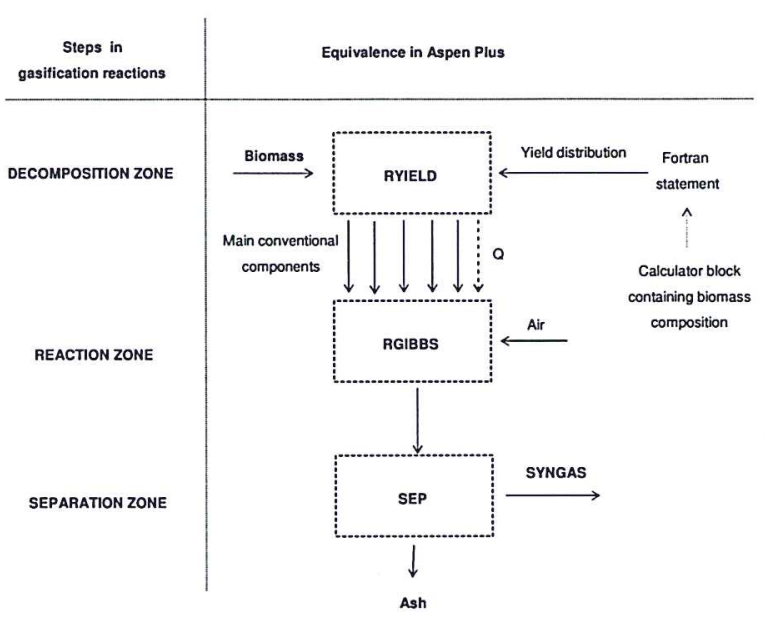

Figure 2: Main stages of gasification and equivalence in Aspen Plus ${ }^{\circledR}$

\subsubsection{Decomposition of feedstock}

A RYIELD reactor was used to convert the nonconventional feed (BIOMASS) into its main conventional components (carbon, oxygen, nitrogen, hydrogen, sulphur and ash) using a FORTRAN statement, where the yield distribution is specified according to the feedstock's ultimate analysis in a calculator block. A heat stream (Q) was introduced to add back the enthalpy loss resulting from the decomposition of feedstock and it was redirected to the following unit. The temperature of the unit was set at $25^{\circ} \mathrm{C}$.

\subsubsection{Reaction zone}

A RGIBBS reactor was applied to simulate the volatile reactions occurring during gasification. The decomposed biomass and the oxidant agent enter into the reactor that calculates the composition of the final gas by minimising the Gibbs free energy applying a nonstoichiometric equilibrium method. All the sulphur and nitrogen in the biomass are considered to react to form $\mathrm{H}_{2} \mathrm{~S}$ and $\mathrm{NH}_{3}$ respectively. Due to the low content of these compounds, the inaccuracies from this simplification have been taken as negligible [11]. The assumption of equilibrium was taken as valid, being the time of reaction the time in which the thermo-chemical conversion of the biomass achieves a value equal to 1 (Section 3.3).

\subsubsection{Separation zone}

The resulting stream enters into a cyclone (SEP) which separates the final gases (SYNGAS) and the residual ash (ASH) on a specified efficiency of $85 \%$ [12].

\subsection{Process parameters}

The input data provided for the sensitivity analysis are shown in Table IV. The flow rate of the biomass stream was held constant for all simulations. The air flow rate was varied to ensure ER values in the interval [0.2$0.4]$, with ER defined as the amount of air added relative to the amount of air required for stoichiometric combustion [13].

Table IV: Process parameters provided as input for the model

\begin{tabular}{lc}
\hline Parameter & Value \\
\hline Biomass feed rate $(\mathrm{kg} / \mathrm{h})$ & 10 \\
Air flow rate $\left(\mathrm{m}^{3} / \mathrm{h}\right)$ & $3-15$ \\
Biomass feed temperature $\left({ }^{\circ} \mathrm{C}\right)$ & 25 \\
Air temperature $\left({ }^{\circ} \mathrm{C}\right)$ & 25 \\
Gasifier temperature $\left({ }^{\circ} \mathrm{C}\right)$ & $700-900$
\end{tabular}

\section{RESULTS AND DISCUSSION}

The model described in Section 2 was used to investigate the effect of the Moisture Content (MC), Equivalence Ratio (ER) and Temperature of reaction (T) on the molar composition of the produced gas and on the parameters defining the overall efficiency of the process: High Heating Value (HHV) and Cold Gas Efficiency (CGE).

The HHV of the produced gas was calculated as:

$$
H H V_{\text {gas }}(M J / k g)=\sum_{i} x_{i} \cdot H H V_{i}
$$

with $x_{i}$ being the molar fraction of each combustible gas in the gas and $\mathrm{HHV}_{\mathrm{i}}$ its corresponding high heating value in $\mathrm{MJ} / \mathrm{kg}$ [13].

The CGE was obtained as:

$$
C G E(\%)=\frac{\dot{m}_{g a s} \cdot H H V_{g a s}}{\dot{m}_{\text {biomass }} \cdot H H V_{\text {biomass }}}
$$

where $\dot{m}_{\text {gas }}$ and $\dot{m}_{\text {biomass }}$ are the mass flow rates of the produced gas and biomass respectively and $\mathrm{HHV}_{\text {gas }}$ and $\mathrm{HHV}_{\text {biomass }}$ are the high heating values of the produced gas and biomass respectively.

\subsection{Effect of the Moisture Content (MC)}

The effect of the initial MC of the biomass on the overall performance of the reactor was firstly addressed.

Figure 3 shows the calculated HHV and CGE corresponding to the variation of MC from $10 \%$ to $30 \%$ for the different materials under study. The equivalence ratio was fixed at $E R=0.2$. The same trends were shown for all the applied conditions of work but were not represented for lack of relevance. 


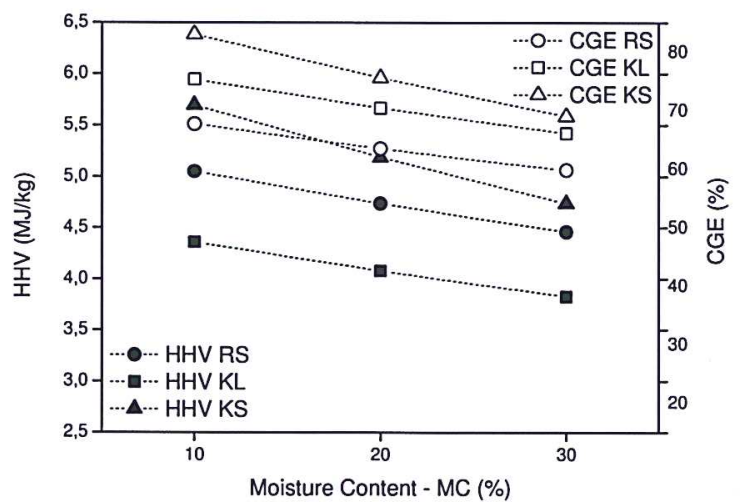

Figure 3: Effect of the Moisture Content (MC) on the HHV and CGE of the reactor

As shown in the figure, the initial MC of the feedstock has a strong negative effect on the gasifier performance for all studied fuels. Increasing values of $\mathrm{MC}$ result in lower production of syngas and, as a consequence, lower HHV and CGE. Therefore, the MC should be as low as possible and biomass should be dried prior its use to achieve values below the $10 \%$.

The high dependence of the final yields of reaction with the initial composition of the biomass can also be seen in Figure 3. KS presents the highest HHV for all given MC. This result is in line with the analysis of atomic ratios described in Section 1. As a consequence of its lower $\mathrm{O} / \mathrm{C}$ and $\mathrm{H} / \mathrm{C}$ ratios, the HHV results to be higher respect to those for KL and RS in which case the higher content of oxygen and hydrogen and lower of carbon provide a lower HHV.

\subsection{Effect of the Temperature of reaction (T)}

The effect of the gasifier temperature on the mole fraction ratio of the components present in the produced gas is shown in Figure 4 for the three types of waste at a fixed $\mathrm{ER}=0.2$.

From a thermodynamic point of view, the rising in the temperature of reaction favours the products of endothermic reactions and simultaneously, the reactants of exothermic reactions.

As shown in the figure, an increase of temperature results in an increase of $\mathrm{CO}$ for $\mathrm{RS}$ and $\mathrm{KL}$ within the whole range of study. For the case of $\mathrm{KS}$, an initial increase is observed until it remains almost constant from $\mathrm{T}=750^{\mathrm{a}} \mathrm{C}$. whereas the opposite trend is seen for $\mathrm{CO}_{2}$.

This fact is attributed to the partial combustion reactions taking place in the first instance (R1). Moreover, the predominance of the endothermic reactions (mainly R5) due to the rising in temperature also favours the production of $\mathrm{CO}$ and consumption of $\mathrm{CO}_{2}$. However, this increasing trend varies its tendency for the case of KS. At that point, all the carbon has been totally oxidised and, as a consequence, combustion reactions become predominant at high temperatures resulting in the production of $\mathrm{CO}_{2}$ and consumption of $\mathrm{CO}$.

$\mathrm{H}_{2}$ decreases in the whole range of temperatures in all cases favouring the production of $\mathrm{H}_{2} \mathrm{O}$.

Finally, $\mathrm{CH}_{4}$ decreased with temperature as a result of the exothermic reaction R6 in which the backwards direction is promoted at high temperatures, producing more $\mathrm{H}_{2}$.
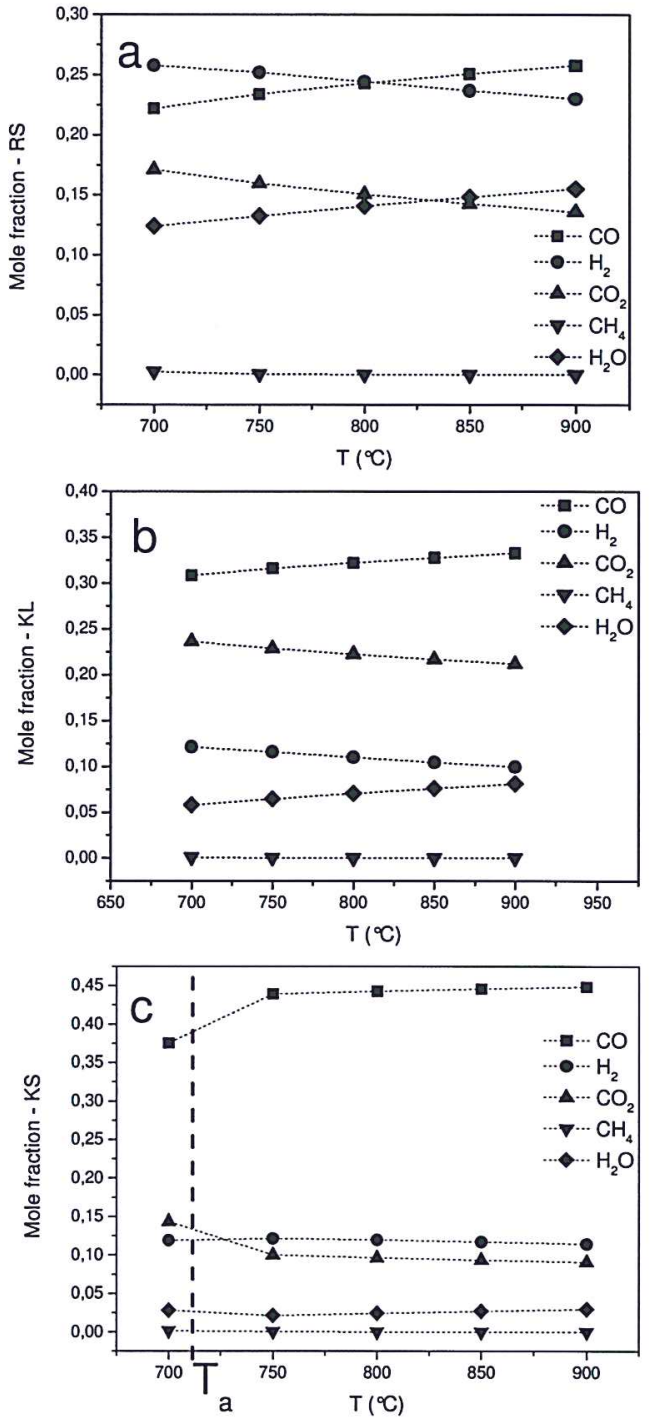

Figure 4: Effect of the Temperature of reaction $(T)$ on the molar composition of the produced gas $(E R=0.2)$

The process was found to be self-sustainable for $\mathrm{ER}=0.2$ at all the studied temperatures for RS and $\mathrm{KL}$. For the case of KS, a certain amount of heat was required to be applied to the system when the temperature $T_{a}$ was surpassed (Figure 4c).

In this sense, in order to evaluate the temperatures that make the process self-sustainable from an energy point of view at all the studied ER, a heat stream was added to the RGIBBS reactor and a Design specification was applied to obtain the $\mathrm{T}_{\mathrm{a}}$ leading to $\mathrm{Q}=\mathbf{0}$ (adiabatic conditions). The results are shown in Table V.

Table V: Variation of the self-sustainable temperature $\left(\mathrm{T}_{\mathrm{a}}\right)$ with the ER

\begin{tabular}{lccc}
\hline & $\mathrm{T}_{\mathrm{a}}\left({ }^{\circ} \mathrm{C}\right)-\mathrm{RS}$ & $\mathrm{T}_{\mathrm{a}}\left({ }^{\circ} \mathrm{C}\right)-\mathrm{KL}$ & $\mathrm{T}_{\mathrm{a}}\left({ }^{\circ} \mathrm{C}\right)-\mathrm{KS}$ \\
\hline $\mathrm{ER}=0.2$ & 1298 & 1060 & 715 \\
$\mathrm{ER}=0.25$ & 1414 & 1188 & 828 \\
$\mathrm{ER}=0.3$ & 1516 & 1302 & 1024 \\
$\mathrm{ER}=0.35$ & 1635 & 1403 & 1123 \\
$\mathrm{ER}=0.4$ & 1713 & 1493 & 1298
\end{tabular}


For the case of $\mathrm{KS}$ and an $\mathrm{ER}=0.2$, values of temperature above $715^{\circ} \mathrm{C}$ require the addition of extra heat to carry out the reactions and an increase of ER would be necessary to ensure an energetically viable process.

The highest content of $\mathrm{O}_{2}$ in the composition of RS and $\mathrm{KL}$ enhanced the oxidation reactions and, as a consequence, higher temperatures were achieved for a given ER.

Moreover, as stated in Section 2.3, SBR should not work at temperatures above the $1000^{\circ} \mathrm{C}$ that could lead to ash melting problems. In order to avoid these negative effects, a decrease of the equivalence ratio would lower the temperature of reaction, as well as a restriction on the biomass entering into the process, limiting the quantity to the desired temperature of work.

The variation of the HHV and CGE with the temperature of reaction was represented in Figure 5 (a) and (b) respectively for RS $(\bullet), \operatorname{KL}(\bullet), \operatorname{KS}(\Delta)$.
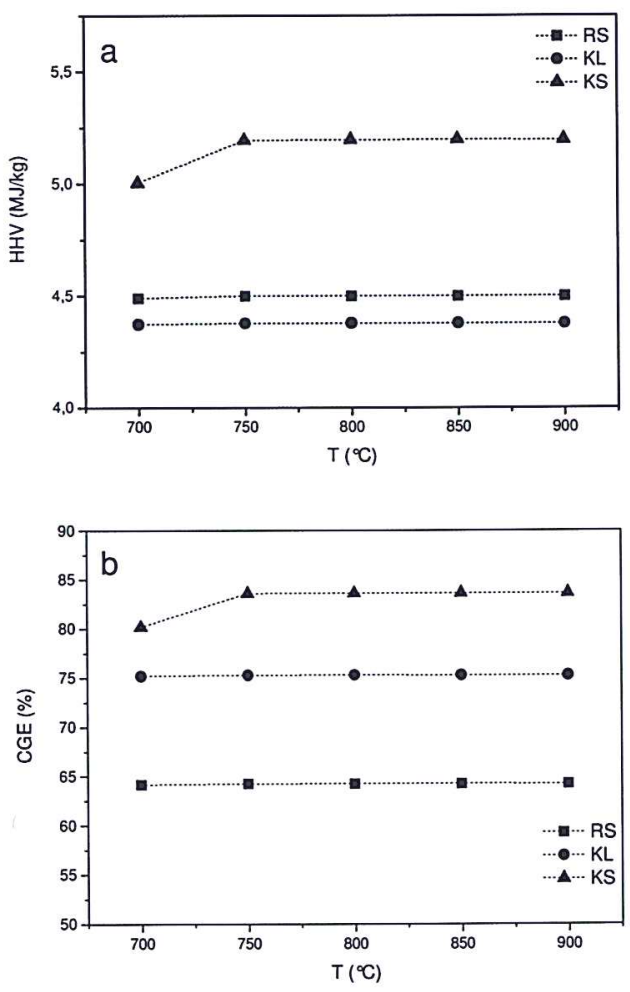

Figure 5: Effect of the Temperature of reaction (T) on the HHV and overall efficiency (CGE) of the process $(\mathrm{ER}=0.2)$

As shown in the figure, the temperature of reaction had little effect on the HHV and CGE of the process for $\mathrm{KL}$ and $\mathrm{KS}$. This behaviour confirms the trend described for the molar composition of the produced gas. The additional heating does not provide better efficiencies due to the total oxidation of the carbon already achieved at low temperatures when working at $\mathrm{ER}=0.2$. Only for the case of KS, a significant increase was observed at lower temperatures, where a CGE $=84 \%$ is obtained at $\mathrm{T}=750^{\circ} \mathrm{C}$.

Finally, the temperature of reaction has a great influence on the kinetic laws that describe the decomposition of the biomass. MATLAB was used to solve the first order differential equations to obtain the conversion of biomass at each of the studied temperatures. The boundary condition was defined as zero conversion when time equals to zero. Figure 6 (a) shows the results of the differential equations against time at each temperature of work for the case of KS.
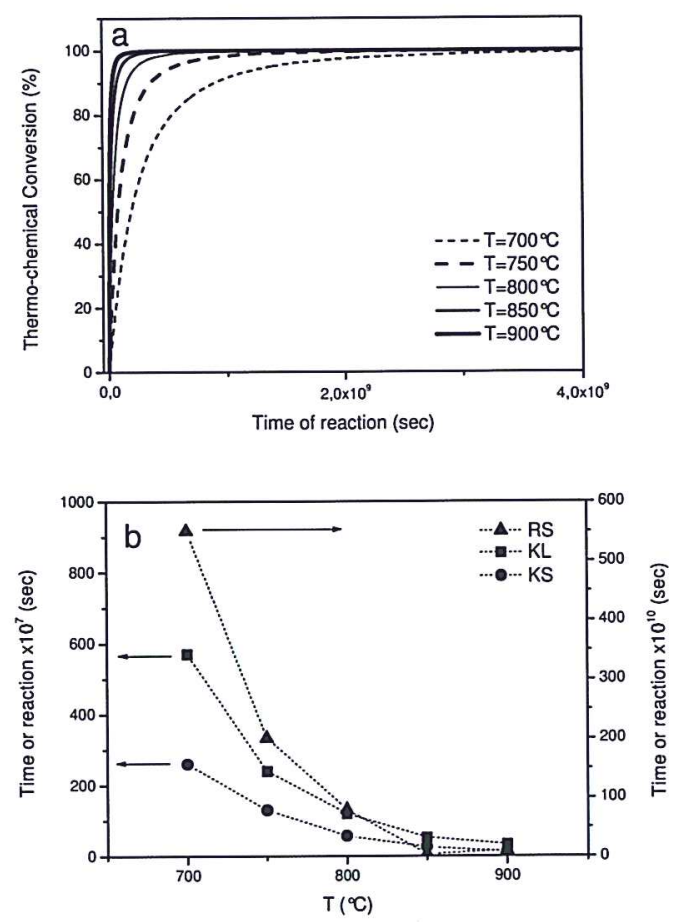

Figure 6: (a) Effect of the Temperature of reaction (T) on the kinetics of reaction (KS) (b) Effect of $T$ on the time of reaction for all types of biomass

It is clear that the temperature has a great effect on the kinetics of reaction, that is, on the times of reaction.

Figure 6 (b) represents the calculated time of reaction to achieve the complete conversion of the biomass at each temperature of work for all the types of biomass. From these results it can be stated that the equilibrium state as considered in the present work is achieved at extremely high times of reaction. However, this option would not be energetically viable and the need of a more detailed model arises in order to take into account these kinetic constraints. These kinetic laws, together with the specific fluid dynamic of the system will be applied to obtain a more accurate and specific model of the process.

As an initial study of the design parameters, the results taken from the equilibrium state assumption provide the thermodynamic limits defining the gasification of the studied types of biomass.

\subsection{Effect of the equivalence ratio (ER)}

The ER is defined as the ratio of the actual amount of oxygen supplied to the reactor and its stoichiometric value. It is clear that, as ER increases, the amount of oxygen supplied to the process also increases and that results in rising conversions of carbon in the fuel.

However, an excess of the oxidant agent produces a complete oxidation of the biomass and, as carbon is no longer available, the formation of $\mathrm{CO}$ declines in contrast with the increase in the production of $\mathrm{CO}_{2}$.

The effect of the ER on the molar fraction of the major components of the produced gas $\left(\mathrm{CO}, \mathrm{CO}_{2}, \mathrm{CH}_{4}\right.$ $\mathrm{H}_{2}$ and $\mathrm{H}_{2} \mathrm{O}$ ) was studied for each type of biomass. The ER was varied in the range of $0.2-0.4$ by varying the air 
flow entering into the reactor. Figure 7 shows the composition of the produced gas for the case of RS (a), $\mathrm{KL}$ (b) and KS (c). The reactor worked at a fixed temperature of reaction $\mathrm{T}=800^{\circ} \mathrm{C}$.

As shown in the figures, the increase in the conversion of the biomass results in a decreasing production of $\mathrm{CO}$ and $\mathrm{H}_{2}$. This behaviour could be explained by the predominance of the combustion reactions ( $\mathrm{R} 2$ and $\mathrm{R} 3$ ) as a consequence of the total conversion of carbon already achieved by $\mathrm{T}=800^{\circ} \mathrm{C}$ that yield higher amounts of $\mathrm{CO}_{2}$ and $\mathrm{H}_{2} \mathrm{O}$ through the consumption of $\mathrm{CO}$ and $\mathrm{H}_{2}$.

Finally, the molar fraction of $\mathrm{CH}_{4}$ decreases with increasing ER due to the methane reforming reaction (R6) that, as stated before, is promoted by high temperatures (equivalent to high ER) in the backwards direction.
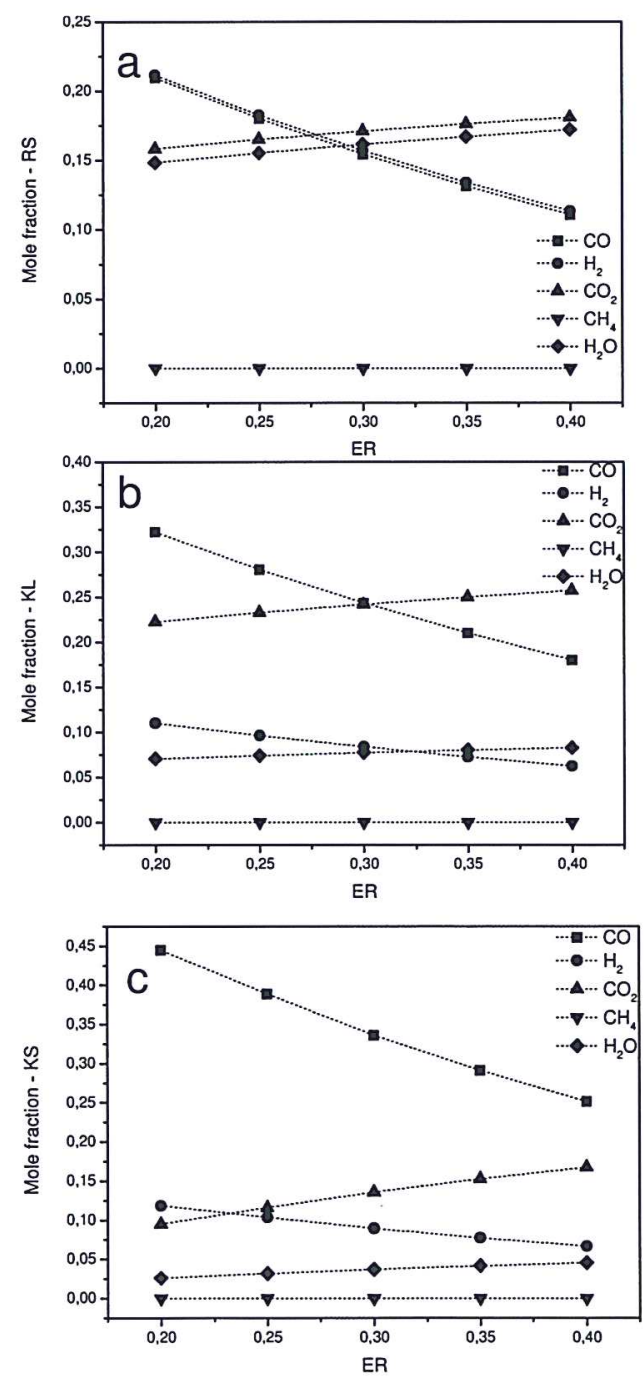

Figure 7: Effect of the Equivalence Ratio (ER) on the molar composition of the produced gas $\left(\mathrm{T}=800^{\circ} \mathrm{C}\right)$

In comparative terms, $\mathrm{KS}$ has the highest molar fraction of $\mathrm{CO}$ and $\mathrm{H}_{2}$ in the produced gas $(0.44$ and 0.12 respectively) for an $\mathrm{ER}=0.2$ whereas $\mathrm{RS}$ results in the lowest values. ER at maximum production of syngas was always in correspondence with the lowest ER.

The variation of the HHV and CGE with the ER is represented in Figure 8 (a) and (b) respectively for RS $(\bullet), \mathrm{KL}(\bullet), \mathrm{KS}(\boldsymbol{\Delta})$.

Higher values of HHV were found at low ER due to the higher content of $\mathrm{CH}_{4}$ in the produced gas. The CGE decreases with the ER even though the flow of produced gas increases. However, this rise is not enough to balance the decreasing behaviour of HHV. It is also worth noting that the maximum CGE corresponds to the point of maximum $\mathrm{CO}+\mathrm{H}_{2}$ content (Figure 7) showing the high dependence of the molar composition of the feedstock on the overall performance of the reactor. The same procedure was applied for all the range of temperatures and the resulting optimal conditions will be further discussed in Section 3.4.
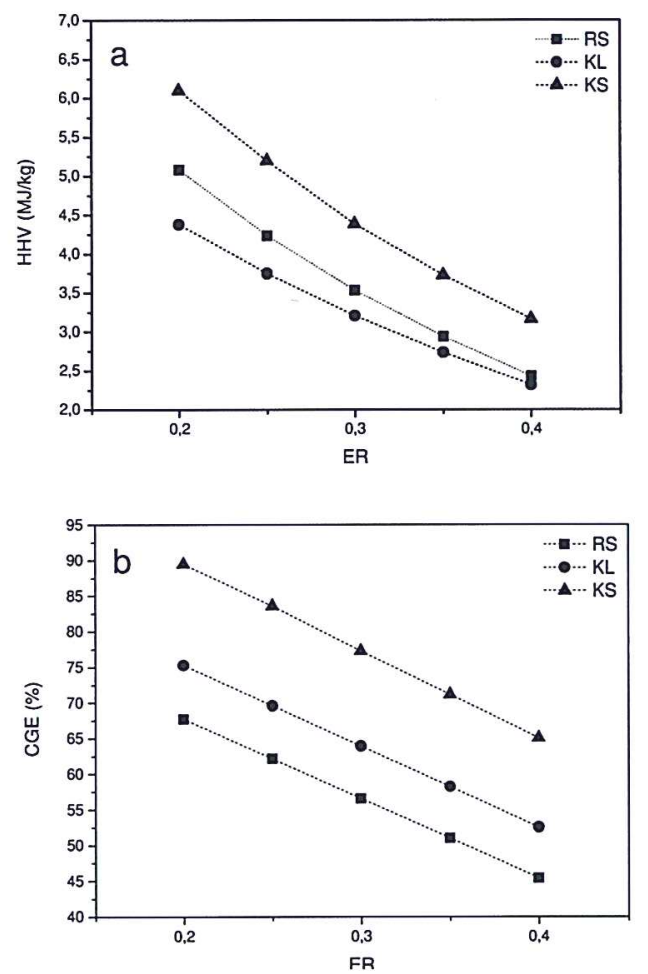

Figure 8: Effect of the Equivalence Ratio (ER) on the HHV and the overall efficiency (CGE) of the process $\left(\mathrm{T}=800^{\circ} \mathrm{C}\right)$

3.4 Obtaining of the optimum operational conditions

Tables VI, VII and VIII gather the values of CGE at each ER and temperature of reaction for each of the fuels under study.

Table VI: CGE at all tested conditions for Rice Straw (RS)

\begin{tabular}{cccccc}
\hline $\mathrm{RS}$ & $700^{\circ} \mathrm{C}$ & $750^{\circ} \mathrm{C}$ & $800^{\circ} \mathrm{C}$ & $850^{\circ} \mathrm{C}$ & $900^{\circ} \mathrm{C}$ \\
\hline $\mathrm{ER}=0.2$ & 64,17 & 64,27 & 64,28 & 64,27 & 64,27 \\
$\mathrm{ER}=0.25$ & 62,11 & 62,18 & 62,19 & 62,18 & 62,17 \\
$\mathrm{ER}=0.3$ & 56,58 & 56,62 & 56,62 & 56,61 & 56,60 \\
$\mathrm{ER}=0.35$ & 49,19 & 49,20 & 49,19 & 49,18 & 49,17 \\
$\mathrm{ER}=0.4$ & 43,63 & 43,63 & 43,62 & 43,60 & 43,60
\end{tabular}


Table VII: CGE at all tested conditions for Kaki Leaves (KL)

\begin{tabular}{cccccc}
\hline $\mathrm{KL}$ & $700^{\circ} \mathrm{C}$ & $750^{\circ} \mathrm{C}$ & $800^{\circ} \mathrm{C}$ & $850^{\circ} \mathrm{C}$ & $900^{\circ} \mathrm{C}$ \\
\hline $\mathrm{ER}=0.2$ & 75,22 & 75,30 & 75,31 & 75,30 & 75,30 \\
$\mathrm{ER}=0.25$ & 70,21 & 70,26 & 70,26 & 70,26 & 70,25 \\
$\mathrm{ER}=0.3$ & 65,19 & 65,22 & 65,21 & 65,21 & 65,20 \\
$\mathrm{ER}=0.35$ & 58,64 & 58,65 & 58,65 & 58,64 & 58,63 \\
$\mathrm{ER}=0.4$ & 52,60 & 52,60 & 52,59 & 52,58 & 52,57
\end{tabular}

Table VIII: CGE at all tested conditions for Kaki Stems (KS)

\begin{tabular}{crrrrr}
\hline $\mathrm{KS}$ & $700^{\circ} \mathrm{C}$ & $750^{\circ} \mathrm{C}$ & $800^{\circ} \mathrm{C}$ & $850^{\circ} \mathrm{C}$ & $900^{\circ} \mathrm{C}$ \\
\hline $\mathrm{ER}=0.2$ & 75.97 & 89.41 & 89.50 & 89.51 & 89.51 \\
$\mathrm{ER}=0.25$ & 80.20 & 83.61 & $\mathbf{8 3 . 6 5}$ & 83.66 & 83.66 \\
$\mathrm{ER}=0.3$ & 77.53 & 77.65 & 77.67 & 77.67 & 77.67 \\
$\mathrm{ER}=0.35$ & 71.47 & 71.53 & 71.54 & 71.53 & 71.53 \\
$\mathrm{ER}=0.4$ & 65.44 & 65.47 & 65.47 & 64.57 & 64.46
\end{tabular}

As shown in the tables, KS provides the highest CGE at all tested conditions respect to those from RS and KL. This fact can be attributed to the most adequate composition of the initial feedstock (higher volatile matter, lower ash content) together with its highest HHV.

The optimum conditions of work for KS providing the highest efficiency (highlighted in bold) were found to be $\mathrm{T}=800^{\circ} \mathrm{C}$ and $\mathrm{ER}=0.25$. Values above the selected temperature (represented in cursive) were demonstrated not energetically self-sustainable for the corresponding ER. For the case of RS and KL, the highest efficiencies were found at higher temperatures of work and lower ER.

However, the ER should be re-adjusted in order to control the enhanced reactions of oxidation as a consequence of the excess of oxidant agent. To do so, the temperature of the reactor was fixed at $900^{\circ} \mathrm{C}$ and a Design Specification was applied to obtain the ER that made $\mathrm{Q}=0$ (adiabatic condition). As a result, $\mathrm{RS}$ required an $E R=0.07$ that led to a $C G E=80.7 \%$ while $E R=0.14$ and a $\mathrm{CGE}=81.3 \%$ were obtained for $\mathrm{KL}$, lower than $\mathrm{KS}$ efficiencies in all cases. These values are in accordance with experimental results obtained from other authors [15].

\section{CONCLUSIONS}

Feasibility studies on the energy valorisation of rice straw and leaves and stems of the kaki fruit were performed with the aid of the commercial software Aspen Plus $^{\circledR}$. The chemical and thermal characterisation of the biomass was defined as input in the model. The increase on the moisture content decreased the overall efficiency in all cases. Lower equivalence ratios and temperatures of reaction led to higher HHV of the produced gas and, consequently, higher CGE. Kaki stem was found to be the residue with the highest yields of produced gas and efficiency with the optimal conditions set at $\mathrm{T}=800^{\circ} \mathrm{C}$ and $\mathrm{ER}=0.25$.

\section{REFERENCES}

[1] A. Kumar, D.D. Jones, M.A. Hanna. Thermochemical biomass gasification: A review of the current status of the technology. Energies 2, 2009, 556-581.

[2] C. Briens, J. Piskorz, F. Berruti. Biomass valorization for fuel and chemical production - a review. International Journal of Chemical Reactor Engineering, 6, 2008, 1-49.

[3] P. McKendry. Energy production from biomass (part 3): gasification technologies. Bioresource Technology 83, 2002, 55-63.

[4] D.W. van Krevelen. Graphical-statistical method for the study of structure and reaction processes of coal. Fuel, 29, 1950, 269-284.

[5] A. Gomez-Barea, B. Leckner. Modelling of biomass gasification in fluidised bed. Progress in Energy and Combustion Science 36, 2010, 444509.

[6] KB Mathur, N. Epstein. Spouted beds. New York: Academic Press, 1974.

[7] S. Jarungthammachote, A. Dutta. Equilibrium modelling of gasification: Gibbs free energy minimization approach and its application to spouted bed and spout-fluid bed gasifiers. Energy Conversion and Management 49, 2008, 1345-1356.

[8] Aspen Plus 8.4. User Manual guide, Aspen Technology (2014).

[9] C. Moliner, B. Bosio, E. Arato, A. Ribes. Comparative study for the energy valorisation of rice straw, Chemical Engineering Transactions 37, 2014, 241-246.

[10] J. Parikh, S.A. Channiwala, G.K.Ghosal. A correlation for calculating HHV from proximate analysis of solid fuels. Fuel 84, 2005, 487-494.

[11] G. Schuster, G. Loffler, K. Weigl, H. Hofbauer. Biomass steam gasification - an extensive parametric modeling study. Bioresource Technology 77, 2001, 71-79.

[12] R. Zhang, P. Basu. A simple model for prediction of solid collection efficiency of a gas-solid separator. Powder Technology 147, 2004, 86-93.

[13] X.T. Li, J.R. Grace, C.J. Lim, A.P. Watkinson, H.P. Chen, J.R. Kim. Biomass gasification in a circulating fluidized bed. Biomass and Bioenergy 26, 2004, 171-193.

[14] L. Waldheim, T. Nilsson, Heating values of gases from biomass gasification. Report for IEA Bioenergy agreement subcommittee on Therml gasification of biomasss, Task 20, 2001.

[15] W. Doherty, A. Reynolds, D. Kennedy. The effect of air preheating in a biomass CFB gasifier using Aspen Plus simulation. Biomass and Bioenergy 2009, 33, 1158-1167. 



\title{
Communication 5.II
}

Simulation activities for the pseudo-equilibrium modeling of the gasification of agricultural residues

\author{
C. Moliner, D. Bove, B. Bosio, A. Ribes, E. Arato.
}

Proceedings of the $24^{\text {rd }}$ European Biomass Conference and Exhibition. 2016. Amsterdam Submitted Abstract 



\title{
Simulation activities for the pseudo-equilibrium modelling of the gasification of agricultural residues
}

\author{
C.Moliner $^{1} *$, D.Bove ${ }^{2}$, B.Bosio $^{1}$, A.Ribes $^{3}$, E.Arato $^{1}$ \\ 1. Dipartimento di Ingegneria Civile, Chimica e Ambientale (DICCA), \\ Università degli Studi di Genova, Via Opera Pia 15, 16145 Genova (Italy) \\ 2. Faculty of Sciences and Technology. Free University of Bozen, Piazza Università 5, 39100 Bolzano (Italy) \\ 3. Instituto Tecnológico de Materiales (ITM,) \\ Universidad Politécnica de Valencia, Camino de Vera s/n, 46022. Valencia (Spain) \\ *corresponding author: cristina.moliner@edu.unige.it
}

The search of new materials acting as sustainable energy vectors to substitute traditional fossil fuels is object of intensive research nowadays. Agricultural residues offer a widespread availability and a suitable potential energy content. The use of these materials as feedstock for thermo-chemical conversions has been proven to be an adequate technique yielding high energy production rates with fewer associated environmental impacts. Gasification is one of the most common technologies applied to convert biomass into valuable products. It normally operates in a temperature range of $600-1400^{\circ} \mathrm{C}$ with a controlled supply of oxygen or steam to convert biomass into a gas mixture (syngas).

Feasibility studies on the performance of alternative fuels and the evaluation of their suitability for gasification purposes become necessary to better define the most adequate operating conditions to obtain the improved results. In general, two different approaches can be followed to address this objective: kinetic and equilibrium modelling, the latter further divided into stoichiometric (based on stoichiometric reactions) and non-stoichiometric (based on the minimisation of the Gibbs free energy) equilibrium. Equilibrium models are widely used to predict the overall performance of a gasifier defining the thermodynamic limits and operational constraints of a specific process. However, they do not represent accurately the real behaviour of the system as the equilibrium situation is hardly achieved due to kinetic limitations. In this sense, pseudo-equilibrium models can be used as an intermediate solution as they profit from the advantages and simplicity of equilibrium modelling while the necessary modifications can be performed to account for the factors moving the system from the ideal situation.

In this framework, the gasification of different agricultural residues (rice straw, residues from kaki fruit) is simulated following the pseudo-equilibrium approach with the aid of a simulation software. The models take into account the main experimental parameters defining the deviation from the thermodynamic equilibrium condition: carbon conversion and influence of the temperature on the equilibrium constants of the reactions.

The effect of the Temperature of reaction (T) and Equivalence Ratio (ER) on the distribution of products in the producer gas and on the performance of the process by the assessment of the High Heating Value (HHV) and the Cold Gas Efficiency (CGE) is evaluated. Finally, based on the developed model, the operating conditions of the gasifier are optimised.

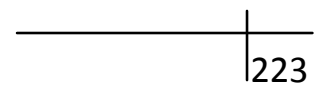





\section{Communication 5.III}

Process simulation of the gasification of rice straw by means of a spouted bed reactor based on its fluid dynamic and kinetic properties

C. Moliner, B. Bosio, A. Ribes, E. Arato.

Manuscript 

Process simulation of the gasification of rice straw by means of a spouted bed reactor based on its fluid dynamic and kinetic properties

\author{
C. Moliner ${ }^{1}$, B.Bosio ${ }^{1}$, A.Ribes ${ }^{2}$, E.Arato ${ }^{1}$ \\ 1. Dipartimento di Ingegneria Civile, Chimica e Ambientale (DICCA) \\ Università degli Studi di Genova, Via Opera Pia 15, 16145 Genova (Italy) \\ 2. Instituto Tecnologico de Materiales (ITM) \\ Universidad Politècnica de València, Camino de Vera s/n, 46022 Valencia (Spain)
}

\title{
Abstract
}

The gasification of rice straw was simulated with the commercial software Aspen Plus ${ }^{\odot}$. The fluid dynamic behaviour of the spouted bed reactor and the specific decomposition kinetics of the feedstock based on its main components were included in the model. The model was used to predict the gasifier performance under different operating conditions. As expected, higher temperatures improved the gasification process, increasing the Cold Gas Efficiency and Carbon Conversion Efficiency values. The Equivalence Ratio resulted to have an optimum value of 0.4 at $900^{\circ} \mathrm{C}$ for which the Cold Gas Efficiency achieved its maximum value $(86 \%)$ coinciding with the maximum production of $\mathrm{CO}$ and $\mathrm{H}_{2}$. At those conditions, the Carbon Conversion Efficiency was $85 \%$ indicating that the biomass is not completely converted even at high temperatures mainly due to kinetic limitations.

Keywords: gasification, rice straw, spouted bed reactor, kinetic approach; fluid dynamic approach

Highlights

- A model for the gasification of rice straw in a spouted bed reactor is developed

- Both fluid dynamic and kinetic properties of the system are considered

- An optimum equivalence ratio of 0.4 is obtained at $900^{\circ} \mathrm{C}$

- A maximum value of cold gas efficiency of $86 \%$ is achieved

Abbreviations

CCE - Carbon Conversion Efficiency

CGE - Cold Gas Efficiency

ER - Equivalence Ratio

ERst - Stoichiometric Equivalence Ratio

HHV - Higher Heating Value (MJ/kg)

SBR - Spouted Bed Reactors

Ums - minimum spouting velocity $(\mathrm{m} / \mathrm{s})$ 


\section{Introduction}

The use of biomass to produce renewable energy can provide a sustainable and low-carbon alternative to traditional fossil fuels based technologies. In particular, agricultural residues are one of the largest potential feedstock to become an important source of energy [1]. Its wide availability together with its renewable nature provide them with the adequate characteristics to become a new major energy vector. In addition, biomass can be comparatively more efficient than coal due to its higher volatile content and its high own percentage of oxygen composing the raw material.

Rice is one of the largest crops cultivated in the world with Spain and Italy being the major producers in Europe (over 850.000 and 1.300 .000 ton/year respectively according to FAOSTAT database [2]). As a result, a large quantity of residues derived from its harvest is yearly produced. The lignocellulosic nature of the straw and its relatively adequate energy content $(\mathrm{HHV}=15 \mathrm{MJ} / \mathrm{kg})$ make these residues suitable potential material to be converted into energy through thermo-chemical processes. Moreover, by doing this, an extra added value is given to an initially considered residual product while also contributing to the elimination of an environmental harmful waste.

Gasification is proven to be one of the most adequate processes to convert carbonaceous materials into valuable products [3]. Among the different technologies, fluidisation stands out as the most efficient technique when biomass is used as feedstock. However, traditional reactors need to adapt to the specific properties of the feed such as big and irregular dimensions in order to achieve optimised results. With this purpose, Spouted Bed Reactors (SBR) represent an adequate tool to carry out these reactions due to its particular configuration based on an enhanced circulation of solids. As a consequence, high mass and energy transfer rates are achieved as well as a uniform temperature profile along the reactor [4].

A deep insight in the complex mechanisms of reaction occurring during the gasification of biomass together with the optimisation of new devices developed to satisfy the new requirements is currently the major challenge for the correct development of the technology. In this sense, simulation activities provide a helpful tool to evaluate, assess and optimise thermo-chemical processes in an easy and effective way. Several attempts have been done to model the gasification of biomass by means of fluidised technologies following different approaches: equilibrium, kinetic and fluid dynamic based models. Equilibrium modelling can be a versatile tool to obtain information regarding the thermodynamic limits imposed by the reactions under consideration and to evaluate the effect of the operating variables on the main parameters of the process in a low time consuming way. However, they lack of specificity as they do not consider the particular kinetics of decomposition of the material or the fluid dynamic properties of the system. As a result, the model results convenient for the initial stages of the design of the process but needs to be upgraded when a more specific and detailed solution is needed. Extensive attempts have been performed to describe the gasification of biomass following the equilibrium approach: Mansaray et al [5] simulated rice husk gasification by means of a fluidised bed reactor and Li et al [6] provided a wide description of the influence of the carbon conversion on the correct use of equilibrium models when applied to fluidised reactors. Doherty et al [7] followed a pseudo-equilibrium approach by correcting the model with experimental data. However, little research has been done in the simulation of spouted bed reactors. Jarungthammachote et al [8] and Moliner et al [9] provided a description of the system following an equilibrium approach but the results failed to predict the main products, showing the importance of the inclusion of the kinetic and fluid dynamic properties of the system.

Several works have addressed a more detailed description of the process by including the specific kinetic rates and the equations defining the fluid dynamic system: Nikoo et al [10] developed a model including the equations of the bubbling bed and the kinetic expressions of char combustion obtaining improved 
results and Abdelouahed et al [11] took into account a detailed kinetic description of the reactions involved achieving accurate predicted values for the gas composition and tar and char final contents.

It is clear that a detailed description of the conversion of biomass during gasification will permit the correct definition of the operating conditions for each case of study. With this purpose, a model describing the gasification of rice straw by means of a pilot spouted bed reactor has been developed. The kinetics of decomposition of the feedstock, based on the sum of the main decomposition rates of the pseudocomponents (i.e. hemicellulose, cellulose and lignin), has been applied. The inclusion of the kinetic rates of the lignocellulosic species provides a tool that may be applied in more general situations than those for specific raw materials. The previous fluid dynamic characterisation of the system [12] provided the specific fluid dynamic inputs that ensure a stable spouting process and were also integrated into the model. The model was used for the further optimisation of the production of syngas from rice straw by means of the studied spouted bed pilot plant. Figure 1 represents the scheme of the methodology based on the integration of the different specific characteristics of the system.

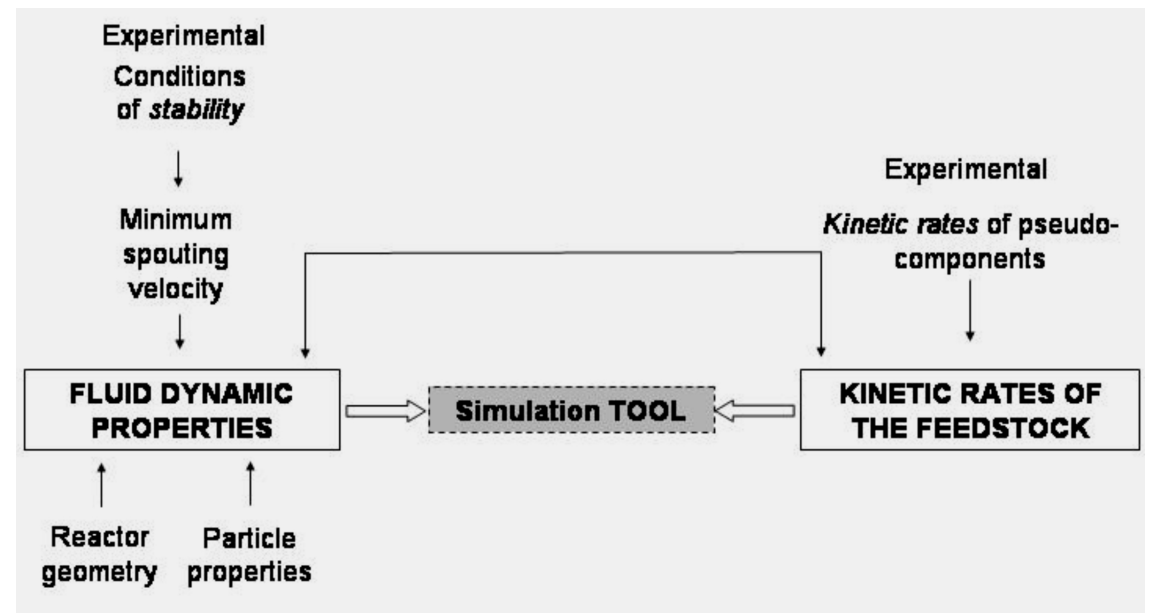

Figure 1. Scheme of the methodology for the integration of the specific characteristics of the system into the model

\section{Methodology}

\subsection{Spouted bed pilot plant}

A previously developed spouted bed pilot plant [12] has been used as the reference unit to model the gasification of the rice straw. Figure 2 shows the schematic diagram of the SBR where the reactions of gasification take place. The gasifying agent enters the system through a single centered orifice situated in the squared base of the device. The spouting velocity is regulated so the particles remain in a state of suspension forming a characteristic parabolic shape, the so-called fountain, and ensuring the cyclic and regular movement of solids at all times. Rice straw is introduced at the top of the reactor and is quickly mixed with the silica acting as bed material, with an extensive exchange of heat and mass. The reactions of gasification can be divided into three main stages: drying and devolatilisation, assumed to be instantaneous, partial oxidation of volatiles and char and finally, char gasification and reforming reactions. 


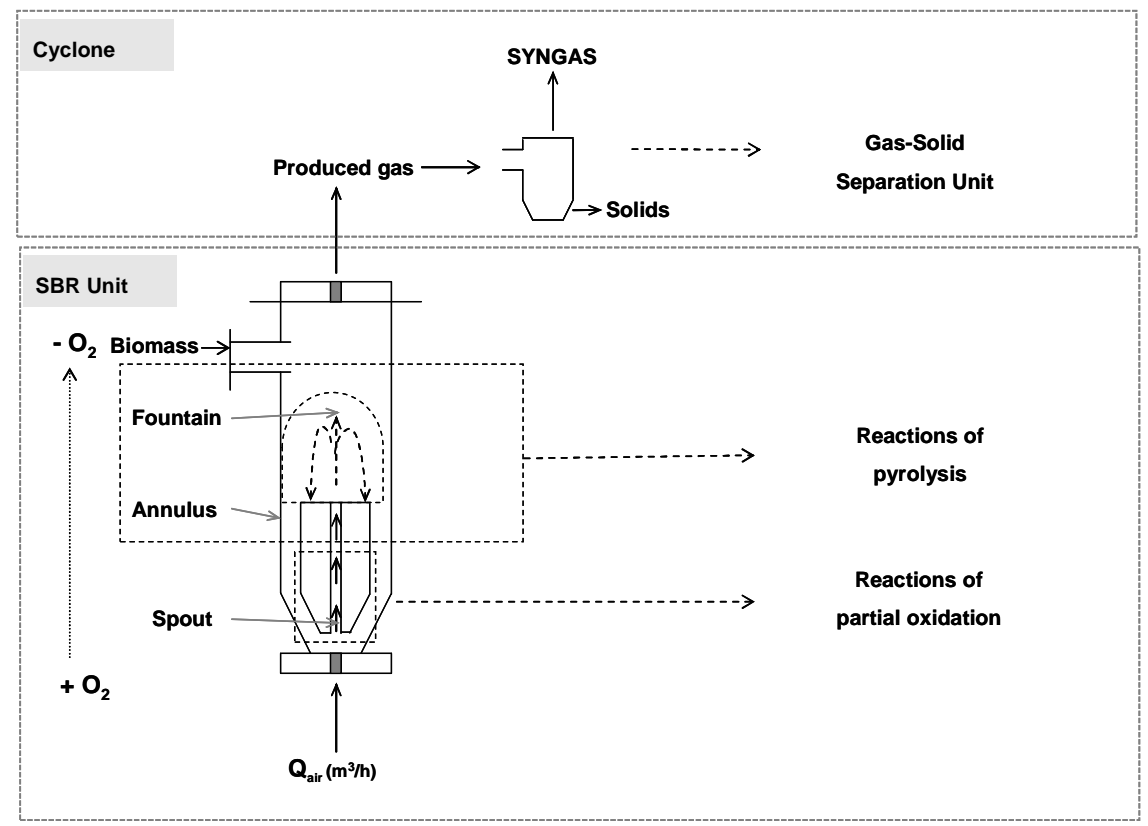

Figure 2. Schematic diagram of the SBR and location of the gasification reactions within it

The amount of gasifying agent to accomplish the fluid dynamic requirements is defined according to the minimum spouting velocity (Ums), defined as the minimum velocity required to maintain the solids in continuous motion [4]. A correct assessment of this parameter is crucial for the adequate behaviour of the spouted bed reactor. Lower values result in no spouting phenomena whereas higher values can lead to large instabilities and preferred channelling effects, having a negative effect on the system and resulting in a loss of efficiency. A previous characterisation of the Ums of the system composed by silica (acting as bed inert material) and rice straw was previously performed [12]. The system under study consisted of a mixture silica-rice straw $(20 \% \mathrm{v} / \mathrm{v})$ which corresponded to $10 \mathrm{~kg}$ of silica and $100 \mathrm{~g}$ of rice straw to achieve the initial bed height of $45 \mathrm{~cm}$. The superficial air velocity was defined as $U=1.1 \mathrm{Ums}$, in order to ensure stable spouting conditions. All the geometric and physical properties of the system applied to the present simulation are gathered in Table 1. Under these conditions, an air mass flow rate of $16 \mathrm{~g} / \mathrm{sec}$ was found to be the minimum quantity required to maintain the stable spouting conditions [12]. Finally, a cyclone is introduced to separate the gas and solid streams.

Table 1: Main geometric and physical properties of the system silica-rice straw

\begin{tabular}{ll|ll}
\hline Geometric Parameter & Value & Physical Parameter & Value \\
\hline Inlet diameter $(\mathrm{m})$ & 0.025 & Effective diameter of particle $(\mathrm{m})$ & $2.8 \cdot 10^{-3}$ \\
Column diameter $(\mathrm{m})$ & 0.2 & Effective density of particles $\left(\mathrm{kg} / \mathrm{m}^{3}\right)$ & 1470 \\
Height of static bed $(\mathrm{m})$ & 0.45 & Density of air $\left(\mathrm{kg} / \mathrm{m}^{3}\right)$ & 1.2
\end{tabular}




\subsection{Properties of feedstock}

The proximate analysis of rice straw (RS) and the ultimate and proximate analysis of the main pseudocomponents (hemicellulose-Hem, cellulose-Cel and lignin-Lig) are presented in Table 2. The values corresponding to RS were experimentally calculated [14] and those for the pseudo-components were taken from [15]. The values introduced for $\mathrm{Hem}$, Cel and Lig were taken in ash-free basis and the corresponding amount of ash in rice straw was added as an additional stream, as it will be further explained in Section 3.2. It is worth highlighting that this ash plays a determinant role in the design of the gasifier due to its high content of silica that can lead to slagging and fouling within the reactor. To avoid them, temperatures below $1000^{\circ} \mathrm{C}$ are recommended and so, the temperature of reaction for all the simulations was limited to that value.

Table 2: Feedstock properties introduced as input in Aspen Plus ${ }^{\odot}$

\begin{tabular}{|c|c|c|c|c|c|c|c|c|}
\hline $\begin{array}{l}\text { Proximate analysis } \\
\text { (wt. \%) }\end{array}$ & RS & Hem & Cel & Lig & $\begin{array}{l}\text { Ultimate analysis } \\
\text { (wt. \%) }\end{array}$ & Hem & Cel & Lig \\
\hline Moisture content (MC)a & 9.1 & - & - & - & Ash $^{\mathrm{b}}$ & 3.9 & 0 & 1.9 \\
\hline Fixed Carbon (FC) & 16.1 & 21.9 & 8.5 & 39.9 & $\mathrm{C}^{\mathrm{c}}$ & 43.4 & 43.6 & 64.4 \\
\hline Volatile Matter (VM)b & 63.3 & 74.2 & 91.5 & 58.2 & $\mathrm{H}^{\mathrm{c}}$ & 5.9 & 6.1 & 5.9 \\
\hline \multirow[t]{2}{*}{ Ash $^{b}$} & 20.6 & 3.9 & 0 & 1.9 & $\mathrm{O}^{c}$ & 50.63 & 50.24 & 27.6 \\
\hline & & & & & $\mathrm{Nc}^{\mathrm{c}}$ & 0.05 & 0.05 & 0.64 \\
\hline $\mathrm{HHV}_{\text {biomass }}{ }^{\mathrm{d}}(\mathrm{MJ} / \mathrm{kg})$ & 11.1 & 16.9 & 17.2 & 26.6 & $\mathrm{Sc}^{\mathrm{c}}$ & 0.02 & 0.01 & 1.46 \\
\hline
\end{tabular}

${ }^{a}$ wet basis, ${ }^{b}$ dry basis, ${ }^{c}$ ash-free basis ${ }^{d}$ according to Parikh [13]

\subsection{Kinetics of gasification}

The reaction mechanisms, kinetic parameters and thermal stability of the rice straw based on the sum of the kinetic behaviour of its main components wereexperimentally calculated through thermogravimetric analysis (TGA) using either $\mathrm{Ar}$ or $\mathrm{O}_{2}$ to simulate the thermal and thermo-oxidative decompositions of the feed, respectively. The kinetic triplets defining the main decomposition processes are presented in Table 3. Their discussion is not presented here as it is beyond the scope of this work. This way, the kinetic model describes in more detail the decomposition of the fuel as a function of its elementary components and not as a global reaction. Also, the model provides a more general simulation tool, suitable for its application to any type of feedstock provided the main decomposition kinetics of its pseudo-components are known.

Table 3: Kinetic parameters of the main decomposition processes for RS

\begin{tabular}{cccc|ccc}
\hline & \multicolumn{3}{c|}{ Combustion } & \multicolumn{3}{c}{ Pyrolysis } \\
\hline Parameter/ Pseudo-component & Hem & Cel & Lig & Hem & Cel & Lig \\
\hline Activation energy (kJ/mol) & 106 & 133 & 123 & 75 & 59 & 121 \\
Pre-exponential factor $\left(\mathrm{sec}^{-1}\right)$ & $6.4 \cdot 10^{2}$ & $2.5 \cdot 10^{4}$ & $1.1 \cdot 10^{6}$ & $1.1 \cdot 10^{7}$ & $1.5 \cdot 10^{7}$ & $8.1 \cdot 10^{6}$ \\
Order of reaction & 0.64 & 0.8 & 1.7 & 1.35 & 0.89 & 1.49
\end{tabular}


The content of each of the pseudo-components in RS was calculated and was equal to $35.7 \%$ wt hemicellulose, $32 \%$ wt cellulose and $22.3 \%$ wt lignin and their molecular formula were $\mathrm{C}_{5} \mathrm{H}_{8} \mathrm{O}_{4}$ (hemicellulose), $\mathrm{C}_{6} \mathrm{H}_{10} \mathrm{O}_{5}$ (cellulose) and $\mathrm{C}_{6} \mathrm{H}_{10} \mathrm{O}_{5}$ (lignin).

The combustion reactions considered for hemicellulose, cellulose and lignin were:

$$
\begin{aligned}
& \mathrm{C}_{5} \mathrm{H}_{8} \mathrm{O}_{4}+5 \mathrm{O}_{2} \longrightarrow 4 \mathrm{H}_{2} \mathrm{O}+5 \mathrm{CO}_{2} \\
& \mathrm{C}_{6} \mathrm{H}_{10} \mathrm{O}_{5}+6 \mathrm{O}_{2} \longrightarrow 5 \mathrm{H}_{2} \mathrm{O}+6 \mathrm{CO}_{2} \\
& \mathrm{C}_{10} \mathrm{H}_{12} \mathrm{O}_{3}+11.5 \mathrm{O}_{2} \longrightarrow 6 \mathrm{H}_{2} \mathrm{O}+10 \mathrm{CO}_{2}
\end{aligned}
$$

Similarly, the reactions of pyrolysis were represented as:

$$
\begin{aligned}
& \mathrm{C}_{5} \mathrm{H}_{8} \mathrm{O}_{4} \longrightarrow 2 \mathrm{H}_{2}+4 \mathrm{CO}+\mathrm{CH}_{4} \\
& \mathrm{C}_{6} \mathrm{H}_{10} \mathrm{O}_{5} \longrightarrow 3 \mathrm{H}_{2}+5 \mathrm{CO}+\mathrm{CH}_{4} \\
& \mathrm{C}_{10} \mathrm{H}_{12} \mathrm{O}_{3} \rightarrow 2 \mathrm{H}_{2}+3 \mathrm{CO}+2 \mathrm{CH}_{4}+5 \mathrm{C}
\end{aligned}
$$

Finally, the reactions considered in the equilibrium, were:

$$
\begin{aligned}
& \mathrm{C}+\mathrm{CO}_{2} \leftrightarrow 2 \mathrm{CO} \\
& \mathrm{C}+2 \mathrm{H}_{2} \leftrightarrow \mathrm{CH}_{4} \\
& \mathrm{CO}+\mathrm{H}_{2} \mathrm{O} \leftrightarrow \mathrm{CO}_{2}+\mathrm{H}_{2}
\end{aligned}
$$

\subsection{Fluid dynamic evaluation of the system}

Once the stable conditions were set, the air flow required to process the biomass was evaluated according to the relation imposed by the Equivalence Ratio (ER) parameter, defined as the amount of air added relative to the amount of air required for a stoichiometric combustion [16]:

$$
E R=\frac{\dot{m}_{\text {air }}}{E R_{\text {st }} \cdot \dot{m}_{\text {biomass }}}
$$

With $\dot{m}_{\text {air }}$ and $\dot{m}_{\text {biomass }}$ the mass flow rate of air and biomass respectively and $\mathrm{ER}_{\mathrm{st}}$ the ratio between the stoichiometric quantity of air required for the complete oxidation of biomass respect to the introduced biomass flow. ER st $_{\text {st }}$ calculated on the basis of the ultimate analysis of the main components defined in Table 2.

According to (10), the quantity of air introduced into the system for the range of $E R=0.15-0.4$ is gathered in Table 4. For the minimum value of ER considered, the amount of air was $79 \mathrm{~g} / \mathrm{s}$. This value is higher than the flow needed to maintain spouting conditions (16 g/s, Section 2.1) and thus, it can be assured that the system fulfils the necessary fluid dynamic requirements. 
Table 4: Air flow rates for the range $E R=0.15-0.4$

\begin{tabular}{cc|cc} 
ER & $\dot{m}_{\text {air }(\mathrm{g} / \mathrm{s})}$ & ER & $\dot{m}_{\text {air }(\mathrm{g} / \mathrm{s})}$ \\
\hline 0.15 & 79 & 0.3 & 158 \\
0.2 & 105 & 0.35 & 184 \\
0.25 & 131 & 0.4 & 210
\end{tabular}

\section{Modelling}

The commercial software Aspen Plus ${ }^{\odot}$ was used to simulate the gasification of rice straw according to the principles of mass, energy and chemical balances. This tool contains a large property database for conventional components and provides the possibility of adding built-in expressions to further personalise the model.

\subsection{Property method and main assumptions}

The property method RK-SOAVE was used to estimate the properties of mixed conventional and inert solid components. HCOALGEN and DCOALIGT models were used to calculate the enthalpy and density of non-conventional components respectively. Ashes were also defined as non-conventional component and were introduced as input into the property set with an ash content set to $100 \%$ for both proximate and ultimate analysis. The stream class was defined as MIXCINC that includes MIXED, NONCONVENTIONAL and SOLIDS streams.

The main assumptions considered in the development of the model were:

- The process is steady-state

- Gasification is considered to occur under isothermal conditions

- The thermal dissipation is neglected

- The system is considered to be in perfect mixing and uniform temperature

- Char contains carbon and ash

- Products of reaction of $\mathrm{N}$ and $\mathrm{S}$ are neglected due to their low concentration in the biomass

- Ash is assumed to be inert and does not participate in the chemical reactions

- The cyclone efficiency is set at $85 \%$ [17]

\subsection{Description of the flowsheet and main inputs of the model}

Figure 3 shows the flowsheet of the overall simulation process. The system is defined as the combination of several main blocks whose descriptions are presented in Table 5. The reaction of gasification is subdivided and its products are obtained as the sum of the products of gasification of each of its pseudocomponents. Each coloured box represents one of the components (hemicellulose - green dotted box, cellulose - grey dotted box and lignin - orange dotted box) and each unit is labelled as Hem, Cel or Lig according to its associated element. 


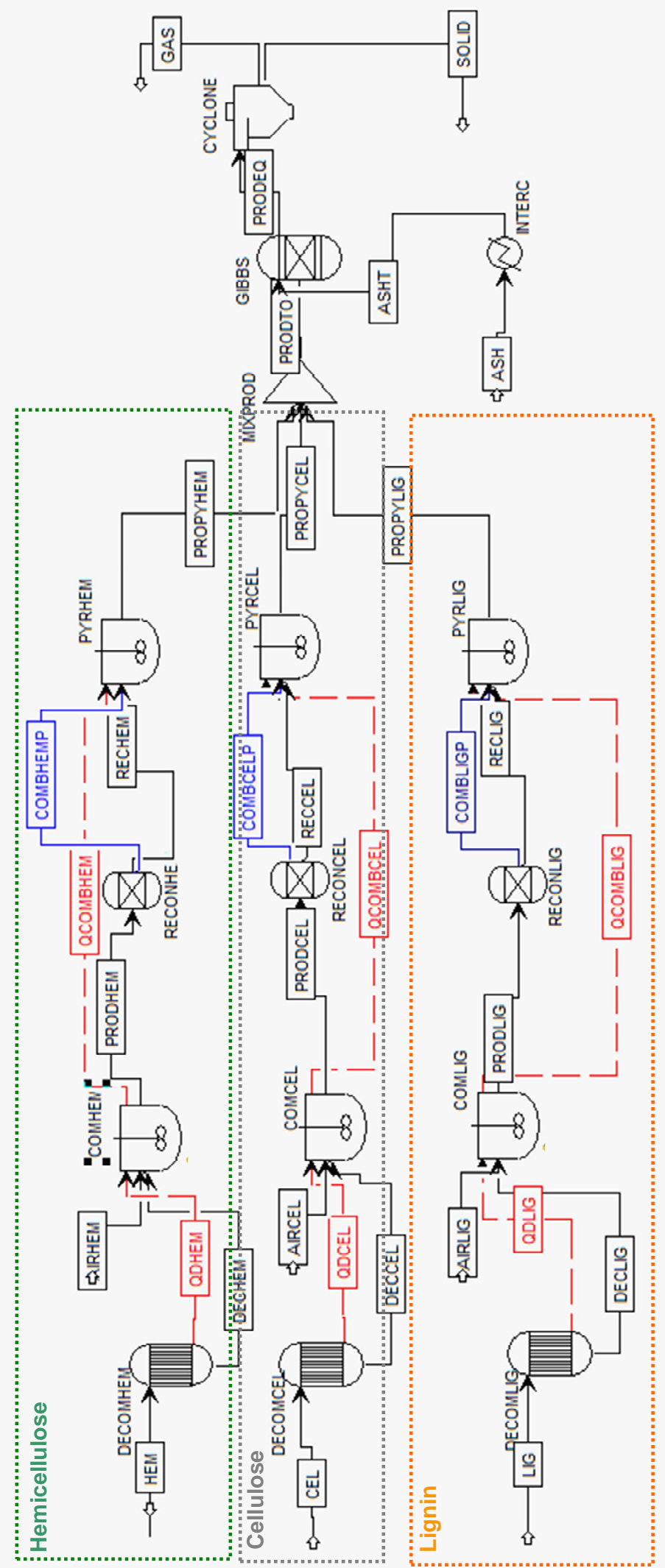

Figure 3. Scheme of the overall simulation process for the gasification of rice straw 
Table 5: Description of the blocks used in the simulation

\begin{tabular}{|c|c|c|}
\hline Block & Aspen unit & Description \\
\hline DECOMHEM/CEL/LIG & RYIELD & $\begin{array}{l}\text { Break down of the fuel into its main constituents (carbon, } \\
\text { hydrogen, oxygen, nitrogen, sulphur, carbon and ash) }\end{array}$ \\
\hline $\begin{array}{l}\text { COMHEM/CEL/LIG } \\
\text { PYRHEM/CEL/LIG }\end{array}$ & RCSTR & $\begin{array}{l}\text { Combustion and Pyrolysis reactions. Sub-routine } \\
\text { implemented with user-specified kinetics }\end{array}$ \\
\hline RECONHEM/CEL/LIG & SEP & $\begin{array}{l}\text { Separation of streams containing products and still not } \\
\text { reacted fuel }\end{array}$ \\
\hline MIXPROD & MIXER & Mix of the three sub-streams \\
\hline GIBBS & RGIBBS & $\begin{array}{l}\text { Restricted Equilibrium. Specification of the percentage of } \\
\text { conversion of } \mathrm{CH}_{4} \text { in the equilibrium. Carbon defined as inert } \\
\text { material }\end{array}$ \\
\hline CYCLONE & CYCLONE & Separation of gas and solid streams \\
\hline
\end{tabular}

Biomass (in form of its main pseudo-components) is introduced into the system as non-conventional compounds (HEM, CEL and LIG streams). A first RYIELD unit (DECOMHEM/CEL/LIG) is used to convert the feedstock into their main elements and enable the software to treat them as conventional components. The total yield of volatiles is assumed to be equal to the volatile content specified in the proximate analysis. Hem, Cel and Lig are independently converted into its constituting components: carbon, hydrogen, oxygen, sulphur, nitrogen and ash by an external sub-routine where the yields are specified using FORTRAN statements in a Calculator Block. A heat stream (QDHEM/CEL/LIG, in red) is introduced to add back the enthalpy loss resulting from the decomposition of the feedstock and it is redirected to the following unit. The temperature of the unit is set at $25^{\circ} \mathrm{C}$.

Three parallel RCSTR (COMHEM/CEL/LIG) simulated the partial oxidation of each pseudo-component. A restricted quantity of oxygen (AIRHEM/CEL/LIG) produced the oxidation of the biomass into $\mathrm{CO}_{2}$ and $\mathrm{H}_{2} \mathrm{O}$. It is assumed that oxidation reactions are fast enough to precede those endothermic and consume this way all of the available oxygen. Moreover, exothermic reactions provide the system with the necessary energy required to carry out the following endothermic reactions. The kinetics of reaction were specified by a user-defined routine according to their kinetic parameters previously calculated. The volume of the RCSTR unit was taken equal to the initial bed of particles, as it is the zone where combustion reactions take place (See Section 2.1). Two different outputs were obtained from the reactor: a heat stream (QCOMBHEM/CEL/LIG, in red) that provides the heat resulting from the exothermic reaction to the pyrolytic step and the product stream (PRODHEM/CEL/LIG) containing both the products of combustion and the remaining components that have not reacted.

The stream PRODHEM/CEL/LIG is directed to a separation unit (RECONHEM/CEL/LIG) in order to divide the streams with the products of combustion (COMBHEMP/CELP/LIGP, in blue) and the compounds that have not reacted yet (RECHEM/CEL/LIG) and will go through pyrolysis. The kinetics of reaction in the pyrolysis step were specified by a user-defined routine according to their kinetic parameters previously presented. No additional feeding was added in this case, as the reactions happen in absence of oxidant reagent. 
The sub-streams are mixed (MIXPROD) and the resulting stream (PRODTOT) is further sent to a Gibbs reactor (GIBBS) where a restricted equilibrium is imposed. The component $\mathrm{C}$ was taken as inert material and an extent of reaction equal to $90 \%$ for $\mathrm{CH}_{4}$ was selected. An additional stream (ASHT) containing the difference in ashes in rice straw respect to those from the pseudo-components (See Section 2.1) is also provided as input of the Gibbs reactor. These ashes (ASH) previously went through a heat exchanger (INTERC) in order to increase their temperature to that of reaction. Finally, a cyclone separates the solid and gas streams.

The input data provided for this study are shown in Table 6. The flow rate of air and biomass were defined according to fluid dynamic and thermo-chemical constraints in order to ensure adequate spouting values as well as an appropriate ER as explained in Section 2.1 and 2.4 .

Table 6: Process parameters provided as input for the model

\begin{tabular}{ll}
\hline Parameter & Value \\
\hline Biomass feed rate $(\mathrm{g} / \mathrm{s})$ & 100 \\
Air flow rate $(\mathrm{g} / \mathrm{s})$ & $15-75$ \\
Biomass feed temperature $\left({ }^{\circ} \mathrm{C}\right)$ & 25 \\
Air temperature $\left({ }^{\circ} \mathrm{C}\right)$ & 25 \\
Gasifier temperature $\left({ }^{\circ} \mathrm{C}\right)$ & $600-900$
\end{tabular}

4. Sensitivity analysis and discussion

The proposed model was used to investigate the effect of the ER and temperature of reaction on the molar composition of the produced gas and to study the performance of the gasification process through the evaluation of the following parameters: Higher Heating Value (HHV), Cold Gas Efficiency (CGE) and Carbon Conversion Efficiency (CCE). The HHV of the produced gas was calculated as:

$$
H H V_{\text {gas }}(M J / \mathrm{kg})=\sum_{i} x_{i} \cdot H H V_{i}
$$

with $x_{i}$ being the molar fraction of each combustible gas in the produced gas and $\mathrm{HHV}_{\mathrm{i}}$ its corresponding higher heating value in MJ/kg [18]. The CGE was obtained as:

$$
C G E(\%)=\frac{\dot{m}_{\text {gas }} \cdot H H V_{\text {gas }}}{\dot{m}_{\text {biomass }} \cdot H H V_{\text {biomass }}} \cdot 100
$$

where $\dot{m}_{\text {gas }}$ and $\dot{m}_{\text {biomass }}$ are the mass flow rates of the produced gas and fed biomass respectively and $\mathrm{HHV}_{\text {gas }}$ and $\mathrm{HHV}_{\text {biomass }}$ are the higher heating values of the produced gas and fed biomass respectively.

Finally, the CCE:

$$
\operatorname{CCE}(\%)=\frac{\dot{m}_{\text {gas }} \cdot C_{\text {gas }}}{\dot{m}_{\text {biomass }} \cdot C_{\text {biomass }}} \cdot 100
$$

where $\mathrm{C}_{\text {gas }}$ and $\mathrm{C}_{\text {biomass }}$ are the percentage of carbon (\%wt) in the produced gas and fed biomass respectively. 
4.1. Effect of the temperature of reaction on the gasification process

\subsubsection{Gas composition}

The gasification temperature is one of the main variables that need to be assessed in a thermo-chemical process, as it affects the whole system varying the chemical reactions involved and their corresponding kinetics. Figure 4 shows the variation of the products distribution with the increasing temperature at a fixed $\mathrm{ER}=0.3$.

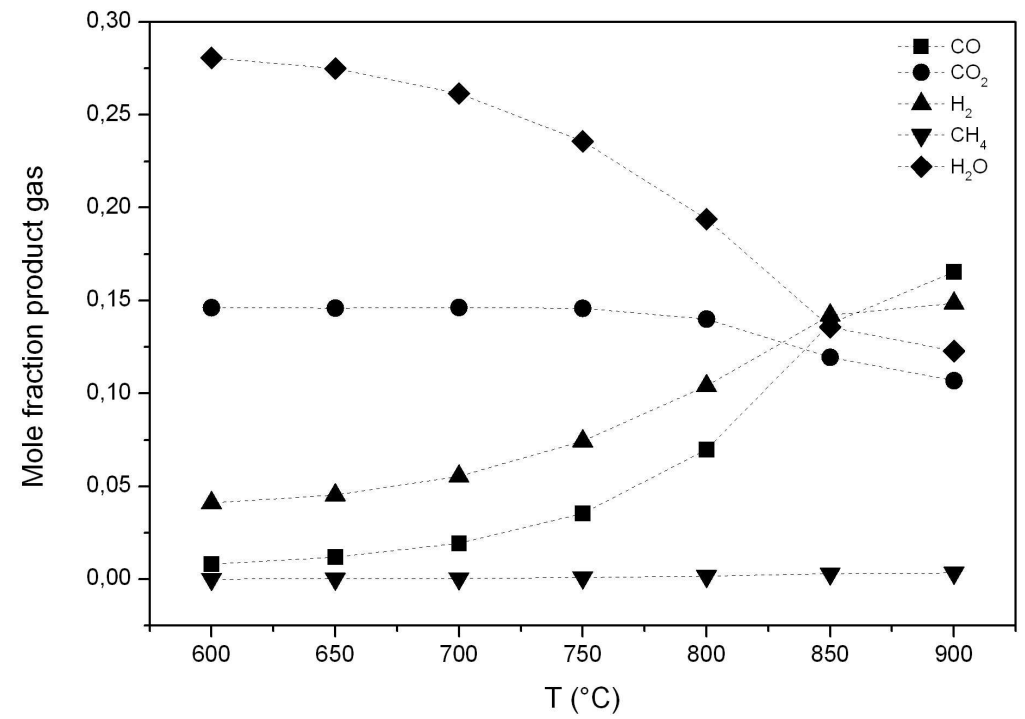

Figure 4. Variation of the molar fraction of the products distribution with the increasing temperature at a fixed $E R=0.3$

The concentration of $\mathrm{H}_{2}$ increases sharply with the increasing temperature as well as that of $\mathrm{CO}$ whereas $\mathrm{CO}_{2}$ revealed an opposite trend. $\mathrm{CH}_{4}$ decreased steadily within the entire range of temperature. At relatively low temperatures $\left(T=600^{\circ} \mathrm{C}\right)$ endothermic reactions are limited by the lack of energy and pyrolysis plays a more dominant role yielding more $\mathrm{CH}_{4}$ at the initial stages of the reaction. As the temperature increases, endothermic reactions are strengthen in accordance to Le Chatelier's principle obtaining higher concentrations of $\mathrm{CO}$ and $\mathrm{H}_{2}$. Moreover, due to the water gas shift reaction $\left(\mathrm{CO}+\mathrm{H}_{2} \mathrm{O} \leftrightarrow \mathrm{CO}_{2}+\mathrm{H}_{2}\right)$ and its tendency to shift towards reactants as temperature increases, $\mathrm{H}_{2}$ is further converted to $\mathrm{CO}$ and so, a faster growth rate of $\mathrm{CO}$ is observed at temperatures over $800^{\circ} \mathrm{C}$.

\subsubsection{Performance of the gasification process}

The effect of the gasification temperature on the performance of the reactor at different $E R(\square E R=0.25$, - $E R=0.3, \Delta E R=0.35$ ) is shown in Figure 5. The increasing temperature enhances the HHV (a) and CGE (b) values effectively in all cases and leads to a better gasification performance. In particular, the most substantial increase in these parameters is observed in the range $750-900^{\circ} \mathrm{C}$ coinciding with the highest increase in the $\mathrm{CO}$ and $\mathrm{H}_{2}$ concentrations in the produced gas. Figure 6 shows the variation on the CCE with the temperature at two different $\mathrm{ER}(\backsim \mathrm{ER}=0.25, \bullet E R=0.35)$. Again, a slow increase is observed at low temperatures speeding up at temperatures above $750^{\circ} \mathrm{C}$. The maximum CCE is achieved at $900^{\circ} \mathrm{C}$ and corresponds to a value of $\mathrm{CCE}=80 \%$. This fact indicates that the biomass is not completely converted into the producer gas. 

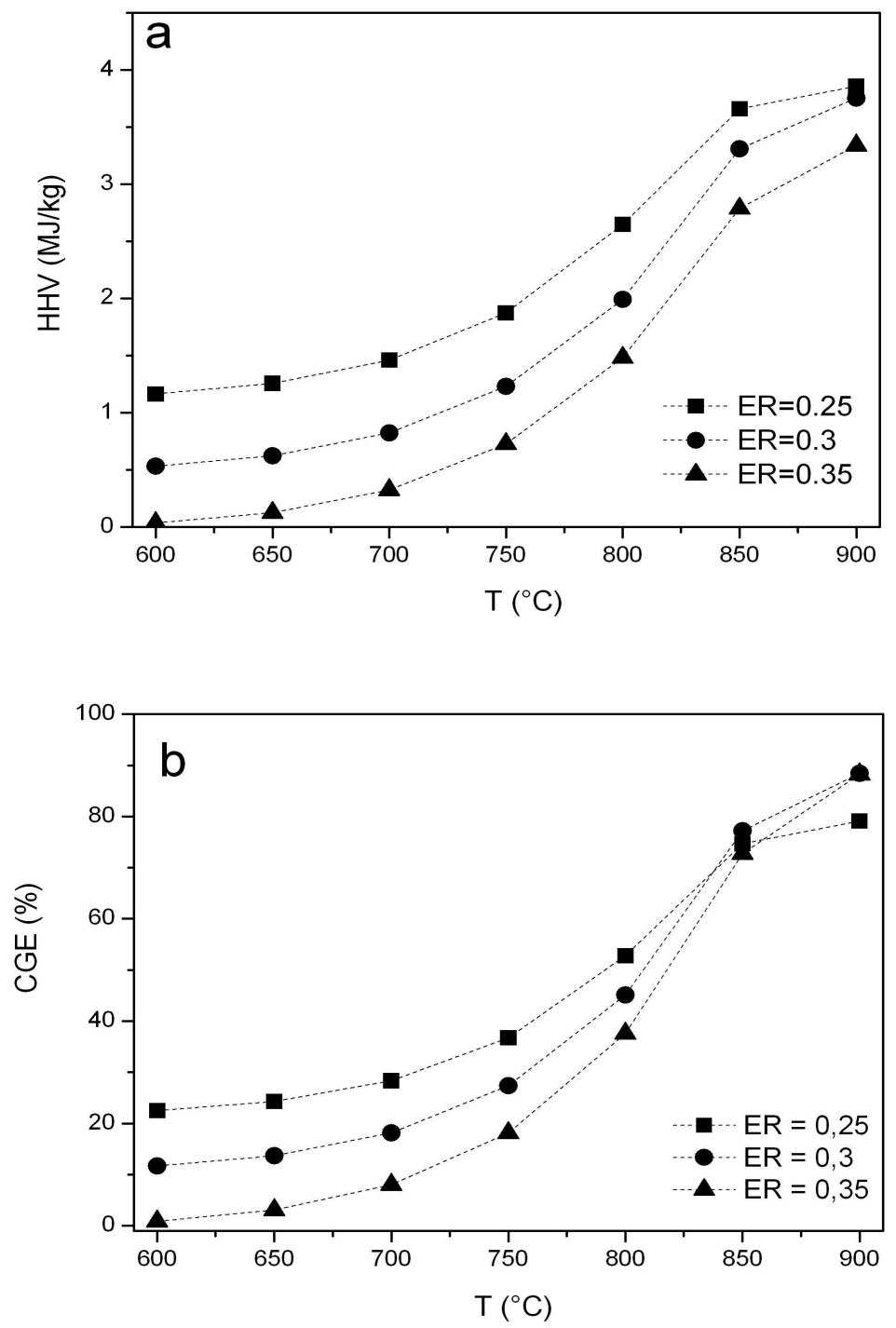

Figure 5. Effect of the gasification temperature on the performance of the reactor at different $E R(\triangle E R=0.25$, $\bullet E R=0.3, \Delta E R=0.35$ )

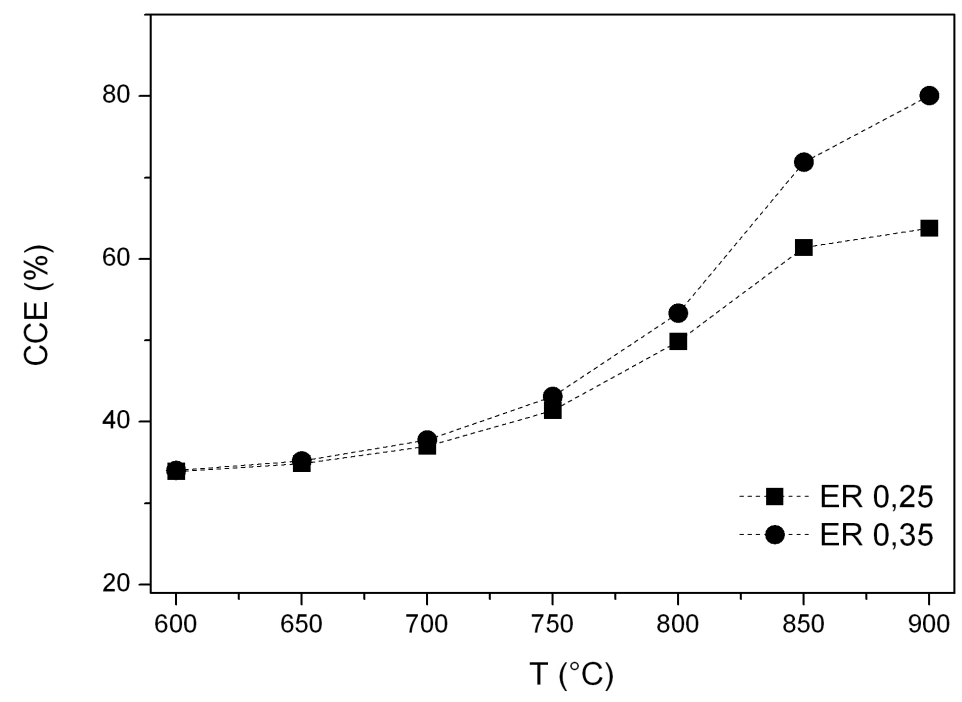

Figure 6. Effect of the temperature on CCE $(\bullet E R=0.25, \bullet E R=0.35)$ 


\subsection{Effect of the ER on the gasification process}

\subsubsection{Gas composition}

The ER is the main operating parameter for an adequate and controlled production of syngas. Figure 7 shows the molar composition of the produced gas with increasing ER values ranging from 0.15 to 0.4 at a fixed $\mathrm{T}=900^{\circ} \mathrm{C}$. The concentration of $\mathrm{CO}$ initially increases with $\mathrm{ER}$ due to its preferential formation at low oxidant conditions. At certain value $(\mathrm{ER}=0.30)$, the fraction of $\mathrm{CO}$ decreases as a result of the predominance of the reactions of oxidation, thus increasing the quantity of $\mathrm{CO}_{2}$ For the entire range of $\mathrm{ER}$, the concentrations of $\mathrm{H}_{2} \mathrm{O}$ and $\mathrm{H}_{2}$ decrease and $\mathrm{CH}_{4}$ remains almost negligible.

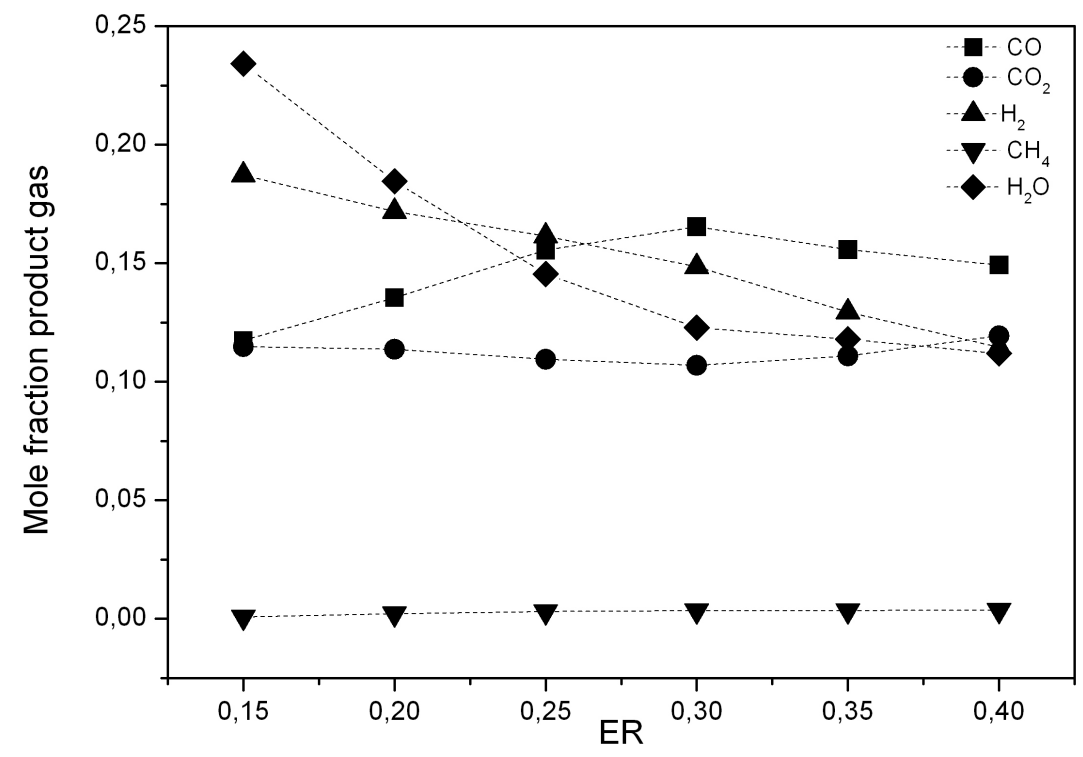

Figure 7. Variation of the molar fraction of the products distribution with the increasing $E R$ at a fixed $T=900^{\circ} \mathrm{C}$

\subsubsection{Performance of the gasification process}

The variation of the HHV and CGE with ER at different temperatures $\left(\bullet T=800^{\circ} \mathrm{C}, \bullet T=850^{\circ} \mathrm{C}\right.$, $\Delta \mathrm{T}=900^{\circ} \mathrm{C}$ ) is represented in Figure 8. Higher values of HHV were found at low ER due to the higher content of $\mathrm{H}_{2}$ in the produced gas. The CGE highly increases in the first instance with the ER until a certain point $(E R=0.3)$ from which the trend is changed and the increase is subtle, achieving almost the same conversion at $E R=0.4$. Figure 9 shows the variation in the CCE with $E R$ at three different $T$ $\left(\boldsymbol{- T}=800^{\circ} \mathrm{C}, \bullet \mathrm{T}=850^{\circ} \mathrm{C}, \boldsymbol{\Delta} \mathrm{T}=900^{\circ} \mathrm{C}\right.$ ). The major conversion is obtained in the range $750-900^{\circ} \mathrm{C}$ and the maximum value is $\mathrm{CCE}=86 \%$. 

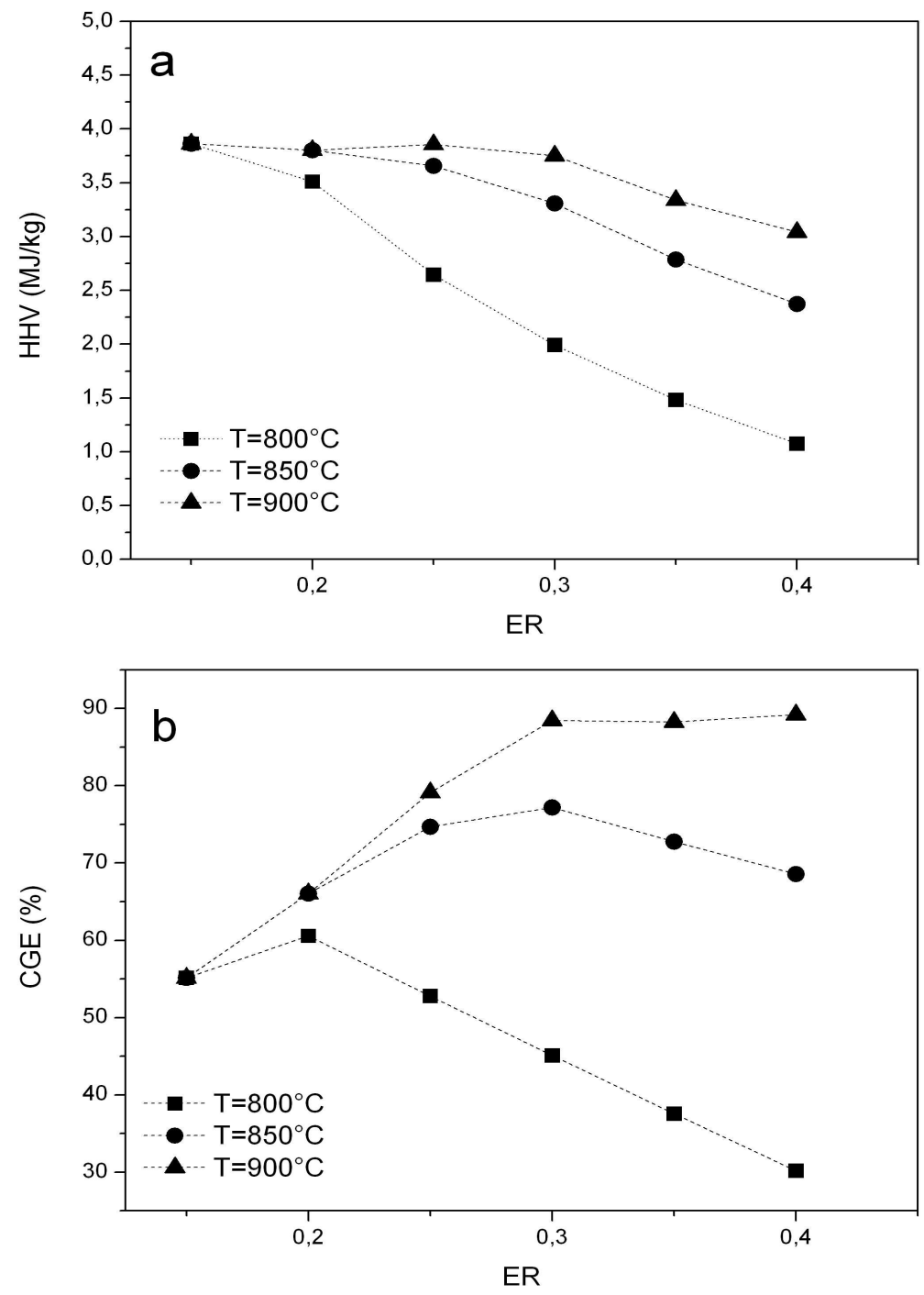

Figure 8. Variation of the HHV and CGE with ER at different temperatures $\left(\boldsymbol{\bullet T}=800^{\circ} \mathrm{C}, \bullet \mathrm{T}=850^{\circ} \mathrm{C}, \boldsymbol{\Delta} \mathrm{T}=900^{\circ} \mathrm{C}\right)$

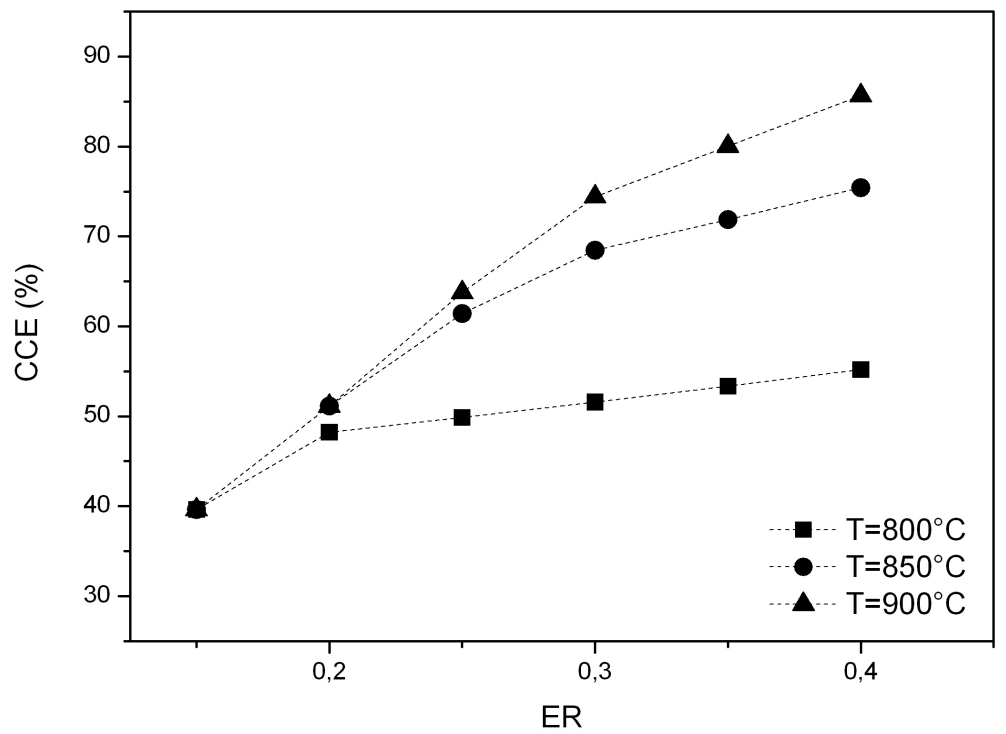

Figure 9. Effect of the ER on CCE $\left(\boldsymbol{- T}=800^{\circ} \mathrm{C}, \bullet \mathrm{T}=850^{\circ} \mathrm{C}, \boldsymbol{\Delta} \mathrm{T}=900^{\circ} \mathrm{C}\right)$ 


\section{Conclusions}

An original model was developed to describe the simulation of the gasification of rice straw in a spouted bed reactor using Aspen Plus ${ }^{\odot}$. First of all, the system was proven to fulfil the specific fluid dynamic requirements for spouted bed reactors. The model also includes the kinetic expressions corresponding to the decomposition of the main components of the feed and the fluid dynamic properties of the reactor, based on previous experimental results on the unit. The flexibility of the model makes it suitable for any type of biomass by only modifying the composition of the feedstock and its own kinetic behaviour.

The effect of the temperature of reaction and equivalence ratio on the composition of the producer gas and efficiency of the process were investigated. As expected, higher temperatures improved the gasification process, improving the CGE and CCE. Due to technological limitations related to the fusibility of ashes, $900^{\circ} \mathrm{C}$ was taken as maximum temperature of study. At this temperature, ER resulted to have an optimum value of 0.4 for which CGE achieved its maximum value (CGE $=86 \%$ ) coinciding with the maximum production of $\mathrm{CO}$ and $\mathrm{H}_{2}$. The highest value of CCE at those conditions was CCE $=85 \%$ indicating that biomass is not completely converted even at high temperatures that could be attributed to kinetic limitations.

\section{References}

[1] S. Arni, B. Bosio, E. Arato. Syngas from sugarcane pyrolysis: an experimental study for fuel cell application. Renewable Energy 35 (2010) pp. 29-35.

[2] FAOSTAT (Food and Agriculture Organization of the United Nations) (2013) Production crops $<$ faostat3.fao.org>, Accessed 15.07.2015

[3] P. Basu, Biomass gasification and pyrolysis (2010) New York: Elsevier

[4] KB. Mathur, N. Epstein. Spouted beds (1974) New York: Academic Press

[5] KG. Mansaray, AM. Al-Taweel, AE. Ghaly, F. Hamdullahpur, V. Ugursal. Mathematical modelling of a fluidised bed rice husk gasifier. Energy sources 22 (2000) pp. 83-98

[6] Li, J.R. Grace, C.J. Lim, A.P. Watkinson, H.P. Chen, J.R. Kim. Biomass gasification in a circulating fluidized bed. Biomass and Bioenergy 26, (2004) pp. 171-193

[7] W. Doherty, A. Reynolds, D. Kennedy. The effect of air preheating in a biomass CFB gasifier using Aspen Plus simulation. Biomass and Bioenergy 33 (2009) pp. 1158-1167

[8] S. Jarungthammachote, A. Dutta. Equilibrium modelling of gasification: Gibbs free energy minimization approach and its application to spouted bed and spout-fluid bed gasifiers. Energy Conversion and Management 49 (2008) pp. 1345-1356

[9] C. Moliner, D. Bove, B. Bosio, A. Ribes, E. Arato. Feasibility studies on the energy valorisation of agricultural residues using Aspen Plus ${ }^{\odot}$. Proceedings of the $23^{\text {rd }}$ European Biomass Conference and Exhibition (Vienna) (2015) pp. 803-809, DOI: 10.5071/23rdEUBCE2015-2DV.1.24

[10] M. B Nikoo, N. Mahinpey Simulation of biomass gasification in fluidised bed reactor using Aspen Plus. Biomass and Bioenergy, 32 (2008) pp. 1245-1254 
[11] L. Abdelouahed, O. Authier, G. Mauviel, J.P. Corriou, G. Verdier, A. Dufour. Detailed modelling of biomass gasification in dual fluidised bed reactors under Aspen Plus. Energy and Fuels 26 (2012) pp. 3840-3855

[12] C. Moliner, M. Curti, B. Bosio, E. Arato, G. Rovero. Experimental tests with rice straw on a conical square-based spouted bed reactor. International Journal of Chemical Reactor Engineering (2015) DOI 10.1515/ijcre-2014-0172

[13] J. Parikh, S.A. Channiwala, G.K. Ghosal. A correlation for calculating HHV from proximate analysis of solid fuels. Fuel 84 (2005) pp. 487-494

[14] C. Moliner, B. Bosio, E. Arato, A. Ribes. Comparative study for the energy valorisation of rice straw, Chemical Engineering Transactions 37 (2014) pp. 241-246. DOI: 10.3303/CET1437041

[15] H.C. Yoon, P. Pozivil, A. Steinfeld. Thermogravimetric Pyrolysis and Gasification of Lignocellulosic Biomass and Kinetic Summative Law for Parallel Reactions with Cellulose, Xylan, and Lignin. Energy and Fuels 26 (2012) pp. 357-364

[16] R.J. Wooley, V. Putsche. Development of an ASPEN PLUS Physical Property Database for Biofuels Components, National Renewable Energy Laboratory, Colorado (1996)

[17] R. Zhang, P. Basu. A simple model for prediction of solid collection efficiency of a gas-solid separator. Powder Technology 147 (2004) pp. 86-93

[18] L. Waldheim, T. Nilsson. Heating values of gases from biomass gasification. Report for IEA Bioenergy agreement subcommittee on Thermal gasification of biomass, Task 20 (2001) 


\section{Communication 5IV}

Comparison and validation with experimental data of different modelling approaches for the gasification of agricultural residues $\mathrm{s}$

C. Moliner, B. Bosio, E. Arato.

$19^{\text {th }}$ Conference on Process Integration, Modelling and Optimisation for Energy Saving and Pollution Reduction (Prague) 2016

Submitted Abstract 



\title{
Comparison and validation with experimental data of different modelling approaches for the gasification of agricultural residues
}

\author{
C. Moliner, E. Arato, B. Bosio \\ University of Genoa, DICCA, Via Opera Pia 15, 16145 Genova, Italy.
}

The obtaining of the optimum operational conditions for a given process is the major goal of pilot and, once scaled, industrial units. For the case of reactions of gasification, the optimal conversion of chemical energy from biomass depends on many factors like the choice of the gasifier, its sizing or the temperature or gasifying medium applied, among others. Experimental trial and error tests provide the most reliable data to evaluate these units even though they are expensive both in time and economic terms. There is, however, a major drawback: the change of one of the parameters of the process may lead to different optimum conditions. It is then when simulation activities play an important role for a reliable design of the gasifier. Achieving the right balance between experimental and modeled results will be the key for a good development of a technology.

Within this framework, the gasification of different agricultural residues by means of a spouted bed reactor pilot unit has been studied. Gasification has been proven a convenient technique for thermo-chemical conversions of biomass through fluidisation processes. Different devices have been developed to carry out these reactions. Among them, spouted bed reactors have been proposed as a solution to overcome the difficulties that conventional reactors face when treating big and heterogeneous particles.

The experimental activity has been carried out in a conical square-based spouted bed reactor. Its main dimensions are: side of $200 \mathrm{~mm}$ and total high of $2 \mathrm{~m}$. The base has an inclined angle of $60^{\circ}$ in order to enhance the recirculation of solids. The air inlet orifice is situated at the center with a diameter of $21 \mathrm{~mm}$. A burner is used to preheat the fluidising gas (air) and the exhaust gases go through a cyclone followed by a water scrubber to cool them and remove fines. The gaseous products $\left(\mathrm{H}_{2}, \mathrm{CO}_{2}, \mathrm{CH}_{4}, \mathrm{CO}, \mathrm{O}_{2}\right.$ and $\mathrm{C} 2-\mathrm{C} 5$ compounds) are analysed using gas chromatograph. The remaining percentage of carbon after the gasification of the residues is also quantified. The temperature in the experimental unit is monitored by several thermocouples connected to a data acquisition system.

The obtained experimental data have been used to validate three different models developed according to different degrees of detail, from the ideal situation (equilibrium models) to a more realistic one in which the specific kinetics and fluid dynamics affecting the process have been specified. A comparison between the main information provided by each of them has been performed and the results have been compared with the experimental data obtained with the pilot unit. The technical operational limits of the reactor and main constraints due to thermodynamic considerations were provided by the solution based on the equilibrium. This model was modified by the addition of empirical parameters based on the quantification of the experimental carbon conversion achieved by the system. Finally, a model including the kinetic law describing the decomposition of the feedstock is developed.

The model presenting the highest accuracy has been used to study the effect of the Temperature of reaction (T) and Equivalence Ratio (ER) on the distribution of products in the producer gas and on the performance of the process by the assessment of the Higher Heating Value (HHV) and the Cold Gas Efficiency (CGE) for a broad range of operational conditions. Finally, the optimum operating conditions of the spouted bed reactor have been provided. 



\section{EXTRACTION OF SILICA}

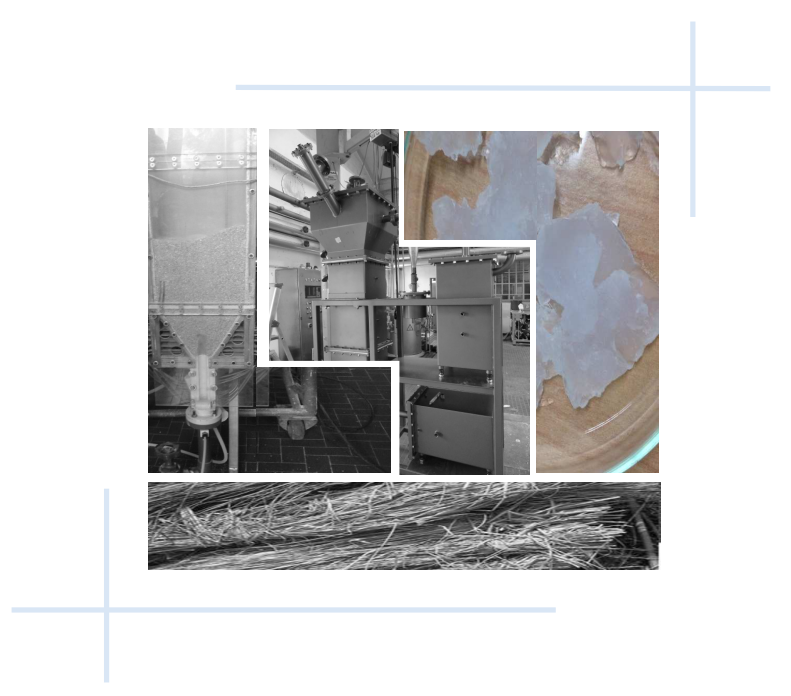

I Summary

249

6.1 Chemical extraction of silica from ashes

250

6.2 Characterisation of silica

6.3 Preliminary adsorption tests

261

6.4 Main results

264

References in this chapter

265 

“Questions of science, science and progress do not speak as loud as my heart"

The scientist. Coldplay

\section{Summary}

The ashes of the gasification explained in Chapter 5 will be the raw material for the extraction of silica. The scope of this chapter is to describe the process to obtain silica from rice straw ash. The chapter is devoted to the description of the chemical reactions involved in the extraction of silica and the main variables influencing the process.

After that, the characterisation of the obtained product is performed by identifying and quantifying its main chemical elements by means of Energy Dispersive X-ray Spectrometry (EDS).

Finally, due to its properties, silica is used as adsorbent agent for the removal of nitrates present in water. Preliminary tests to evaluate the capacity for the retention of nitrates of the produced silica are performed. 


\subsection{Chemical extraction of silica from ashes}

The major constituents of rice straw are cellulose (32-47\%), hemicellulose (19-27\%), lignin (524\%) and ash (13-20\%) (Karimi et al. 2006). The constituents of the ash mainly depend on the type of rice, the climate and the geographical location of growth. The high percentage of ash in the straw produces a high quantity of residual product when it is submitted to thermal conversion processes. This residue, which is rich in silica, can become a precursor of new added value materials, starting a new bio-production chain.

Rice plants cumulate silica through polimerisation of the water-soluble silicic acid $\left(\mathrm{H}_{4} \mathrm{SiO}_{4}\right)$ absorbed from soil into insoluble polysilicic acids, followed by precipitation as amorphous silica and deposition in exterior plant cell walls (Van Soest, 2006). The obtainment of silica from rice husk has been widely reported in the recent decades (Conradt et al, 1992, Real et al, 1996, Liou and $\mathrm{Wu}, 2010)$. Taking into account that approximately two thirds of rice residues are straw, the production of silica from straw has twice the potential of rice husk. It is clear that the use of straw to obtain silica presents several economic and environmental advantages that need to be further explored.

Silica $\left(\mathrm{SiO}_{2}\right)$ is an inorganic material extensively used in a wide range of applications such as glasses, optical fibres, food additives, electrical and thermal insulators, absorbents, pharmaceutical products (Bansal et al., 2006). Its production commonly involves the reaction of minerals, such as quartz sand, with sodium carbonate at temperatures above the $1000^{\circ} \mathrm{C}$. This means a great demand of energy input to achieve the desired temperatures and also for the purification of the minerals. Low temperature extraction of amorphous silica from biomass can represent an eco-friendly and cost-effective alternative to the traditional manufacturing processes (Lu et al., 2012).

\subsubsection{Preparation of rice straw ash}

Rice straw was collected in the region of Valencia after the harvest season. After its collection, the straw was cut and kept in a dried place before the experiments were carried out. The dry clean rice straw samples ( $20 \pm 3 \mathrm{~g})$ were burned to ash in a programmable muffle furnace. The reagents used for the chemical reactions were $0.5 \mathrm{M} \mathrm{H}_{2} \mathrm{SO}_{4}, 1 \mathrm{M} \mathrm{NaOH}$ and sodium dodecyl 
sulphate (SDS). The production of ash and further extraction of silica was performed at the laboratories of the DREMAP (UPV).

The production of the straw ash was simulated in a muffle furnace according to the decomposition profile obtained in Chapter 3. Figure 6.1 shows the decomposition of rice straw under oxidative atmosphere at a heating rate $\beta=5^{\circ} \mathrm{C} / \mathrm{min}$.

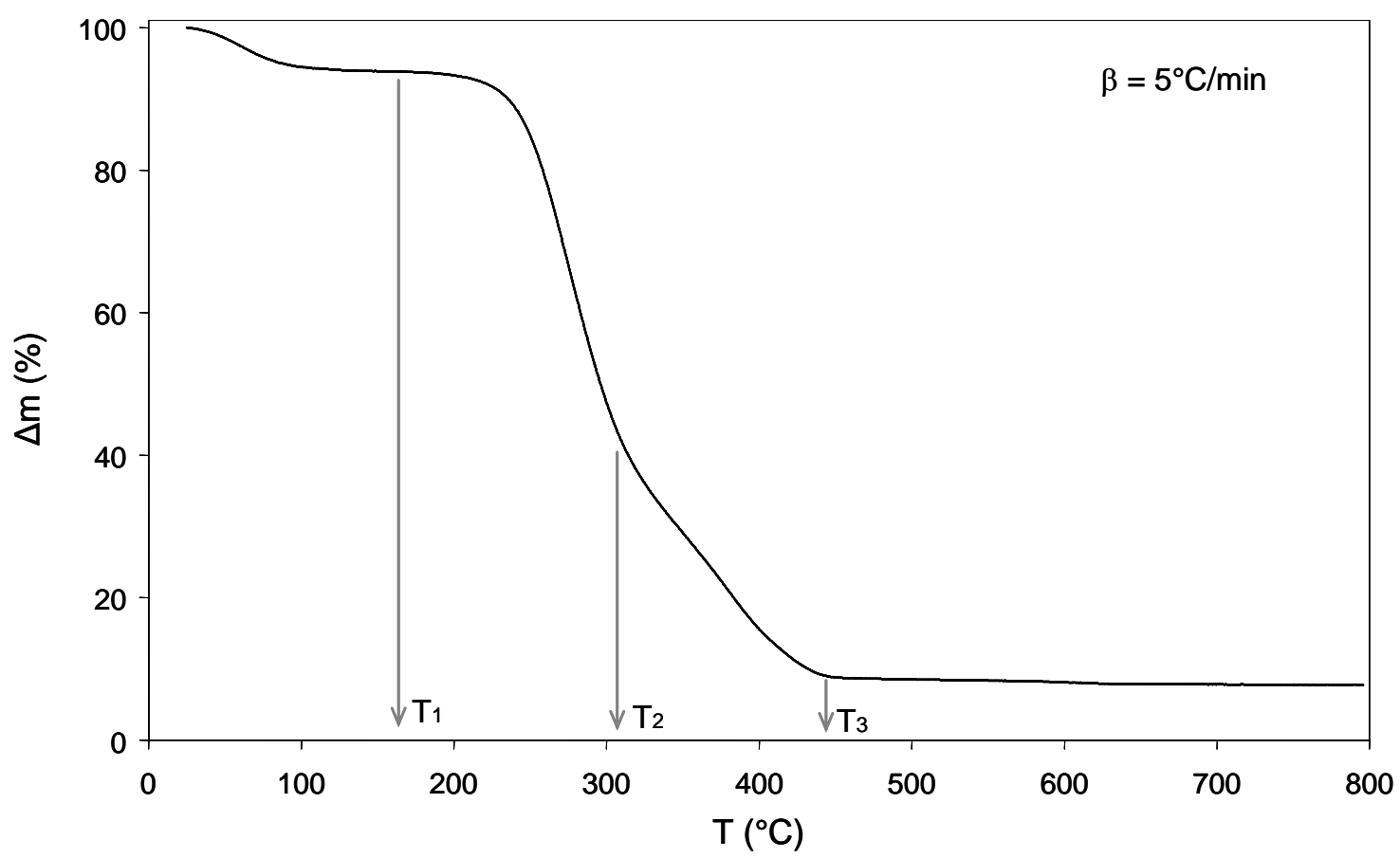

Figure 6.1. Decomposition profile of rice straw under oxidative conditions ( $\left.\beta=5^{\circ} \mathrm{C} / \mathrm{min}\right)$

As it was discussed in Chapter 3, the samples presented three stages during thermal decomposition: (i) removal of moisture (up to $\mathrm{T}_{1}$ ), (ii) removal of volatile matter (in two substages, up to $T_{2}$ and $T_{3}$ respectively) and (iii) oxidation of fixed carbon (above $T_{3}$ ). It is clear that the minimum temperature required for the oxidation of fixed carbon implies a minimum furnace temperature above $T_{3}$ to ensure the complete combustion of rice straw to produce silica. The heating rate of the muffle furnace was programmed according to these temperatures ranges as schematically represented in Figure 6.2 


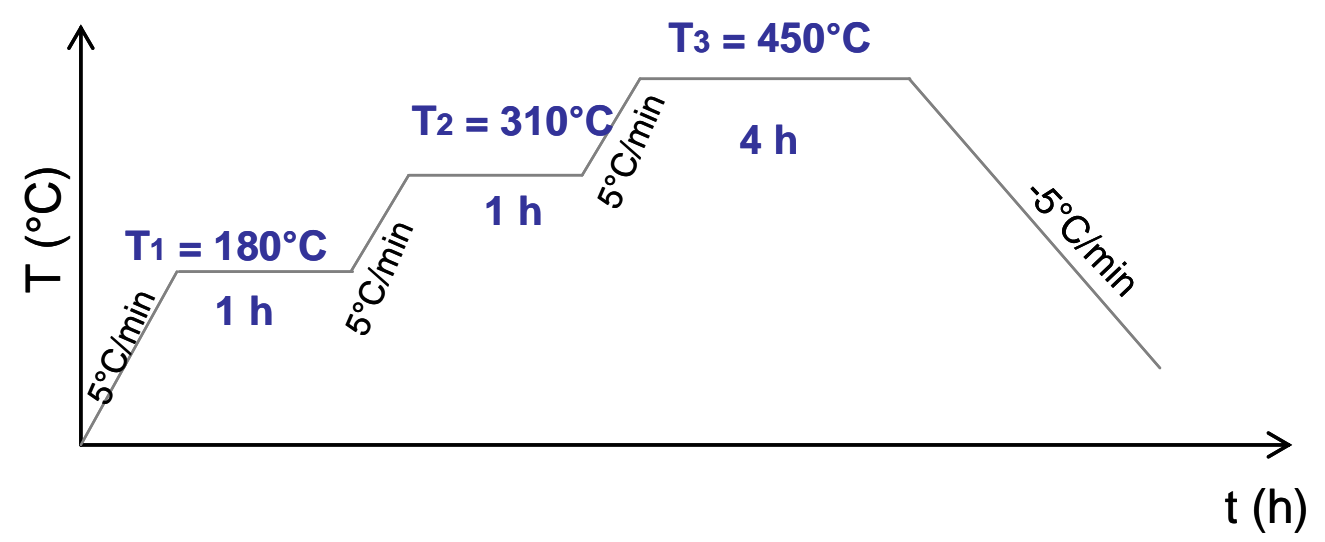

Figure 6.2. Scheme of heating programme for the obtainment of ashes in the muffle furnace

An initial heating was performed at $5^{\circ} \mathrm{C} / \mathrm{min}$ until the furnace reached $180^{\circ} \mathrm{C}$, temperature that was held for an hour. At that temperature, all the moisture is supposed to have been evaporated (as seen in Figure 6.1). Then the sample was heated to achieve $310^{\circ} \mathrm{C}$ and held for another hour and finally, heated again until $450^{\circ} \mathrm{C}$, held for the next 4 hours to ensure the release of all the volatiles of the straw. The final quantity of obtained ashes was $3 \pm 0.3 \mathrm{~g}$. The yield of the production of ash was $15.5 \pm 0.3 \%$.

Figure 6.3 shows the samples prior to the heating programme (a) and after completing it (b). The ashes presented a grey colour, indicating a possible presence of carbon from incomplete oxidation of the samples.

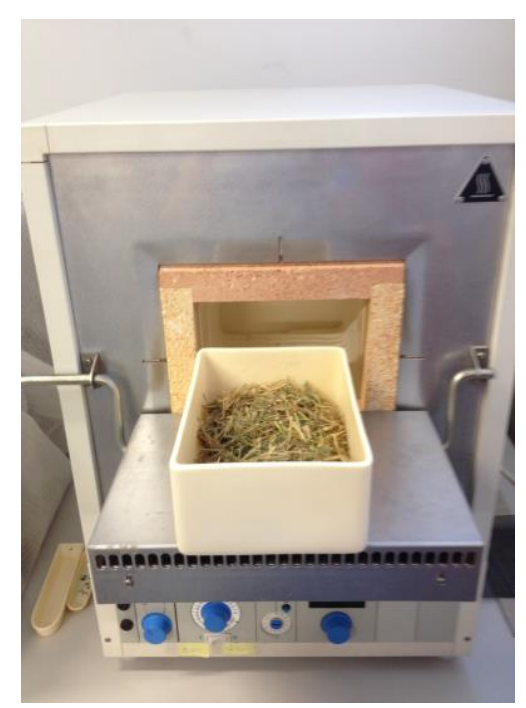

(a)

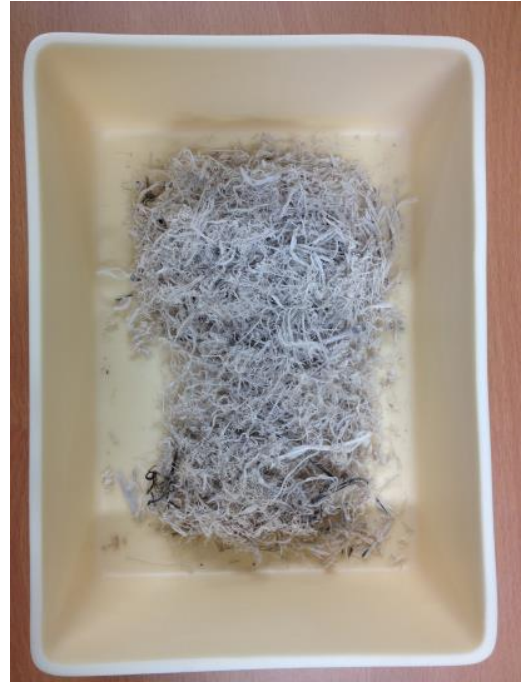

(b)

Figure 6.3. Rice straw before (a) and after (b) the heating process 


\subsubsection{Extraction of silica from rice straw ash}

The ash produced in Section 6.1.1 was sealed in plastic bags and kept in a dried place until its use for the extraction of silica. The chemical process consisted in an initial dissolution in a basic solution and a further acid precipitation process. The influence of the addition of a surfactant (sodium dodecyl sulphate-SDS) was also studied. Figure 6.4 shows a scheme of the chemical process carried out.

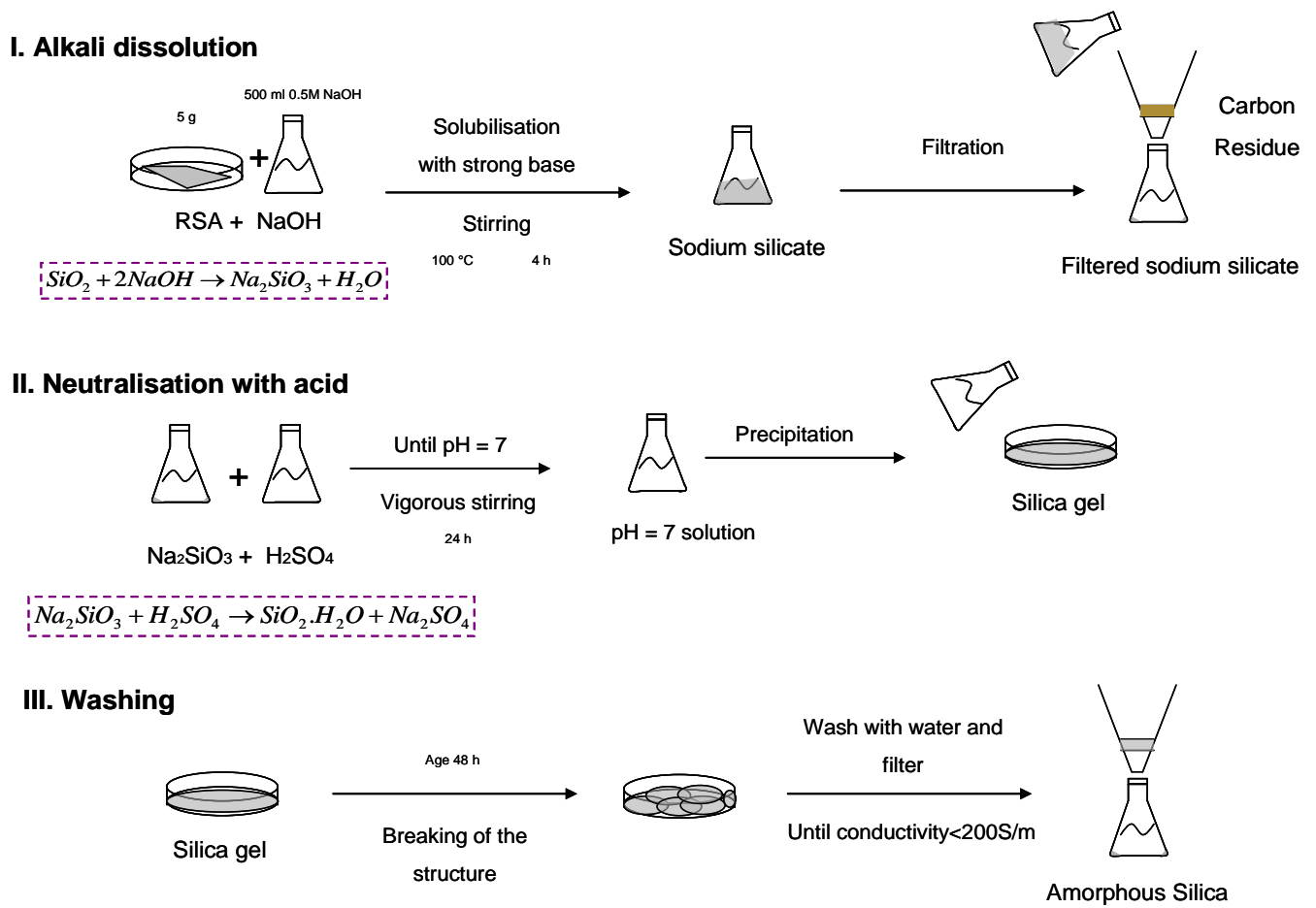

Figure 6.4. Scheme of the chemical extraction of silica from rice straw ash

Table 6.1 gathers the factors and levels tested for the extraction of silica.

Table 6.1. Factors and levels tested for the extraction of silica

\begin{tabular}{l|cccc}
\multicolumn{1}{c}{ Factors } & \multicolumn{4}{c}{ Levels } \\
\hline Molar ratio ash-NaOH & $1: 2$ & $1: 3$ & $1: 4$ & $1: 5$ \\
Presence of SDS & 0 ppm & $200 \mathrm{ppm}$ & $400 \mathrm{ppm}$ &
\end{tabular}

The variation on the molar ratio ash- $\mathrm{NaOH}$ permitted to evaluate the influence of the initial alkali dissolution on the dissociation of Si-O-Si particles. Moreover, the presence of SDS allowed the study of the influence of the presence of a surfactant (i.e. compound that lowers the surface tension of the solution) and its effect on the nucleation rate and, consequently, on the size of particle of the product.

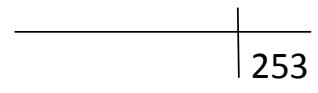


The description of the reactions taking place is presented in the following paragraphs.

\section{Alkali dissolution}

Silica in rice straw ash was firstly solubilised by reaction with a strong base $(\mathrm{NaOH})$ to form water soluble sodium silicate (R6.1)

$$
\mathrm{SiO}_{2}+2 \mathrm{NaOH} \rightarrow \mathrm{Na}_{2} \mathrm{SiO}_{3}+\mathrm{H}_{2} \mathrm{O}
$$

Rice straw ash ( 3 g.) was dispersed in a $1 \mathrm{~N} \mathrm{NaOH}$ aqueous solution and heated at $90^{\circ} \mathrm{C}$ for $4 \mathrm{~h}$ under vigorous stirring to dissolve silica and produce sodium silicate (Figure 6.5a). Table 6.2 shows the quantity of $\mathrm{NaOH}$ in which the ash was dispersed to achieve the desired molar ratios ash- $\mathrm{NaOH}$ in each chemical extraction.

Table 6.2. Volume of $\mathrm{NaOH}$ added in each experiment

\begin{tabular}{cccccc} 
Molar relation ash-NaOH & $1: 2$ & $1: 3$ & $1: 4$ & $1: 5$ \\
\hline Volume added of $\mathrm{NaOH}$ for $3 \mathrm{~g}$ of rice straw ash & $100 \mathrm{~mL}$ & $150 \mathrm{~mL}$ & $200 \mathrm{~mL}$ & $250 \mathrm{~mL}$
\end{tabular}

The resulting solution (Figure 6.5b) was filtered and washed with water to remove impurities. The transparent filtrate sodium silicate solution was left to cool to room temperature. The residue left in the filter (Figure 6.5c) was kept and sealed in a plastic bag. This residue was supposed to be products of the incomplete decomposition of lignin, as it is reported that its range of decomposition is $400-900^{\circ} \mathrm{C}$ ( $\mathrm{Lu}$ et al. 2012), being these values higher than the applied maximum temperature $\left(\mathrm{T}=450^{\circ} \mathrm{C}\right)$

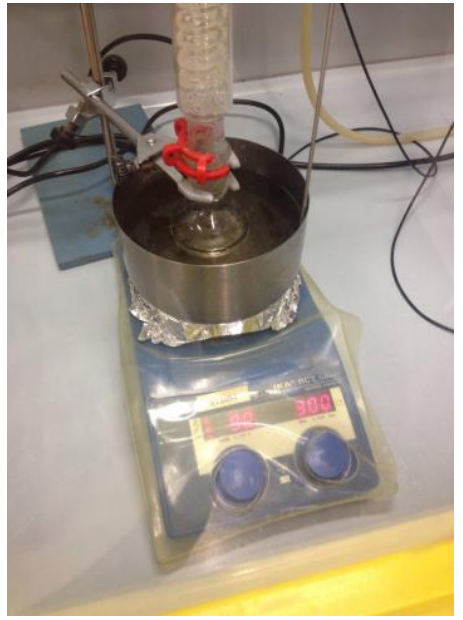

(a)

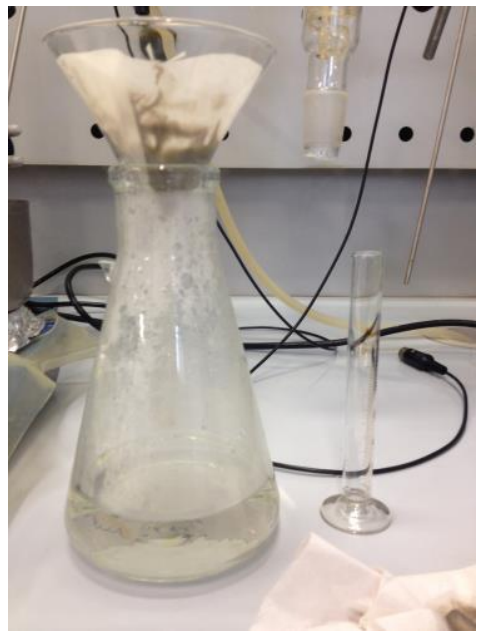

(b)

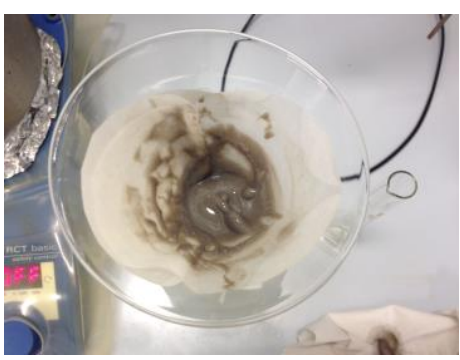

(c)

Figure 6.5. Alkali dissolution of rice straw: dissolution (a), sodium silicate solution (b) and residue (c) 


\section{Neutralisation with acid}

Sodium silicate was then slowly neutralised with diluted sulfuric acid solution to $\mathrm{pH} 7$ to precipitate silica (R6.2). This slow reaction was performed under vigorous stirring (Figure 6.6a) to allow the diffusion of sodium sulfate and prevent the formation of large aggregates.

$\mathrm{Na}_{2} \mathrm{SiO}_{3}+\mathrm{H}_{2} \mathrm{SO}_{4} \rightarrow \mathrm{SiO}_{2} \cdot \mathrm{H}_{2} \mathrm{O}+\mathrm{Na}_{2} \mathrm{SO}_{4}$

Upon reaching $\mathrm{pH}$ 7, silica was gradually precipitated to form a gel over a period of 18 hours (Figure 6.6b).

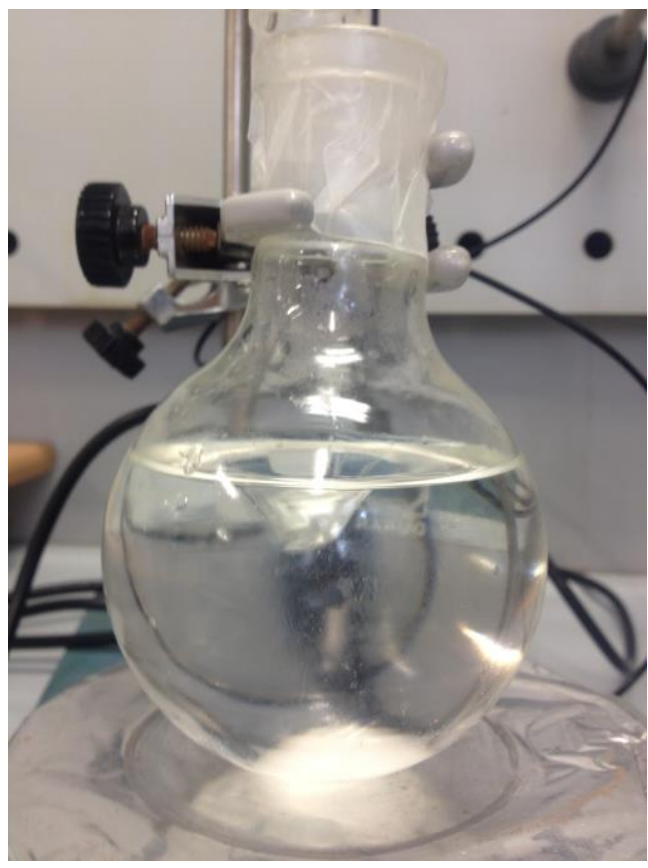

(a)

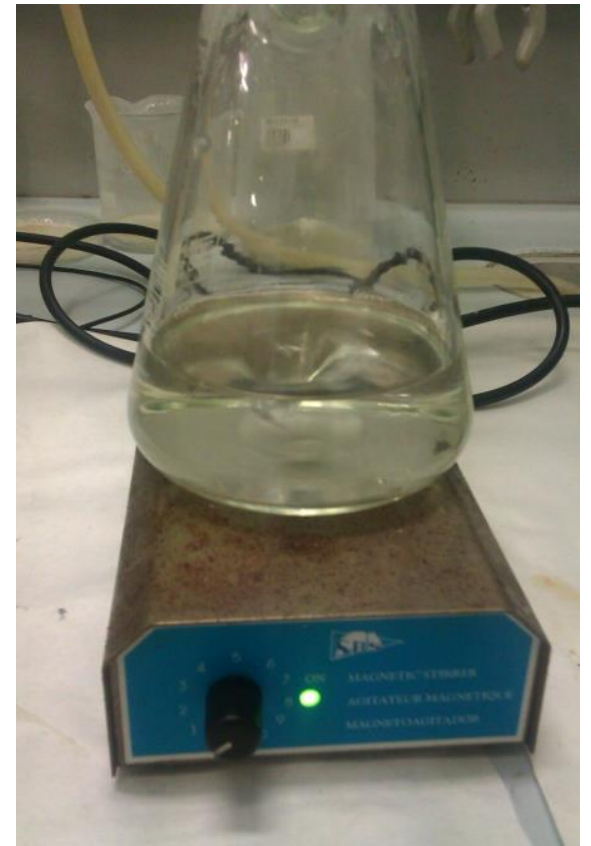

(b)

Figure 6.6. Neutralisation with sulfuric acid (a) and precipitation of gel (b)

\section{Washing}

The resultant silica gel was broken and washed repetitively with copious amount of water (Figure 6.7a). The silica gel was then filtered and left until dried. After 48 hours, the dried silica appeared as white powders (Figure 6.7b) 


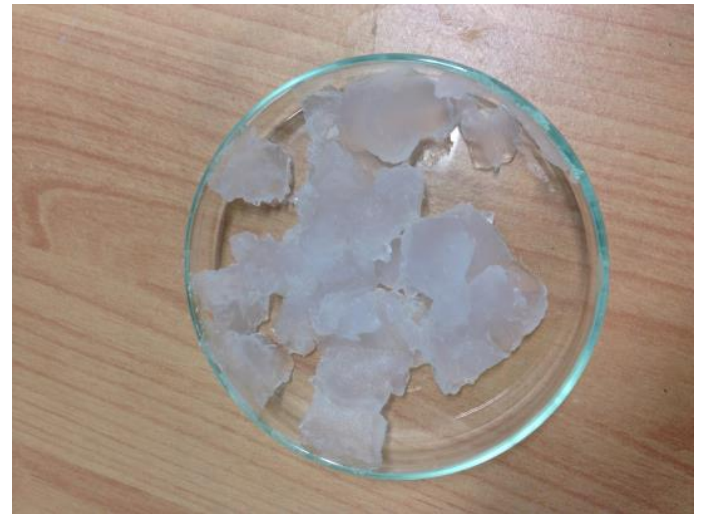

(a)

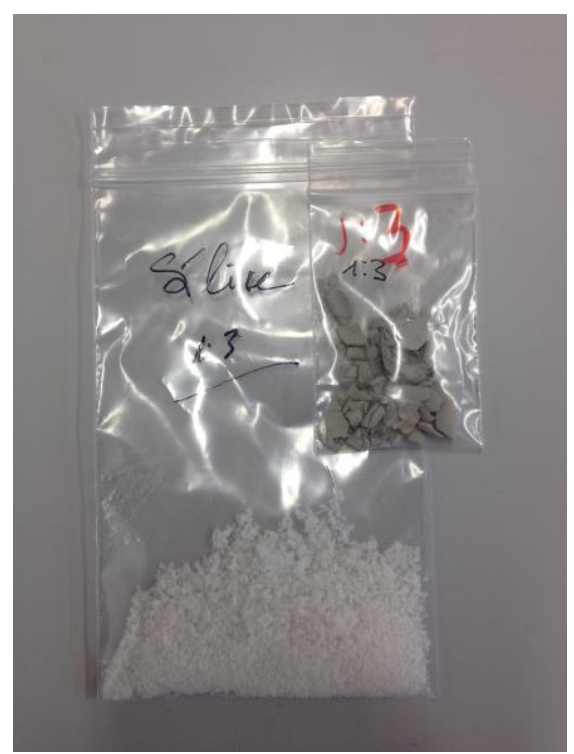

(b)

Figure 6.7. Products of reaction: silica gel (a) and silica powders (b)

Figure 6.8 depicts the products obtained through the different steps of the process.

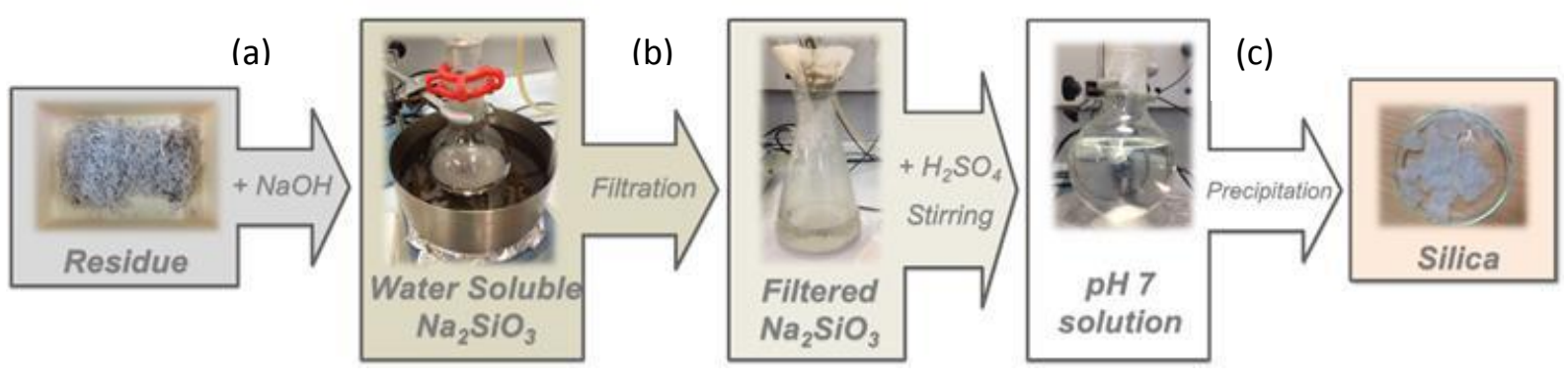

Figure 6.8. Scheme of the products obtained throughout the chemical extraction of silica 


\subsection{Characterisation of silica}

Silica obtained in Section 6.1 was characterised by means of Energy Dispersive X-ray Spectrometry (EDS). All the experiments were carried out at the laboratories of the Departament of Analytical Chemistry (Faculty of Chemistry, Universitat de València, Burjassot).

\subsubsection{Fundamentals of EDS}

EDS is a technique that consists of bombarding the target sample with high energy electrons in an electron microscope and detecting the characteristic produced X-rays. These emitted X-rays are intimately connected with the atomic structure of each element present in the sample. Qualitatively, as the atomic structure of each element is different, it follows that, when stimulated, each element emits a specific pattern of X-rays. Quantitatively, the amount of Xrays emitted by each element bears a direct relationship with the concentration of that element (mass or atomic fraction). This way, X-ray measurements are converted into a final X-ray spectrum used to assess the concentrations of the various chemicals present in a sample (Ametek. Materials Analysis Division, 2015).

EDS is used to identify and evaluate materials, including detecting contaminants or determining unknown elements, as well as for quality control screening, verification and certification. In practice, EDS's range of applications encompasses alloy design, analyzing pigments in historical documents, conducting environmental studies of pollution particulates, investigating insurance claims and monitoring asbestos levels in construction.

The process is described by the following steps (Figure 6.9): an electron beam hits the sample and an X-ray is generated. The resulting X-ray escapes the sample and hits the detector which creates a charge pulse in the detector. This current is then converted into a voltage pulse proportional to the energy of the detected X-ray. Finally, this voltage pulse is converted to a digital signal and one more count is added to the corresponding energy channel. Once the measurement is completed, the accumulated counts produce the X-ray spectrum. 


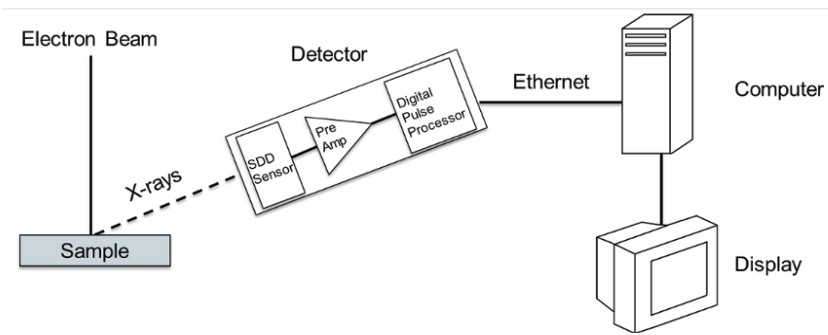

Figure 6.9. Methodology of EDS (Ametek. Materials Analysis Division, 2015)

\section{EDS Spectrum}

The output of an EDS analysis is an EDS spectrum. The EDS spectrum is a plot of how frequently an X-ray is received for each energy level. The ED spectrum is displayed in digitized form with the $\mathrm{x}$-axis representing X-ray energy (usually in channels 10 or $20 \mathrm{eV}$ wide) and the $y$-axis representing the number of counts per channel. Each of these peaks is unique to an atom, and therefore corresponds to a single element. The higher a peak in a spectrum, the more concentrated the element is in the specimen.

Qualitative analysis involves the identification of the lines in the spectrum and is fairly straightforward owing to the simplicity of X-ray spectra.

Quantitative analysis (determination of the concentrations of the elements) entails measuring line intensities for each element in the sample and for the same elements in calibration Standards of known composition.

\subsubsection{Results}

The samples of silica extracted from rice straw ash as described in Section 6.1 were submitted to EDS characterisation. Figure 6.10 shows the spectrum of the samples with a molar ratio ash$\mathrm{NaOH}$ 1:5 (a), molar ratio ash-NaOH 1:5 and 200 ppm of SDS (b) and molar ratio ash-NaOH 1:5 and $400 \mathrm{ppm}$ of SDS. 


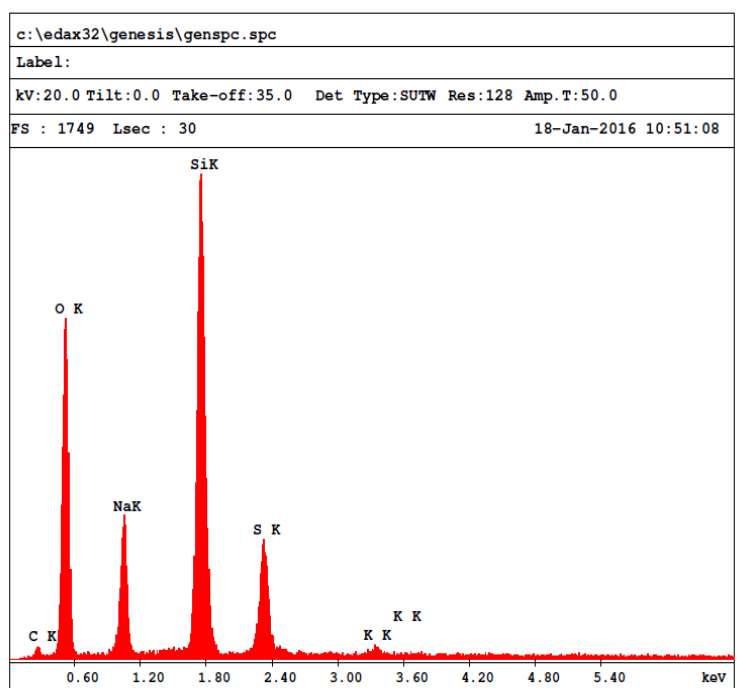

(a)

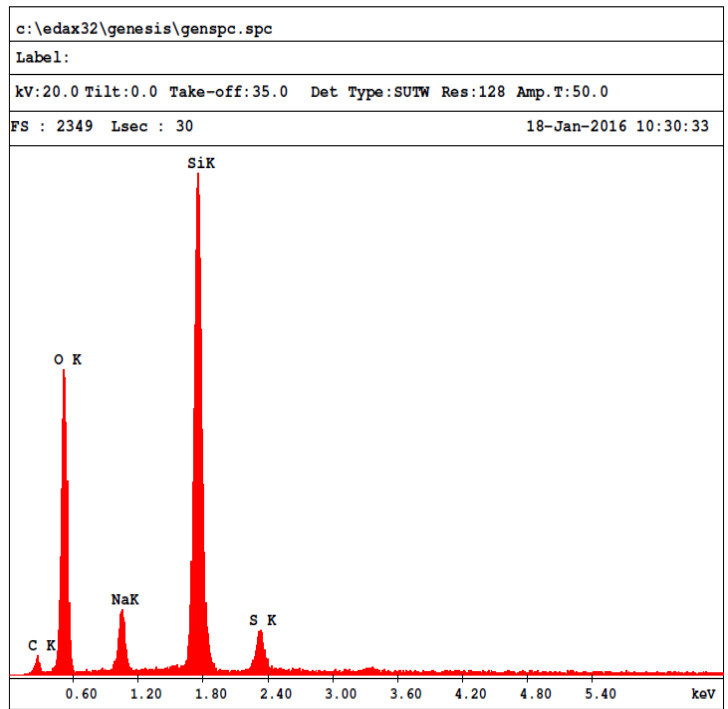

(b)

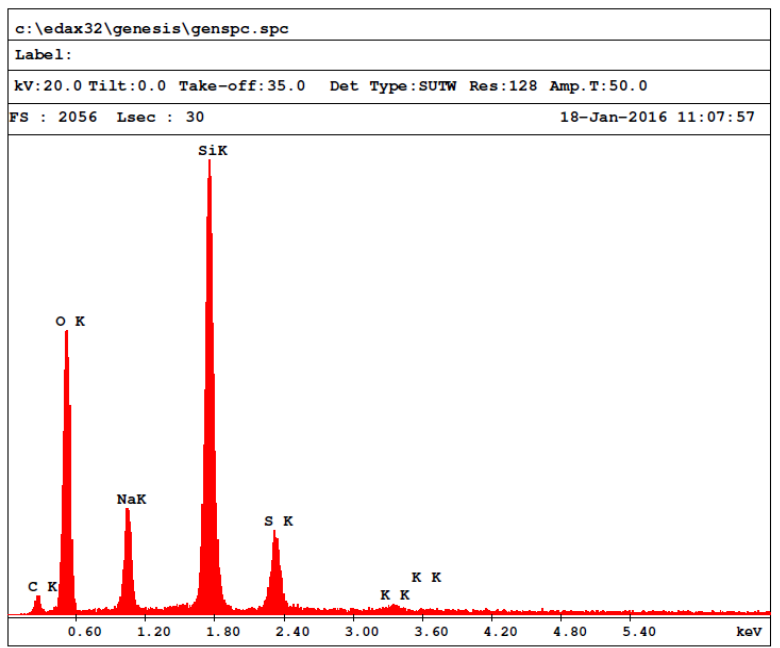

(c)

Figure 6.10. EDS spectrum of the samples: molar ratio ash-NaOH 1:5 (a), molar ratio ash$\mathrm{NaOH}$ 1:5 and 200 ppm of SDS (b) and molar ratio ash-NaOH 1:5 and 400 ppm of SDS (c).

As it can be seen in the figure, the main elements present in the sample are indeed $\mathrm{Si}$ and O, confirming the existence of silica in the product obtained after the performed extraction.

In order to perform a quantitative analysis, the following tables present the results of the Standardless EDAX ZAF quantification. 


\section{Sample Molar ratio ash-NaOH 1:5}

Table 6.3. EDAX quantification of the sample ash-NaOH 1:5

\begin{tabular}{c|ccccccccc} 
Element & wt \% & At \% & K-ratio & Z & A & F & Net area & Bkd Area & Area Error \\
\hline C K & 11,05 & 16,72 & 0,017 & 1,034 & 0,1491 & 1,0006 & 6,23 & 0,73 & 8,13 \\
O K & 51,1 & 58,05 & 0,167 & 1,0167 & 0,3214 & 1,0004 & 189,4 & 1,33 & 1,34 \\
Na K & 9,68 & 7,65 & 0,0375 & 0,9517 & 0,406 & 1,0025 & 87,47 & 3,3 & 2,02 \\
Si K & 20,86 & 13,49 & 0,1537 & 0,9747 & 0,7543 & 1,0025 & 376,13 & 4,8 & 0,95 \\
S K & 6,76 & 3,83 & 0,0494 & 0,9572 & 0,763 & 1,0002 & 94,7 & 5 & 1,97 \\
K K & 0,54 & 0,25 & 0,0045 & 0,9232 & 0,905 & 1 & 7,47 & 4,77 & 10,08
\end{tabular}

Being wt the weight percentage, At the atomic percentage, K-ratio the ratio between the intensity in the filtered peak respect to that taken as reference, $\mathrm{Z}$ the atomic number correction, A the absorption correction and $\mathrm{F}$ the fluorescence correction.

\section{Sample Molar ratio ash-NaOH 1:5 and $200 \mathrm{ppm}$ of SDS}

Table 6.4. EDAX quantification of the sample ash-NaOH 1:5 and $200 \mathrm{ppm}$ of SDS

\begin{tabular}{c|ccccccccc} 
Element & wt \% & At \% & K-ratio & Z & A & F & Net area & Bkd Area & Area Error \\
C K & 15,37 & 22,31 & 0,0261 & 1,0291 & 0,1647 & 1,0006 & 10,97 & 0,77 & 5,89 \\
O K & 52,61 & 57,32 & 0,1701 & 1,0119 & 0,3195 & 1,0003 & 221,97 & 1,53 & 1,23 \\
Na K & 5,21 & 3,95 & 0,0197 & 0,9472 & 0,3994 & 1,0028 & 53 & 3,97 & 2,69 \\
Si K & 24,01 & 14,9 & 0,1828 & 0,9701 & 0,7843 & 1,001 & 514,77 & 4,5 & 0,81 \\
S K & 2,81 & 1,53 & 0,0203 & 0,9521 & 0,7572 & 1 & 44,7 & 4,33 & 2,98 \\
K K & 15,37 & 22,31 & 0,0261 & 1,0291 & 0,1647 & 1,0006 & 10,97 & 0,77 & 5,89
\end{tabular}

\section{Sample Molar ratio ash-NaOH 1:5 and 400 ppm of SDS}

Table 6.5. EDAX quantification of the sample ash-NaOH 1:5 and 400 ppm of SDS

\begin{tabular}{c|ccccccccc} 
Element & wt \% & At \% & K-ratio & Z & A & F & Net area & Bkd Area & Area Error \\
\hline C K & 16,04 & 23,4 & 0,0269 & 1,0308 & 0,1626 & 1,0005 & 11,7 & 0,9 & 5,73 \\
O K & 50,07 & 54,83 & 0,1554 & 1,0136 & 0,3061 & 1,0004 & 209,47 & 1,73 & 1,27 \\
Na K & 8,02 & 6,11 & 0,031 & 0,9488 & 0,4065 & 1,0024 & 85,97 & 4,7 & 2,07 \\
Si K & 20,41 & 12,73 & 0,1526 & 0,9717 & 0,7679 & 1,0019 & 443,8 & 5,6 & 0,88 \\
S K & 4,94 & 2,7 & 0,0364 & 0,9538 & 0,7727 & 1,0002 & 82,97 & 5 & 2,12 \\
K K & 0,52 & 0,23 & 0,0044 & 0,9201 & 0,9176 & 1 & 8,5 & 4,17 & 8,81
\end{tabular}




\subsection{Preliminary adsorption tests}

Silica obtained in Section 6.1 was used as adsorbent material in water treatment methodologies. Water with high content of nitrates was submitted to preliminary adsorption tests at the laboratories of the Departament of Analytical Chemistry (Faculty of Chemistry, Universitat de València, Burjassot)

\subsubsection{Description of methodology}

The previously obtained silica was firstly activated at $110^{\circ} \mathrm{C}$ for 48 hours. After that, the activated samples were acidified with 49\% sulphuric acid (Merck 98\%) to obtain acidic silica. Finally, the samples were left air drying (Moliner-Martinez et al, 2009).

$50 \mathrm{mg}$ of each dry silica sample was weighted and set in a cartridge (Figure 6.11a). $0.5 \mathrm{~mL}$ of a $25 \mathrm{ppm}$ of a $\mathrm{NO}_{3}$ - solution was passed through the cartridge containing the silica. (Figure 6.11b).

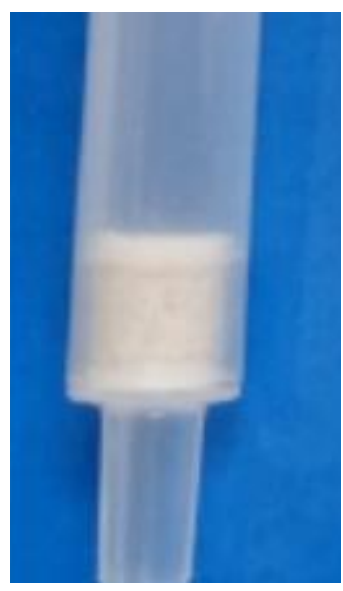

(a)

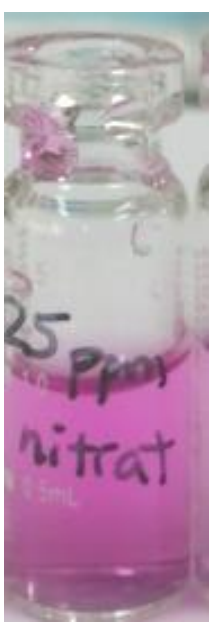

(b)

Figure 6.11. Cartridge containing silica samples (a) and initial nitrate solution (b) 
In order to determine the presence of nitrates in the resulting solution, the reaction of derivation with the Griess reagent was carried out (Manor-Jayawardane et al, 2014). With this purpose, the Griess reagent was prepared by dissolving 50 mM sulphanilamide Sigma-Aldrich, >99\%), 330 $\mathrm{mM}$ of citric acid (Panreac, 99,5\%) and $10 \mathrm{mM}$ of $\mathrm{N}$-(1-naphthyl)-ethylenediamine dihydrochloride (Sigma-Aldrich $>98 \%$ ). Some drops of a Zn solution (Panreac, 95\%) was also added.

A second aliquot of $0.5 \mathrm{~mL}$ of the $25 \mathrm{ppm}^{\text {a }} \mathrm{NO}_{3}$ - solution was passed for the second time through the cartridge and the procedure previously reported was performed.

\subsubsection{Experimental results}

The determination of nitrates by application of the Griess reagent is based on the conversion of the analyte colorimetrically undetectable (nitrate form) into a colorimetrically detectable one (nitrite form) that can be easily detected.

The Griess reaction is a color reaction that enables the nitrite detection (Sun et al, 2003). It is based on the reaction between nitrite and a primary aromatic amine (i.e. sulphanilamide) under acidic conditions forming a diazonium salt. This salt further reacts with an aromatic compound containing an amino group (i.e. N-(1-naphthyl)-ethylenediamine dihydrochloride) to form an intensely colored azo dye. In order be able to perform this procedure, nitrate must be reduced to nitrite first using a suitable reductant, in our case metallic Zn.

Figure 6.12 shows the results of the preliminary tests. First of all, the blank of water (Figure 6.12a) is presented as the final target of the reaction. Figure $6.12 \mathrm{~b}$ presents the result of the Griess reaction on the $25 \mathrm{ppm} \mathrm{NO}_{3}{ }^{-}$solution which shows a intense azo dye color. Figures 6.13c, $d$ and e show the result of the initial nitrate solutions after passing through cartridges containing different silica samples (tested treatments: 1:5 $\mathrm{NaOH}-\mathrm{H}_{2} \mathrm{SO}_{4}$ (Figure 6.14c), 1:5 $\mathrm{NaOH}-\mathrm{H}_{2} \mathrm{SO}_{4} / 200 \mathrm{ppm}$ SDS (Figure 6.15d) and 1:5 NaOH- $\mathrm{H}_{2} \mathrm{SO}_{4} / 400 \mathrm{ppm}$ SDS (Figure 6.16e) once the Griess reaction has been carried out. 


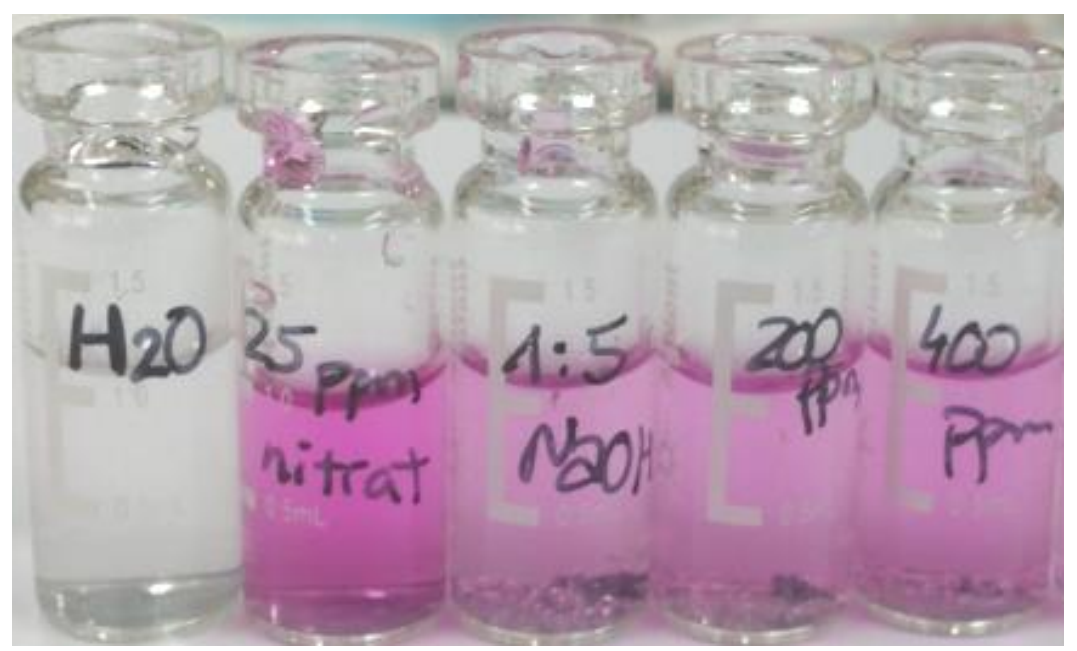

(a)

(b)

(c)

(d)

(e)

Figure 6.12. Blank of water (a), initial 25 ppm nitrate solution (b), initial solution after passing through 1:5 NaOH- $\mathrm{H}_{2} \mathrm{SO}_{4}$ (c), initial solution after passing through 1:5 NaOH- $\mathrm{H}_{2} \mathrm{SO}_{4} / 200 \mathrm{ppm}$ SDS (d), initial solution after passing through 1:5 NaOH- $\mathrm{H}_{2} \mathrm{SO}_{4} / 400 \mathrm{ppm}$ SDS (e)

As shown in the figures, the obtained solutions present a lighter color indicating less presence of nitrate respect to the initial solution and thus, confirming its retention in the silica materials. However, the retention was not complete as it did not achieve the target (Figure 6.12a).

Moreover, no significant results were obtained when a second aliquot of nitrate solution was passed through the already used cartridge, indicating a possible saturation of the material.

These results confirm the adsorbent capacity of the silica obtained from the ashes of the rice straw but further modifications in the chemical structure will be needed to achieve the complete and efficient removal of nitrates. 


\subsection{Main results}

Silica ash was obtained at lab scale by simulating the thermal decomposition profile of the samples with a muffle furnace. The yield of ash production was $15.5 \pm 0.3 \%$. From the obtained product, the extraction of silica was performed. An initial dissolution in $\mathrm{NaOH}$ was carried out and the influence of the ash-NaOH molar ratio was evaluated. After that, a reaction of precipitation (using acid or a dissolution of acid and a surfactant) and further washing of the samples resulted in silica white powders.

The characteristation of samples was performed through Energy Dispersive X-ray Spectrometry (EDS) to identify and quantify the main chemical elements present in the samples. From the results, it is clear that the obtained product is mainly composed by silicon and oxygen, suggesting that the extracted product consists of silica.

The results of the preliminary tests using the obtained silica for the removal of nitrates in a water dissolution showed that the tested samples presented certain degree of retention. However, this retention was not complete and further modifications on the chemical structure will be required to optimise its behaviour. 


\section{References Chapter 6}

Ametek. Materials Analysis Division. Energy Dispersive Spectroscopy. John Wiley \& Sons (2015)

Bansal V., Ahmad A., Sastry M. Fungus-mediated biotransformation of amorphous silica in rice husk to nanocrystalline silica. Journal of the American Chemical Society 128, 14059-14066 (2006)

Chakraverty A., Kaleemullah S. Production of amorphous silica and combustible gas from rice straw. Journal of Materials Science 26, 4554-4560 (1991)

Conradt R., Pimhhaokham P., Leelaadisorn U. Nano-structured silica from rice husk. Journal of NonCrystalline Solids 145, 75-79 (1992)

Hessien M.M. Rashad M.M., Zaky R.R., Abdel-Aal E.A., El-Barawy K.A. Controlling the synthesis conditions for silica nanosphere from semi-burned rice straw. Materials Science and Engineering B 162, 14-21 (2009)

Kalderis D., Koutoulakis D., Paraskeva P., Diamadopoulos E., Otal E., Olivares del Valle J., FernandezPereira C. Adsorption of polluting substances on activated carbons prepared from rice husk and sugarcane bagasse. Chemical Engineering Journal 144, 42-50 (2008)

Karimi K., Emtiazi G., Taherzadeh M.J. Production of ethanol and mycelial biomass from rice straw hemicellulose hydrolyzate byMucor indicus. Process Biochem. 41, 653-658 (2006)

Liou T.H., Wu S.J. Kinetics study and characterisation of silica nanoparticles produced from biomassbased material. Industrial and Engineering Chemistry Research 49, 8379-8387 (2010)

Lu P., Hsieh Y. Highly pure amorphous silica nano-disks from rice straw. Powder Technology 225, 149155 (2012)

Manori Jayawardane B., Wei S., McKelvie I.D., Kolev D.S. Microfluidic paper-based analytical device for determination of nitrite and nitrate. Analytical Chemistry 86, 7274-7279 (2014)

Moliner-Martinez Y., Campins-Falco P., Molins-Legua C., Segovia-Martinez L., Seco-Torrecillas A. Miniaturised matrix solid phase dispersion procedure and solid phase microextraction for the analysis of organochlorinated pesticides and polybrominated diphenylethers in biota samples by gas chromatography electron capture detection. Journal of Chromatography A, 126, 6741-6745 (2009)

Pijarn N., Jaroenworaluck A., Sunsaneeyametha W., Stevens R. Synthesis and characterisation of nanosized-silica gels formed under controlled conditions. Powder Technology 203, 462-468 (2010)

Real C., Alcala M-D., Criado J.M. Preparation of silica from rice husks. Journal of the American Ceramic Society 79, 2012-2016 (1996)

Shao L., Xu Z.X., Yin H.L., Chu H.Q. Rice husk as carbon source and biofilm carrier for water denitrification . Journal of Biotechnology 136S, S647-S677 (2008)

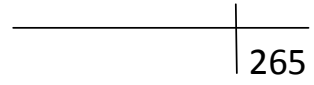


Sun J., Zhang X., Broderick M., Fein H. Measurement of nitric oxide production in biological systems by using Griess reaction assay. Sensors 3, 276-284 (2003)

Umamaheswaran K., Batra V.S., Bhagavanulu D.V.S. Development of biomass ash filters for high temperature applications. International Symposium of Research Students on Materials Science and Engineering. India (2004)

Van Soest P.J. Rice straw, the role of silica and treatments to improve quality. Animal Feed Science and Technology 130, 137-171 (2006)

Zaky R.R., Hessien M.M., El-Midany A.A., Khedr M.H., Abdel-Aal E.A, El-Barawy K.A. Preparation of silica nanoparticles from semi-burned rice straw ash. Powder Technology 185, 31-35 (2008) 


\section{CONCLUSIONS AND FURTHER WORK}

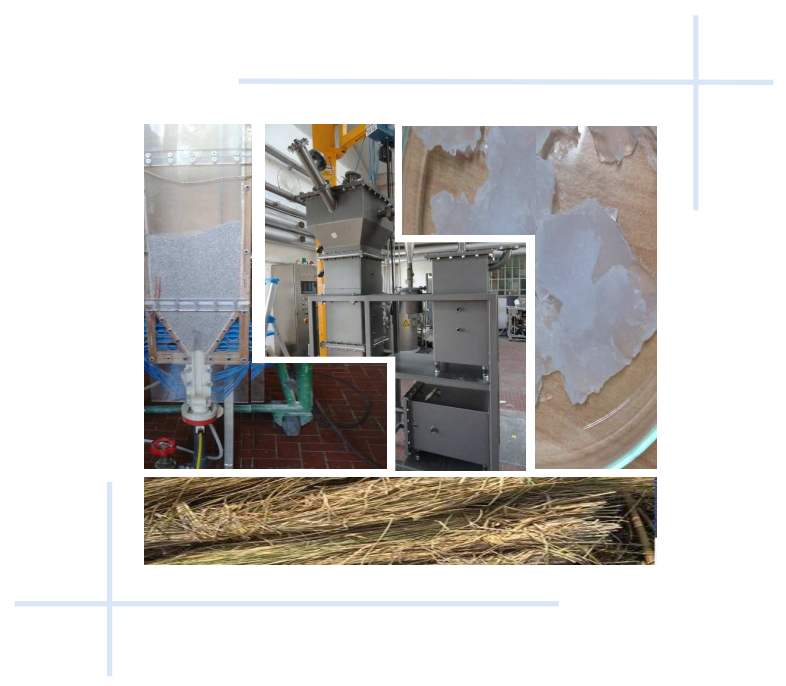

7.1. Conclusions

....... 269

7.2 Future research lines

....... 274

7.3 Other benefits of this thesis 

"You've got to find what you love. And that is as true for your work as it is for your lovers. As with all matters of the heart, you'll know when you find it. And, like any great relationship, it just gets better and better as the years roll on.

So keep looking until you find it. Don't settle.

Stay Hungry. Stay Foolish.”

Steve Jobs. Stanford Graduation Speech 2005

\subsection{Conclusions}

Waste management requires a rigorous multidisciplinary assessment of all the involved processes. This thesis presented a methodology for a correct and sustainable use of agricultural residues, with particular attention paid to rice straw. Initially, an energy recovering process based on the gasification of residues in a spouted bed reactor was studied. After that, the ashes obtained after the thermal treatment were further used to produce silica. Specific parameters and indicators were found to ensure the reliability of the proposed conversion technologies. Overall, an enhancement of knowledge regarding the use of agricultural residues in the energy sector has been achieved thanks to this research

In particular, the conclusions of the present thesis were classified according to the following topics:

\section{Biomass and its characterisation}

The importance of an accurate definition of the main properties of the biomass was demonstrated crucial for the application of the adequate conversion technology.

The main physical properties of biomass were obtained and discussed.

The dimension and shape of solids had a great influence on the fluid dynamic behaviour of the system. These characteristics also represented the main experimental difficulties for the correct performance of the feeding system in the scaled-up unit. In the case of rice straw, the samples were chopped and considered as a cylinder with constant diameter. Two

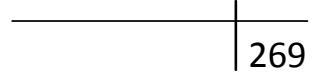


averaged length of 1 and $3.7 \mathrm{~cm}$ were obtained from the size distribution performed on a representative sample. Due to the nature of the straw, length was taken as its characteristic dimension.

The density of solids directly influences the volume requirements of the storage and operational units. The density of rice straw was calculated according to standard procedures and was found to be $56 \mathrm{~kg} / \mathrm{m}^{3}$. The difference of density between solid phases was the main cause of instabilities in the spouting process.

The main chemical properties of biomass were also obtained and discussed.

The ultimate analysis provided the main constituting elements of the biomass. The high relative amounts of oxygen $(57.8 \% \mathrm{w} / \mathrm{w})$ made the rice straws a more reactive feed compared to coal but also resulted in relatively low heating values. The remarkably low sulphur content $(0.2 \% \mathrm{w} / \mathrm{w})$ provided a major environmental advantage for the use of biomass as energy vector instead of coal.

The proximate analysis indicated the content of water, fixed carbon, volatiles and ash in the sample. High percentages of ash $(20.6 \% \mathrm{w} / \mathrm{w})$ were found in rice straw and the operational temperature was limited to $1000^{\circ} \mathrm{C}$ to prevent their melting.

The energy content of biomass in terms of Higher Heating Value (and Lower Heating Value) was calculated with the aid of existing correlations and were found to be $\mathrm{HHV}=11.6 \mathrm{MJ} / \mathrm{kg}$ and $\mathrm{LHV}=10 \mathrm{MJ} / \mathrm{kg}$ respectively.

The main thermal properties of biomass were calculated.

The characterisation of the thermal and thermo-oxidative behaviour of the feedstock and the further study of their kinetics was carried out by Thermogravimetric Analysis (TGA).

The profiles of decomposition were obtained using Argon and Oxygen as carrier gases to simulate the thermal and thermo-oxidative decompositions respectively. All the tested biomass samples presented several degradation stages corresponding to the main pseudocomponents (hemicellulose, cellulose and lignin) and successive combustion of the remaining char. The residual values were higher under inert conditions (20\%) than oxidative ambients (5\%) as a result of a less reactive ambient. 
The thermal performance of all samples was predicted under any linear heating rate by the function Thermal Decomposition Behaviour (TDB). The values of $\mathrm{ZDT}_{0}$ provided the thermal stability of the samples, closely related to the temperature of start-up for the thermal process. A minimum of $\mathrm{T}=273^{\circ} \mathrm{C}$ (inert conditions) and $\mathrm{T}=264^{\circ} \mathrm{C}$ (oxidative conditions) will be necessary to start yielding volatile compounds. The use of $\mathrm{ZDT}_{\text {peak }}$ was useful to monitor the decomposition of each pseudo-component.

The application of isoconversional methods (Friedman, Flynn-Wall-Ozawa, KissingerAkashira-Sunose, Vyazovkin, Master Curves and Perez-Maqueda criterion along with Coats-Redfern equation) permitted the obtainment of the kinetic parameters (Ea, ln A and n) of the biomass for both inert and oxidative conditions. The simplified kinetic triplet defined the thermal decomposition of the tested samples and the kinetic law was further applied in the design of the reactor.

Particularly, the model that kinetically described the decomposition of rice straw was the type of $F_{n}$ : order of reaction. Lower activation energies, order of reaction and preexponential factor values were required to carry out reactions of pyrolysis due to the absence of complex oxidant reactions.

\section{Characterisation of the Spouted Bed Reactor}

The fluid dynamic study of systems with different solid characteristics (density, size of particle, irregular shapes ....) was performed. The main design properties are evaluated in order to guarantee the stability and correct performance of the pilot reactor.

An initial set of room temperature experiments using sand and rice straw at different operational conditions was performed.

A maximum load of rice straw of $20 \% \mathrm{v} / \mathrm{v}$ was defined to guarantee a stable process of spouting. Higher initial bed of particles led to higher air flow requirements and higher pressure drop values. The presence of coarse particles also increased the minimum spouting requirements.

Existing correlations to calculate the minimum spouting velocity were applied but did not show a fair agreement with the experimental results. A new correlation was proved valid for its prediction in the conical square-based spouted bed reactor under study. 
A statistical Design of Experiments (DoE) was applied and several cold flow tests were carried out on six different systems varying in density, dimension and shape.

Similar density ratios between the particles of the bed improved the performance of the system in all cases.

Segregation phenomena were not observed in any tests with volumetric ratios lower than $5 \% \mathrm{v} / \mathrm{v}$ of biomass. The increase of coarse particles resulted in increasing instabilities in all cases.

A new variable, $\mathrm{Q}^{*}$, was defined as the minimum inflow required to prevent segregation phenomena.

A CFD model was developed to simulate and predict the behaviour of the studied systems and was validated with experimental data.

The Euler-Euler approach was applied with the aid of the commercial software ANSYS 14.5 workbench. The variables fountain height and pressure drop along the bed of particles were used as validating parameters.

The model represented the height of the fountain with good accuracy in all cases with maximum error below $5 \%$. This result allowed the identification of the region where the fountain will develop and so, where the mass and energy transfer reactions between gas and solids will take place.

The model developed by the group did not predict, with the same precision, the pressure drop along the bed of particles. An upgrade of the model obtaining the 3D solution will be carried out to improve these results.

\section{Reactions of gasification in a Spouted Bed Reactor}

Different models were applied for the study of the reactions of gasification of biomass.

The energy that can be recovered through the gasification of agricultural residues was maximised at the Carbon Boundary Layer. The overuse of oxygen resulted in undesired combustion reactions that lowered the heating value of the produced gas and, consequently the efficiencies of the process. 
In the case of the rice straw, the optimum operational conditions that maximised the process of gasification in the studied spouted bed reactor were found to be: $\mathrm{ER}=0.4 ; \mathrm{T}=900^{\circ} \mathrm{C}$.

\section{Extraction of silica from rice straw ash}

Silica was chemically extracted from rice straw ash produced as the final residue of the gasification reactions.

Ashes were obtained in a muffle furnace with a yield of ash production of $15.5 \pm 0.3 \%$ $(\% \mathrm{w} / \mathrm{w})$.

Different silica powders were obtained by varying the parameters: ash-NaOH molar ratio $(1: 1 ; 1: 2 ; 1: 3 ; 1: 4 ; 1: 5)$ and addition of a surfactant agent (No SDS, 200 ppm SDS, 400 ppm SDS).

Energy Dispersive X-ray Spectrometry (EDS) was used to identify and quantify the main chemical elements present in the samples. The spectra indicated that the obtained product was mainly composed of silicon and oxygen.

Preliminary tests using the obtained silica for the removal of nitrates in a water dissolution were performed. Samples with higher ash- $\mathrm{NaOH}$ molar ratios and higher concentration of surfactant agent showed certain degree of nitrates retention. However, this retention was not complete and further modifications on the chemical structure will be required to optimise its behaviour. 


\subsection{Further work}

Rice straw is proven to be a suitable and reliable source of energy. Following the methodology carried out in this Thesis, new agricultural residues are being/will be studied for the same purpose. Moreover, in order to widen the acquired knowledge, the following research lines are envisaged to be followed in the near future:

- to study the joint valorisation of the residues present in an area of interest and a period of the year. That way, the economical benefits of not having to separate them would be enhanced;

- to develop a more detailed CFD model to account with all the potential interactions between components with the application of the Euler-Lagrangian approach;

- to explore the use of different residues in the already developed Spouted bed pilot plant to optimise the working parameters according the nature of the feedstock;

- to improve the nitrates retention capacity in silica by modifications of its chemical structure in order to promote the presence of positive charges in the molecule;

- to widen the application of silica powders for the removal of different pollutant species by producing the most suitable chemical structures according to the desired target. 


\subsection{Other Benefits of the PhD Thesis}

As described in the first sections of this thesis, these $\mathrm{PhD}$ studies have been performed within the framework of a co-supervised partnership between the Università degli Studi di Genova (UNIGE, Genova, Italy) and the Universitat Politècnica de València (UPV, Valencia, Spain).

The scientific results and the cooperation frameworks consolidated during these past few years will be very useful for future $\mathrm{PhD}$ students and will also enhance the collaboration between both universities.

Moreover, the development of some activities, research actions and collaborations, has promoted the research of the renewable energies area which is now very active and continually growing. In particular, the work has been focused on the use of rice straw as a new energy vector. As a result of the developed methodology, the main residues present in the areas of study (wine pruning, apple pruning, kaki fruit, ...) will benefit from the advancement of technology achieved. 

Glossaries 



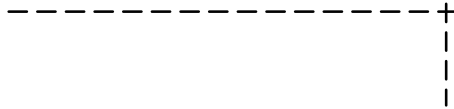

Table 1.1 Gross consumption of solid biomass for energy production in the European Union (Mtoe)

Table 1.2 Estimated greenhouse emissions savings from the use of renewable energy $\left(\mathrm{t} \mathrm{CO}_{2} \mathrm{eq} \cdot 10^{6}\right.$ ) (Data extracted from the Second Progress Reports by Italy and Spain, 2013)

Table 1.3. Main gasification reactions (McKendry, 2002b)

Table 2.1. Summary of SB gasification studies

Table 2.2. Contributions using the Eulerian-Eulerian approach for the simulation of SBR

Table 3.1 Dry bulk volumes and densities of several types of biomass (McKendry, 2001)

......... 79

Table 3.2. Density values for the tested materials

Table 3.3. Dimensions and characteristics of samples

Table 3.4 Chemical composition of several types of biomass (Anwar et al, 2014)

…..... $\quad 80$

Table 3.5. Ultimate analysis of rice straw

Table 3.6. Proximate analyses of different types of biomass (\%wt dry basis). Coal is reported as a reference (Gaur and Reed, 1998)

Table 3.7. Proximate analysis of rice straw

Table 3.8. Ultimate analyses of different types of biomass (\%wt dry and ash free basis). Coal is reported as a reference (Gaur and Reed, 1998)

Table 3.9. Calorific value of rice straw

Table 3.10. Summary of models used in the description of thermal degradation processes

Table 4.1. Main dimensions of the spouted bed reactor

Table 4.2. Maximum spoutable bed height for the bed materials under study

Table 4.3. Variation of peak pressure drop with $\mathrm{H}_{\mathrm{b}}$ and biomass volumetric ratio

Table 4.4. Variation of stable pressure drop with $\mathrm{H}_{\mathrm{b}}$ and biomass volumetric ratio 
Table 4.5. Comparison of the stable pressure drop with and without draft tube

Table 4.6 Summary of Factors (F), Levels (L) and general characteristics of the DoE applied for this study

......... $\quad 142$

Table 4.7 Physical properties of the solids used for the segregation studies

(......... $\quad 142$

Table 4.8. Properties of materials and simulated operational conditions

Table 4.9. Mesh characteristics

Table 5.1. Operational conditions for the reaction of combustion air-GPL

(........ $\quad 200$

Table 6.1.. Factors and levels tested for the extraction of silica

Table 6.2. Volume of $\mathrm{NaOH}$ added in each experiment

Table 6.3. EDAX quantification of the sample ash- $\mathrm{NaOH}$ 1:5

Table 6.4. EDAX quantification of the sample ash- $\mathrm{NaOH} 1: 5$ and 200 ppm of SDS 260

Table 6.5. EDAX quantification of the sample ash-NaOH 1:5 and 400 ppm of SDS 
Figure 1.1. Carbon natural cycle

Figure 1.2. Biomass sources

Figure 1.3. Rice straw residues

Figure 1.4. Production of rice, straw and husk (FAOSTAT, 2015)

Figure 1.5. Location of Albufera - Valencia (Spain). Source: Google Maps

Figure 1.6. Map of technologies for lignocellulosic materials

Figure 1.7. Bus with on-board gasifier used during the Second World War 38

Figure 1.8. Scheme of the methodology and main aims of the thesis

Figure 2.1. Scheme of an updraft gasifier (a) and a cross-flow gasifier (b)

Figure 2.2. Scheme of a bubbling bed reactor

Figure 2.3. Schematic representation of a SBR

Figure 2.4. Flow regime for the system PET-rice straw (5\%v/v). Initial bed height:

$50 \mathrm{~cm}$

Figure 2.5. Evolution of the pressure drop across the bed with the inlet velocity (Rice straw 10\%v/v)

Figure 2.6. Example of a regime map with the different transitions occurring in SBR

Figure 2.7. Segregation in a standard fluidisation reactor (a) and in a spouting bed reactor $(b)$

Figure 2.8. Draft tube (a) and secondary fluidisation (b)

Figure 2.9. Schematic representation of the flow regimes in granular flows

Figure 3.1. Rice straw and main dimensions of sample

Figure 3.2. Chemical structure of cellulose

Figure 3.3. Chemical structure of hemicellulose

Figure 3.4. Structural units of lignin

Figure 3.5. Cell wall structure and distribution of pseudo-components within it

Figure 3.6. Van Krevelen diagram

Figure 3.7. Eurovector EuroEA Elemental Analyser

Figure 3.8. Muffle furnace used for the determination of the proximate analysis 
Figure 3.9. $\mathrm{TG}$ of rice straw $\left(20^{\circ} \mathrm{C} / \mathrm{min}\right.$ and inert atmosphere $)$

Figure 3.10. DTG of rice straw $\left(20^{\circ} \mathrm{C} / \mathrm{min}\right.$ and inert atmosphere $)$

Figure 3.11. TGA equipment used in this thesis

Figure 3.12. Example of deconvoluted curves for leaves of kaki $\left(10^{\circ} \mathrm{C} / \mathrm{min}\right.$; oxidative ambient)

Figure 3.13. Example of application of isoconversional methods to rice straw: (a) evolution of Ea with $\alpha$ considering it as single component under $\mathrm{O}_{2}$; (b) Application of FWO method under $\mathrm{O}_{2}$ (single component); (c) evolution of Ea for the first DTG peak with $\alpha$; (d) Application of FWO method under $\mathrm{O}_{2}$ (multicomponent)

Figure 3.14. Master plots based on the integral $(\operatorname{MPg}(\alpha))$ form of the general law compared to the experimental data obtained by the thermal process applied (circles). Kinetic Models: $\mathrm{D}_{\mathrm{n}}$ : diffusion controlled, blue lines, $\mathrm{A}_{\mathrm{n}}$ : nucleation and growth, red lines, $F_{n}$ : $n$-order reaction, orange lines, $\mathrm{R}_{\mathrm{n}}$ : reaction controlled, green lines

Figure 3.15. Example of the application of the Coats-Redfern criterion for the case of rice straw under inert (a) and oxidative (b) conditions

Figure 4.1 Regions within a SBR (System PET/straw 5\%v/v; Initial bed height=50 $\mathrm{cm})$

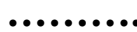

Figure 4.2. Scheme of the experimental set-up used for the present thesis

Figure 4.3. Main components of the experimental set up: air inlet (a); flow meter (b); water U-manometer (c); Hg U-manometer (d); spouted bed reactor (e); draft tube (f)

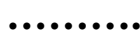

Figure 4.4. Introduction of biomass (a) and view of the bed of particles from the top of the reactor (b)

Figure 4.5. Effect of the initial bed height on $U_{m s}$ and $U_{\text {onset }}$ for a bed of silica

Figure 4.6. Effect of the initial bed height on $U_{m s}$ and $U_{\text {onset }}$ for a system containing $10 \% \mathrm{v} / \mathrm{v}$ (circles) and $20 \% \mathrm{v} / \mathrm{v}$ of rice straw (triangles)

Figure 4.7. Evolution of pressure drop with air inlet for a bed of silica particles (triangle: $25 \mathrm{~cm}$ of initial height; square: $45 \mathrm{~cm}$ of initial bed height)

Figure 4.8. Position and dimension of the non-porous draft tube

Figure 4.9. Scheme of the modelling methodology using FLUENT

Figure 4.10. Diagram of the mesh

Figure 5.1. Scheme of the gasification of biomass

Figure 5.2. Influence of ER (a) and $T$ (b) on the efficiency of gasification of rice 
straw

Figure 5.3. CGE with the varying $T$ (a) and ER (b) according to equilibrium conditions $(\square)$ and taking into account kinetic expressions $(\mathbf{\square}) \quad$.......... 196

Figure 5.4. Description of the pilot $\mathrm{SBR}^{\odot} \quad$.......... 198

Figure 5.5. Feeding system after the modification on the initial design ${ }^{\odot} \quad$.......... 199

Figure 5.6. Calibration curve for the $\mathrm{GC}^{\odot}{ }^{\odot} \quad$............ 201

Figure 5.7. Setting of main properties on Aspen Plus ${ }^{\circledR} \quad$......... 204

Figure 5.8. Setting of simulation properties on Aspen Plus ${ }^{\odot} \quad$.......... 205

Figure 5.9. Setting of calculator block on Aspen Plus ${ }^{\circledR} \quad$......... 205

Figure 5.10. Sensitivity analysis on Aspen Plus ${ }^{\odot} \quad$......... 206

Figure 6.1. Decomposition profile of rice straw under oxidative conditions ( $\left.\beta=5^{\circ} \mathrm{C} / \mathrm{min}\right)$

Figure 6.2. Scheme of heating programme for the obtainment of ashes in the muffles

Figure 6.3. Rice straw before (a) and after (b) the heating process

Figure 6.4. Scheme of the chemical extraction of silica from rice straw ash

Figure 6.5. Alkali dissolution of rice straw: dissolution (a), sodium silicate solution (b) and residue (c)

Figure 6.6. Neutralisation with sulphuric acid (a) and precipitation of gel (b)

Figure 6.7. Products of reaction: silica gel (a) and silica powders (b)

Figure 6.8. Scheme of the products obtained throughout the chemical extraction of silica

Figure 6.9.Methodology of EDS (Ametek Materials Analysis Division, 2015)

Figure 6.10.EDS spectrum of the samples: ash- $\mathrm{NaOH} \mathrm{1:5} \mathrm{(a);} \mathrm{ratio} \mathrm{1:5+200ppm}$ SDS (b); ratio 1:5+400ppm SDS (c)

Figure 6.11.Cartdridge containing silica samples (a) and initial nitrate solution (b)

Figure 6.12.Blank of water (a), initial $25 \mathrm{ppm}$ nitrate solution (b), initial solution after passing through 1:5 $\mathrm{NaOH}-\mathrm{H}_{2} \mathrm{SO}_{4}$ (c), initial solution after passing through 1:5 $\mathrm{NaOH}-\mathrm{H}_{2} \mathrm{SO}_{4} / 200 \mathrm{ppm}$ SDS (d), initial solution after passing through 1:5 $\mathrm{NaOH}-\mathrm{H}_{2} \mathrm{SO}_{4} / 400 \mathrm{ppm}$ SDS (e) 



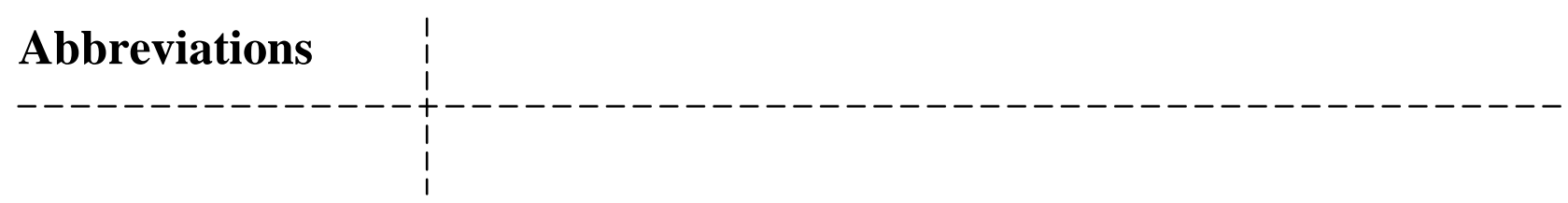

A - absorption correction (spectrometry)

$\mathrm{Ar}-$ Archimedes number

BFBR - Bubbling Fluidised Bed Reactor

CBL - Carbon Boundary Layer

CCE - Carbon Conversion Efficiency

CFBR - Circulating Fluidised Bed Reactor

CFD - Computational Fluid Dynamics

CGE - Cold Gas Efficiency

DEM - Discrete Element Method

DoE - Design of Experiments

DT - Draft Tube

DTG - differential thermogravimetric curve

EDS - Energy Dispersive X-ray Spectrometry

ER - Equivalence Ratio

$\mathrm{ER}_{\mathrm{st}}-$ Stoichiometric Equivalence Ratio

F - Factors (Statistical analysis)

FC - Fixed Carbon

FBR - Fluidised Bed Reactors

Fl - fluorescence correction (spectrometry)

FTIR - Fourier-Transformed Infrared Analysis

FWO - Flynn-Wall-Ozawa

$f(\alpha)$ - differential kinetic function

$g(\alpha)$ - integral kinetic function

IGCC - Integrated Gasification Combined Cycle

IP - Interaction Plots 
KAS - Kissinger-Akahira-Sunose

$\mathrm{L}$ - Levels (Statistical analysis)

M - Moisture content

MEP - Main Effects Plots

MP - Master Plots

$\mathrm{MP}_{\mathrm{f}}-$ Master Plots based on the differential form of the general kinetic equation

$\mathrm{MP}_{\mathrm{fg}}$ - Master Plots based on the differential and integral form of the general kinetic equation

$\mathrm{MP}_{\mathrm{g}}$ - Master Plots based on the integral form of the general kinetic equation

$\mathrm{MP}_{\mathrm{t}}-$ Theoretical Master Plots

MS - Mass Spectroscopy

QET - Quasi Equilibrium Temperature approach

$\mathrm{R}^{2}$ - linear regression coefficient

Re - Reynolds number

SBR - Spouted Bed Reactor

SDS - sodium dodecyl sulphate

TDB - Thermal Decompostition Behaviour

TFM - Two Fluid Model

TGA - thermogravimetric analysis

TG - thermogravimetric curve

VM - Volatile Matter

VYZ - Vyazokvin

$\mathrm{Z}$ - atomic number correction (spectrometry)

ZDT - Zero-Decomposition Temperature, ${ }^{\circ} \mathrm{C}$ 


\section{Nomenclature}

$\alpha$ - conversion degree

$\alpha_{c}-$ cone angle

$\beta$ - heating rate, ${ }^{\circ} \mathrm{C} / \mathrm{min}$

$\beta_{\mathrm{i}}$ - interaction between fluid and particles in the drag force

$\gamma_{s}$ - dissipation fluctuation energy, $\mathrm{kg} / \mathrm{m}^{3} \cdot \mathrm{s}$

$\varepsilon_{0}$ - average void fraction

$\varepsilon_{\mathrm{mf}}-$ void fraction at minimum fluidisation

$\varepsilon_{s, \max }-$ maximum particle volume fraction

$\varsigma$ - particle-particle interactions coefficient

$\lambda_{s}$ - solid bulk viscosity, $\mathrm{Pa} \cdot \mathrm{s}$

$\mu_{\mathrm{g}}$ - air viscosity, $\mathrm{Pa} \cdot \mathrm{s}$

$\mu_{\mathrm{s}, \mathrm{k}}$ - solid shear viscosity, Pa·s

$v_{\mathrm{i}}$ - stoichiometric coefficient

$\rho_{\text {apparent }}$ - apparent density, $\mathrm{kg} / \mathrm{m}^{3}$

$\rho_{\text {bulk }}-$ bulk density, $\mathrm{kg} / \mathrm{m}^{3}$

$\rho_{\mathrm{g}}$ - density of gas, $\mathrm{kg} / \mathrm{m}^{3}$

$\rho_{\mathrm{s}}-$ density of solid, $\mathrm{kg} / \mathrm{m}^{3}$

$\tau_{\mathrm{q}}$ - stress tensor, $\mathrm{Pa}$

$\square$ - shape factor

$\Delta G_{f, i}^{0}$ - Gibbs free energy of formation of species i at the standard pressure of $1 \mathrm{bar}, \mathrm{kJ} / \mathrm{mol}$

$\Delta \mathrm{m}$ - mass loss during thermal decomposition

$\Delta \mathrm{P}_{\mathrm{b}}-$ pressure drop along the bed of particles, $\mathrm{Pa}$

$\Delta \mathrm{P}_{\max }-$ maximum pressure drop along the bed of particles, $\mathrm{Pa}$

$\Delta \mathrm{P}_{\mathrm{ms}}-$ pressure drop along the bed of particles at minimum spouting conditions, $\mathrm{Pa}$ 
$\Delta \mathrm{P}_{\text {onset }}-$ pressure drop along the bed of particles at initiation of spout, $\mathrm{Pa}$

$\Delta \mathrm{P}_{\mathrm{s}}-$ stable pressure drop along the bed of particles, $\mathrm{Pa}$

$\Delta \mathrm{P}_{\mathrm{T}}-$ total pressure drop of the system, $\mathrm{Pa}$

$\Delta \mathrm{P}^{*}$ - pressure drop along the bed of particles at conditions for prevention of segregation, $\mathrm{Pa}$

$\Theta_{s}-$ granular temperature, $\mathrm{m}^{2} / \mathrm{s}^{2}$

$\Phi_{\mathrm{S}}$ - sphericity of particles

A - pre-exponential factor $\left(\mathrm{s}^{-1}\right)$

$\mathrm{C}_{\mathrm{D}}$ - drag coefficient

$C_{f r}$ - coefficient of friction between the two solid phases

$d$ - diameter of particle, $m$

$\mathrm{D}_{\mathrm{C}}-$ diameter of column, $\mathrm{m}$

$\mathrm{D}_{\mathrm{dt}}-$ diameter of draft tube, $\mathrm{m}$

$\mathrm{D}_{\mathrm{i}}-$ diameter of fluid inlet, $\mathrm{m}$

$\mathrm{D}_{\mathrm{s}}$ - diameter of spout, $\mathrm{m}$

$\mathrm{E}$ - expansion of the bed of particles, $\mathrm{m}$

$\mathrm{Ea}$ - activation energy, $\mathrm{kJ} / \mathrm{mol}$

$e_{s s}-$ interparticle coefficient of restitution

$\mathrm{G}$ - superficial mass flux of fluid, $\mathrm{kg} / \mathrm{m}^{2} \mathrm{~s}$

$\mathrm{g}-$ acceleration of gravity, $\mathrm{m} / \mathrm{s}^{2}$

$\mathrm{g}_{0}$ - radial distribution function

$\mathrm{H}_{\mathrm{b}}$ - static initial bed height, $\mathrm{m}$

$\mathrm{H}_{\mathrm{C}}$ - cone height, $\mathrm{m}$

$\mathrm{H}_{d}$ - disengagement height (draft tube), m

$\mathrm{H}_{\mathrm{F}}$ - fountain height, measured from the bottom of the reactor, $\mathrm{m}$

$\mathrm{H}_{\mathrm{m}}$ - maximum spoutable bed height, $\mathrm{m}$

$\mathrm{H}_{\mathrm{R}}$ - reactor height, $\mathrm{m}$ 
HHV - Higher Heating Value, MJ/kg

$\mathrm{L}_{\mathrm{dt}}-$ length of draft tube, $\mathrm{m}$

LHV - Lower Heating Value, MJ/kg

$\mathrm{Q}_{\mathrm{ms}}$ - flow of gasifying agent at minimum spouting conditions, $\mathrm{m}^{3} / \mathrm{s}$

$\mathrm{Q}_{\text {onset }}-$ flow of gasifying agent at initiation of spout, $\mathrm{m}^{3} / \mathrm{s}$

$\mathrm{Q}^{*}$ - flow of gasifying agent to prevent segregation, $\mathrm{m}^{3} / \mathrm{s}$

$p$ - fluid pressure, $\mathrm{Pa}$

$p_{s, k}$ - kinetic solid pressure, $\mathrm{Pa}$

$\mathrm{P}^{0}$ - standard pressure, $\mathrm{Pa}$

$\mathrm{T}_{\text {endset }}$ - endset temperature, ${ }^{\circ} \mathrm{C}$

$\mathrm{T}_{0}$ - onset temperature, ${ }^{\circ} \mathrm{C}$

$\mathrm{T}_{\text {peak }}$ - temperature of maximum decomposition rate, ${ }^{\circ} \mathrm{C}$

$\vec{u}_{g}$ - gas velocity, $\mathrm{m} / \mathrm{s}$

$\vec{u}_{s}$ - particle velocity, $\mathrm{m} / \mathrm{s}$

$\mathrm{U}_{\text {in }}-$ inlet velocity, $\mathrm{m} / \mathrm{s}$

$\mathrm{U}_{\mathrm{mf}}-$ superficial velocity at minimum fluidisation, $\mathrm{m} / \mathrm{s}$

$\mathrm{U}_{\mathrm{ms}}-$ minimum spouting velocity, $\mathrm{m} / \mathrm{s}$

$\mathrm{U}_{\text {onset }}$-velocity at the start of spouting, $\mathrm{m} / \mathrm{s}$

$\mathrm{V}_{\mathrm{b}}$ - volume of the bed of particles, $\mathrm{m}^{3}$

$\mathrm{W}$ - weight of solids, $\mathrm{kg}$

$x_{i}$ - mole fraction of species $i$ 



\section{Gracias. Grazie. Thank you. Gràcies}



y aquí llega mi mimuto (o alfuro nés) de sloria... Aprú estoy, censaudo una etapa ( y abriiendo otra?) de mi vida. Etapa que definiría como dice Coldplay.

"The adventure of a Lifetime"

Una bellissina avuentura gratie a te, Elisabetta. Gratie per condividere la tha inesauribile sagette Cchi sa cro puante z!) scientifica. Ma supratutto, gratie per condividere TE stessa. Grztie perhe' ni hai dato la possibilita di cuere non ma ma due ferriglie in piü: La prima a Ville PerT. La secounda a Villa Arato. Grzie per it caffè delle 11 . E delle $u, E$ delle... Gratie per ridere sempre se gualche wolta (poooodo) ti prendicmo in gio. Potrei cutimare per une vita ma supratutto pretie perché so che sempre ci saria une mano dove potro tevermi guando avró punra a volare. 
Por supuerto, gracias Amparo. Porque rado de ento habría ocurrido si no me hubieras unvitado a ena gran familia: $5 k$. Gralies por tener la paciencia de esperes a que me perdiera para luepo encontrerne. Gralias por enseñarme que si lo quieres. y luches. lo consigues. Siempre.

Cara Barbera... innanzitutto, gratie per me Here la colonna sonora nella mia vita. Senta di te in ufficio, solo ce il reoto. Gratie per tutte le dis unssione su gassificetione, fluidizztione e Lablaione. Ma sopratutts, gretie per tutte le althe su cose senta - ione.

Con unestro permiso, apradecimiento súper especial a mi querido 5K. Robi Sorcy... da igual a maitor km entenos, yo té que entais siempre conmigo. Jose cuantas cosas se gralias a ti... y cuántas me quedan por aprender!! SId Las jolondivines... of $\delta$ Alf, gralias por contapiarne tu parión I entusiasmo, nos vernos en afune inded europla... Laura, pienso en ti y sonwó!! Eres la aldigía heche persona! 
Carlos y Oscar, riempre disponibles para echar una mano ... o las dos!

L'altra farriglia a villa pert no rimane indietro peì. Michela. gratie per condividere uffilio con me, anche guando nou coglio chiudere la porta il giorro puí freddo dell anno. Sia dove tia che finibia, fai sempire quello che ti dicail wore. Dario. dai dre tur sei il prorsmo!. Getie per essere sempre prorts a gualsichi petria che li vieve in mente. Ci vediano all'aula Bill Grtor! Burwa dien percarso!

Vovei ringratiare specialmente it Prof.Giorjis Lovers e Massino Curti, del Politecrinco di Tonwo. Gretie per la voshe duponibilite, simpatia e dispositione a wlleborar sempre. Grclias tembién a Carmen Molins y al Depertzmento de Químice Arelitica de le Univervided de valencic. Gratios parfue munce me quedon dudos silices sin resolver. 
Gralias a mis Falleritas. Me sients muy aforturada de poder decir que sris mis amigas de toda le vide. Grecies par hecorme participe de cada una de unentras vidos. Gracias por hacerre sentir corro is munce me hubiera ido cada vet gre onelos.

Gracias a la pequerre temilia fenovesa. Tary, temerte como velino es lo negar gue me podia pasar, dé que siempue entás ahr para cudpuier cosa, srande o pequeza. Ighanio. gracias por dejorros entres en th caos. Jamc's dejaris de sorprenderne! Ay leti carro mobas!! Si, thi tembien Niluei! Miviaur, gralias porpue hiempre tienes une sarrisa, un comenteio grecioss y gaves de tomar una leveta o peseer por kmontzaz! Dol y Meir, siempre me acorderé del da de vuentro anivers cubl! Todos, acordaos que svis parte de mi lista VIP, y une vet que se entra ya no de puede salor!

Marco, Eli y Aquese, sois mis ikliaws fevontos!! 
Gratie a tulti gli studenti che sorvo passeti de me. Tutti voi avete fatto un piccolo conhibuto in presto sel puxtle.

Bellissino purtle grene a to lesvis. E sai che oghi settimana imparo cosenove graxie ate!

Thank you kate. Thank you for your prouf reading. Thank jon for heving ne stay any time $I$ devide $J$ wout to vint. Thenk you for your suppost before, now and coming. Thank you for walking with me. Thenk you for letting me be part of your life and femily. Thenk jon for declip my Enghis mum.

Y por jupuestínimo, oratias papá y mamá. Por apoyar, entender y aceptor diempre mis deliriones. Aunque me lleven lejos de casa. Grelias porque hapa to gue hapa y sea como tea, vosotros siempre entais ahr.

Gralias Nucia, porque en todo ento. tur eres la gran perjudicada, funts con los papás. Porfie tever una hermana mazor 
que vive a $1000 \mathrm{~km}$. no debe molar rada. Gracias porque 70 puedo entzr tranfuila aquí sabiendo que tie entás allí.

Gracias a to dos los gue han pasado por mi vida. A los gue entzis ehora. I a los que tienen que keger.

Yo estoy preparede para afrouter mewas aventuras. Ga lo dile Barrey...

cimallonve aclepted 